\title{
Towards a Framework for Smart Manufacturing adoption in Small and Medium-sized Enterprises
}

\author{
SAMEER MITTAL \\ West Virginia University, samittal@mix.wvu.edu
}

Follow this and additional works at: https://researchrepository.wvu.edu/etd

Part of the Industrial Engineering Commons

\section{Recommended Citation \\ MITTAL, SAMEER, "Towards a Framework for Smart Manufacturing adoption in Small and Medium-sized Enterprises" (2019). Graduate Theses, Dissertations, and Problem Reports. 4061. \\ https://researchrepository.wvu.edu/etd/4061 \\ This Dissertation is protected by copyright and/or related rights. It has been brought to you by the The Research Repository @ WVU with permission from the rights-holder(s). You are free to use this Dissertation in any way that is permitted by the copyright and related rights legislation that applies to your use. For other uses you must obtain permission from the rights-holder(s) directly, unless additional rights are indicated by a Creative Commons license in the record and/ or on the work itself. This Dissertation has been accepted for inclusion in WVU Graduate Theses, Dissertations, and Problem Reports collection by an authorized administrator of The Research Repository @ WVU. \\ For more information, please contact researchrepository@mail.wvu.edu.}


Towards a Framework for Smart Manufacturing Adoption in Small and Medium-sized Enterprises

\author{
Sameer Mittal
}

Dissertation submitted to the

College of Engineering and Mineral Resources at

West Virginia University

in partial fulfillment of the requirements for the degree of

Doctor of Philosophy in Industrial Engineering

\author{
Thorsten Wuest, Ph.D., Chair \\ Kenneth R. Currie, Ph.D., P.E. \\ Leily Farrokhvar, Ph. D. \\ David Romero, Ph.D. \\ David A. Wyrick, Ph.D., P.E.
}

Department of Industrial and Management Systems Engineering

Morgantown, West Virginia, 2019

Keywords: Smart Manufacturing, Industry 4.0, Small and Medium-sized Enterprises, Framework, Case Study Research

Copyright 2019 Sameer Mittal 


\section{Abstract \\ Towards a Framework for Smart Manufacturing Adoption in Small and Medium-sized Enterprises}

\section{Sameer Mittal}

Smart Manufacturing (SM) paradigm adoption can scale production with demand without compromising on the time for order fulfillment. A smart manufacturing system (SMS) is vertically and horizontally connected, and thus it can minimize the chances of miscommunication. Employees in an SME are aware of the operational requirements and their responsibilities. The machine schedules are prepared based on the tasks a machine must perform. Predictive maintenance reduces the downtime of machines. Design software optimizes the product design. Production feasibility is checked with the help of simulation. The concepts of product life cycle management are considered for waste reduction. Employee safety, and ergonomics, identifying new business opportunities and markets, focus on employee education and skill enhancement are some of the other advantages of SM paradigm adoption.

This dissertation develops an SM paradigm adoption framework for manufacturing SMEs by employing the instrumental research approach. The first step in the framework identified the technical aspects of SM, and this step was followed by identifying the research gaps in the suggested methods (in literature) and managerial aspects for adopting SM paradigm. The technical and the managerial aspects were integrated into a toolkit for manufacturing SMEs. This toolkit contains seven modular toolboxes that can be installed in five levels, depending on an SME's readiness towards SM. The framework proposed in this dissertation focuses on how an SME's readiness can be assessed and based on its present readiness what tools and practices the SMEs need to have to realize their tailored vision of SM. The framework was validated with the help of two SMEs cases that have recently adopted SM practices.

This dissertation follows the structure of a compilation thesis (dissertation by publications) and includes seven original and refereed publications (three in peer-reviewed journals and four published in peer-reviewed international conferences) with the doctorate student as the first author. Six of these seven publications (two published in journals and four published in conferences) have already been published, whereas, the final publication (journal publication) of this dissertation was revised and submitted in July 2019. 


\section{Acknowledgement}

My $\mathrm{Ph}$. D. has been a learning experience. I believe I have grown both personally and professionally during my $\mathrm{Ph}$. D. I decided to pursue $\mathrm{Ph}$. D. during my final year of undergraduate, and finally I am close to achieving this goal. Here, I want to thank the people who made this journey possible.

To start with, I would like to thank Dr. Thorsten Wuest for everything that I have learned under his guidance. His presence cannot be described in words. He is someone whose footsteps I would always like to follow. Without his support and inspiration, this journey would have been very different.

I also want to thank Dr. David Romero. He has always inspired me to achieve my goals. He was an amazing host during my short trip in Monterrey, Mexico. I learned a lot from all the discussions we had on the phone.

I would also like to thank my committee members Dr. Kenneth Currie, Dr. Leily Farrokhavar, and Dr. David Wyrick who have improved my research with their feedback. I would also like to thank other IMSE faculty and staff members. Dr. Ashish Nimbarte was always to assist me. I also learned a lot from the courses I had with Dr. Rashpal Ahluwalia, Dr. Majid Jaridi, Dr. Feng Yang, Dr. Bhaskaran Gopalakrishnan, and Dr. Xiaopeng Ning. Similarly, Ms. Marie Owen and Mr. Howard Frank were always there to help me. My mentors from my undergraduate and master's institute were always supportive and motivated during my journey. In this regard, I would like to thank Dr. Punit Kumar, Dr. Ajay Pratap Singh Rathore, Dr. Rakesh Jain, Dr. Milind Sharma, Dr. Govind Sharan Dangayach, Dr. Gunjan Soni, Dr. Murari Lal Mittal, and Dr. Jayant Purohit.

I want to dedicate my Ph. D. to my maternal grandfather Lt. Mr. Ballabh Ram Gupta, because of whom I developed an aptitude for learning and research. I would also thank my maternal grandmother and other relatives. I would also like to thank my parents Mr. Banwari Lal Mittal and Mrs. Sudha Mittal for focusing on my education since my childhood. My brothers Prateek and Arpit have always been there for me. I would also like to thank my beautiful fiancée Mikita Vijay and her family for supporting my decisions. My U.S. east coast trip with them was the most fantastic trip I ever had. I want to thank baby Kashvi Vijay for the lovely moments she provides while I talk to her.

Finally, I would like to thank my friends I made during my Ph. D. Ashwini, Chandrashekhar, Vivek, Prasoon, Debashish, Bona, Hari, Deepak, Neel, Priyash, Pandit, Aanand, Bishleshan, Bruno, Phat, Vishal, Moiz, Chirag are just a few of them. I would also like to thank my lab members Muztoba, Juergen, Karan, Chris, Patrick, Ephraim, Samantha, Josh, Joseph and Assem for their inputs in my research. I also want to thank Omar, Vivek, Kaushik, Sri Charan, Gautham, Vikram, Nazmus, Sachin, Unique, Everest, Saman, Faisal, Hammad, Mohammad, Hussain, and Chatura, who are some of my friends from the IMSE department. 


\section{List of Appended Publications}

This references for the seven publications included in the dissertation have been represented in the text using Roman numerals (Table A). Table A also mentions the journal/conference and corresponding to the publication and its (google scholar) citations and status. Three among the seven publications were published (submitted) in refereed journals, and four others were published in international conferences.

Table A: Publication and their publication status.

\begin{tabular}{|c|c|c|c|}
\hline $\begin{array}{l}\text { Publi- } \\
\text { cation }\end{array}$ & Reference & $\begin{array}{c}\text { Journal/ } \\
\text { Conference }\end{array}$ & Status \\
\hline I. & $\begin{array}{l}\text { S. Mittal, M. A. Khan, \& T. Wuest (2016), "Smart Manufacturing: } \\
\text { Characteristics and Technologies." Proceedings of the } 13^{\text {th }} \text { IFIP } \\
\text { International Conference on Product Lifecycle Management, July } \\
\text { 11-13, University of South Carolina, Columbia, (USA). DOI } \\
10.1007 / 978-3-319-54660-548\end{array}$ & Conference & $\begin{array}{l}\text { Published } \\
\text { Citations: } 7\end{array}$ \\
\hline II. & $\begin{array}{l}\text { S. Mittal, M. A. Khan, D. Romero, \& T. Wuest (2017), "Smart } \\
\text { Manufacturing: Characteristics, Technologies and Enabling } \\
\text { Factors." Part B: Journal of Engineering Manufacture, Online First } \\
\text { DOI 10.1177/0954405417736547. }\end{array}$ & $\begin{array}{l}\text { Journal } \\
\text { IF } 2017 \text { : } \\
1.445\end{array}$ & $\begin{array}{l}\text { Published } \\
\text { Citations: } 38\end{array}$ \\
\hline III. & 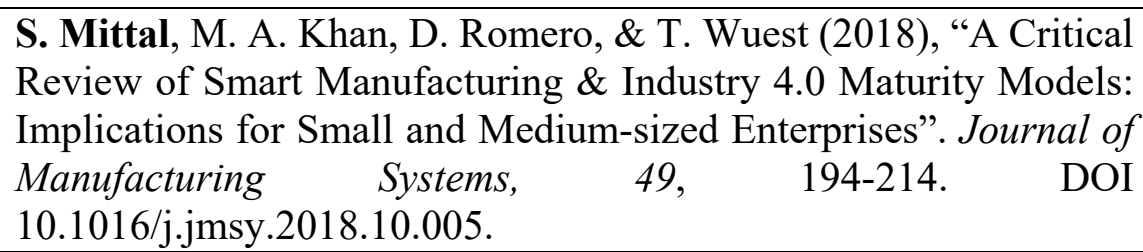 & $\begin{array}{l}\text { Journal } \\
\text { IF } 2017 \text { : } \\
3.699\end{array}$ & $\begin{array}{l}\text { Published } \\
\text { Citations: } 25\end{array}$ \\
\hline IV. & $\begin{array}{l}\text { S. Mittal, D. Romero, \& T. Wuest (2018), "Towards Smart } \\
\text { Manufacturing Toolkit for Small and Medium Enterprises." } \\
\text { Proceedings of the } 15^{\text {th }} \text { IFIP International Conference on Product } \\
\text { Lifecycle Management, July 1-4, Politecnico di Torino, Torino, } \\
\text { (Italy). DOI 10.1007/978-3-030-01614-2 } 44\end{array}$ & Conference & $\begin{array}{l}\text { Published } \\
\text { Citations: } 3\end{array}$ \\
\hline V. & $\begin{array}{l}\text { S. Mittal, D. Romero, \& T. Wuest (2018), "Towards Smart } \\
\text { Manufacturing Maturity Model for Small and Medium } \\
\text { Enterprises." Proceedings of the IFIP International Conference on } \\
\text { Advances in Production Management Systems, August 26-30, } \\
\text { Seoul National University, Seoul, (Korea). DOI 10.1007/978-3- } \\
\text { 319-99707-0 20 }\end{array}$ & Conference & $\begin{array}{l}\text { Published } \\
\text { Citations: } 3\end{array}$ \\
\hline VI. & $\begin{array}{l}\text { S. Mittal, M. A. Khan, D. Romero \& T. Wuest (2019), "Building } \\
\text { Blocks for Adopting Smart Manufacturing." } \text { Proceedia } \\
\text { Manufacturing, June 10-14, Penn State University, Erie, (USA). } \\
\text { DOI: } 10.1016 / \text { j.promfg.2019.06.098 }\end{array}$ & Conference & Published \\
\hline VII. & $\begin{array}{l}\text { S. Mittal, M. A. Khan, J. K. Purohit, K. Menon, D. Romero, \& T. } \\
\text { Wuest (20XX), "A Smart Manufacturing Adoption Framework for } \\
\text { SMEs." Currently under review. }\end{array}$ & Journal & $\begin{array}{l}\text { Revised and } \\
\text { Submitted in } \\
\text { July } 2019 \\
\text { (Under } \\
\text { Review) }\end{array}$ \\
\hline
\end{tabular}




\section{Doctorate Student's Contribution on Refereed Publications}

Table B: Contribution of Publications to Dissertation.

\begin{tabular}{|c|c|}
\hline Publication I & Smart Manufacturing: Characteristics and Technologies \\
\hline Contribution & $\begin{array}{l}\text { In this publication, the doctorate student contributed by reviewing the literature and } \\
\text { finding the appropriate characteristics and technologies associated with SM. Finally, the } \\
\text { doctorate student clustered synonymous characteristics and technologies. }\end{array}$ \\
\hline Publication II & Smart Manufacturing: Characteristics, Technologies and Enabling Factors \\
\hline Contribution & $\begin{array}{l}\text { In this publication, the doctorate student contributed by expanding the literature (from } \\
\text { Publication I) and identifying the appropriate characteristics, technologies, and enabling } \\
\text { factors associated with SM. In addition, the doctorate student also clustered the } \\
\text { synonymous characteristics, technologies, and enabling factors and discussed why } \\
\text { Industry } 4.0 \text { is synonymous with SM. }\end{array}$ \\
\hline Publication III & $\begin{array}{l}\text { A Critical Review of Smart Manufacturing \& Industry } 4.0 \text { Maturity Models: } \\
\text { Implications for Small and Medium-sized Enterprises }\end{array}$ \\
\hline Contribution & $\begin{array}{l}\text { In this publication, the doctorate student first identified the specific requirements of } \\
\text { manufacturing SMEs with the help of a literature review and then developed a } \\
\text { methodology to find the methods that can assist in an organization's journey towards } \\
\text { SM paradigm adoption. In addition, the doctorate student critically discussed how well } \\
\text { the requirements of manufacturing SMEs are satisfied by the available methods to adopt } \\
\text { SM paradigm. Finally, the doctorate student identified the research gaps that obstruct } \\
\text { the existing methods in guiding an SME's journey towards SM paradigm adoption. }\end{array}$ \\
\hline Publication IV & Towards a Smart Manufacturing Toolkit for Small and Medium Enterprises \\
\hline Contribution & $\begin{array}{l}\text { In this publication, the doctorate student visited manufacturing SMEs and studied } \\
\text { literature to define an SM Toolkit for SMEs. In addition, the doctoral student also } \\
\text { discussed the application of two toolboxes (present in the toolkit) with the help of the } \\
\text { industrial cases. }\end{array}$ \\
\hline Publication $V$ & Towards a Smart Manufacturing Maturity Model for Small and Medium Enterprises \\
\hline Contribution & $\begin{array}{l}\text { In this publication, the doctorate student designed a three-dimensional maturity model } \\
\text { for the manufacturing SMEs. Toolkit (from Publication IV), levels and the } \\
\text { organizational dimensions were the three dimensions of this maturity model. In addition, } \\
\text { the doctorate student also defined the exemplary activities that are performed by the } \\
\text { cloud/storage toolbox under an organizational dimension and a level. }\end{array}$ \\
\hline Publication VI & Building Blocks for Adopting Smart Manufacturing \\
\hline Contribution & $\begin{array}{l}\text { In this publication, the doctorate student contributed by developing a systematic } \\
\text { mapping review (of literature) methodology to identify the most frequently utilized } \\
\text { building blocks (a collective term for characteristics, technologies and enabling factors) } \\
\text { for adopting SM paradigm. In addition, the doctorate student also added to the existing } \\
\text { list of technologies identified earlier (in Publication II). }\end{array}$ \\
\hline
\end{tabular}




\begin{tabular}{|c|l|}
\hline $\begin{array}{c}\text { Publication } \\
\text { VII }\end{array}$ & A Smart Manufacturing Adoption Framework for SMEs \\
\hline Contribution & $\begin{array}{l}\text { In this publication, the doctorate student develops a framework that can be employed by } \\
\text { the manufacturing SMEs in their SM paradigm adoption journey. In addition, the } \\
\text { doctorate student validated the developed framework with the help of unique SMEs that } \\
\text { have recently adopted SM practices. }\end{array}$ \\
\hline $\begin{array}{c}\text { Publication } \\
\text { VIII* }^{*}\end{array}$ & $\begin{array}{l}\text { Review on upgradability- } \text { A product lifetime extension strategy in the context of product } \\
\text { service systems }\end{array}$ \\
\hline $\begin{array}{c}\text { Contribution } \\
\text { In this publication, the doctorate student assisted in screening the articles and developing } \\
\text { a methodology for a systematic review. }\end{array}$ \\
\hline
\end{tabular}

* Note: Publication VIII (reference given below) co-authored during my Ph.D. does not directly contribute towards this dissertation.

Khan M. A., S. Mittal, S. West \& T. Wuest (2018). Review on upgradability-A product lifetime extension strategy in the context of product service systems. Journal of cleaner production, 204, 1154-1168. DOI 10.1016/j.jclepro.2018.08.329 (IF 2017: 5.651) 


\section{Table of Contents}

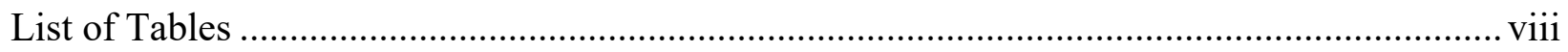

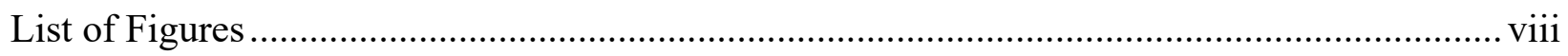

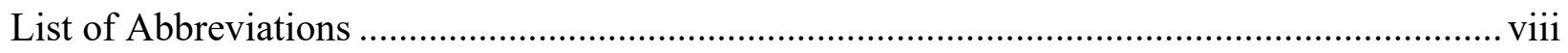

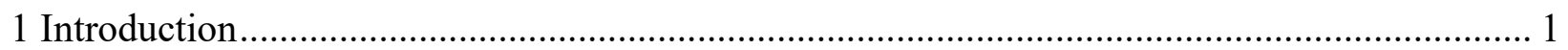

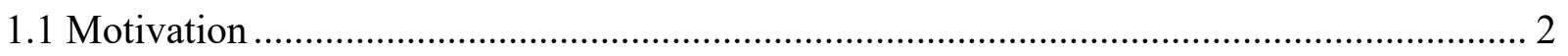

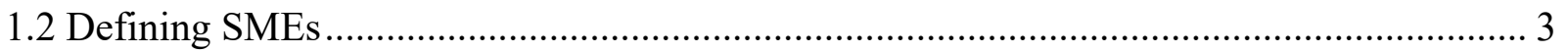

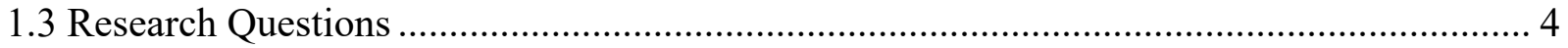

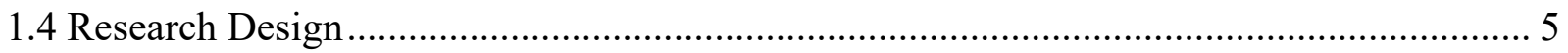

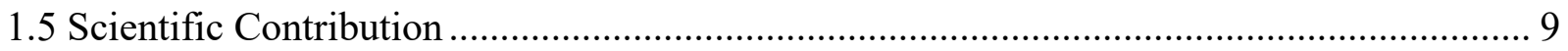

1.6 Publications Corresponding to the Research Design Phases ............................................. 10

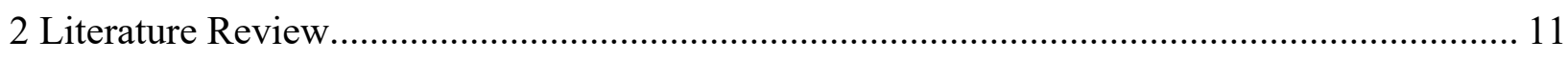

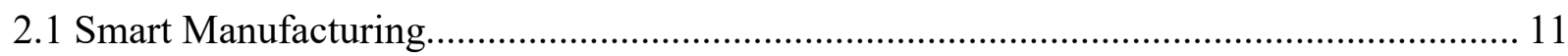

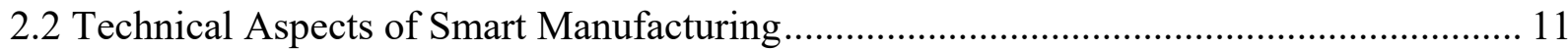

2.3 Managerial and Operational aspects of Smart Manufacturing ........................................... 12

2.4 Requirements of Manufacturing SMEs.......................................................................... 12

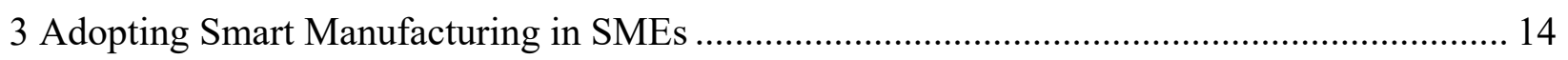

3.1 Smart Manufacturing: Characteristics \& Technologies (Publ. I)....................................... 15

3.2 Smart Manufacturing: Characteristics, Technologies \& Enabling Factors (Publ. II) ......... 16

3.3 A Critical Review of Smart Manufacturing \& Industry 4.0 Maturity Models: Implications

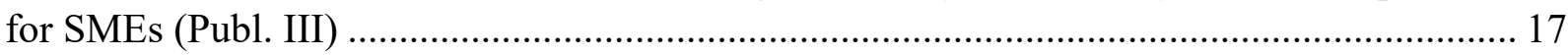

3.4 Towards a Smart Manufacturing Toolkit for SMEs (Publ. IV) ………........................... 18

3.5 Towards Smart Manufacturing Maturity Model for SMEs (Publ. V) ................................... 19

3.6 Building Blocks for Adopting Smart Manufacturing (Publ. VI) ....................................... 20

3.7 A Smart Manufacturing Adoption Framework for SMEs (Publ. VII) ................................. 21

4 Conclusion, Limitations and Recommendation for Future Works ............................................ 22

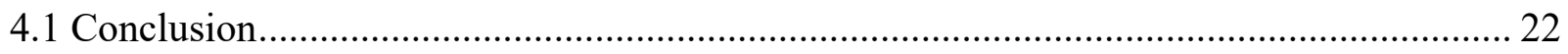

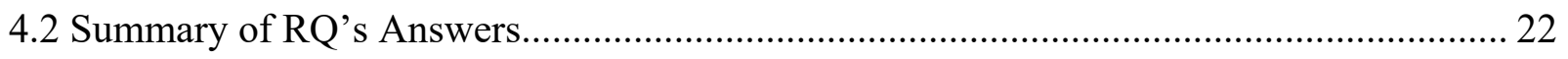

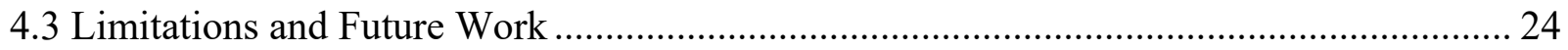

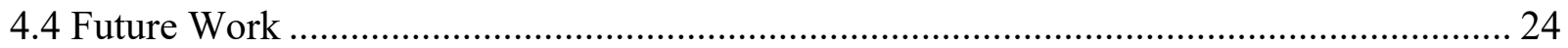

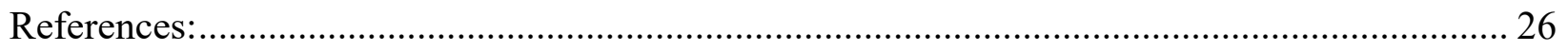




\section{List of Tables}

Table 1: Summarizing the Industrial Revolutions (Fama and French, 1997; Katari, 2018).......... 1

Table 2: SMEs Definition (European Commission, 2003) .................................................. 3

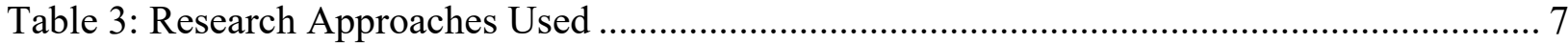

Table 4: General Characteristics of Research Methods (Yin, 2003) ........................................ 9

Table 5: Publications Corresponding to the Research Process ............................................... 10

Table 6: Smart Manufacturing Building Blocks Identified in Publication I............................. 15

Table 7: Smart Manufacturing Building Blocks Identified in Publication II ........................... 16

\section{List of Figures}

Figure 1: Research Design Followed During this Dissertation. ......................................... 6

Figure 2: Schematic Showing How Publications are Linked ............................................... 14

Figure 3: Smart Manufacturing Maturity Model for SMEs....................................................... 19

Figure 4: Most Frequently Used Building Blocks for Adopting Smart Manufacturing .............. 20

\section{List of Abbreviations}

\begin{tabular}{|l|l|}
\hline CESMII & Clean Energy Smart Manufacturing Innovation Institute \\
\hline CNC & Computer Numerical Control \\
\hline ICT & Information and Communication Technologies \\
\hline IT & Information Technology \\
\hline FMS & Flexible Manufacturing System \\
\hline MNEs & Multi-National Enterprises \\
\hline SM & Smart Manufacturing \\
\hline SM $^{3}$ E & Smart Manufacturing Maturity Model Small and Medium-sized Enterprises \\
\hline SMEs & Small and Medium-sized Enterprises \\
\hline SMLC & Smart Manufacturing Leadership Coalition \\
\hline SMS & Smart Manufacturing System \\
\hline OT & Operations Technology \\
\hline
\end{tabular}




\section{Introduction ${ }^{1}$}

During the era of craft production, the products were made by hands or by using hand tools. The manufacturing related activities like processing of raw materials, production, and customer dealing were also performed by the owner. Four industrial revolutions succeeded the craft production. During Industry 1.0, machines like weaving loom were created to support the existing manufacturing practices. Similarly, during Industry 2.0, electrical energy was used to generate power, and workers created separate parts to be assembled later. The era of Industry 3.0 began with the use of computers and electronics on the shop floor and further reduced the amount of manual work. Finally, it is the era of SM/Industry 4.0 where information and data are used to make predictions. These predictions can assist in a more precise calculation of items like product demand, resource allocation, and the preventive maintenance time for machines. Table 1 presents a summary of the four industrial revolutions.

Table 1: Summarizing the Industrial Revolutions (Thoben et al., 2017)

\begin{tabular}{|c|c|c|c|}
\hline Revolution & Year & Focus & Sample Tools \\
\hline Industry 1.0 & late 18th century & mechanization & weaving loom \\
\hline Industry 2.0 & early 20th century & division of work, mass production & lathe, mill, weld \\
\hline Industry 3.0 & early 1970s & automation, computer, electronics & ERP, CAD, CAM \\
\hline SM/Industry 4.0 & today & information sharing, data & data analytics, IoT, CPS \\
\hline
\end{tabular}

The term SM has been coined recently (emerging from previous initiatives such as intelligent manufacturing, among others by the Smart Manufacturing Leadership Coalition (SMLC) (a collaboration of the U.S. government, universities and private enterprises that recently established the Clean Energy Smart Manufacturing Innovation Institute (CESMII)). CESMII considers SM as the convergence of IT and OT. In broad terms, SM is defined as the integration of data and IT with manufacturing (Marr, 2015).

Although data has been present in manufacturing enterprises (Tao et al., 2018) for decades, however, the realization, of how data can be exploited to make decisions was missing (Kusiak, 2017). For the use of data in manufacturing enterprises, there is a need to develop approaches that can collect, store, and process, visualize data, and ultimately make data-driven decisions (Tao et al., 2018).

Most existing methods have focused on MNEs' needs to reap benefits from SM. However, SMEs lack a framework guiding them in their SM paradigm journey (Mittal et al., 2018a). Some SMEs still follow the practices established during craft production. Some SMEs are not yet aware about SM and its implications (study in West Virginia, U.S., showed that only $60 \%$ of the respondents from industry have heard about "Smart Manufacturing" (Wuest et al., 2018)), whereas, for some (that are aware of SM) the shift towards SM is still challenging. In other words, the SME owners/managers still lack the guidance and support towards the technical and, managerial and operational perspectives of adopting SM paradigm. Therefore, the objective of this dissertation is

\footnotetext{
${ }^{1}$ This dissertation project is structured as a cumulative thesis. Therefore, some of the content in the following is derived from the papers previously published by the PhD student (see table A)
} 
to provide a framework that appropriately acknowledges the SME's perspective and assist in their SM paradigm adoption journey.

This dissertation identifies the research gaps when it comes to introducing SM in the manufacturing SMEs and plans to develop a novel approach for the SMEs in analyzing their current readiness for adopting SM paradigm. It also suggests the set of activities that can be performed with the help of modular toolboxes to support the manufacturing SMEs shift towards SM. The framework developed in the current study was validated with the help of in-depth case study research performed in two manufacturing SMEs that have recently adopted SM practices.

A systematic literature review led to the conclusion that an SMS may be defined with the help of various characteristics, technologies, and enabling factors (Publ. I \& II). These technical aspects also helped in establishing that other manufacturing initiatives like Industry 4.0 are synonymous with SM. In the future, these aspects may also be utilized to determine whether a manufacturing system can be referred to as SM. The current research identified the requirements of manufacturing SMEs and mapped these requirements with the available methods of SM paradigm adoption that are present in the literature. It was found that the existing methods were developed for large enterprises and may not help SMEs (Publ. III). Therefore, these research gaps were discussed further for modifying the existing methods and leading towards a new framework that can help SMEs in its SM paradigm adoption journey. Finally, this dissertation develops a novel framework for guiding the manufacturing Small and Medium-sized Enterprises (SMEs) in their SM paradigm adoption journey (Publ. VII). The framework focused on assessing an SME's SM readiness with the help of data present in the SMEs. During the next step, a SM tailored vision of SME was developed, and in the last step is to support this SME tailored vision with the help of technical and managerial tools. The current research also suggests a modular toolkit composed of seven individual modular toolboxes (Publ. IV), which supports an SME's organizational dimensions through five maturity levels (Publ. V). The presence of the toolboxes makes this suggested framework 'smart' (Publ. VI).

This section briefly introduces SM. The following sub-sections present the motivation behind the current research work, followed by defining SMEs and the research questions that need to be answered to achieve the research objective, the research design deployed to answer the research questions, the scientific contributions of the dissertation, and finally highlights how the publications correspond to the research design phases, and the research questions. Section 2 presents a condensed literature review on SM, and the technical, managerial, and operational aspects of adopting SM paradigm in SMEs, and the challenges faced by SMEs. Section 3 presents a summary of all the publications that were published during this dissertation, and section 4 presents a summary of the scientific contribution, limitations and future of the dissertation research. Finally, section 5 appends the publications (I-VII) related to this dissertation.

\subsection{Motivation}

The advances in manufacturing have led to affordable and faster technology means. Therefore, a product's lifecycle data may be captured with the help of sensors and networks (Chiang and Lee 2017; Kusiak 2017; Wang et al. 2012; Zhong et al. 2017; Zhong 2018). For example, there are software and ERP packages available for the specific needs of the organizations (Strozzi et al. 
2017, Gershwin 2018). Similarly, the availability of economic cloud and processors (Moore's Law) has ensured that analysis does not requires supercomputers anymore (Marr 2015; Syafrudin et al. 2019). As a result, the large amounts of data can be efficiently used to improve the existing manufacturing practices (Marr 2015).

Initiatives have been launched by the governments of various countries to accelerate the growth of their manufacturing industries. Some of these initiatives are Industry 4.0 (Germany), Smart Factory (Korea), Made in China 2025, Make in India, Fabrica Intelligente (Italy), Catapult (U.K.), Smart Manufacturing (U.S.A.) (Trotta \& Garengo, 2018). These initiatives aim to overcome the challenges arising due to the dynamic socio-technical systems, and tangible, intangible and human elements (Thoben et al., 2017). These initiatives also support the development of their manufacturing enterprises by providing grants, funding their research, offering favorable policies, and subsidized lands, just to name a few.

The depleting natural resources, reducing product lifecycle, and an increasing product variety has emphasized on the concept of product lifecycle management. Design software has features to suggest the most optimized design for the given products and do the process simulation before the actual manufacturing. Similarly, the product prototypes are prepared to check the functionality of the product before manufacturing the end product. Data analysis and prediction in demand shifts is performed to support decision making. Therefore, manufacturing enterprises are going towards the era, in which they need to zero the number of failures. Similarly, customers are not only considering the factors like price, quality, and value of a product while purchasing. They consciously purchase the products that are recyclable and manufactured using sustainable practices. An enterprise can become more efficient by adopting SM paradigm and enabling the above-mentioned functionalities.

There are methods for MNEs to transform themselves towards SM. However, the SMEs viewpoint has not been regarded. As a result, the main objective of this dissertation is to develop a methodology for manufacturing SMEs to assist them in their challenging SM paradigm adoption journey.

\subsection{Defining SMEs}

The current research follows the guidelines of the European Commission (European Commission, 2003) to define the SMEs. European Commission (2003) described SMEs as the industrial sector with less than 250 employees, and its annual turnover does not exceed $€ 50$ million (Table 2).

Table 2: SMEs Definition (European Commission, 2003)

\begin{tabular}{|c|c|c|c|}
\hline Enterprise & $\begin{array}{c}\text { Max. People } \\
\text { Employed }\end{array}$ & $\begin{array}{c}\text { Max. Annual } \\
\text { Turnover }\end{array}$ & $\begin{array}{c}\text { Max. Annual } \\
\text { Balance Sheet Total }\end{array}$ \\
\hline Small & $<50$ & $\leq € 10$ million & $\leq € 10$ million \\
\hline Medium & $<250$ & $\leq € 50$ million & $\leq € 43$ million \\
\hline
\end{tabular}

There are different spectrums of SMEs and generalizing them is complicated. Despite the small number of employees, maximum annual turnover and the maximum annual balance sheet total, the SMEs may have other resources available, because the SMEs are an ancillary of an MNE. Similarly, some SMEs are more advanced (e.g., aerospace and defense) as compared to the 
'genuine' SMEs (European Commission, 2006). Therefore, the scope of the current research is limited to the SMEs that are autonomous and have a partnership of less than $25 \%$ with other enterprises.

\subsection{Research Questions}

The following three research questions (RQ1-3) were derived, formulated and considered to achieve the objective of this dissertation.

\section{RQ1: What makes a manufacturing system smart?}

The phrase 'smart manufacturing' has become popular both in academia and industries, and therefore, any development is manufacturing is often associated with an SMS. As a result, a literature review of SM might help in identifying the various prerequisites that can help in understanding if a development lies under the umbrella of SM. Therefore, RQ1 will help in identifying if a manufacturing development in manufacturing may be categorized as smart, and similarly, might help in finding the similarities and the differences of SM with other manufacturing initiatives such as Industry 4.0, smart factory, and intelligent manufacturing.

\section{RQ2: Are the current SM adoption methods a good fit for the specific requirements of the manufacturing SMEs?}

It is not only the technical aspects but also the managerial aspects that will help in the shift towards SM paradigm adoption. Therefore, the objective of RQ2 is to check if a method for adopting SM fit SMEs, regarding their shift. Following are the sub-questions for RQ2:

2a) What are the specific requirements of manufacturing SMEs?

- This question aims to identify requirements that are specific to the manufacturing SMEs (compared to larger manufacturing companies).

2b) What are the current methods supporting SM paradigm adoption?

- This question aims to identify all currently available methods that are intended to support enterprises in their journey towards SM paradigm adoption.

2c) Are the currently available methods a good fit for the requirements of manufacturing SMEs?

- This question addresses how well the adoption methods fit the requirements of the manufacturing SMEs.

2d) What are the research gaps that prevent current SM maturity models from providing the missing SME specific support?

- If the answer to question $2 \mathrm{c}$ is that the current methods are not a good fit for the needs of manufacturing SMEs, question $2 \mathrm{~d}$ aims to specify the research gap(s) that highlights the mismatch between the adoption methods and the SMEs' requirements.

2e) How can the current SM maturity models be adapted to support SMEs' specific requirements in their evolutionary path and the paradigm shift towards SM and Industry 4.0? 
- The question 2e expands the research gaps (identified in $2 \mathrm{~d}$ ) and modifies the existing maturity models to adapt to the identified needs of manufacturing SMEs.

\section{RQ3: How can SMEs adopt SM paradigm?}

There may be SMEs that have followed a common framework towards adopting SM paradigm and studying how SM has contributed to SMEs progress seems promising. Therefore, the objective of RQ3 is to evaluate the role of SM paradigm adoption in the success of SMEs.

3a) Considering the adoption of SM paradigm in SMEs, how should a suitable framework/guideline be designed?

- The question 3a inquiries regarding the requirements towards a suitable framework that SMEs can follow for SM paradigm adoption in their enterprise.

3b) What lessons learned can be drawn from use cases of SMEs recently adopting SM practices and how can they help to validate the framework suggested in $3 a$ ?

- SMEs can learn from their peers (and prefer that over advise from consultants and/or academics in many cases). As a result, the objective of $3 b$ is to understand how some SMEs have already adopted the SM paradigm and to what extent the SM framework has been used/not used by the SMEs that have adopted SM paradigm.

3c) Why this framework can be referred to as SM framework?

- Question 3c discusses technical aspects of SM that are present in the developed framework, and therefore, explains the rationale behind referring to this framework as smart.

\subsection{Research Design}

This dissertation combines qualitative instrumental research approach and case study research (Figure 1). Instrumental research includes activities for the design of instruments (systems, methods) to achieve the objectives of the organizations (Martek, 1986; Mattessich, 1978; Moreira, 2015). During instrumental research, a normative state (in this case, the need for an SM adoption framework for SMEs) is created to define the objective (see section 1), and a set of instrumental hypotheses leading to factual or conceptual instrument is created (e.g., the modification in the existing methods for adopting SM paradigm) (Moreira, 2015). If the proposed instrument can help users to achieve their goals, then the instrument is verified. This dissertation plans to employ a case study approach to validate and improve the proposed instrument. The instrumental research is performed in two macro-phases: intelligence and conception (Martek, 1986 in Moreira, 2015). During the intelligence phase, the current research employed the foundation of literature review (i.e., the technical, managerial, and operational aspects of the SM paradigm) and investigated the existing work related to the studied phenomenon. This phase resulted in the research gaps focusing towards development of a framework. During the conception phase, the instrument (framework) is developed, and then the instrument hypotheses are validated. 


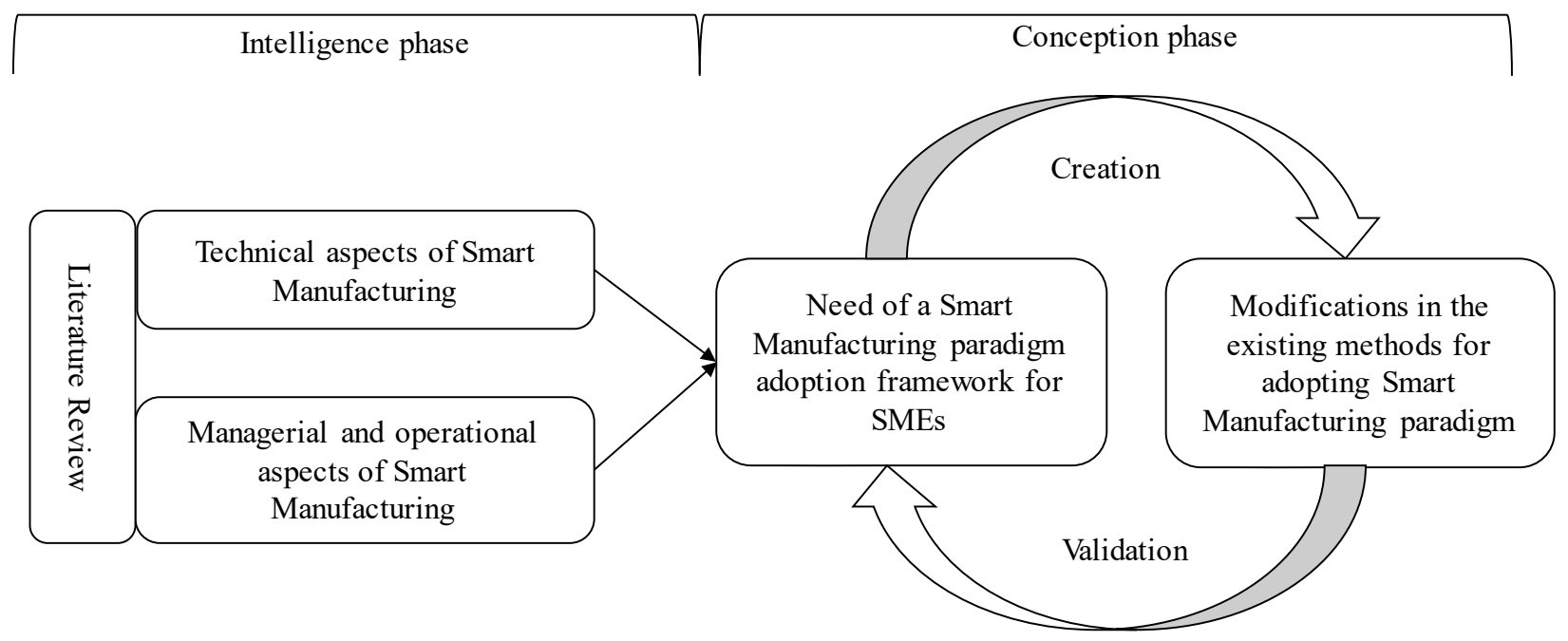

Figure 1: Research Design Followed During this Dissertation

As the first step during the intelligence phase, an SMS was defined with the help of technical aspects, and a comprehensive systematic review of the literature (Grant \& Booth, 2009) was performed to do so. During the review, it was found that literature defines SM, in terms of characteristics, technologies and the enabling factors, and different terms were used to refer to the same characteristic (or technology or the enabling factor). As a result, the principle of semantic similarity (Harispe et al., 2015) was utilized to cluster such similar terms. It was also determined that the presence of these technical aspects (characteristics, technologies and enabling factors) of SM can also help in evaluating whether a manufacturing system is smart or not. Finally, the most frequently considered technical aspects for adopting SM paradigm were identified. This identification can inform SMEs about the generalized options of the building blocks that they may consider having in their enterprises. The list of technical aspects of SM (from phase one) was also extended. This review identified the technical aspects of SM, but it was found that the managerial aspects required for adopting SM paradigm were still missing. Therefore, the need for performing a second literature review was realized.

During the second step of the intelligence phase, a literature review on various methods of adopting SM paradigm was performed. This review provided information on the various managerial and operational aspects of adopting SM paradigm and utilizing the technical aspects determined in the first phase of the research. As the research focused on adopting SM paradigm in SMEs, a critical review discussing how well the methods of SM paradigm adoption do when it comes to satisfying the specific requirements of manufacturing SMEs was also performed.

The research gaps identified during the intelligence phase led to the conception phase. These research gaps helped in highlighting the need (or the creation) of an SM paradigm adoption framework for SMEs, and secondly, it reflected how the existing methods can be improved from the operational perspective of adopting SM paradigm in SMEs.

To create an SM paradigm adoption framework for SMEs, the manufacturing SMEs were visited, and during the discussions with the SME managers and owners, it was found that the SMEs need 
economic and modular tools. As a result, a modular and economic toolkit composing of both the technical and the managerial aspects for the manufacturing enterprises, and a maturity model (acknowledging some of the research gaps identified earlier) were proposed. Toolbox, organizational dimensions, and levels were the three dimensions of the maturity model. Maturity model was integrated with the readiness assessment tool, and it can be adopted at five levels (starting with level 0). Since the maturity model did not consider all the research gaps identified earlier, therefore, this maturity model was integrated with the framework.

During the next step of the conception phase, the suggested framework was validated with the help of the lessons learned by the SMEs that have recently adopted SM practices. Finally, why the framework may be referred to as an SM framework was discussed.

The research approach should be based on the researcher's experiences, and understanding of the research objective (Akerman, 2018; Creswell, 2014). An overview of different research design phases, the steps performed during the research design phase and the corresponding research approach employed for the current research is highlighted in Table 3. The explanation of the research methods and why they were employed is elaborated in the remaining section 1.4.

Table 3: Research Approaches Employed

\begin{tabular}{|c|c|c|c|c|}
\hline$\#$ & $\begin{array}{c}\text { Research Design } \\
\text { Phase }\end{array}$ & Steps in Research Design & $\begin{array}{c}\text { Research Design } \\
\text { Informed By } \\
\text { (Research Approach) }\end{array}$ & $\begin{array}{c}\text { Research Approach } \\
\text { Defined By }\end{array}$ \\
\hline A & Intelligence phase & $\begin{array}{c}\text { Identifying technical aspects } \\
\text { of SM } \\
\text { Clustering similar terms }\end{array}$ & $\begin{array}{c}\text { Literature Review } \\
\text { Semantic Similarity }\end{array}$ & Grant \& Booth (2009) \\
Harispe et al. (2015)
\end{tabular}

Literature Review: A literature review can determine the previous work that has the potential to be included from the body of knowledge (Grant \& Booth, 2009). The results of the literature review may be analyzed and contributed in the form of text, table, and graphs (Grant \& Booth, 2009). during the current research work, it was necessary to study the existing literature during different steps in research design. Firstly, a comprehensive literature review was performed to know the 
technical aspects that are often associated with SM. Secondly, the literature review leads to the identification of specific SME requirements and the methods for adopting SM paradigm. Thirdly, the literature review informed about the toolboxes, levels, and organizational dimensions, related to initiatives like Industry 4.0 and smart factory.

Critical Review: A critical review evaluates the value of previous research (Grant \& Booth, 2009). It provides the starting point for further research, in the form of a hypothesis or model (not an answer), involves analysis and synthesis of the diverse sources and thus leads towards conceptual innovation (Grant \& Booth, 2009). Therefore, the critical review goes further as compared to a literature review. "The resultant model may constitute a synthesis of the existing models or schools of thought, or it may be a completely new interpretation of the existing data" (Grant \& Booth, 2009). In the current research, the critical review was utilized to check the fit of existing methods toward satisfying SME requirements. The evaluation of the critical discussion resulted in the fact that the existing methods cater to the needs of MNEs, and therefore, there are research gaps that obstruct existing methods in supporting SMEs towards adopting SM paradigm. Thus, an adapted method from the synthesis of the existing methods was proposed.

Semantic Similarity: Semantic similarity may be considered as a metric defined to relate a set of terms. The idea of the distance between these terms is founded on the likeliness of their meaning or the semantic content and not on the similarity of the words (Harispe et al., 2015). The current research work utilized the concept of "semantic similarity" to cluster the semantically similar aspects of SM. Thus, semantic similarity made the process of clustering more transparent.

Systematic Mapping Review: Systematic mapping review can unbiasedly categorize and summarize the information on a research question (Fernandez et al., 2011). Thus, a systematic mapping review can assist in mapping how well some factors have been used in some methods. During this dissertation, the systematic mapping review was utilized to identify how frequently the same sets of SM building blocks have been suggested in the scientific literature to adopt SM paradigm. It also highlighted the SM building blocks that were present in the framework proposed during the current research.

Case Study Research Method: Case Study Research Method helps in understanding a complex social phenomenon (Yin, 2003) because they can "retain the holistic and meaningful characteristics of the real-life events" (Yin, 2003).

Various research methods have been described in Table 4 (Yin, 2003). Based on the analysis in Table 4, the current study shows that the case study research is the best method to validate the framework suggested during the current research. Firstly, the primary research question of this study includes a "how"; therefore, case study research becomes a viable option. Secondly, the researchers involved in this study did not have any control over how an SME would like to adopt SM paradigm. As a result, case study research is a good option. Thirdly, SM is a recent phenomenon, and its adoption in SMEs pertains to real-life context, and therefore, a case study is an option. After considering all the three conditions, it was found that overall, the case study research method is the best method for the current research. 
Table 4: General Characteristics of Research Methods (Yin, 2003)

\begin{tabular}{|c|c|c|c|c|c|c|}
\hline & & \multicolumn{5}{|c|}{ Research Methods } \\
\hline$\#$ & Conditions & Case Study & Experiments & Surveys & Histories & $\begin{array}{c}\text { Analysis of } \\
\text { Archival Info. }\end{array}$ \\
\hline 1 & Research Question & How, Why & How, Why & $\begin{array}{c}\text { Who, What, } \\
\text { Where, How } \\
\text { many, How } \\
\text { much }\end{array}$ & How, Why & $\begin{array}{l}\text { Who, What, } \\
\text { Where, How } \\
\text { Many, How } \\
\text { Much }\end{array}$ \\
\hline 2 & $\begin{array}{c}\text { Extent of control } \\
\text { over behavioral } \\
\text { events }\end{array}$ & $\begin{array}{l}\text { Little control/ } \\
\text { No control }\end{array}$ & Yes & No & No & No \\
\hline 3 & $\begin{array}{c}\text { General } \\
\text { circumstances of } \\
\text { the phenomenon } \\
\text { studied }\end{array}$ & $\begin{array}{c}\text { Yes } \\
\text { (Contemporary } \\
\text { phenomenon } \\
\text { in real-life } \\
\text { context) }\end{array}$ & Yes & Yes & No & Yes/No \\
\hline
\end{tabular}

\subsection{Scientific Contribution}

Any scientific contribution should contribute to the theory and practice. In the following scientific contributions pertaining to the current research are summarized and presented.

Following are the scientific contribution of the current research work to the theory:

- It identified the design principles, i.e., the characteristics, technologies, and enabling factors that can be associated with an SM. The design principles of SM were found to be similar to the design principles of Industry 4.0, and it was identified that the initiatives 'Smart Manufacturing' and 'Industry 4.0' were synonymous.

- It identified the specific requirements from the perspective of manufacturing SMEs.

- It identified the current methods suggested in the literature from the perspective of SM paradigm adoption. It also identified the research gaps that prevent the existing methods in supporting SMEs in their SM paradigm adoption journey.

- It developed an SM paradigm adoption framework from SME viewpoint by acknowledging the research gaps identified in the literature.

- It suggested the key activities that can be performed with the help of various SM toolboxes corresponding to the SME organizational dimensions.

- It identified the most preferred characteristics, technologies, and enabling factors suggested in methods (from literature) to adopt SM paradigm.

Following are the scientific contribution of the current research work to the practice:

- It developed modular and economic SM tools and practices that can be adopted by SMEs to perform the various operational functions effectively.

- It demonstrated the success stories of SMEs that have already taken their initial steps in their SM paradigm adoption journey. The success stories will inspire other SMEs regarding the profits that were enabled by better planning and decision-making during SM paradigm adoption. 


\subsection{Publications Corresponding to the Research Design Phases}

All the research design phases of the current research were covered with the help of publications. Table 5 depicts how the publications correspond to the steps in the research design phase, the corresponding research question acknowledged, name of the publication, whether the publication outlet is a journal, or a conference and the status of the publication.

Table 5: Publications Corresponding to the Research Process

\begin{tabular}{|c|c|c|c|c|c|c|}
\hline \# & $\begin{array}{l}\text { Research } \\
\text { Design } \\
\text { Phase }\end{array}$ & Steps in Research Design & $\begin{array}{l}\text { Research } \\
\text { Question }\end{array}$ & Publication & $\begin{array}{l}\text { Journal/ } \\
\text { Conference }\end{array}$ & Status \\
\hline \multirow[t]{2}{*}{ A } & \multirow[t]{2}{*}{$\begin{array}{l}\text { Intelligence } \\
\text { phase }\end{array}$} & $\begin{array}{l}\text { - Identifying technical } \\
\text { aspects (characteristics } \\
\text { and technologies) of SM } \\
\text { - } \quad \text { Clustering similar items }\end{array}$ & RQ1 & Publication I & Conference & Published \\
\hline & & $\begin{array}{l}\text { Identifying technical } \\
\text { aspects (characteristics, } \\
\text { technologies and } \\
\text { enabling factors) of SM } \\
\text { - Clustering similar items }\end{array}$ & RQ1 & Publication II & Journal & Published \\
\hline \multirow[t]{3}{*}{ B } & \multirow{3}{*}{$\begin{array}{l}\text { Intelligence } \\
\text { phase }\end{array}$} & \multirow{3}{*}{$\begin{array}{l}\text { - } \quad \text { SME requirements } \\
\text { SM paradigm adoption } \\
\text { methods }\end{array}$} & RQ2a & \multirow[t]{3}{*}{ Publication III } & \multirow[t]{3}{*}{ Journal } & \multirow[t]{3}{*}{ Published } \\
\hline & & & RQ2b & & & \\
\hline & & & RQ2c & & & \\
\hline \multirow[t]{3}{*}{$\mathrm{C}$} & \multirow{3}{*}{$\begin{array}{l}\text { Conception } \\
\text { phase }\end{array}$} & \multirow{3}{*}{$\begin{array}{lc}\text { - } & \text { Map SME requirements } \\
\text { with SM paradigm } \\
\text { adoption methods } \\
\text { - } \quad \text { Identify research gaps } \\
\text { - } \quad \text { Modifications in the } \\
\text { current SM paradigm } \\
\text { adoption methods } \\
\end{array}$} & RQ2c & \multirow[t]{3}{*}{ Publication III } & \multirow[t]{3}{*}{ Journal } & \multirow[t]{3}{*}{ Published } \\
\hline & & & RQ2d & & & \\
\hline & & & RQ2e & & & \\
\hline \multirow[t]{3}{*}{$\mathrm{D}$} & \multirow{3}{*}{$\begin{array}{l}\text { Conception } \\
\text { phase } \\
\text { (creation) }\end{array}$} & - $\quad$ Propose SM toolkit & RQ3a & Publication IV & Conference & Published \\
\hline & & $\begin{array}{c}\text { - } \\
\text { Propose SM maturity } \\
\text { model }\end{array}$ & RQ3a & Publication V & Conference & Published \\
\hline & & $\begin{array}{c}\text { Propose SM paradigm } \\
\text { adoption framework }\end{array}$ & RQ3a & \multirow[t]{2}{*}{ Publication VII } & \multirow[t]{2}{*}{ Journal } & \multirow{2}{*}{$\begin{array}{l}\text { Submitted } \\
\text { on May } \\
11^{\text {th }}, 2019\end{array}$} \\
\hline $\mathrm{E}$ & $\begin{array}{l}\text { Conception } \\
\text { phase } \\
\text { (validation) }\end{array}$ & $\begin{array}{l}\text { Validation of the } \\
\text { proposed SM paradigm } \\
\text { adoption framework }\end{array}$ & RQ3b & & & \\
\hline $\mathrm{F}$ & - & $\begin{array}{l}\text { - Why SM paradigm } \\
\text { adoption framework may } \\
\text { be referred as "smart" }\end{array}$ & RQ3c & Publication VI & Conference & Accepted \\
\hline
\end{tabular}




\section{Literature Review}

The sub-sections in section 2 present a summarized literature review related to this dissertation, for an in-depth review, please refer to the Publications I-VII (attached in chapter 5).

The success of SMEs depends on how their managers/owners understand the technical, managerial, and operational aspects (White, 2009). The selection of appropriate technical and managerial aspects during decision making (Carson \& Gilmore, 2000) provides a competitive edge to the manufacturing SMEs. Therefore, a framework for adopting SM paradigm in SMEs should be informed with the help of technical, managerial, and operational aspects. Technical aspects are related with the understanding of the state-of-art technologies that will help in providing enterprises with a competitive edge, whereas, the managerial and operational aspects are the business plans and the practices that can appropriately introduce the technical aspects (Carson \& Gilmore, 2000).

\subsection{Smart Manufacturing}

During the age of craft production, manufacturing was about converting raw materials into finished form (Offodile \& Abdel-Malek, 2002), but with time manufacturing has become more complicated (Esmaeilian et al., 2016). Information plays a crucial role in understanding the needs of the market and in improving the overall system performance (Jung et al., 2016). SM can employ the available information to identify when the outbreaks occur with the help of technologies like enterprise technology, interoperability, tracking raw materials (Davis et al., 2012). SM may be referred to as the marriage of manufacturing data with information technology (Marr, 2015). In an SMS, information flow is free within the system boundary, and the information flow is controlled outside the system boundary (Jung et al., 2015). Thus, an SMS can enable the products to tailor themselves with the market requirements, where an increased demand and product variety highlighted the necessity of prediction and data-driven decision making (Wang et al., 2018).

Various technical aspects have been suggested for achieving SM. However, a list of these technical aspects, that can inform the manufacturing initiatives have been missing. The information technologies that can integrate the entire production system is available, but they are rare in MNEs and absent in the SMEs (Davis et al., 2012). As a result, before understanding the adoption of SM, it is vital to understand the various technical aspects that can be utilized in the journey towards SM paradigm adoption.

\subsection{Technical Aspects of Smart Manufacturing}

SM is about utilizing ICTs and communication technologies in manufacturing practices (Davis et al., 2015; Kang et al., 2016). Networked data, ICTs, CPS, IoT, cloud computing, data science, AI, AR, VR, robots, blockchain, 3D printing, cyber-security, IT-based production management, intelligent products, data analytics, simulation, energy-saving, real-time communication (Mittal et al., 2017; Saucedo-Martínez et al., 2017; Ghobakhloo, 2018; Xu et al., 2018) are some of the technologies that are often associated with SM.

Considering new technical aspects can be beneficial to the enterprises, as installing technologies can reduce the costs of production, increase the product quality, decrease the delivery cycles, lower the inventory levels (Skinner, 1984; Mellor et al., 2014). The technical aspects are the engineering 
prerequisites that play a vital role in adopting SM paradigm. Therefore, it is very crucial to understand the technical aspects that are related to SM. Although understanding the technical aspects is necessary, however, it is not enough for adopting SM paradigm in SMEs. The manager/owner of SMEs also needs to know when and where to implement technology and up to what extent.

\subsection{Managerial and Operational aspects of Smart Manufacturing}

The managerial and operational aspects should complement the technical aspects of SM. They may be defined as the concepts, ideas, and practices necessary for the organizational transformation towards SM/Industry 4.0 (Črešnar et al., 2018). The managerial aspects include organizational practices as business models, lean thinking, organizational culture, employee involvement (Črešnar et al., 2018; Van de Vrande et al., 2009).

Various methods for SM/Industry 4.0 adoption are present in the literature. These methods (Rockwell Automation, 2014; Anderl et al., 2015; Lichtblau et al., 2015; Weyer et al.; 2015; Ganzarain \& Errasti, 2016; Geissbauer et al., 2016; Jung et al., 2016; Qin et al., 2016; Schumacher et al., 2016; Gökalp et al., 2017; Kannan et al., 2017; Lee et al., 2017; Schuh et al., 2017; Akdil et al., 2018; Scremin et al., 2018) are in the form of frameworks, maturity models, roadmaps, readiness assessment methods. Although, these terms appear similar, however, there is a slight difference in their approaches. Frameworks consist of the guidelines for designing a system (Storey, 2005). Maturity models suggest steps to reach a more sophisticated level (Mettler, 2011). Readiness assessments can evaluate the preparedness of capabilities towards a goal (Benedict et al., 2017). Roadmaps are procedures to attain technical short-term and long-term goals (Garcia \& Bray, 1997).

Adopting SM/Industry 4.0 in SMEs context needs a well-defined methodology. The abovementioned methods suggested in the literature for adopting SM paradigm consider the use of items such as expensive high-tech technologies, highly skilled employees, similarly, these methods assume the presence of items such as a positive organizational culture that facilitates learning new skills, employee participation in decision making. But these technical and managerial aspects

might not be present in many manufacturing SMEs. As a result, the technical, managerial and operational aspects for adopting SM paradigm does not seem do not acknowledge the challenges faced by SMEs, and therefore, these methods may rather focus on adopting SM paradigm in MNEs. As a result, there is a need to develop a unique set of operational aspects for adopting SM paradigm in SMEs.

\subsection{Requirements of Manufacturing SMEs}

SMEs form a large part in the economy $(99.7 \%$ of businesses in the U.S. have less than 500 workers (Census Bureau's Annual Survey of Entrepreneurs, 2018), and similarly, 99\% of enterprises in the European Union are SMEs (European Union, 2006)). However, there are limited studies that focus on the requirements of the manufacturing SMEs. These studies (Julien \& Ramangalahy, 2003; Kennedy \& Hyland, 2003; Terziovski, 2010; Wuest \& Thoben, 2011; Kumar et al., 2014; Vasudevan \& Chawan, 2014; Dyerson et al., 2016; Müller and Voigst, 2017) were performed in different parts of the world and focused towards the limitations of the manufacturing SMEs. The results of these studies have shown that financial resources, use of advanced 
manufacturing technologies, use of software, product specialization, adherence to industrial standards, organizational culture, employee participation, alliances with Universities/ research institutions, collaboration with customers/suppliers are the broad requirements of the manufacturing SMEs.

Overall, to adopt SM paradigm, the SMEs must facilitate the learning of its employees. Similarly, the employees should also be ready to continuously transform them towards learning new skills and accepting the organizational changes. As a result, it might be said that SMEs should become a learning organization to adopt SM paradigm (Senge, 1991). 


\section{Adopting Smart Manufacturing in SMEs}

This chapter presents a summary of the peer-reviewed publications associated with this dissertation project. The subsections 3.1-3.7 depict a summary of publications I-VII, with the help of a short description, results, and the discussion and the conclusions.

Figure 2 presents a schematic showing how the publications I-VII were associated with each other. Figure 2 also shows how the answers to the three research questions (developed in the current dissertation), were able to attain the overall objective of developing a framework for guiding the SMEs in their SM paradigm adoption journey.

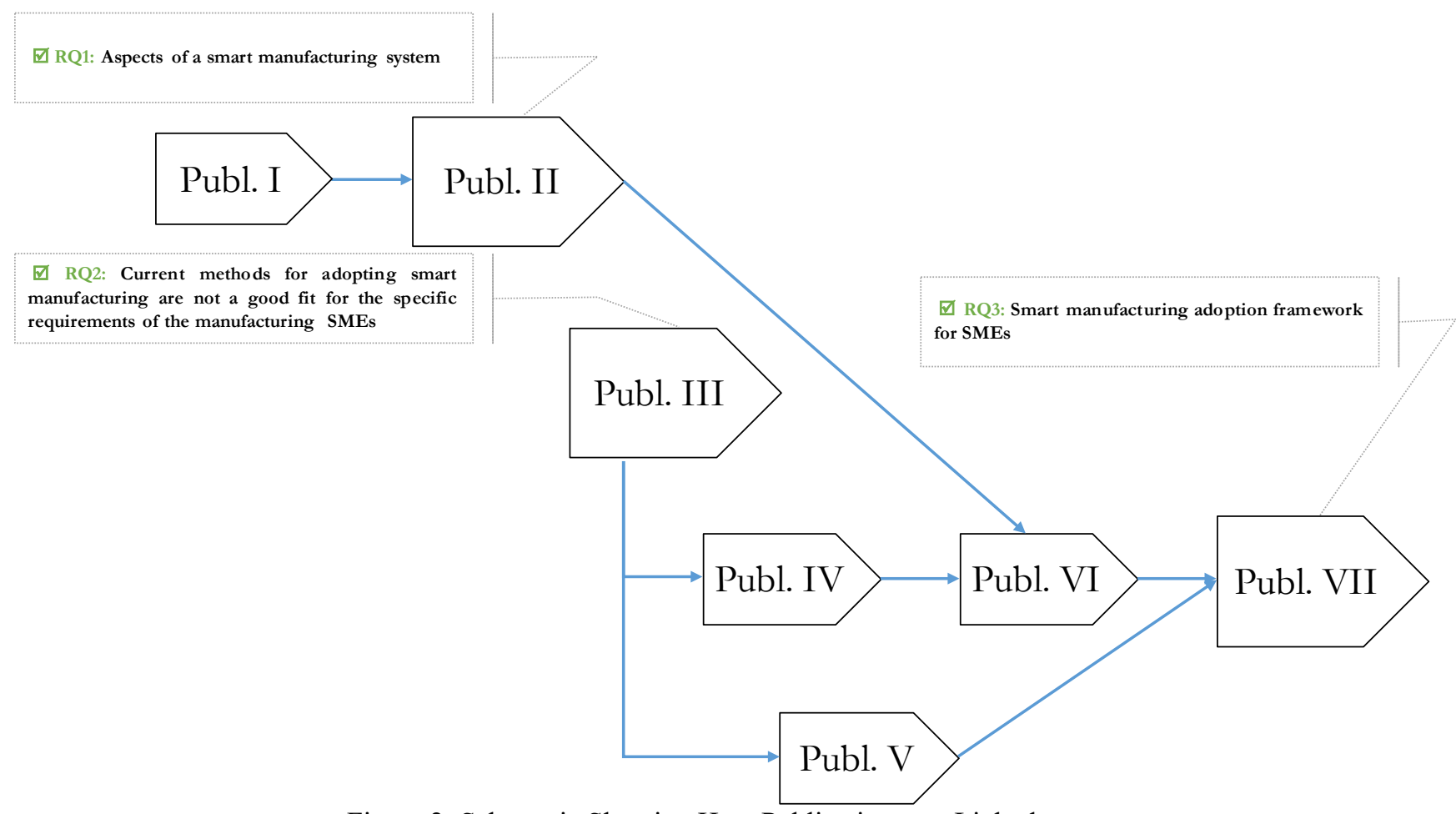

Figure 2: Schematic Showing How Publications are Linked

All published publications (and the preprint versions for publications VI \& VII only) are attached in the appendix of this document for your reference. 


\subsection{Smart Manufacturing: Characteristics \& Technologies (Publ. I)}

\section{Citation}

Mittal, S., Khan, M. A., \& Wuest, T. (2016, July). Smart manufacturing: characteristics and technologies. In IFIP International Conference on Product Lifecycle Management (pp. 539-548). Springer, Cham.

\section{Short Description}

Although, SM is often used in scientific literature, however, a proper definition of SM is not mentioned. The technical aspects of SM, that might help in defining it has been missing. As a result, the Publication I review and collects these building blocks (a common term for technical prerequisites that can help in installing SM). The review was limited to "Smart Manufacturing" and the other terms like Industry 4.0, smart factory, intelligent manufacturing that are related to SM were not considered.

\section{Results}

The results identified that there are characteristics and technologies that relate to SM, and at times, the researchers have referred to the same characteristics, and technologies with different terminology.

\section{Discussion and Conclusion}

Publication I contribute by finding that building blocks for SM and clusters them into five characteristics and ten technologies (Table 6). These building blocks may also be used to determine if a manufacturing initiative may be referred to as SM or not.

\begin{tabular}{|c|c|}
\hline Characteristics & Technologies \\
\hline $\begin{array}{ll}\text { - } & \text { Context Awareness } \\
\text { - } & \text { Modularity } \\
\text { - } & \text { Heterogeneity } \\
\text { - } & \text { Compositionality } \\
\text { - } & \text { Interoperability }\end{array}$ & $\begin{array}{ll}\text { - } & \text { Intelligent Control } \\
\text { - } & \text { Energy Saving/Energy Efficiency } \\
\text { - } & \text { Cyber Security } \\
\text { - } & \text { Cyber Physical Infrastructure } \\
\text { - } & \text { Visual Technology } \\
\text { - } & \text { IoT/IoS } \\
\text { - } & \text { Cloud Computing/Manufacturing } \\
\text { - } & \text { 3-D Printing/Additive Manufacturing } \\
\text { - } & \text { Smart Products/Parts } \\
\text { - } & \text { Data Analytics }\end{array}$ \\
\hline
\end{tabular}




\subsection{Smart Manufacturing: Characteristics, Technologies \& Enabling Factors (Publ. II)}

\section{Citation}

Mittal, S., Khan, M. A., Romero, D., \& Wuest, T. (2017). Smart manufacturing: characteristics, technologies and enabling factors. Proceedings of the Institution of Mechanical Engineers, Part B: Journal of Engineering Manufacture, 233(5), 1342-1361.

\section{Short Description}

A more comprehensive literature review (expansion of Publication I) was performed to find the technical aspects that are often associated with SM. Here also "Smart Manufacturing" was deployed as the search term, and the other manufacturing initiatives were not considered. The concept of semantic similarity was used to cluster the keywords that denoted similar items.

\section{Results}

It was found that there are characteristics, technologies and enabling factors that may be associated with a SM. Researchers have denoted these building blocks by using different terminology.

\section{Discussion and Conclusion}

Publication II contributes by clustering twenty-seven characteristics, thirty-eight technologies and seven enabling factors into the clusters of five characteristics, eleven technologies and three enabling factors (Table 7) with the help of principle of semantic similarity (Harispe et al., 2015). These are the building blocks that an SMS may find appropriate. The SM building blocks were compared with the Industry 4.0 design principles and the proposed manifestations of Industry 4.0, and it was found that both SM and Industry 4.0 are synonymous.

Table 7: Smart Manufacturing Building Blocks (Comprehensive) Identified in Publication II

\begin{tabular}{|c|c|c|}
\hline Characteristics & $\begin{array}{c}\text { Technologies } \\
\end{array}$ & Enabling Factors \\
\hline $\begin{array}{ll}\text { - } & \text { Context Awareness } \\
\text { - } & \text { Modularity } \\
\text { - } & \text { Heterogeneity } \\
\text { - } & \text { Compositionality } \\
\text { - } & \text { Interoperability }\end{array}$ & $\begin{array}{ll}\text { - } & \text { Intelligent Control } \\
\text { - } & \text { Energy Saving/Energy Efficiency } \\
\text { - } & \text { Cyber Security } \\
\text { - } & \text { Cyber Physical Infrastructure } \\
\text { - } & \text { Visual Technology } \\
\text { - } & \text { IoT/IoS } \\
\text { - } & \text { Cloud Computing/Manufacturing } \\
\text { - } & \text { 3-D Printing/Additive } \\
\text { - } & \text { Manufacturing } \\
\text { - } & \text { Data Analytics } \\
\text { - } & \text { IT-based production management }\end{array}$ & $\begin{array}{ll}\text { - } & \text { Laws and regulations } \\
\text { - } & \text { Innovative education and training } \\
\text { - } & \text { Data sharing systems and standards }\end{array}$ \\
\hline
\end{tabular}




\subsection{A Critical Review of Smart Manufacturing \& Industry 4.0 Maturity Models: Implications for Small and Medium-sized Enterprises (SMEs) (Publ. III)}

\section{Citation}

Mittal, S., Khan, M. A., Romero, D., \& Wuest, T. (2018). A critical review of smart manufacturing \& Industry 4.0 maturity models: Implications for small and medium-sized enterprises (SMEs). Journal of manufacturing systems, 49, 194-214.

\section{Short Description}

This publication first discussed and compared the stand of SMEs and MNEs when it comes to the features of manufacturing industries. The features for which SMEs needed to improve were referred to as SME specific requirements. It was found that financial resources, advanced manufacturing technologies, industrial standards, organizational culture, employee participation, research alliances with universities and institutions are the requirements of the manufacturing SMEs. In addition, the roadmaps, frameworks, and maturity models leading towards SM, Industry 4.0 and Smart Factory were studied. As there were not many methods that guided enterprises towards SM, this publication also reviewed the methods orienting towards Industry 4.0, and Smart Factory.

\section{Results}

When the SME specific requirements were mapped with the methods of adopting SM, a critical review led to the finding that currently there are no methods that can fulfill all the SME requirements and help SMEs in their SM paradigm adoption journey.

\section{Discussion and Conclusion}

Publication III identified the unique requirements of the SMEs and performed a critical review on how well the existing methods can satisfy these requirements and based on the critical review it determines the research gaps that might help in modifying the existing methods for SM paradigm adoption from an SME's perspective. The potential answers for the identified research gaps were also discussed.

The identified research gaps are:

- Firstly, the current starting or the "level 1" of most maturity models is disconnected from the actual readiness level of many SMEs.

- Secondly, the transition from this new base level, "level 0", to the current "level 1" requires significant efforts including a mind-set change.

- Thirdly, maturity models and readiness assessments need to be integrated with an SM toolkit.

- Fourthly, SMEs need to develop their tailored vision of SM that can be realized with the help of the SM toolkit. 


\subsection{Towards a Smart Manufacturing Toolkit for SMEs (Publ. IV)}

\section{Citation}

Mittal, S., Romero, D., \& Wuest, T. (2018, July). Towards a smart manufacturing toolkit for SMEs. In IFIP International Conference on Product Lifecycle Management (pp. 476-487). Springer, Cham.

\section{Short Description}

A toolkit is a set of methods, tools, practices, and technologies (Odedairo and Bell, 2010) that might help in enhancing some capabilities. Importance of modular and economic toolkits was realized during the visit to SMEs, and the discussion with the SME managers. Toolkits may be installed in SMEs to improve their existing capabilities. This publication proposes a toolkit for SM with the help of a literature review and discussions held during the SME visits.

\section{Results}

The toolkit consists of seven toolboxes that acknowledge both technical and managerial aspects of an enterprise. The seven toolboxes are: i) Fabrication and Manufacturing Tools, ii) Design and Simulation Tools, iii) Robotics \& Automation Tools, iv) Sensors and Connectivity Tools, v) Cloud/ Storage Tools, vi) Data Analytics Tools, and the vii) Business Management Tools. Each toolbox was proposed in five levels, namely, novice, beginner, learner, intermediate and experts, where the degree of SM realization increases from novice to expert.

\section{Discussion and Conclusion}

Publication IV develops an SM toolkit that contains seven modular toolboxes. The toolboxes acknowledge both the technological and managerial perspectives of the industry. The inputs required for each toolbox at all five levels were also mentioned. Finally, two demonstrations that deployed these toolboxes were presented. The first demonstration showed how the old analogue lathe and mill machines were made smarter with the help of the sensors and connectivity tools, whereas the second demonstration proposed how a visual inspection machine (a robotic \& automation tool) may be deployed in a garment inspection SME to detect the garment defects more consistently. 


\subsection{Towards Smart Manufacturing Maturity Model for SMEs (Publ. V)}

\section{Citation}

Mittal, S., Romero, D., \& Wuest, T. (2018, August). Towards a Smart Manufacturing Maturity Model for SMEs (SM 3 E). In IFIP International Conference on Advances in Production Management Systems (pp. 155-163). Springer, Cham.

\section{Short Description}

Maturity models can define its levels in terms of components and sub-components, and therefore they might be a channel for SMEs journey towards SM paradigm adoption. This publication proposes a three- dimensional SM maturity model for manufacturing SMEs $\left(\mathrm{SM}^{3} \mathrm{E}\right)$.

\section{Results}

$\mathrm{SM}^{3} \mathrm{E}$ have organizational dimensions on $\mathrm{X}$-axis, the toolkit on $\mathrm{Y}$-axis and the five maturity levels on the Z-axis. The five organizational dimensions, finance, people, strategy, process, and product serve the basic organizational structure and enterprise functions of SME. The dimensions acknowledged the evolution of manufacturing systems and were designed with an SME perspective and their specific requirements.

\section{Discussion and Conclusion}

Publication V develops an SM maturity model (Figure 3) towards the SM framework for the SMEs. It also mentions the key activities corresponding to how the organizational dimensions are served by a toolbox at different levels.

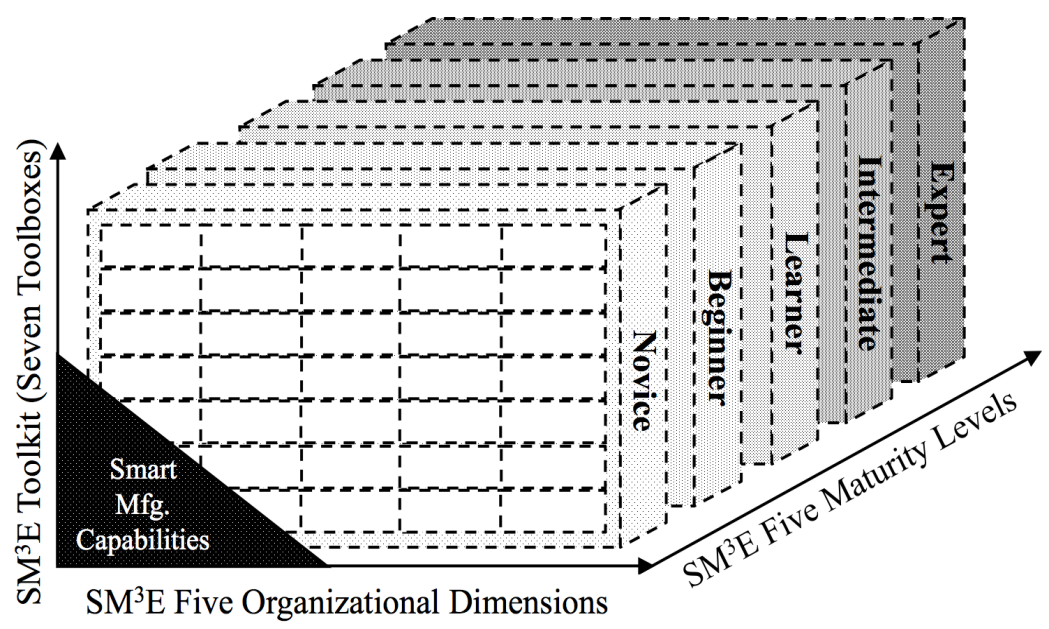

Figure 3: Smart Manufacturing Maturity Model for SMEs (Mittal et al., 2018b) 


\subsection{Building Blocks for Adopting Smart Manufacturing (Publ. VI)}

\section{Citation}

Mittal, S., Khan, M. A., Romero, D., \& Wuest, T. (2019). Building Blocks for adopting Smart Manufacturing. In Procedia Manufacturing Vol. 24 (pp. 978-985).

\section{Short Description}

SM paradigm adoption can reduce the cost of production on the one hand and can help in the faster demand fulfillment on the other side. As a result, manufacturing enterprises plan to align themselves towards SM. However, the manufacturing enterprises are still not confident about what are the building blocks that might assist them in aligning themselves towards SM. As a result, publication VI performs a systematic mapping review to identify the most frequently used building blocks for adopting SM paradigm.

\section{Results}

Robots and blockchain were added to the existing list of SM building blocks. The most frequently utilized building blocks for adopting SM were identified (Figure 4).

\section{Discussion and Conclusion}

Publication VI identified that intelligent control, data sharing systems and standards, data analytics, interoperability, IT-based production management are the most frequently used building blocks preferred for adopting SM paradigm. Whereas, blockchain, robots, visual technology are the least used building blocks for SM.

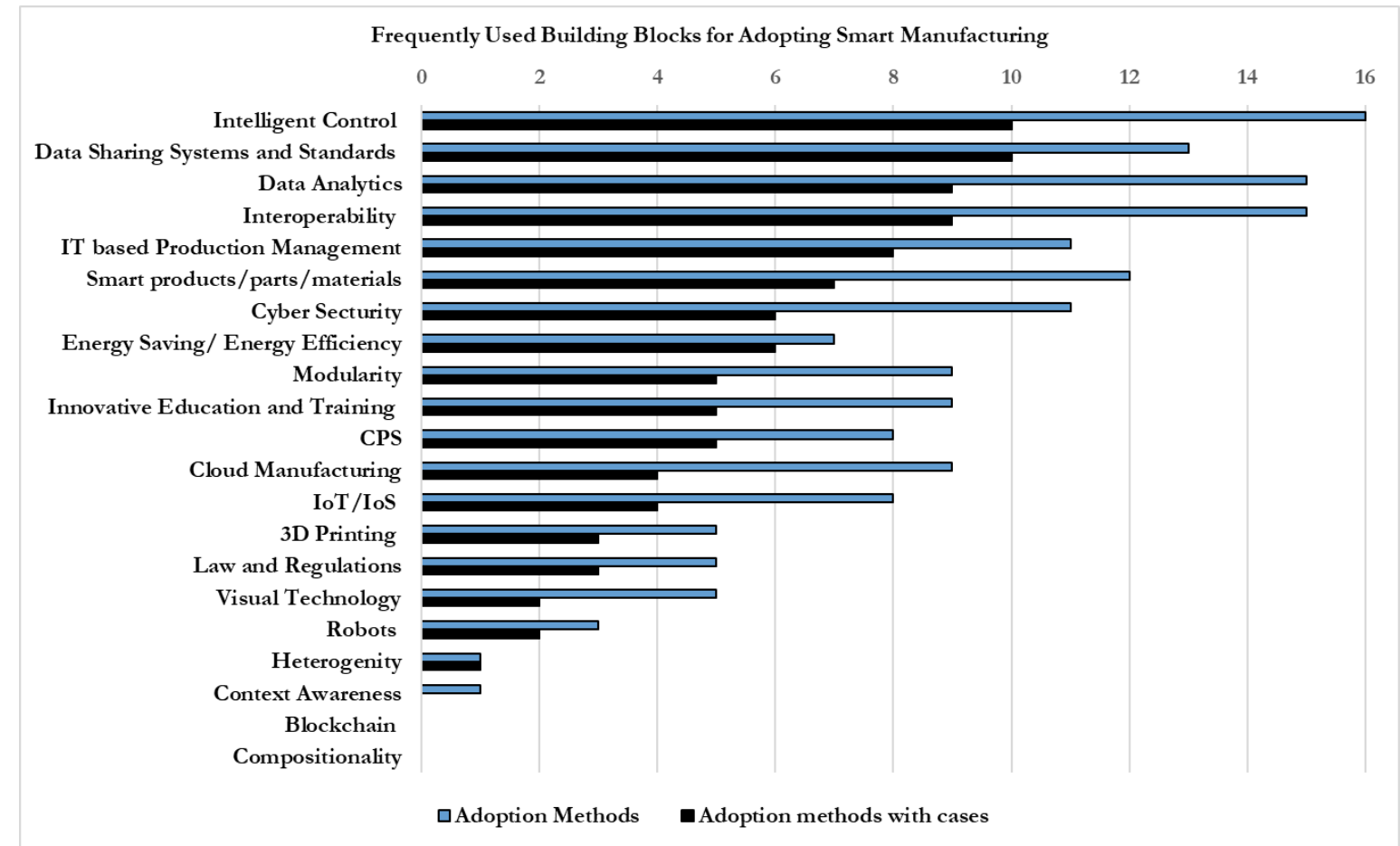

Figure 4: Frequently Used Building Blocks for Adopting Smart Manufacturing (Mittal et al., 2019) 


\subsection{A Smart Manufacturing Adoption Framework for SMEs (Publ. VII)}

\section{Citation}

Mittal, S., Khan, M., Purohit, J., Menon, K., Romero, D. \& Wuest, T. (20XX). A smart manufacturing adoption framework for SMEs. Currently under review.

\section{Short Description}

Adopting SM is a challenging task for SMEs, but straightforward steps for adopting SM paradigm might help SMEs. An SME framework should include the guidelines towards finding the readiness and then defining a tailored vision with the help of appropriate tools.

\section{Results}

The instrumental research approach was applied, and the necessity of developing an SM paradigm adoption framework for SMEs was realized. The developed SM paradigm adoption framework was validated by employing multiple case studies in the two unique manufacturing SMEs that have already taken their steps towards SM.

\section{Discussion and Conclusion}

Publication VII presented an SM paradigm adopting framework that used existing data in the manufacturing SMEs to assess its SM readiness. Based on the readiness level and SMEs understanding of the market, SMEs can develop their tailored vision of SM. Finally, the tailored vision was realized with the help of SM tools and practices. Various findings related to SM paradigm adoption in case SMEs were also shared. 


\section{Conclusion, Limitations and Recommendation for Future Works}

In the following sub-sections, the conclusion, summary of the answers to the research questions, limitations and the recommendations for the future work have been presented.

\subsection{Conclusion}

This section presents the concluding remarks from the doctorate student.

The objective of this thesis was to support manufacturing SMEs towards SM paradigm adoption. This overarching objective was achieved with the help of three broad research questions (RQ 13). The summarized answers of these research questions have been discussed in section 4.2.

Various manufacturing initiatives were started by the international governments to support the manufacturing industries of their own countries. SM was an initiative that started with the collaboration of the U.S. government, universities, and private agencies. It was observed that the scientific publications and the white papers did not defined SM. As a result, a review was performed to identify the various aspects that define SM. It was found that there were sets of characteristics, technologies, and enabling factors that are associated with the SM.

The scientific literature and the white papers suggested various methods for adopting SM. However, when these methods were critically discussed from the perspective manufacturing SMEs, it was identified that the current literature does not include a method that can support in manufacturing SMEs' transition towards SM. The current methods were also critically discussed to identify where they lack when it comes to guiding SMEs. It was found that these methods assume the presence of resources like advanced manufacturing technologies, favorable organizational culture, and a skilled workforce. However, SMEs do not possess these resources.

Finally, an SM adoption framework from SMEs perspective was developed. The framework acknowledged the existing data-related activities in the manufacturing SMEs and assessed the SM readiness of the SMEs based on these activities. The present readiness of SMEs, and the SM awareness helped SMEs in developing their own tailored vision of SM. The SME tailored vision was achieved with the help of modular tools and practices. These modular tools and practices were associated with the aspects of SM. Thus, the overall objective of this dissertation was realized.

\subsection{Summary of RQ's Answers}

Here is discussed the answers to the original research questions outlined in the section 1.3.

\section{RQ1: What makes a manufacturing system smart?}

This question was answered with the help of a systematic literature review. It was found that there were similar characteristics, technologies and enabling factors that were referred by different terms. As a result, the principle of semantic similarity was used to cluster such similar terms. This question was answered with the help of Publication I and II. Finally, SM was associated with five characteristics, eleven technologies and three enabling factors.

\section{RQ2: Are the current SM paradigm adoption methods a good fit for the specific requirements of the manufacturing SMEs?}


A critical review was performed to answer this question and its sub-questions. This question was answered in the Publication III. It was found that the existing methods do not serve the specific requirements of the manufacturing SMEs.

2a) What are the specific requirements of manufacturing SMEs?

- This question was answered with the help of a literature review. Broadly, financial resources, advanced manufacturing technologies, industrial standards (like ISO), organizational culture, employee participation, alliances with Universities and research institutions and collaborations with other enterprises were identified as the requirements of the manufacturing SMEs.

2b) What are the current methods supporting SM paradigm adoption?

- This question was also answered with the help of a literature review. Fifteen different methods supporting SM paradigm adoption were identified. These methods were in the form of maturity models, readiness models, roadmaps and frameworks.

2c) Are the currently available methods a good fit for the requirements of manufacturing SMEs?

- An analysis using critical review was performed to answer this question. It was found that, the currently available methods in the literature are not a good fit for the requirements of manufacturing SMEs.

2d) What are the research gaps that prevent current SM maturity models from providing the missing SME specific support?

- The answer of this question was the result of the critical analysis performed in $2 c$ ). Four research gaps were identified in this regard.

2e) How can the current SM maturity models be adapted to support SMEs' specific requirements in their evolutionary path and the paradigm shift towards SM and Industry 4.0?

- To answer this question the research gaps identified in 2d) were acknowledged and a solution was proposed.

\section{RQ3: How can SMEs adopt SM paradigm?}

This question and its sub-questions were answered with the help of the publications IV-VII. In this regard, a framework expanding on the suggestions provided in 2e) was proposed and validated with the help of SME cases that have already started their SM paradigm adoption journey.

3a) Considering the adoption of SM in SMEs, how should a suitable framework/guideline be designed?

- To answer this question the research gaps proposed in 2d) were acknowledged to develop an SM paradigm adoption framework for SMEs.

3b) What lessons learned can be drawn from use cases of SMEs recently adopting SM practices and how can they help to validate the framework suggested in $3 a$ ? 
- This question employed case study research to validate the framework proposed in $3 a$ ).

3c) Why this framework can be referred to as SM framework?

- The various tools and practices used in this framework were mapped with the building blocks of SM. It was found that many SM technologies and enabling factors were a part of SM enabling factors. Therefore, it was right to refer to this framework as smart.

\subsection{Limitations and Future Work}

This section outlines the limitations of this dissertation. Overall, it summarizes the specific limitations that existed in the seven peer-reviewed publications.

The publications I and II clustered the building blocks of SM into characteristics, technologies, and enabling factors. Literature did not directly mention a building block as a characteristic, technology, or an enabling factor. As a result, the subjective perspective of the authors was employed to consider it as a characteristic, technology, or an enabling factor. Similarly, at times, the exact definitions of the building blocks were not provided. Therefore, the clusters in the publication I \& II were based on the knowledge and experience of the authors.

The publication III was developed with the help of a literature review. There was no primary research data to support the findings. Similarly, the cultural, political, and location-based biases that play an important role during technology adoption. However, these biases were not considered in the publication. In addition, there were not many adoption methods available in the literature during the development of this manuscript. As a result, there were five white papers considered.

The publications IV and V proposed an SM toolkit and an SM maturity model. However, they were not validated with the help of a quantitative study. Instead, its inputs were established with the help of multiple case study research (in the framework developed in Publication VII).

The publication VI performed a systematic mapping review. However, the building blocks in the review were identified from the reviewed articles only. Similarly, the methods for adopting SM considered white papers as well.

The publication VII proposed an SM paradigm adoption framework for SMEs. However, this framework might need an expert. Similarly, the SMEs cases considered during the current research followed the production policies based on engineer-to-order principles only.

\subsection{Future Work}

This section outlines the future work of this dissertation. It also presents a solution to the limitations that existed in the original seven peer-reviewed publications.

The list of clusters mentioned in the publications I and II may be expanded by further reviewing the state-of-art building blocks that are associated with the SM. In this regard, when new technologies were reviewed in publication VI, some technologies were included in the existing technology cluster, whereas some other technologies formed a new cluster. 
In publication II, the design principles of SM and Industry 4.0 were compared, and it was found that the two initiatives are synonymous. The design principles of other manufacturing initiatives like the smart factory, intelligent manufacturing, may be compared and evaluated to identify if they are similar or different from SM.

The specific requirements of manufacturing SMEs may be identified with the help of primary data. Similarly, primary data may be employed to check if the current methods for adopting SM fit to these requirements of manufacturing SMEs. The cultural, political, and location-based factors might also be studied. In addition, when more methods for adopting SM are available in the scientific literature, the researchers can avoid considering the white papers.

The SM toolkit and the SM maturity model proposed in the publications IV and V may be validated with the help of quantitative studies based on the primary data collected from the manufacturing SMEs.

The findings in the publication VI may be checked and updated with a more exhaustive review of the state-of-the-art methods employed to find the most preferred building blocks for adopting SM paradigm.

The framework proposed in the publication VII can be refined and adapted in the form of a selfevaluation tool. The tool can also be complemented by sharing lessons learned from successful SMEs that have successfully adopted SM tools and practices. Similarly, the framework may be applied to the SMEs that follow make-to-stock, make-to-order, and assemble-to-order production principle.

The SM adoption framework may also employ the concept of temporal think $\left.\operatorname{tank}^{\mathrm{TM}} \mathbf{( T 3}^{\mathrm{TM}}\right)$ to create cross-departmental teams that can regularly interact to discuss the new ideas (Lindeke et al., 2009). This concept may also be evaluated with the help of primary data collected from the manufacturing enterprises. 


\section{References:}

Anderl, R., Picard, A., Wang, Y., Fleischer, J., Dosch, S., Klee, B., \& Bauer, J. (2015). Guideline Industrie 4.0-guiding principles for the implementation of Industrie 4.0 in small and medium sized businesses. In VDMA Forum Industrie, Vol. 4. ISBN: 978-3-8163-0687-0

Akdil, K. Y., Ustundag, A., \& Cevikcan, E. (2018). Maturity and readiness model for Industry 4.0 strategy. In Industry 4.0: Managing the Digital Transformation (pp. 61-94). Springer, Cham. DOI: 10.1007/978-3-319-57870-5_4.

Åkerman, M. (2018). Implementing shop floor IT for Industry 4.0. Chalmers University of Technology.

Benedict, N., Smithburger, P., Donihi, A. C., Empey, P., Kobulinsky, L., Seybert, A., ... \& Meyer, S. (2017). Blended simulation progress testing for assessment of practice readiness. American journal of pharmaceutical education, 81(1), 14.

Carson, D., \& Gilmore, A. (2000). SME marketing management competencies. International Business Review, 9(3), 363-382.

Census Bureau's Annual Survey of Entrepreneurs (2018). Retrieved in June 2019 from https://www.census.gov/data/tables/2016/econ/ase/allcompanytables.html

Chiang, Y., \& Lee, D. (2017). Smart manufacturing with the internet of makers. Journal of the Chinese Institute of Engineers, 40(7), 585-592.

Creswell, J. W. (2014). Research design: International student edition. Sage publications.

Črešnar, R., Protcan, V., Nedelko, Z. (2018). Management tools for supporting the transition of manufacturing organizations to Industry 4.0: The case of Slovenia. IACSC 2018 - IACLPM 2018 joint conference proceedings.

Davis, J., Edgar, T., Porter, J., Bernaden, J., \& Sarli, M. (2012). Smart manufacturing, manufacturing intelligence and demand-dynamic performance. Computers \& Chemical Engineering, 47, 145-156.

Davis, J., Edgar, T., Graybill, R., Korambath, P., Schott, B., Swink, D., ... \& Wetzel, J. (2015). Smart manufacturing. Annual review of chemical and biomolecular engineering, 6, 141-160.

Dyerson, R., Spinelli, R., \& Harindranath, G. (2016). Revisiting IT readiness: An approach for Small firms. Industrial Management \& Data Systems, 116(3):546-563.

European Commission (2003). Retrieved in April 2018 from http://ec.europa.eu/growth/smes/business-friendlyenvironment/sme-definition_en

European Commission (2006). Retrieved in October 2018 from

http://ec.europa.eu/regional_policy/sources/conferences/state aid/sme/smedefinitionguide_en.pdf

Esmaeilian, B., Behdad, S., \& Wang, B. (2016). The evolution and future of manufacturing: A review. Journal of Manufacturing Systems, 39, 79-100.

Fernandez, A., Insfran, E., \& Abrahão, S. (2011). Usability evaluation methods for the web: A systematic mapping study. Information and software Technology, 53(8), 789-817.

Ganzarain, J., \& Errasti, N. (2016). Three stage maturity model in SME's toward Industry 4.0. Journal of Industrial Engineering and Management, 9(5):1119-1128.

Garcia, M. L., \& Bray, O. H. (1997). Fundamentals of technology roadmapping (pp. 3-31). Albuquerque, NM: Sandia National Laboratories. 
Geissbauer, R., Vedso, J., \& Schrauf, S. (2016). Industry 4.0: Building the digital enterprise: 2016 Global Industry 4.0 survey. PricewaterhouseCoopers, Munich. Retrieved April 2018 from https://www.pwc.com/gx/en/industries/industries-4.0/landing-page/industry-4.0-building-your-digital-enterpriseapril-2016.pdf

Gershwin, S. B. (2018). The future of manufacturing systems engineering. International Journal of Production Research, 56(1-2), 224-237.

Ghobakhloo, M. (2018). The future of manufacturing industry: A strategic roadmap toward Industry 4.0. Journal of Manufacturing Technology Management, 29(6), 910-936.

Gökalp, E., Şener, U., \& Eren, P. E. (2017). Development of an assessment model for Industry 4.0: Industry 4.0-MM. In International Conference on Software Process Improvement and Capability Determination (pp. 128-142). Springer, Cham.

Grant, M. J., \& Booth, A. (2009). A typology of reviews: an analysis of 14 review types and associated methodologies. Health Information \& Libraries Journal, 26(2), 91-108.

Harispe, S., Ranwez, S., Janaqi, S., \& Montmain, J. (2015). Semantic similarity from natural language and ontology analysis. Synthesis Lectures on Human Language Technologies, 8(1), 1-254.

Julien, P. A., \& Ramangalahy, C. (2003). Competitive strategy and performance of exporting SMEs: An empirical investigation of the impact of their export information search and competencies. Entrepreneurship Theory and Practice, 27(3), 227-245.

Jung, K., Morris, K. C., Lyons, K. W., Leong, S., \& Cho, H. (2015). Mapping strategic goals and operational performance metrics for smart manufacturing systems. Procedia Computer Science, 44, 184-193.

Jung, K., Kulvatunyou, B., Choi, S., \& Brundage, M.P. (2016). An overview of a smart manufacturing system readiness assessment. IFIP International Conference on Advances in Production Management Systems, pp. 705-712, Cham, Switzerland: Springer.

Kang, H. S., Lee, J. Y., Choi, S., Kim, H., Park, J. H., Son, J. Y., ... \& Do Noh, S. (2016). Smart manufacturing: Past research, present findings, and future directions. International Journal of Precision Engineering and ManufacturingGreen Technology, 3(1), 111-128.

Kannan, S.M., Suri, K., Cadavid, J., Barosan, I., Brand, M.V.D., Alferez, M., \& Gerard, S. (2017). Towards Industry 4.0: Gap analysis between current automotive MES and industry standards using model-based requirement engineering. arXiv preprint arXiv:1704.02824.

Kennedy, J., \& Hyland, P. (2003). A comparison of manufacturing technology adoption in SMEs and large companies. Proceedings of 16th Annual Conference of Small Enterprise Association of Australia and New Zealand, pp. 1-10, Ballarat, City in Victoria, Australia.

Kumar, M., Khurshid, K.K., \& Waddell, D. (2014). Status of Quality Management Practices in Manufacturing SMEs: A Comparative Study between Australia and the UK. International Journal of Production Research, 52(21):64826495 .

Kusiak, A. (2017). Smart manufacturing must embrace big data. Nature News, 544(7648), 23.

Lee, J., Jun, S., Chang, T.W., \& Park, J. (2017). A Smartness Assessment Framework for Smart Factories Using Analytic Network Process. Sustainability, 9(5):794-808.

Lichtblau, K., Stich, V., Bertenrath, R., Blum, M., Bleider, M., Millack, A., et al. (2015). IMPULS-Industrie 4.0Readiness. Impuls-Stiftung des VDMA, Aachen-Köln. Retrieved April 2018 from http://www.impulsstiftung.de/documents/3581372/4875835/Industrie+4.0+Readniness+IMPULS+Studie+Oktober+2015.pdf/447a6187 -9759-4f25-b186-b0f5eac69974 
Lindeke, R. R., Wyrick, D. A., \& Chen, H. (2009). Creating change and driving innovation in highly automated and lean organizations: The Temporal Think Tank ${ }^{\mathrm{TM}}\left(\mathrm{T}^{\mathrm{TM}}\right)$. Robotics and Computer-Integrated Manufacturing, 25(6), 879-887.

Marr, B. (2015). Big Data: Using SMART big data, analytics and metrics to make better decisions and improve performance. John Wiley \& Sons.

Martek, A. (1986). La recherche instrumentale sectorielle en sciences de l'administration1. La Production Des Connaissances Scientifiques de L'administration, 1, 281.

Mattessich, R. (2012). Instrumental reasoning and systems methodology: an epistemology of the applied and social sciences (Vol. 15). Springer Science \& Business Media.

Mellor, S., Hao, L., \& Zhang, D. (2014). Additive manufacturing: A framework for implementation. International Journal of Production Economics, 149, 194-201.

Mettler, T. (2011). Maturity assessment models: a design science research approach. International Journal of Society Systems Science (IJSSS), 3(1/2), 81-98.

Mittal, S., Khan, M. A., Romero, D., \& Wuest, T. (2017). Smart manufacturing: Characteristics, technologies and enabling factors. Proceedings of the Institution of Mechanical Engineers, Part B: Journal of Engineering Manufacture, 0954405417736547.

Mittal, S., Khan, M. A., Romero, D., \& Wuest, T. (2018a). A critical review of smart manufacturing \& Industry 4.0 maturity models: Implications for small and medium-sized enterprises (SMEs). Journal of manufacturing systems, 49, 194-214.

Mittal, S., Romero, D., \& Wuest, T. (2018b, August). Towards a smart manufacturing maturity model for SMEs (SM 3 E). In IFIP International Conference on Advances in Production Management Systems (pp. 155-163). Springer, Cham.

Mittal, S., Khan, M. A., Romero, D., \& Wuest, T. (2019). Building Blocks for adopting Smart Manufacturing. In SME North American Research Conference. Procedia Manufacturing Vol. 34 (pp. 978-985).

Moreira, N., de Santa-Eulalia, L. A., Aït-Kadi, D., Wood-Harper, T., \& Wang, Y. (2015). A conceptual framework to develop green textiles in the aeronautic completion industry: a case study in a large manufacturing company. Journal of Cleaner Production, 105, 371-388.

Müller, J.M., \& Voigt, K.I. (2017). Industry 4.0-Integration Strategies for Small and Medium-Sized Enterprises. In International Association for Management of Technology (IAMOT), pp. 1-15, Vienna, Austria.

Odedairo, B. O., \& Bell, D. (2010). Framework for introducing and implementing value methods: a novel toolkit for small and medium scale industries in developing nations. International Journal of Basic \& Applied Sciences IJBAS, 9(10), 130-146.

Offodile, O. F., \& Abdel-Malek, L. L. (2002). The virtual manufacturing paradigm: The impact of IT/IS outsourcing on manufacturing strategy. International Journal of Production Economics, 75(1-2), 147-159.

Qin, J., Liu, Y., \& Grosvenor, R. (2016). A Categorical Framework of Manufacturing for Industry 4.0 and Beyond. Procedia CIRP, 52, 173-178.

Rockwell Automation (2014). The connected enterprise maturity model. Rockwell Automation. Retrieved April 2018 from http://iterature.rockwellautomation.com/idc/groups/literature/documents/wp/cie-wp002 -en-p.pdf

Saucedo-Martínez, J. A., Pérez-Lara, M., Marmolejo-Saucedo, J. A., Salais-Fierro, T. E., \& Vasant, P. (2017). Industry 4.0 framework for management and operations: a review. Journal of Ambient Intelligence and Humanized Computing, 1-13. 
Schuh, G., Anderl, R., Gausemeier, J., Hompel, M., \& Wahlster, W. (2017). Industrie 4.0 maturity index. Retrieved April 2018 from http://www.acatech.de/fileadmin/user_upload/Baumstruktur_nach_Website/Acatech/root/de/Publikationen/Projektb erichte/acatech_STUDIE_Maturity_Index_eng_WEB.pdf

Schumacher, A., Erol, S., \& Sihn, W. (2016). a maturity model for assessing Industry 4.0 readiness and maturity of manufacturing enterprises. Procedia CIRP, 52, 161-166.

Scremin, L., Armellini, F., Brun, A., Solar-Pelletier, L., \& Beaudry, C. (2018). towards a framework for assessing the maturity of manufacturing companies in Industry 4.0 adoption. In Analyzing the Impacts of Industry 4.0 in Modern Business Environments (pp. 224-254). IGI Global.

Senge, P. M. (1991). The fifth discipline, the art and practice of the learning organization. Performance+ Instruction, 30(5), 37-37.

Skinner, W. (1984). Operations technology: Blind spot in strategic management. Interfaces, 14(1), 116-125.

Strozzi, F., Colicchia, C., Creazza, A., \& Noè, C. (2017). Literature review on the 'Smart Factory' concept using bibliometric tools. International Journal of Production Research, 55(22), 6572-6591.

Storey, M. A. (2005, May). Theories, methods and tools in program comprehension: Past, present and future. In Program Comprehension, 2005. IWPC 2005. Proceedings. 13th International Workshop on (pp. 181-191). IEEE.

Syafrudin, M., Fitriyani, N., Alfian, G., \& Rhee, J. (2019). An affordable fast early warning system for edge computing in assembly line. Applied Sciences, 9(1), 84 .

Tao, F., Qi, Q., Liu, A., \& Kusiak, A. (2018). Data-driven smart manufacturing. Journal of Manufacturing Systems, 48, 157-169.

Terziovski, M. (2010). Innovation Practice and its Performance Implications in small and medium enterprises (SMEs) in the manufacturing sector: A resource-based view. Strategic Management Journal, 31(8):892-902.

Trotta, D., \& Garengo, P. (2018, March). Industry 4.0 key research topics: A bibliometric review. In Industrial Technology and Management (ICITM), 2018 7th International Conference on (pp. 113-117). IEEE.

Thoben, K. D., Wiesner, S., \& Wuest, T. (2017). "Industrie 4.0” and smart manufacturing-a review of research issues and application examples. International Journal of Automation Technology, 11(1), 4-16.

Vasudevan, H., \& Chawan, A. (2014). Demystifying Knowledge Management in Indian manufacturing SMEs. Procedia Engineering, 97, 1724-1734.

Wang, J., Ma, Y., Zhang, L., Gao, R. X., \& Wu, D. (2018). Deep learning for smart manufacturing: Methods and applications. Journal of Manufacturing Systems, 48, 144-156.

Wang, M. L., Qu, T., Zhong, R. Y., Dai, Q. Y., Zhang, X. W., \& He, J. B. (2012). A radio frequency identificationenabled real-time manufacturing execution system for one-of-a-kind production manufacturing: a case study in mould industry. International Journal of Computer Integrated Manufacturing, 25(1), 20-34.

Weyer, S., Schmitt, M., Ohmer, M., \& Gorecky, D. (2015). Towards Industry 4.0: Standardization as the crucial challenge for highly modular, multi-vendor production systems. IFAC-PapersOnLine, 48(3):579-584.

White, G. (2009). Strategic, tactical, \& operational management security model. Journal of Computer Information Systems, 49(3), 71-75.

Wuest, T., \& Thoben, K. D. (2011, September). Information management for manufacturing SMEs. In IFIP International Conference on Advances in Production Management Systems (pp. 488-495). Springer, Berlin, Heidelberg. 
Wuest, T., Schmid, P., Lego, B., \& Bowen, E. (2018). Overview of smart manufacturing in West Virginia. Bureau of Business \& Economic Research, West Virginia University.

Xu, L. D., Xu, E. L., \& Li, L. (2018). Industry 4.0: state of the art and future trends. International Journal of Production Research, 56(8), 2941-2962.

Yin, R. K. (2003). Case study research design and methods third edition. Applied social research methods series, 5, Thousand Oaks, Sage Publications, Inc.

Zhong, R. Y., Xu, C., Chen, C., \& Huang, G. Q. (2017). Big data analytics for physical internet-based intelligent manufacturing shop floors. International journal of production research, 55(9), 2610-2621.

Zhong, R. Y. (2018, March). Analysis of RFID datasets for smart manufacturing shop floors. In 2018 IEEE 15th International Conference on Networking, Sensing and Control (ICNSC) (pp. 1-4). IEEE. 


\section{Original Papers}

\section{Publication I}

\section{Smart Manufacturing: Characteristics and Technologies}

By

Sameer Mittal, Muztoba Ahmad Khan and Thorsten Wuest, July 2016

Mittal, S., Khan, M. A., \& Wuest, T. (2016, July). Smart manufacturing: characteristics and technologies. In IFIP International Conference on Product Lifecycle Management (pp. 539-548). Springer, Cham.

2016 Springer Nature. Print rights of the final author's accepted manuscript. 


\title{
Smart Manufacturing: Characteristics and Technologies
}

\author{
Sameer Mittal ${ }^{1}$, Muztoba Ahmad Khan ${ }^{1}$, Jim Davis$^{2}$ and Thorsten Wuest ${ }^{1}$ \\ ${ }^{1}$ Department of Industrial and Management Systems Engineering, West Virginia University, \\ Morgantown, West Virginia, USA \\ \{samittal,mdkhan\}@mix.wvu.edu; thwuest@mail.wvu.edu \\ ${ }^{2}$ Institute for Digital Research and Education, Office of Information Technology, University \\ of California, Los Angeles, California, USA \\ jdavis@oit.ucla.edu
}

\begin{abstract}
The purpose of this paper is to collect and structure the various features of Smart Manufacturing (SM). Researchers have previously identified various characteristics and technologies of Smart Manufacturing System (SMS); this paper collects, discusses and merges some of those characteristics and technologies available in the current body of knowledge. In the future, it is expected that this selection of characteristics and technologies will help to compare and distinguish other initiatives like Industry 4.0, smart factory, intelligent manufacturing, distributive manufacturing, etc. which are frequently used synonymous with SM. The result of this paper is a comprehensive list of characteristics and technologies that are associated with a SMS. As many of the listed items show variating overlaps, certain technologies and characteristics are merged and clustered. This results in a set of five defining characteristics and ten technologies that are considered relevant for a SMS. The authors hope to provide a basis for a broad and interdisciplinary discussion within the SM community about the defining technologies and characteristics of a SMS.
\end{abstract}

Keywords: Smart Manufacturing, Characteristics and Technologies, Industry 4.0, Smart Factory, Intelligent Manufacturing.

\section{Introduction}

Smart Manufacturing (SM) has significant gained momentum in industry and academia in recent years. SM is set of practices that use networked data and information technology [1], [2] to architect the future manufacturing systems. Many manufacturing systems are presenting themselves as Smart Manufacturing Systems (SMS). However, there is still a lack of commonly accepted understanding what defines a manufacturing system as being 'smart'.

What aspects make a manufacturing system smart? Literature suggests to consider these aspects in the form of characteristics and technologies. Only two papers were found relevant to the list of characteristics and technologies associated with smart manufacturing when we used "Smart Manufacturing" as the search term in the 
electronic journals of Taylor and Francis, Science Direct, Wiley, Emerald and Springer. We did the same at Google and Google Scholar, and found only one relevant journal paper and few grey papers published by NIST (National Institute of Standards and Technology) and SMLC (Smart Manufacturing Leadership Coalition). In this study, we focused on characteristics and technologies of only SMS; and kept characteristics and technologies associated with Industry 4.0, smart factory and other such manufacturing initiatives out of our focus. The reason is, that this allows us to create a comprehensive list of SM-specific characteristics and technologies, which later may be compared to the aforementioned other concepts to analyze the similarities and differences among them.

This paper starts with the literature review of a comprehensive list of various characteristics and technologies that are associated with SMS. Later on, it discusses the individual characteristics and technologies and suggests a clustering based on their definition. Finally it concludes by presenting a more compact list of characteristics and technologies that are associated with SM as a basis for further discussion within the SM community.

\section{Literature Review}

Various researchers have identified different characteristics and technologies associated with SMS. Some of these characteristics and technologies have been specifically mentioned as such and the authors identified others by thoroughly going through the content. Depending on the application of SM, it may need a different set of characteristics and technologies. Therefore, the question arises if a SMS has to incorporate all of the identified characteristics and technologies simultaneously or if it is enough to define a manufacturing system as smart when only a certain selection is employed.

A characteristic is a property that is peculiar to something and can be varied to make elements look similar or different for example modularity, heterogeneity, flexibility, etc. Technology on the other hand is the use of science for practical purposes for example data analytics, 3-D printing, etc. Technology are also the identifiable parts of a larger construction that can provide a particular function or a group of related functions. This paper presents a discussion on various SM related characteristics and technologies that have been defined in the following section.

Table 1 presents a list of 19 characteristics identified in literature defining a SMS. The last column 'Cluster' in Table 1 will be elaborated in the discussion section. In Table 1 the characteristics have been shown in italic font and the technologies have been represented in bold font to make the paper more communicative to the readers.

Table 1. List of characteristics associated with a Smart Manufacturing System.

\begin{tabular}{|c|c|c|c|}
\hline Sl. No. & Characteristic & Reference(s) & Cluster \\
\hline 1 & Digital Presence & {$[3],[4]$} & Context Awareness \\
\hline 2 & Modularity & {$[4]$} & Modularity \\
\hline 3 & Heterogeneity & {$[3],[4]$} & Heterogeneity \\
\hline
\end{tabular}




\begin{tabular}{|c|c|c|c|}
4 & Scalability & {$[3],[4]$} & Intelligent Control \\
\hline 5 & Context Awareness & {$[4]$} & Context Awareness \\
\hline 6 & Autonomy & {$[3],[4]$} & Intelligent Control \\
\hline 7 & Adaptability & {$[3]$} & Intelligent Control \\
\hline 8 & Robustness & {$[5]$} & Intelligent Control \\
\hline 9 & Flexibility & {$[6]$} & Intelligent Control \\
\hline 10 & Fully Automated & {$[6]$} & Intelligent Control \\
\hline 11 & Asset Self-awareness & {$[5]$} & Context Awareness \\
\hline 12 & Interoperability & {$[3],[4]$} & Interoperability \\
\hline 13 & Networkability & {$[4]$} & Interoperability \\
\hline 14 & Information Appropriateness & {$[5]$} & Interoperability \\
\hline 15 & Integrability & {$[5]$} & Interoperability \\
\hline & Sustainability & {$[5]$} & $\begin{array}{c}\text { Energy saving/ Energy } \\
\text { Efficiency }\end{array}$ \\
\hline 16 & Compositionality & {$[3]$} & Compositionality \\
\hline 17 & Composability & {$[3]$} & Modularity \\
\hline 18 & Proactivity & {$[5]$} & Intelligent Control \\
\hline 19 & & &
\end{tabular}

Table 2 presents a list of 19 technologies that are associated with SMS. The last column in Table 1 has been framed after the discussion. Similar to the previous Table 1 , certain items can be identified as being rather closely related. This is partly due to different authors using different terminology but also the level of detail the authors chose to describe relevant subcategories of technologies. This issue will be addressed in the following discussion section. As in Table 1, the technology cluster in Table 2 are shown in bold.

Table 2. List of technologies associated with a Smart Manufacturing system.

\begin{tabular}{|c|c|c|c|}
\hline S. No. & Technology & Reference(s) & Cluster \\
\hline 1 & Intelligent & {$[6]$} & Intelligent Control \\
\hline 2 & Intelligent Control & {$[6]$} & Intelligent Control \\
\hline 3 & Energy Saving/ Energy Efficiency & {$[3],[7],[6]$} & $\begin{array}{c}\text { Energy saving/ } \\
\text { Energy Efficiency }\end{array}$ \\
\hline 4 & Cyber Security & {$[7],[5]$} & Cyber Security \\
\hline 5 & Holograms & {$[6],[7]$} & Visual Technology \\
\hline 6 & VR (Virtual Reality) & {$[7]$} & Visual Technology \\
\hline 7 & AR (Augmented Reality) & {$[7]$} & Visual Technology \\
\hline & Real-time Communication & {$[6]$} & $\begin{array}{c}\text { Cloud } \\
\text { Manufacturing }\end{array}$ \\
\hline 8 & Big Data & {$[6]$} & Data Analytics \\
\hline 10 & Cyber-Physical Infrastructure & {$[3],[5],[6]$} & CPS/CPPS \\
\hline & CPS(Cyber Physical Systems)/ & & {$[6],[7]$} \\
\hline 11 & CPPS(Cyber Physical Production & Systems) & CPS/CPPS \\
\hline 12 & IoT/ IoS/ IIoT & & IoT/ IoS \\
\hline
\end{tabular}




\begin{tabular}{|c|c|c|c|}
\hline 13 & Advanced Manufacturing & [3] & \\
\hline 14 & $\begin{array}{l}\text { Cloud Computing /Cloud } \\
\text { Manufacturing }\end{array}$ & [6], [7] & $\begin{array}{c}\text { Cloud } \\
\text { Manufacturing }\end{array}$ \\
\hline 15 & 3- D Printing/ Additive Manufacturing & {$[6],[7]$} & $\begin{array}{l}\text { 3- D Printing/ } \\
\text { Additive } \\
\text { Manufacturing }\end{array}$ \\
\hline 16 & Tracking and Tracing & [6] & Smart Product/ Part \\
\hline 17 & Smart Sensors & [6] & Smart Product/ Part \\
\hline 18 & Smart Product/ Part & [6] & Smart Product/ Part \\
\hline 19 & Data Analytics & {$[3],[4]$} & Data Analytics \\
\hline
\end{tabular}

The items presented in the Table 1 and 2 are derived from various literature sources. As mentioned, this leads to some of these items being similar. In the next section, we present a perspective on how we may cluster different characteristics and technologies.

\section{Discussion}

The presented characteristics and technologies have been mentioned and described in current SM literature. However, the detailed definitions of these characteristics and technologies suggest that some of them might be synonyms of each other and some of these may be merged to present a more focused result. In the following, the previously identified characteristics and technologies (Table $1 \& 2$ ) will be critically discussed and a clustering is proposed to develop a more comprehensive and targeted list. This is depicted in the fourth column in Table 1 and 2, which indicates the suggested clusters for each characteristic and technology. In the forthcoming analysis, the following format has been chosen for better illustration and transparency: characteristic cluster has been given the italics font whereas the technology cluster has been mentioned in bold font; similarly, to enhance the readability of the paper we have discussed them using the italics and bold fonts respectively.

\subsection{Characteristics Clusters}

Context Awareness: Context awareness is an important characteristic of a SMS [4] [8] and it can be seen as a combination of different attributes. Identity- A SMS should have a unique identity. As a SMS often operates in a digital environment, we may say that a SMS should have its own digital presence [4] and therefore digital presence is inherent when we consider context awareness. Location- It is used to describe the physical location of the system itself or subsystems within. Status- This is used to describe the present state of the activities that are being carried within the SMS. Asset selfawareness will also mean that the SMS should be able to know about its present state [5]. Time: The SMS should be able to define its timely priorities, and it might even need to consider the local time. 
Modularity: Modularity is the property of a system, by virtue of which a unit can be decomposed into components that can be combined to form different configurations [4]. Composability is the property of the system when it could be developed from its sub-systems [3]. As both of these properties consider a unit being made from sub-units and by modularity we can have a different unit arising, therefore composability may be considered as a part of modularity.

Heterogeneity: Heterogeneity considers the diversity and dissimilarities in the units and components. However, it does not consider the combination of units and as a result it should be considered as a separate characteristic [4].

Compositionality: Compositionality is the property that deals with the understanding of the whole system based on the definition of its components and the combination of the constituents [3]. As, neither modularity nor heterogeneity deal with the system or component definitions compositionality should be considered as a separate characteristic.

Interoperability: Interoperability is the characteristic due to which units would be able to exchange and share information with each other [4] [3]. With the help of networkability, systems are able to collaborate in different process related aspects and for this collaboration they have to allow each other to share and exchange their information [4]. Therefore, networkability is covered by interoperability. Information appropriateness, describes that information is available, accessible and understandable when needed; this should be a characteristic of information to be shared otherwise the information will be of no use [5]. Integrability is the characteristic due to which different units can be integrated, but two units are integrated if they have an access to each other's information and therefore this characteristic is included in interoperability [5]. However, integrability is different from modularity because modularity combines the systems physically resulting into a new configuration, whereas integrability is inclined towards the exchange of information between two systems and therefore it is a part of interoperability.

\subsection{Technologies Clusters}

Intelligent Control: An important characteristic of manufacturing is that the systems are very quick to response. Papers referred to this response using different words. Scalability is considered as the property by which it can easily handle the fluctuations in load [4], by adaptability it can decide about its own diagnosis, prognosis, and the best system performance even when it has uncertain information [9], a machine has robustness when under uncertain conditions it can perform well [5] and it possesses flexibility when it can adapt to changes in the external environment [10]. With the help of intelligent technology a system is able to change its action based on its own experience [11] and it has intelligent control technology than it can make use of artificial intelligence techniques to control its mechanisms [11]. These characteristics and technologies converge towards being responsive to changes and may use artificial 
intelligence techniques for doing so and therefore, they should be considered as a part of Intelligent Control. A manufacturing unit possess autonomy if a) it can adapt with feedback and pursue its activities to achieve the objective [4] and b) the unit wants the feedback mechanism to work it will need the technology of intelligent control therefore autonomy should be a part of intelligent control. A system is said to be fully automated if it can do its own work completely but the extent of automation may vary from system to system. For a system to be fully automated it will also need some intelligent control mechanisms and more sophisticated are the control mechanisms the degree of automation would increase. Therefore, fully automated should also be covered by intelligent control. Proactivity is the characteristic that can help units to eliminate failures before they happen by sensing the situation [5]. As, this characteristic considers sensing and controlling the mechanism of system, it will need intelligent control mechanism and therefore we can consider it as a part of intelligent control. But, proactivity senses the present situation that might involve data so this characteristic might be involved in the data analytics cluster as well.

Energy saving/ Energy Efficiency: Products and processes are said to possess sustainability if they are reusable and they cause minimum environmental footprints [5] thus making the products and processes more economical, social and environment friendly. Energy saving/ Energy Efficiency is the technology due to which the energy required to provide a product and service can be reduced and various studies have been done to decrease the use of energy in manufacturing systems [7]. If a system can reuse its products then the amount of energy required will decrease and therefore sustainability can be arguable seen as part of energy saving. Although, researchers have considered energy saving/ energy efficiency on par with the other technologies, it should be rather considered as a necessity for any manufacturing system and not only SMS. The choice of terminology 'energy saving' as a technology was derived from literature.

Cyber Security: Data should be secured from cyber threats. As SM is largely based on digitization and data based services, cyber security becomes an important technology for SMS [8]. Even though this also involves data, it should still be considered separate from interoperability because interoperability is about data sharing and availability whereas this is about data privacy and security.

Visual Technology: Hologram is the technology that makes use of a 3-D image formed by a light field in a three dimensional space [12]; Virtual Reality (VR) is a technology that creates 3-D image with the help of a computer and it can be interacted with the help of electronic devices and the user can feel as if he has been "immersed in a synthesized environment" [13][14]; Augmented Reality (AR) is a technology that can superimpose a computer generated 3-D numerical format in the real world, but one cannot interact with it [15][16]. Since all these technologies deal with the visual representation of an object they may be considered as a part of the visual technology cluster [15].

Data Analytics: Big data is the technology that can analyze large data sets including real-time data that is difficult to analyze by traditional methods; data analytics deal 
with turning the volume, variety, velocity and veracity of data into actions and insights in a manufacturing system [3] [16]. As data analytics can deal with a very high volume of data so big data can be placed under it and it can even deal with a high velocity of data therefore it can communicate in real-time with the customers.

Cyber Physical Infrastructure: Cyber-physical System (CPS)/ Cyber-Physical Production Systems (CPPS) are the same [3] and they are the technology used by computer algorithms to solve physical mechanisms [18]; CPPS is an applied form of CPS in production [19]. We will consider all these technologies as CPS.

IoT/ IoS: The IoT enables the communication between physical and internet-enabled devices [7] and when IoT capabilities are seen as services they are referred as IoS [20]. Although both CPS and IoT/IoS consider physical world but the computer algorithms may or may not use the internet. There are examples when CPS has been considered as a foundation for IoT/IoS [21]. But they might not always help each other so they are considered as separate technologies in this case. In this paper we are considering IoT as ubiquitous in the global sense and as a combination of national IoT, industrial IoT and local IoT [22].

Advanced Manufacturing: Advanced Manufacturing is the technology that can integrate technology based production systems like FMS (Flexible Manufacturing System), RMS (Reconfigurable Manufacturing System), CIM (Computer Integrated Manufacturing), Additive Manufacturing etc. [23]. Overall, advanced manufacturing may be understood as an integration of different production technologies and therefore it should not be considered as a technology for Smart Manufacturing. Rather it could be an important discussion if various advanced manufacturing systems could be referred to as SMS. One possible distinction is that SM are reliable on data analytics and the advanced manufacturing is more physical manufacturing-technology focused.

Cloud Manufacturing: Cloud Manufacturing is driven by cloud computing [16] that can, e.g., use real-time demand to decide the production planning and scheduling. Data analytics may be considered as a part of cloud manufacturing, but as the applications of data analytics are so diverse that we should not consider it to be a part of cloud manufacturing. Real-time communication is the technology that would enable the users to exchange data with the systems in real-time. As it involves exchange of information between system and humans therefore it is not a part of interoperability.

3-D Printing/ Additive Manufacturing: 3-D Printing/ Additive Manufacturing is the technology that can print a 3-D image into an object with the help of laser beam, electron beam etc., as the objects are printed layer by layer therefore this technology is also referred as additive manufacturing [8]. Additive Manufacturing is often referred to as being part of the Advanced Manufacturing domain [23].

Smart Products/ Parts: Tracking and tracing is the technology due to which one can find the past and present locations of unique objects as information carrying identities [24]. But we need some (sensing) technology which can help to monitor tracking and tracing, and these sensors are referred as smart sensors; when the smart sensors, have 
processors and software for an efficient exchange of data they are called as smart products/ parts. IT has not been considered as a separate technology as almost all other technologies need inputs from it. It may be argued that tracking and tracing is to be considered as a characteristic or a technology, but as it has been finally kept under a technology group and it has been considered as a technology [6]. Tracking and tracing could also be considered as Tracking and tracing in Real-time but in this paper Realtime communication is considered as a separate technology placed under Cloud Manufacturing and therefore it is rather referred as Tracking and tracing.

From our discussion we can observe that there are many characteristic act as the building block for a technology and therefore we have less number of characteristics and more number of technologies. It can also be seen that the cluster intelligent control consists of six characteristics namely scalability, adaptability, flexibility, autonomy, fully automated, proactivity and 2 technologies intelligent and intelligent control; making it the biggest cluster. It has also been discussed that why some of the technologies like data analytics and cloud manufacturing that have many common elements are being considered as separate?

Commercial implementation of SM for 4 different kind of industries has also been presented in the literature [1]. NIST has also presented some of the characteristics and technologies discussed in this paper and considered as standards. The list of aggregated characteristics and technology clusters presented in this paper is expanding on the basic ones presented in [25]. A landscape consisting of standards has also been suggested for reaching the goal of SM [25]. The standards are presented in terms of the three lifecycle dimensions: product, production system and business. Later, the standards that are present today and the one that are required in the future for establishing an SM are analyzed. These characteristics and definitions are from a small set of research and there might be some others which were not reviewed and in future we plan to consider a more comprehensive list.

\section{Conclusion}

This paper identified, discussed and clustered characteristics and technologies that define a Smart Manufacturing System (SMS). Overall, it was found that there are five characteristics, namely context awareness, modularity, heterogeneity, interoperability and compositionality, and ten technologies, namely intelligent control, energy saving/ energy efficiency, cyber security, CPS/CPPS, visual technology, IoT/IoS, cloud computing/ cloud manufacturing, 3-D printing/ additive manufacturing, smart product/ part and data analytics, that are required in a SMS. These characteristics and technologies can also be used to classify a manufacturing system as smart. With the help of this list of characteristics and technologies we can classify if the initiatives like Industry 4.0, and manufacturing systems like smart factory, intelligent manufacturing, distributive manufacturing, etc. are similar, and if by what degree, to smart manufacturing. In this paper, we can also observe that there is a smaller number of clustered characteristics compared to the number of clustered technologies. One 
possible explanation for this is, that technologies needed some characteristics as their inputs and it would have been redundant to consider such characteristics separately, for example the characteristics scalability, flexibility, adaptability, robustness, autonomy, fully automated and proactivity were clustered in the technology intelligent control. However, for the same reason we do not have technology/technologies clustering into a characteristic. It was also discussed why advanced manufacturing is a manufacturing system itself and should not be considered as a part of technologies.

The resultant list is to be understood as a first step in defining a comprehensive list of commonly agreed upon SM characteristics and technologies. The authors encourage industry and academic SM professionals to provide feedback in order to develop this list further. This can lead to a further expansion or reduction of the list. A similar development is expected if new SM literature will be published in the future containing additional characteristics and technologies.

A limitation of this paper is that, while extracting the characteristics and technologies from literature sources where they were not directly mentioned and classified as such, the subjective perspective of authors plays a part in the decision of choosing either technology or characteristic as the defining element. The clusters made here were made by the knowledge and perspective of the authors. Some of the characteristics and technologies were listed in the literature but there definitions were not provided and therefore these characteristics and technologies were defined from other papers and author's knowledge. The authors tried to increase the transparency of the clustering by explaining the reasoning of the decisions. However, this paper is understood as a first step towards a commonly accepted list of defining characteristics and technologies for Smart Manufacturing. Readers are actively encouraged to provide feedback and challenge the selection.

\section{References}

1. Davis, J., Edgar, T., Graybill, R., Korambath, P., Schott, B., Swink, D., Wang, J. and Wetzel, J.: Smart Manufacturing. In: Annual review of chemical and biomolecular engineering, vol. 6, pp. 141-160 (2015)

2. Smart Manufacturing Leadership Coalition, https://smartmanufacturingcoalition.org/ (visited on 05/30/2016)

3. Rachuri, S.: Smart Manufacturing Systems Design and Analysis. In: National Institute of Standards and Technology (2015)

4. Kühnle, H., Bitsch, G.: Smart Manufacturing Units. In: Foundations \& Principles of Distributed Manufacturing, pp. 55-70. Springer International Publishing (2015)

5. Smart Process Manufacturing Engineering Virtual Organization Steering Committee: Smart process manufacturing: an operations and technology roadmap. Full Report (2009)

6. Park, J., Lee, J.: Presentation on Korea smart factory program. In: $12^{\text {th }}$ International Conference on Advances in Production Management Systems. (presentation on 09/08/2015)

7. Kang, H.S., Lee, J.Y., Choi, S., Kim, H., Park, J.H., Son, J.Y., Do Noh, S.: Smart manufacturing: Past research, present findings, and future directions. In: International Journal of Precision Engineering and Manufacturing-Green Technology, vol. 3, pp. 111128. Springer, Berlin, Germany (2016)

8. Abowd, G.D., Ebling, M., Hung, G., Lei, H., Gellersen, H.W.: Context- aware computing [Guest Editors' Intro.]. Pervasive Computing, IEEE, vol. 1, pp. 22-23 (2002) 
9. Zuehlke, D.: SmartFactory-Towards a factory-of-things. In: Annual Reviews in Control, vol. 34, pp. 129-138 (2010)

10. De Weck, O.L., Ross, A.M., Rhodes, D.H.: Investigating relationships and semantic sets amongst system lifecycle properties (Ilities). In: Third international engineering systems symposium CESUN, vol. 1, pp. 18-20 (2012)

11. Stengel, R.: Robotics and Intelligent Systems! (2015)

12. Matsushima, K., Nakahara, S., Arima, Y., Nishi, H., Yamashita, H., Yoshizaki, Y., Ogawa, K.: Computer holography: 3D digital art based on high-definition CGH. In: Journal of Physics: Conference Series, vol. 415, pp. 12-53. IOP Publishing (2013)

13. Steuer, J.: Defining virtual reality: Dimensions determining telepresence. In: Journal of communication, vol. 42, pp. 73-93 (1992)

14. Earnshaw, R.A.: Virtual reality systems. Academic press (2014)

15. Azuma, R.T.: A survey of augmented reality. In: Teleoperators and virtual environments, vol. 6, pp. 355-385 (1997)

16. Yu, C., Xu, X., Lu, Y.: Computer-Integrated Manufacturing, Cyber-Physical Systems and Cloud Manufacturing-Concepts and relationships. In: Manufacturing Letters, vol. 6, pp. 59 (2015)

17. Salehan, M., Kim, D. J.: Predicting the performance of online consumer reviews: A sentiment mining approach to big data analytics. In: Decision Support Systems, vol. 81, pp. 30-40 (2016)

18. Lee, Edward A.: Cyber physical systems: Design challenges. In: $11^{\text {th }}$ IEEE International Symposium on Object Oriented Real-Time Distributed Computing, pp. 363-369 (2008)

19. Monostori, L. Cyber-physical production systems: Roots, expectations and R\&D challenges. In: Procedia CIRP, vol. 17, pp. 9-13. Elsevier (2014)

20. Alberti, A.M., Singh, D. Internet of Things: Perspectives, Challenges and Opportunities. In: International Workshop on Telecommunications, pp. 1-6 (2013)

21. Klotzer, C., Pflaum, A.: Cyber-physical systems as the technical foundation for problem solutions in manufacturing, logistics and supply chain management. In: 5th International Conference on Internet of Things (IOT), pp. 12-19. IEEE (2015)

22. Ning, H., Wang, Z.: Future internet of things architecture: like mankind neural system or social organization framework? In: Communications Letters, vol. 15, pp. 461-463. (2011)

23. Tao, F., Cheng, Y., Zhang, L., Nee, A.Y.C.: Advanced manufacturing systems: socialization characteristics and trends. In: Journal of Intelligent Manufacturing, vol. 1, pp. 1-16 (2014)

24. Paunescu, D., Stark, W. J., \& Grass, R. N.: Particles with an identity: Tracking and tracing in commodity products. In: Powder Technology, vol. 291, pp. 344-350 (2016)

25. Lu, Y., Marris, KC \& Frechette, S. (2016). Current Standards Landscape for Smart Manufacturing Systems. (NISTIR 8107). doi: 10.6028/NIST.IR.8107 


\section{Original Papers}

\section{Publication II}

\section{Smart Manufacturing: Characteristics, Technologies and Enabling Factors}

By

Sameer Mittal, Muztoba Ahmad Khan, David Romero and Thorsten Wuest, August 2017

Mittal, S., Khan, M. A., Romero, D., \& Wuest, T. (2019). Smart manufacturing: characteristics, technologies and enabling factors. Proceedings of the Institution of Mechanical Engineers, Part B: Journal of Engineering Manufacture, 233(5), 1342-1361.

2017 Sage. Open Access Permission. 


\section{Smart manufacturing: Characteristics, technologies and enabling factors}

\author{
Sameer Mittal', Muztoba Ahmad Khan', David Romero \\ and Thorsten Wuest'
}

Proc IMechE Part B:

J Engineering Manufacture

$\mathrm{I}-20$

(c) IMechE 2017

(c) (i) (8)

Reprints and permissions: sagepub.co.uk/journalsPermissions.nav DOI: $10.1177 / 0954405417736547$ journals.sagepub.com/home/pib @SAGE

\begin{abstract}
The purpose of this article is to collect and structure the various characteristics, technologies and enabling factors available in the current body of knowledge that are associated with smart manufacturing. Eventually, it is expected that this selection of characteristics, technologies and enabling factors will help compare and distinguish other initiatives such as Industry 4.0, cyber-physical production systems, smart factory, intelligent manufacturing and advanced manufacturing, which are frequently used synonymously with smart manufacturing. The result of this article is a comprehensive list of such characteristics, technologies and enabling factors that are regularly associated with smart manufacturing. This article also considers principles of "semantic similarity" to establish the basis for a future smart manufacturing ontology, since it was found that many of the listed items show varying overlaps; therefore, certain characteristics and technologies are merged and/or clustered. This results in a set of five defining characteristics, II technologies and three enabling factors that are considered relevant for the smart manufacturing scope. This article then evaluates the derived structure by matching the characteristics and technology clusters of smart manufacturing with the design principles of Industry 4.0 and cyber-physical systems. The authors aim to provide a solid basis to start a broad and interdisciplinary discussion within the research and industrial community about the defining characteristics, technologies and enabling factors of smart manufacturing.
\end{abstract}

\title{
Keywords
}

Smart manufacturing, Industrie 4.0, Industry 4.0, cyber-physical systems, smart factory, intelligent manufacturing, industrial Internet, advanced manufacturing, digital manufacturing

Date received: 20 December 2016; accepted: 27 August 2017

\section{Introduction}

Smart manufacturing (SM), a term originated in the United States but increasingly used globally, has gained significant momentum in industry and academia in recent years. Many manufacturing systems are presenting themselves as SM systems (SMSs). SM is a set of manufacturing practices that use networked data and information and communication technologies (ICTs) for governing manufacturing operations. ${ }^{1}$ ICTs deal with planning and control of production. ${ }^{2}$ Traditionally, manufacturing was limited to a process or a sequence of processes through which raw material is converted into finished goods. However, the common understanding of manufacturing comprises much more. Manufacturing today considers the data-driven business operation at different levels leading to the growth of various paradigms in manufacturing, of which emerged SM. ${ }^{3}$ Future SMS will possess unique properties of self-assembly to produce complex and customized products to exploit the new and existing markets. ${ }^{4}$ SM uses information to continuously maintain and improve performance. ${ }^{5}$ Several frameworks have been proposed in the SM realm. One of them is an accuracy assured framework, based on four factors, namely, physics conscious, operations planning, intelligent monitoring and on-machine shape measurement and error source estimation for an SMS. ${ }^{6}$ Additionally, the President's Council of Advisors on Science and Technology (PCAST) has mentioned in its report that the share of gross domestic product (GDP) by

\footnotetext{
'Department of Industrial and Management Systems Engineering, West Virginia University, Morgantown, WV, USA

${ }^{2}$ Tecnológico de Monterrey, Mexico City, Mexico

\section{Corresponding author:}

Thorsten Wuest, Department of Industrial and Management Systems Engineering, West Virginia University, Morgantown, WV 26506, USA. Email: thwuest@mail.wvu.edu
} 
manufacturing has been decreasing recently, and advancement in science, technology and innovation will help the United States become a global leader in manufacturing. ${ }^{7}$ However, despite the rapidly growing body of literature, applications and use of the term smart manufacturing in academia and industry, there is still a lack of commonly accepted understanding about what defines a manufacturing system as being "smart." SM and other systems such as intelligent manufacturing, advanced manufacturing/advanced manufacturing systems, ${ }^{1,7,8}$ additive manufacturing, ${ }^{9}$ digital manufacturing, ${ }^{10}$ smart factory ${ }^{11}$ and Industry $4.0^{12}$ are actually being used synonymously on occasion by some authors.

The overarching question remains, "What aspects make a manufacturing system smart?" The literature on SM has suggested various characteristics, technologies and enabling factors that define a manufacturing system as "smart." This article investigates the suggested characteristics, technologies and enabling factors through a literature review and tries to form clusters for the homogeneous items. This work collects a comprehensive list for each of the items based on a literature review of 83 articles that use the specific term "smart manufacturing."

\section{Research methodology}

The schematic of the research methodology used in this article has been shown in Figure 1. First, the electronic journals of Taylor and Francis (T\&F), Science Direct (SD), Wiley, Emerald, SAGE and Springer, and additionally Google Scholar (GS) and Google, were searched with the keyword "smart manufacturing." In the second step, the title and abstracts of the articles found from step 1 were read for the initial screening. It was also made sure that these articles/reports are in English only. The literature available in other language was not considered. In the third step, all the articles found from initial screening were thoroughly reviewed to find their relevancy with SM. After this step there were 67 articles and 16 reports that were found relevant. Finally, the list of characteristics, technologies and enabling factors was prepared with the help of relevant literature. In this study, we focused on characteristics, technologies and enabling factors specifically associated with SM and kept characteristics, technologies and enabling factors associated with similar terms, for example, Industry 4.0, smart factory, advanced manufacturing, cyber-physical production system (CPPS) and other similar manufacturing initiatives out of our focus. The reason for this rather strict system boundary is that it allows us to create a comprehensive list of SMspecific characteristics, technologies and enabling factors, which later may be compared to the aforementioned concepts. This comparison will help analyze the similarities and differences among them and determine whether they are indeed synonymous with SM or

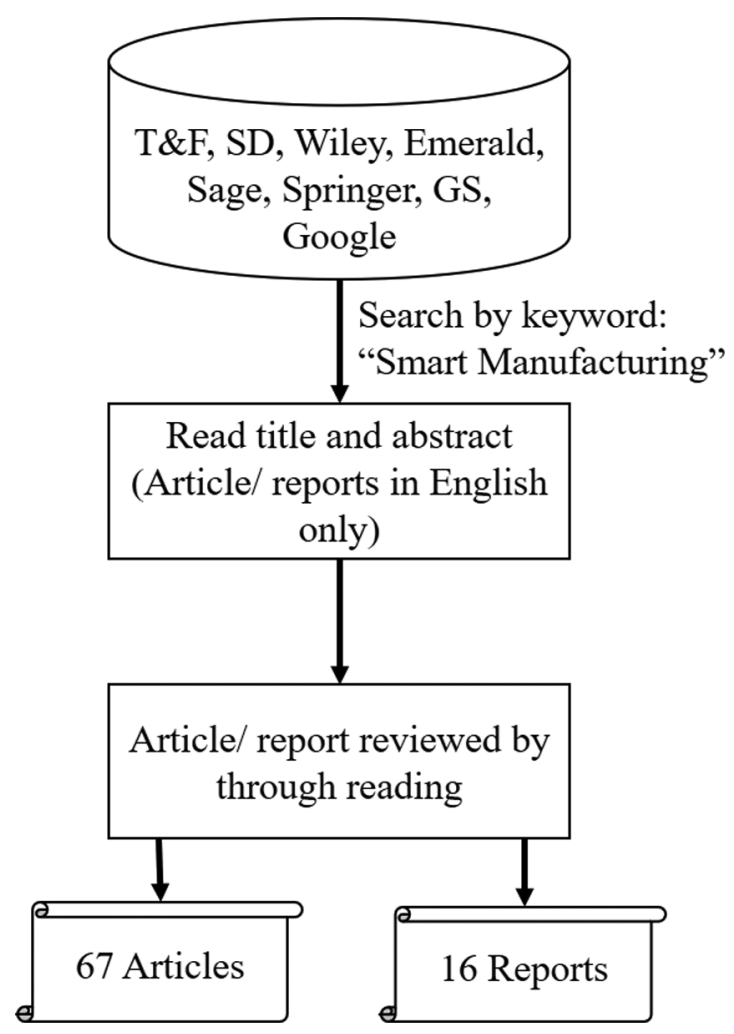

Figure I. Schematic for methodology adopted in this article.

whether there are certain distinct differences. This article is structured as follows: first, a literature review of current indexed scientific articles containing the term "smart manufacturing" is presented along with a comprehensive list of SM-associated characteristics, technologies and enabling factors. The characteristics, technologies and the enabling factors are classified based on how they are defined in the reference article and how the authors interpret them.

Interestingly, more than $95 \%$ of these articles and reports were published in and after 2013. This might be an indication of the novelty of SM (compared to more established terms such as "intelligent manufacturing" or "Industry 4.0") and shows how fast its popularity in academia and industry has increased within recent years. There are several gray papers and reports published by federal agencies, for example, National Institute of Standards and Technology (NIST) and other institutions, for example, the Smart Manufacturing Leadership Coalition (SMLC) leading the newly established Clean Energy Smart Manufacturing Innovation Institute (CESMII). This gray literature was used mainly as motivation for this research and to define the system borders.

The following section defines and sensibly clusters the individual characteristics, technologies and enabling factors. The authors' clustering was based on the use of established ontologies in relation to SM vocabulary (e.g. glossaries) and the consideration of the semantic 
distance between the terms being classified. Semantic similarity in this context is understood as

a metric defined over a set of documents or terms, where the idea of distance between them is based on the likeliness of their meaning or semantic content as opposed to similarity which can be estimated regarding their syntactical representation (e.g. the string format). ${ }^{13}$

Finally, a condensed list of characteristics, technologies and enabling factors associated with SM is presented as a basis for further discussion within the SM community. In a first attempt to compare the identified SM identifiers with other popular manufacturing initiatives, it is discussed how they compare to established design principles of (1) Industry 4.0 and (2) cyber-physical systems (CPSs). The various manifestations associated with these principles are also stated. The article concludes by providing a brief overview of the results and a discussion of the limitations of the study.

\section{Literature review}

Researchers have previously identified a variety of characteristics, technologies and enabling factors associated with SM. Some of these characteristics, technologies and enabling factors have been specifically mentioned as such. However, this is not always the case, and thus, the authors identified additional items that can be associated with these categories by thoroughly going through the relevant material. SMLC has suggested some SM platforms considering integration of different technologies in the system, ${ }^{1,14}$ From the facility level, $\mathrm{SM}$ is the vertical and horizontal integration of manufacturing systems. ${ }^{15}$ Therefore, an SMS should be aware of the state of its predecessor machines, successor machines and the machines running in parallel. A computational-based learning system that incorporates interconnected data, integrated automation and intelligent information has also been used in literature ${ }^{16}$ to create an SMS. Nevertheless, in this case, the SMSs' scope is limited to computation. A strategic model for SM considering agility as the goal and a model that can be adapted to other goals has been presented by NIST. ${ }^{17}$ Agility, asset utilization and sustainability were considered as the metrics for the classification of SMS. ${ }^{18}$ Similarly, there are other characteristics and technologies that have been used to define SM. Four steps toward SM have also been mentioned: ${ }^{19}$ (1) establish forums where problem definitions can be discussed, (2) develop cyber-platforms, (3) data sharing and (4) introduce SM-friendly policies. However, there is no research that presents a comprehensive list of characteristics, technologies and enabling factors that make a manufacturing system "smart." The set of characteristics, technologies and enabling factors, which are required in an SMS, will differ. For example, a smart pharmaceutical system focused on improving drugs and other medicines may not require visual technologies such as augmented reality (AR). However, another healthcare system that, for example, develops artificial limbs may profit from using this technology. Therefore, this answers the question, whether an SMS has to incorporate all the identified characteristics, technologies and enabling factors simultaneously or whether it is sufficient to define a manufacturing system as smart when only a certain selection is used. The degree of SM engagement often varies significantly between SMEs and large corporations. Generally, it can be observed that only few SMEs, while often having partly automated processes installed, have an IT-based production management system in place. However, a majority of the large, multinational corporations already incorporate IT systems for real-time communication among other things. Of all companies, only a handful of hightech organizations such as Tesla, LG, Samsung and Siemens already have a customized production based on Internet of Things (IoT) CPS in use. ${ }^{20}$

To create a common basis for the following discussion, the terminology will be reviewed. A characteristic may be defined as a property that is particular to something and can be varied to make elements look similar or different. Examples for characteristics are modularity, heterogeneity and flexibility. Technology, however, is the use of science for practical purposes. This includes but is not limited to data analytics and threedimensional (3D) printing. Technologies are also the identifiable parts of a larger construction that can provide a particular function or a group of related functions. Enabling factors are the standards and managerial practices that need to be maintained. For the successful implementation of characteristics and technologies in SM, this includes, for example, laws and regulations, innovative education and training of employees. This article presents a discussion on various SM-related characteristics, technologies and enabling factors that are essential for the installation and operation of an SMS. Table 1 presents a list of 27 characteristics identified in literature defining SM (or an SMS). The items will be analyzed for clustering in the next section.

Table 2 presents a list of 38 technologies that are associated with SM. Some of these technologies can be merged and clustered together as certain items are rather closely related. This is motivated by two main reasons. First, different authors may use different terminology, as no established ontologies exist in the field of SM. Second, the level of detail that authors decided to use in their respective publications to describe relevant subcategories of technologies differs significantly as well. The clustering of closely related items based on their "semantic similarity" 13 is addressed in the following section.

In addition to the various characteristics and technologies, there are a set of enabling factors, which facilitate the successful implementation of characteristics and technologies in SM. ${ }^{3}$ These may also be referred to as guidelines that an organization has to maintain to 
Table I. List of characteristics associated with smart manufacturing.

\begin{tabular}{lll}
\hline S. no. & Characteristics & Reference(s) \\
\hline 1 & Digital presence & 10,21 \\
2 & Modularity & 10 \\
3 & Heterogeneity & 10,21 \\
4 & Scalability & 10,21 \\
5 & Context awareness & 10 \\
6 & Autonomy & 10,21 \\
7 & Adaptability & 21,22 \\
8 & Robustness & 23,24 \\
9 & Flexibility & 20,22 \\
10 & Fully automated & 16,20 \\
11 & Asset self-awareness & 23,25 \\
12 & Interoperability & 10,21 \\
13 & Networkability & $10,16,22,26$ \\
14 & Information appropriateness & 23 \\
15 & Integrability & 23 \\
16 & Sustainability & $1,4,18,23,25,27,28$ \\
17 & Compositionality & 21 \\
18 & Composability & 21 \\
19 & Proactivity & 23 \\
20 & Reliability & $17,22,29$ \\
21 & Agility & $17,18,25,27$ \\
22 & Responsiveness & 17 \\
23 & Accuracy & 6 \\
24 & Reusability & 24 \\
25 & Decentralized & 22 \\
26 & Distributed & 22 \\
27 & Resilience & 25 \\
\hline
\end{tabular}

adopt SM characteristics and technologies. Table 3 presents a list of seven enabling factors that may be associated with SM. It has to be considered that this selection is solely based on the available literature and (a) is most likely not complete and (b) the different enabling factors are not necessarily always required in combination.

The items presented in Tables $1-3$ are derived from current literature. As mentioned, this leads to some of these items being rather similar. In the next section, we present a perspective on how the different characteristics, technologies and enabling factors can be clustered to create a consolidated list.

\section{Analysis}

The presented characteristics, technologies and enabling factors have been mentioned and described in current SM literature. However, the detailed definitions, as discussed in this article, suggest that some of these characteristics, technologies and enabling factors are used synonymously and may be merged to present a more focused result. In the following section, the previously identified characteristics, technologies and enabling factors (Tables 1-3) are critically discussed and a clustering is proposed to develop a more comprehensive and targeted list. Clusters will include a set of similar characteristics or technologies, or a combination of characteristic and technologies. It is also important to understand that the clusters may contain
Table 2. List of technologies associated with smart manufacturing.

\begin{tabular}{|c|c|c|}
\hline S. no. & Technology & Reference(s) \\
\hline I & Intelligent & $16,20,29$ \\
\hline 2 & Intelligent control & 6,20 \\
\hline 3 & Energy saving/efficiency & $4,2|| 5,20,30,,3 \mid$ \\
\hline 4 & Cyber security & $23,29,30$ \\
\hline 5 & Holograms & 20,30 \\
\hline 6 & VR & $30,3,32$ \\
\hline 7 & $A R$ & 30 \\
\hline 8 & $\begin{array}{l}\text { Real-time communication/ } \\
\text { data }\end{array}$ & $20,25,33$ \\
\hline 9 & Big data & 20 \\
\hline 10 & $\begin{array}{l}\text { Cyber-physical } \\
\text { infrastructure }\end{array}$ & $21,20,23$ \\
\hline II & CPS/CPPS & $20,30,34$ \\
\hline 12 & loT/loS/lloT & 20,30 \\
\hline 13 & Advanced manufacturing & $|, 7,2|, 22$ \\
\hline 14 & $\begin{array}{l}\text { Cloud computing/cloud } \\
\text { manufacturing }\end{array}$ & $1,30,35$ \\
\hline 15 & $\begin{array}{l}\text { 3D printing/additive } \\
\text { manufacturing }\end{array}$ & $9,20,30$ \\
\hline 16 & Smart sensors & 20,28 \\
\hline 17 & Smart product/part & 20,36 \\
\hline 18 & $\begin{array}{l}\text { Data analytics/big data } \\
\text { analytics }\end{array}$ & $10,21,37,38,39,28$ \\
\hline 19 & Predictive analytics & 37,28 \\
\hline 20 & Data visualization & 3,40 \\
\hline 21 & Modeling & 4,40 \\
\hline 22 & GIS & 38 \\
\hline 23 & Simulation & $4,41,28$ \\
\hline 24 & Forecasting & 4 \\
\hline 25 & ERP & 42 \\
\hline 26 & RFID & 43 \\
\hline 27 & Machine learning & $6,37,38,44,45,28$ \\
\hline 28 & SCM & 42,28 \\
\hline 29 & MES & 42 \\
\hline 30 & PLM & 27,42 \\
\hline 31 & Smart materials & 4,46 \\
\hline 32 & $\begin{array}{l}\text { Interface } \\
\text { (SCOR, DCOR, MESA, } \\
\text { ISA 95/88) }\end{array}$ & 42,28 \\
\hline 33 & CAM, CAD, CAx & 27 \\
\hline 34 & Operations planning & 6 \\
\hline 35 & $\begin{array}{l}\text { IT-based production } \\
\text { management }\end{array}$ & 20 \\
\hline 36 & Tracking and tracing & 20,47 \\
\hline 37 & $\begin{array}{l}\text { Knowledge decision- } \\
\text { making techniques }\end{array}$ & $3,48,25$ \\
\hline 38 & SPC & 3 \\
\hline
\end{tabular}

VR: virtual reality; AR: augmented reality; CPS: cyber-physical system; CPPS: cyber-physical production system; loT: Internet of Things; loS: Internet of Services; lloT: Industrial Internet of Things; 3D: threedimensional; GIS: Geographic Information Science; ERP: enterprise resource planning; RFID: radio-frequency identification; SCM: supply chain management; MES: manufacturing execution system; PLM: product lifecycle management; SCOR: Supply Chain Operations Research; DCOR: Design Chain Operations Reference; MESA: Manufacturing Enterprise Solutions Association; CAM: computer-aided manufacturing; CAD: computer-aided design; CAx: computer-aided X; SPC: statistical process control.

technologies and characteristics at the same time but after final review are considered to belong in either a technology or characteristic cluster. This is due to the overlaps in terminology and the strong 
Table 3. List of enabling technologies associated with smart manufacturing.

\begin{tabular}{lll}
\hline S. no. & Enabling factor & Reference(s) \\
\hline 1 & Law and regulations & 3,49 \\
2 & Innovative education and training & 3,41 \\
3 & STEP AP 242 & $50,35,42$ \\
4 & Knowledge workers & 4,51 \\
5 & CMSD & 25 \\
6 & MTConnect & $37,42,52$ \\
7 & Enterprise integration & 41 \\
\hline
\end{tabular}

CMSD: core manufacturing simulation data.

interdependencies between various items. While this is not ideal and adds additional complexity, it is a reflection on the inherit complexity of the topic and the importance of starting to work toward a common understanding and terminology. The enabling factor clusters, dealing with guidelines for organization or people, cannot have characteristics and technologies, and similarly characteristics and technologies should not contain enabling factors.

In the forthcoming analysis, the following format has been chosen for better illustration and transparency: characteristics are represented in italics, whereas technologies are represented in boldface; enabling factors do not have a different notation. Each cluster is also illustrated according to a similar visual representation method used in literature. ${ }^{3}$ There were some items that could have been arguably placed in another cluster; nevertheless, they are placed in a specific cluster because of the discussion below. For some items, the authors used their subjective judgment on determining the most suitable cluster. However, the authors fully acknowledge that one might argue that the respective item(s) might fit into another cluster as well based on the individual background and experience. Therefore, the items in question are highlighted in the figures with a gray background in the following illustrations of clusters.

\section{Characteristics clusters}

Context awareness. Context awareness is an important characteristic of an SMS, ${ }^{10,53}$ and it can be seen as a combination of the following attributes:

1. Identity: An SMS should have a unique identity. As an SMS often operates in a digital environment, we may say that an SMS should have its own digital presence, thus providing with a unique identification in the digital world, for example, a network interface address. ${ }^{10}$ Therefore, digital presence is inherent when we consider context awareness.

2. Location: It is used to describe the physical location of the system itself or sub-systems within.

3. Status: This is used to describe the present state of the activities that are being carried within the SMS.

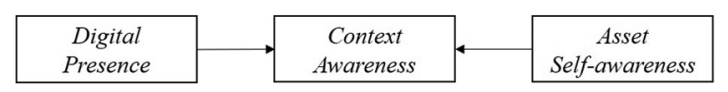

Figure 2. Visual representation of context awareness cluster with its corresponding characteristics.

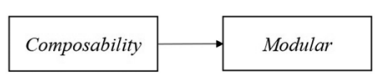

Figure 3. Visual representation of modularity cluster with its corresponding characteristic.

Asset self-awareness will also mean that the SMS should be able to know about its present state. ${ }^{23}$

4. Time: The SMS should be able to define its timely priorities, and it might even need to consider the local time. Figure 2 presents the characteristics that make the context awareness cluster.

Modularity. Modularity is the property of a system by virtue of which a unit can be decomposed into components that can be combined to form different configurations. ${ }^{10}$ Composability is the property of the system when it could be developed from its sub-systems. ${ }^{21}$ As both these properties consider a unit being made from sub-units and by modularity, we can have a different unit arising; therefore, composability may be considered as a part of modularity. Figure 3 visually represents composability that is included in the modularity cluster.

Heterogeneity. Heterogeneity considers the diversity and dissimilarities in the units and components. However, it does not consider the combination of units such as modularity, and as a result, it should be considered as a separate characteristic. ${ }^{10}$

Compositionality. Compositionality is the property that deals with the understanding of the whole system based on the definition of its components and the combination of the constituents. ${ }^{21}$ As neither modularity nor heterogeneity deal with the system or component definitions, compositionality should be considered as a separate characteristic.

Interoperability. Interoperability is the characteristic due to which, system units would be able to exchange and share information with each other, ${ }^{10,21}$ With the help of networkability, systems are able to collaborate in different process-related aspects, and for this collaboration, they have to allow each other to share and exchange information. ${ }^{10}$ Similarly, distributed systems allow the information and data of one system to be accessed by other systems in the network. Therefore, 
networkability and distributed characteristics of systems are covered by interoperability. Information appropriateness describes that information is available, accessible and understandable when needed; this should be a characteristic of information to be shared, otherwise the information will be of no use. ${ }^{23}$ Integrability is the characteristic due to which different units can be integrated, but two units are integrated only if they have an access to each other's information. Therefore, this characteristic of integrability is included in interoperability. ${ }^{23}$ Decentralized is the characteristic by virtue of which SM can be operated by other attached units, and consequently it may be considered as part of interoperability. However, integrability is different from modularity because modularity physically combines the systems resulting in a new configuration, whereas integrability is inclined toward the exchange of information between two systems and therefore it is a part of interoperability. It is important to discuss why interoperability and cloud computing/ manufacturing are different. Cloud is like a database where information can be saved and accessed by all the systems that are part of this cloud. In contrast, interoperability also allows systems to access data and information, which has not been shared, for example, in the cloud. Figure 4 visually represents all the characteristics present in the interoperability cluster.

\section{Technology clusters}

Intelligent control. An important characteristic of manufacturing systems is the speed of response to events. Responsiveness may be considered as the ability of an SMS to speedily provide the desired products to the customers. ${ }^{17}$ Peer-reviewed papers refer to this response using various terms. Agility is the ability of a system to respond to external influences; in SMS, this could be the response to market changes. ${ }^{17}$ Scalability is considered as the property by which it can easily handle the fluctuations in load, ${ }^{10}$ hence the change in response. Adaptability describes the ability of the system to decide about its own diagnosis, prognosis and the best system performance even when it has uncertain information. ${ }^{54} \mathrm{~A}$ system can be considered to have a high level of robustness when it can perform well under

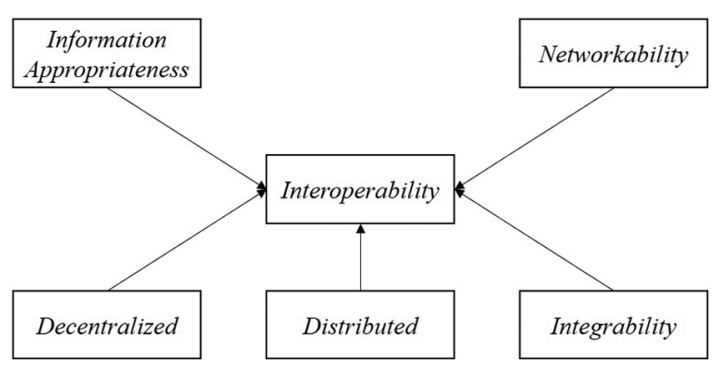

Figure 4. Visual representation of interoperability cluster with its corresponding characteristics. uncertain conditions, ${ }^{23}$ and it possesses flexibility when it can adapt to changes in the external environment. ${ }^{55}$ Reliability is the ability to perform activities as expected, and therefore it also makes the results predictable. ${ }^{17}$ Accuracy is the ability to provide the result exactly or very close to the actual result. The definitions of all characteristics appear homogeneous and therefore are placed in the same cluster.

With the help of intelligent technology, a system is able to change its action based on its own experience, ${ }^{56}$ and if it possesses intelligent control technology, it can make use of, for example, artificial intelligence techniques to control its mechanisms ${ }^{56}$ and is able to be reliable and accurate. These characteristics and technologies converge toward being responsive to changes and may use artificial intelligence techniques for doing so, and therefore, they should be considered as a part of intelligent control. A manufacturing unit possesses autonomy if (a) it can adapt with feedback and pursue its activities to achieve the objective ${ }^{10}$ and (b) the unit wants the feedback mechanism to work. It will need the technology of intelligent control; therefore, autonomy should be a part of intelligent control. A system is said to be fully automated if it can do its own work completely, but the extent of automation may vary from system to system. For a system to be fully automated, it will also need some intelligent control mechanisms. The more sophisticated the control mechanisms, the higher the degree of automation. Therefore, this characteristic should also be covered by intelligent control. Proactivity is the characteristic that can help units eliminate failures before they happen by sensing the situation. ${ }^{23}$ As this characteristic considers sensing and controlling the mechanisms of the system, it will need intelligent control mechanism. Therefore, we can consider it as a part of intelligent control. However, proactivity senses the present situation that might involve data, so this characteristic might be involved in the data analytics cluster as well. Figure 5 shows the different characteristics and technologies included in the intelligent control cluster. The reason why machine learning may not be a part of intelligent

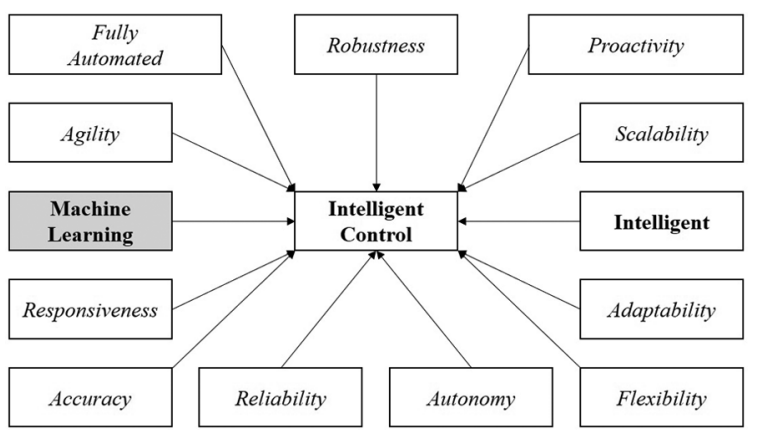

Figure 5. Visual representation of intelligent control cluster with its corresponding characteristics and technologies. 


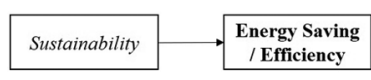

Figure 6. Visual representation of energy saving/efficiency cluster with its corresponding characteristic.

control and might be a part of data analytics has been discussed in the data analytics section.

Energy saving/efficiency. Products and processes are said to possess sustainability if they are reusable and cause minimum environmental footprints, ${ }^{23}$ thus making the products and processes more economical, social and environment-friendly. The importance of energy cost savings through SM has been discussed frequently, and energy saving is among the main drivers for SM. ${ }^{15} \mathrm{~A}$ sustainable SM process for extracting olive oil has also been proposed. ${ }^{57}$ Energy saving/efficiency is the technology due to which the energy required to provide a product and service can be reduced. Various studies have been done to decrease the use of energy in manufacturing systems. ${ }^{30}$ If a system can reuse its products, then the amount of energy required will decrease in most cases. Thus, sustainability can arguably be seen as part of energy saving. Although researchers have considered energy saving/efficiency on par with the other technologies, it may be considered as a necessity for any manufacturing system and not only SMS. The choice of terminology "energy saving" as a technology was derived from literature and as such not altered based on the employed methodology. Figure 6 presents the characteristics included in the energy saving/efficiency cluster.

Cyber security. Data should be secured from cyber threats. As SM is largely based on digitization and data-based services, cyber security is an integral technology for SMS. ${ }^{53}$ Even though this characteristic also involves data, it should still be considered separate from interoperability because interoperability is about data sharing and availability, whereas cyber security is about data privacy and security.

Visual technology. Hologram is a technology that makes use of a 3D image formed by a light field in a 3D space. ${ }^{58}$ Virtual reality (VR) described the technology to create $3 \mathrm{D}$ images with the help of a computer and the interaction in that space with the help of electronic devices for the user to feel as if he or she has been "immersed in a synthesized environment." ${ }^{59,60}$ Augmented Reality (AR) is a technology that can superimpose a computer-generated 3D numerical format in the real world, but one cannot interact with it. ${ }^{61,62}$ Since all these technologies encompass the visual representation of an object, built with the help of electronic devices, they may be considered as a part of the visual technology cluster. ${ }^{61}$

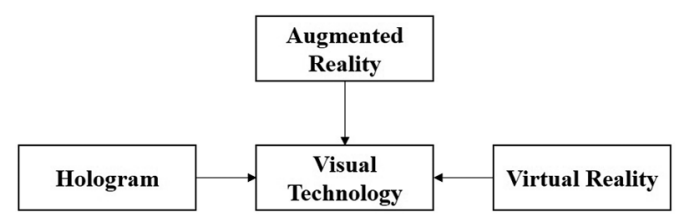

Figure 7. Visual representation of visual technology cluster with its corresponding technologies.

Figure 7 shows the various technologies included in visual technology cluster.

Data analytics. Big data is the technology that can analyze large data sets including real-time data that are difficult to analyze by traditional methods. Data analytics generally deals with turning the volume, variety, velocity and veracity of data into actions and insights within a manufacturing system. ${ }^{21,62}$ A demonstration showing use of simulation in data analytics and data visualization has also been presented. ${ }^{40}$ As data analytics can deal with a very high volume of data, the popular technology "big data" can be understood as being part of this technology; since data analytics can also process a high velocity of data, it can communicate in real-time with the customers. Machine learning involves the selfteaching of computer programs based on their experiences and pattern recognition; ${ }^{63}$ it does not need any human involvement so it might be included in intelligent control as well. However, we are considering that it also recognizes patterns when exposed to new data, and therefore, it should be a part of the data analytics cluster.

Predictive analytics finds results with finding some results with the help of measurable variables in the data, and data mining is the field of exploring large amounts of data. ${ }^{64}$ Since predictive analytics also deal with analysis of data, it is included in data analytics. Data visualization is the technique of representing data with the help of graphs and other visual representations, which can lead to the development of graph patterns to analyze the data. ${ }^{65}$ It should also be considered as a part of data analytics rather than the visual technologies cluster as the latter focuses on technology, whereas data visualization focuses on the content. Geographic Information Science (GIS) provides information about space and time. This information helps in data visualization and data analysis. ${ }^{38}$ It could be discussed whether GIS should be a part of smart part/ product/material as well because there could be some sensor attached to the system to store the data.

Modeling is the representation of a real-world scenario by a mathematical expression and/or a simplification of the real-world system. Simulation uses a model to generate data and these data could be analyzed later. Forecasting deals with the prediction of what could happen in the future with the help of available data. 


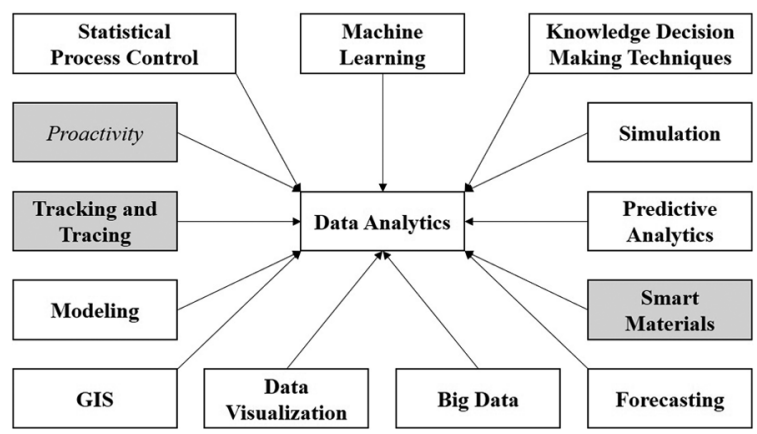

Figure 8. Visual representation of data analytics cluster with its corresponding characteristics and technologies.

Since all three, modeling, simulation and forecasting, rely on data to make decisions, they are included in the data analytics cluster. Knowledge decision-making techniques are techniques such as multi-criteria decisionmaking (MCDM), mathematical programming techniques and artificial intelligent techniques ${ }^{66}$ that help make decisions. As these techniques also help make decisions based on data, they should be involved in data analytics.

Statistical process control (SPC) is a process of controlling quality through advanced statistics. It is being used in a manufacturing environment for a long time, but is still valid and widely used today to control and monitor operations. It uses data and derives suggestions for improvements, and thus should be considered as being part of data analytics. Statistics has been used in a variety of manufacturing applications, for example, in smart chemical process diagnosis. ${ }^{24}$ Figure 8 presents the various technologies that are placed in the data analytics cluster. Items such as proactivity, tracking and tracing and smart materials that are a part of different clusters but could have been a part of this cluster are shown with a gray background.

CPS/CPPS. CPSs/CPPSs are often used interchangeably $^{21}$ and describe technologies used by computer algorithms to solve and work with physical mechanisms/components. ${ }^{67} \mathbf{C P P S}$ is an applied form of CPS in production. ${ }^{68}$ We will consider all these technologies as CPS. Figure 9 shows the technologies present in the CPS/CPPS cluster.

IoT/loS. The IoT enables the communication between physical and Internet-enabled devices ${ }^{30}$ and can be used to improve the existing manufacturing systems. For example, a scheduling model for a hybrid workshop facilitated by IoT has also been proposed. ${ }^{69}$ There are many varieties used commonly, for example, when IoT capabilities are seen as services, they are referred as Internet of Services (IoS) ${ }^{70}$ Although both CPS and IoT/IoS consider physical and virtual world, a major difference is that the computer algorithms may or may

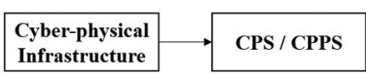

Figure 9. Visual representation of CPS/CPPS cluster with its corresponding technology.

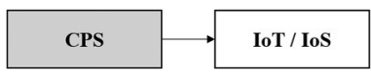

Figure 10. Visual representation of loT/loS cluster with its corresponding technology.

not use the Internet. There are examples when CPSs have been considered as a foundation for IoT/IoS. ${ }^{71}$ However, this is not necessarily the case for all applications; therefore, they are considered as separate technologies in this case. In this article, we are considering IoT as ubiquitous in the global sense and as a combination of national IoT, industrial IoT and local IoT. ${ }^{72}$ Figure 10 shows that CPS might have been placed in IoT/IoS cluster.

Advanced manufacturing. Advanced manufacturing is the technology that can integrate technology-based production systems such as flexible manufacturing system (FMS), reconfigurable manufacturing system (RMS), computer integrated manufacturing (CAM) and additive manufacturing. ${ }^{8}$ Overall, advanced manufacturing may be defined as integration of different production technologies, and therefore, it should not be considered as a technology for SM. Rather it could be an important discussion if various advanced manufacturing systems could be referred to as SMS. One possible distinction is that SM focuses more on the data aspects of manufacturing (data analytics), whereas advanced manufacturing is more focused on physical manufacturing technology.

Cloud manufacturing. Cloud manufacturing is driven by cloud computing ${ }^{62}$ that can, for example, use real-time demand to decide the production planning and scheduling. Data analytics may be considered as a part of cloud manufacturing, but as the applications of data analytics are so diverse, we should not consider it to be a part of cloud manufacturing. Real-time communication is the technology that would enable the users to exchange data with the systems in real-time. As it involves exchange of information between system and humans, it is not a part of interoperability. Figure 11 shows various technologies in the cloud-manufacturing cluster. Cloud manufacturing has also been considered to be supported by IoT, VR and cloud computing, ${ }^{73}$ but again since IoT and VR can stand as independent technologies, this article considers them as different technologies. 


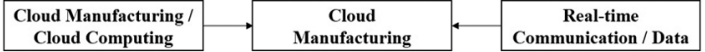

Figure I I. Visual representation of cloud manufacturing cluster with its corresponding technologies.

3D printing/additive manufacturing. 3D printing/additive manufacturing is the technology that can print a $3 \mathrm{D}$ image into an object with the help of laser beam, electron beam and so on; and as the objects are printed layer by layer, this technology is also referred to as additive manufacturing. ${ }^{53}$ Additive manufacturing is often referred to as being part of the advanced manufacturing domain. ${ }^{8}$

Smart products/parts/materials. Reusability is the property of products/parts/materials by which they can be recycled or used again in the system. It can be discussed whether reusability should be a part of energy saving/ efficiency or smart products/parts/materials. If one considers the recycling part, then reusability can be included in energy saving; but if it is considered as a characteristic of a material that can change its configuration to be reused in the same form or other, then it is a smart material. In this article, we consider it as characteristic of smart material. Resilience is the ability by which a product/part/material would be able to retain its original form. Resilience can be placed in the intelligent control cluster because a part may require intelligent control to return in its original form. Nevertheless, it could be an inbuilt characteristic of smart materials as well.

Tracking and tracing is the technology by which one can find the past and present locations of unique objects as information-carrying identities. ${ }^{74}$ Nevertheless, we need some (sensing) technology, which can help monitor tracking and tracing, and these sensors are referred to as smart sensors. Advanced temperature sensors and smart sensors have been used in production of hydrogen from methane. ${ }^{75}$ Other applications include the use of anti-metallic radio-frequency identification (RFID) in manufacturing environments; ${ }^{8}$ printed circuit boards ${ }^{76}$ have also been demonstrated. When the smart sensors have processors and software for an efficient exchange of data, they are called as smart products/parts. ${ }^{77}$ Use of RFID for tracking work-in-progress in shop floor has also been shown. ${ }^{78}$

Tracking and tracing may also be used to provide data regarding location; and if that data are used for analysis, then it could be considered as a part of the data analytics cluster as well. Tracking and tracing could also be replaced by tracking and tracing in real time, as we can track the location of objects in the real time. However, in this article, real-time communication is considered as a separate technology and it has been placed under the umbrella of cloud manufacturing.

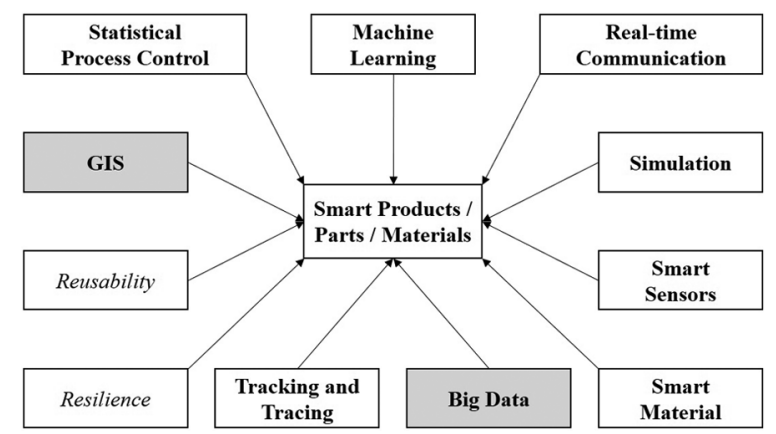

Figure 12. Visual representation of smart products/parts/ materials' cluster with its corresponding characteristics and technologies.

Smart materials can sense the change in environment and operations with the help of sensors and can take the corrective actions using actuators, ${ }^{79}$ and they can also provide data for analysis as well, which may lead to improved part design. ${ }^{80}$ Since smart materials require the use of sensors and actuators, they should be considered to be in the same cluster. Smart materials may also have the ability to change their structure as a response to external stimuli. A review of smart materials such as piezoelectric devices and shape memory alloys and their uses in industry has also been conducted. ${ }^{81}$ Therefore, the containing cluster is named smart products/parts/ materials. Figure 12 shows various characteristics and technologies that are a part of this smart products/ parts/materials' cluster.

IT-based production management. Enterprise resource planning (ERP) is the information system that helps integrate and coordinate different parts of a business, such as marketing, inventory and human resources. ${ }^{82}$ Supply chain management (SCM) is the flow of information, material and finance from one member to another. ${ }^{83}$ Manufacturing execution systems (MESs) are ITenabled systems that manage all changes happening to the product from raw material to finished good. ${ }^{84}$ Product lifecycle management (PLM) is about effectively managing a product through its entire lifecycle. ${ }^{85}$

Operations planning is the planning of all activities of an organization to achieve the final objective. It seems that life of a product, when coordinated by an IT system, could be considered as MES, while MES, ERP, SCM and operations planning could be seen as tools to connect everything happening within the organization through the help of IT. For this reason, we include these technologies in the cluster IT-based production management. Computer-aided design (CAD), computer-aided manufacturing (CAM), computeraided technology $(\mathrm{CAx})$ and so on are tools that allow to design, analyze and facilitate the design and production. ${ }^{86}$ Therefore, these CAx tools are included in the IT-based production management cluster as well. 


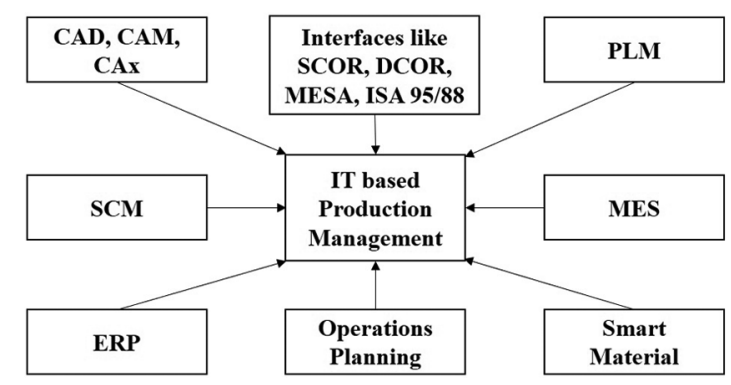

Figure 13. Visual representation of IT-based production management cluster with its corresponding characteristics and technologies.

Interfaces and high-level frameworks such as Supply Chain Operations Research (SCOR), ${ }^{87}$ Design Chain Operations Reference (DCOR), ${ }^{88}$ Manufacturing Enterprise Solutions Association (MESA) and ISA 95/88 consider the various levels of business processes and provide a computer-based package support. These should also be considered within the IT-based production management cluster. Figure 13 presents various technologies cumulated within the cluster IT-based production management. Digital manufacturing is the integration of technologies such as CAD, CAM, VR, ERP and modeling and simulation; ${ }^{90}$ however, this article discusses why they could be clustered in different groups of technologies.

\section{Enabling factors}

Characteristics and technologies are not the only platform required for SM. There are also standards and aspects of organization culture to be considered for a successful transformation toward SM. NIST has also presented some of the characteristics and technologies discussed in this article and considered them as standards. ${ }^{91}$ However, this article has considered characteristics, technologies and enabling factors (similar to standards referred to by NIST) as different groups and has tried to merge the ones that overlap. In the following section, selected standards and aspects of organizational culture associated with SM in literature, referred to as enabling factors, are discussed.

Law and regulations. There are various laws and regulations such as environmental laws, ${ }^{92,93}$ intellectual property rights and labor law that an organization has to follow depending on the nature of its work. These laws should be strictly followed for continued operation of an organization.

Innovative education and training. Education should help an individual to not only do their own work but also think about how the product or service he or she is working for can be improved for the benefit of the end user. This knowledge and innovation mindset can only

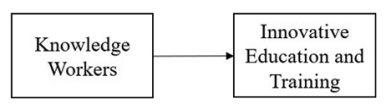

Figure 14. Visual representation of innovative education and training with its corresponding enabling factor.

be instilled in the workers with the help of proper training and entrepreneurial culture. Therefore, knowledge workers should be a part of innovative education and training. For example, a case study presents the importance of people and their training in SM at Alcoa. ${ }^{51}$ Figure 14 shows the cluster for innovative education and training.

Data sharing systems and standards. International Organization for Standardization (ISO) has defined STEP AP 242 and other STEP modules as universally standardized information models that can be used to exchange data and designs on common computer formats by various organizations. ${ }^{50}$ Similarly, core manufacturing simulation data (CMSD) can share simulation data. ${ }^{25}$ Enterprise integration also facilitates data sharing between small and medium enterprises (SMEs) and original equipment manufacturers (OEMs). A web-based visualization tool for energy management, following ISO 50001, has also been proposed. ${ }^{94}$ All these organizations such as STEP AP 242 and CMSD are working to provide a common platform for exchange of information, and therefore, they might be considered as the standards for different data sharing systems and thus could be clustered in data sharing systems and their standards. The selected systems are some of the examples, as there are other systems available and in use with SMSs. The selection of these specific examples is again based on the identified reference in literature.

Interoperability is different from data sharing systems and their standards because interoperability is the characteristic to share data and access a system in the network, whereas data sharing systems and their standards would provide the license to do so. This is a standard platform set by the manufacturing industry to receive information from numerically controlled machines that could later be used for data analytics. Figure 15 shows the cluster of data sharing systems.

\section{Discussion}

From our analysis in section "Analysis," we can observe that some of the identified characteristics act as building blocks of a technology, but the definition of technologies does not allow them to merge in a characteristic cluster. However, both technology and characteristic could be a part of another technology cluster. As a result, we have a lower number of characteristic 
Table 4. Clusters mentioning the names and numbers of characteristics and technologies.

\begin{tabular}{|c|c|c|c|c|c|}
\hline Clusters & Name of characteristic(s) & Name of technology(ies) & $\begin{array}{l}\text { No. of } \\
\text { Char. }\end{array}$ & $\begin{array}{l}\text { No. of } \\
\text { Tech. }\end{array}$ & Total \\
\hline Compositionality & Compositionality & & I & & 1 \\
\hline Context awareness & $\begin{array}{l}\text { Digital presence, context } \\
\text { awareness, asset, self-awareness }\end{array}$ & & 3 & & 3 \\
\hline Heterogeneity & Heterogeneity & & I & & I \\
\hline Interoperability & $\begin{array}{l}\text { Interoperability, networkability, } \\
\text { information appropriateness, } \\
\text { integrability, decentralized, } \\
\text { distributed }\end{array}$ & & 6 & & 6 \\
\hline Modularity & Composability, modularity & & 2 & & 2 \\
\hline $\begin{array}{l}\text { 3D printing/additive } \\
\text { manufacturing }\end{array}$ & & $\begin{array}{l}\text { 3D printing/additive } \\
\text { manufacturing }\end{array}$ & & I & I \\
\hline Cloud manufacturing & & $\begin{array}{l}\text { Real-time communication/data, } \\
\text { cloud computing/cloud } \\
\text { manufacturing }\end{array}$ & & 2 & 2 \\
\hline CPS/CPPS & & $\begin{array}{l}\text { Cyber-physical infrastructure, } \\
\text { CPS/CPPS }\end{array}$ & & 2 & 2 \\
\hline Cyber security & & Cyber security & & I & I \\
\hline Data analytics & & $\begin{array}{l}\text { Big data, data analytics/big data } \\
\text { analytics, predictive analytics, } \\
\text { data visualization, modeling, GIS, } \\
\text { simulation, forecasting, machine } \\
\text { learning, knowledge decision- } \\
\text { making techniques, statistical } \\
\text { process control }\end{array}$ & & II & II \\
\hline Energy saving/efficiency & Sustainability & Energy saving/efficiency & 1 & 1 & 2 \\
\hline Intelligent control & $\begin{array}{l}\text { Scalability, autonomy, } \\
\text { adaptability, robustness, } \\
\text { flexibility, fully automated, } \\
\text { proactivity, reliability, agility, } \\
\text { responsiveness, accuracy }\end{array}$ & Intelligent, intelligent control & 11 & 2 & 13 \\
\hline loT/loS & & loT/loS/lloT & & I & I \\
\hline $\begin{array}{l}\text { IT-based production } \\
\text { management }\end{array}$ & & $\begin{array}{l}\text { ERP, SCM, MES, PLM, interface } \\
\text { (SCOR, DCOR, MESA, ISA 95/ } \\
\text { 88), CAM, CAD, CAx, } \\
\text { operations planning, IT-based } \\
\text { production management }\end{array}$ & & 8 & 8 \\
\hline Smart product/part/material & Reusability, resilience & $\begin{array}{l}\text { Smart sensors, smart product/ } \\
\text { part, RFID, smart materials, } \\
\text { tracking and tracing }\end{array}$ & 2 & 5 & 7 \\
\hline Visual technology & & Holograms, VR, AR & & 3 & 3 \\
\hline
\end{tabular}

3D: three-dimensional; CPS: cyber-physical systems; CPPS: cyber-physical production system; GIS: Geographic Information Science; loT: Internet of Things; loS: Internet of Services; IloT: Industrial Internet of Things; ERP: enterprise resource planning; SCM: supply chain management; MES: manufacturing execution system; PLM: product lifecycle management; SCOR: Supply Chain Operations Research; DCOR: Design Chain Operations Reference; MESA: Manufacturing Enterprise Solutions Association; CAM: computer-aided manufacturing; CAD: computer-aided design; CAx: computer-aided X; RFID: radio-frequency identification; VR: virtual reality; AR: augmented reality.

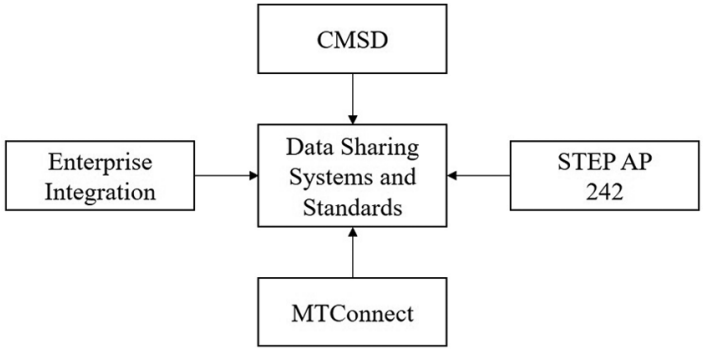

Figure 15. Visual representation of data sharing systems and their standards with corresponding enabling factors. clusters and a higher number of technology clusters. It can also be seen that the intelligent control cluster consists of 12 characteristics, namely, scalability, adaptability, flexibility, autonomy, fully automated, proactivity, robustness, reliability, agility, responsiveness, accuracy and two technologies intelligent and intelligent control, thus making it the biggest cluster. Table 4 presents a comprehensive overview of the names and numbers of characteristics and technologies in each cluster. However, while Table 4 presents the clusters for characteristics and technologies, it does not include enabling factors. The main reason for this omission is that the 


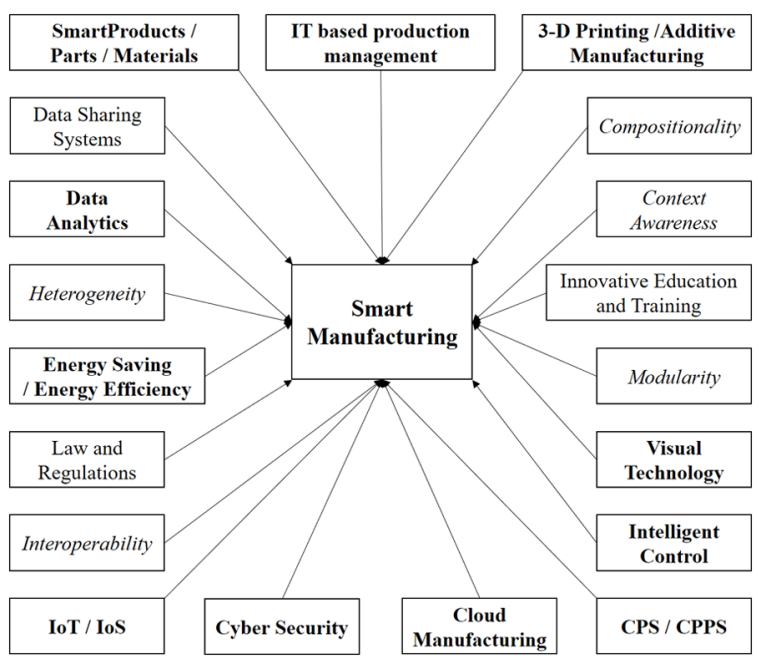

Figure 16. Visual representation of all characteristics and technologies that can define an SM.

enabling factors are more of a foundational aspect and that just a few of the identified articles actually referred to them. When the body of literature on SM expands in the future as expected, it might be possible to include enabling factors in a joint clustering similar to what has been done for technologies and characteristics in this article. Figure 16 shows the various characteristics, technologies and enabling factors that build an SMS. It has also been discussed why some technologies, such as data analytics and cloud manufacturing, although having many common elements, are being considered separately.

From our discussion, we derived a comprehensive list of 27 characteristics and 38 technologies associated with SM in current literature. We propose that such characteristics become the aspiring "qualities of being" (QoBs) or smart features that current and future manufacturing systems should pursue in order to acquire a certain degree of smartness toward becoming an advanced "smart" manufacturing system. QoBs aim to act as the "smart features" that are necessary for considering a manufacturing system "smart" (see Table 5). Technologies will change, as they evolve with time, but the smart features will remain the same. Hence, only the characteristics have been defined and mentioned in Table 5.

For example, a CPS-based architecture that uses PLCs and makes decisions for energy management ${ }^{95}$ should be based on technology clusters such as CPS, smart product/part/material, data analytics and energy saving/efficiency. Another example of how VR and AR can lead to sustainability, better training and knowledge is presented in Blümel. ${ }^{96}$ This example case includes the clusters visual technology, energy saving/ efficiency for the technology cluster and innovative education and training as the enabling factor cluster.

Such key characteristics and technologies are aimed, on one hand, to act as the capabilities to enable SM to comply with the six design principles of Industry 4.0 scenarios. ${ }^{97}$ These principles being (1) interoperability as the ability of SMSs and technologies (e.g. machines, devices, sensors, systems and people) to connect and communicate with each other in the IoT, Services and People (IoTSP) (also known as the Internet of Everything (IoE)); (2) virtualization or information transparency as the ability of manufacturing information systems to create a digital/virtual copies of things in the physical world, which are created by linking sensor data with virtual models and simulation models; (3) decentralization as the ability of SMSs and technologies to make decisions on their own and to perform their tasks as autonomous as possible, including exceptions, interferences and/or conflicting goals' handling; (4) real-time capability as the ability to collect and analyze data and immediately provide the derived insights; (5) service orientation as the offering of services via the IoS and (6) modularity as the flexible adaptation of manufacturing systems (cf FMSs) to the changing requirements by replacing or expanding individual modules. Altogether, these key characteristics and technologies guide the design and engineering of SMSs that are Industry 4.0 -enabled. Table 6 presents the SM characteristics and technologies associated with the Industry 4.0 design principles; ${ }^{97}$ various manifestations corresponding to them are also mentioned.

However, the identified SM key characteristics and technologies should also be related to the 6Cs characteristics of CPSs and big data analytics ${ }^{97}$ as core enabling technologies associated with the smartness attribute of manufacturing systems, including (1) connectivity with sensors and networks (e.g. IoT/IoS/ IIoT), (2) cloud computing and data on-demand (e.g. cloud manufacturing), (3) cyber model and memory (e.g. CPSs), (4) content/context meaning and correlation (e.g. analytics), (5) community sharing and collaboration (e.g. intelligent control) and (6) customization through personalization and value (e.g. IT-based production management). In this way, SM will be enabled to provide useful insights to the shop-floor management to utilize data and information to increase the flexibility of manufacturing processes and respond rapidly to changes in demand at low cost to the SM enterprise. Table 7 presents the SM characteristics and technologies associated with the 6Cs characteristics of CPSs and big data analytics; ${ }^{98}$ the various manifestations corresponding to them are also mentioned.

\section{Conclusion and limitations}

This article identified, discussed and clustered characteristics, technologies and enabling factors that might be used to define SM and SMSs and thus provide a foundation for a future comprehensive SM ontology. Overall, it was determined that there are five characteristics, namely, context awareness, modularity, 
Table 5. Smart features for manufacturing system.

\begin{tabular}{|c|c|c|}
\hline SI no. & Qualities of being & Smart features \\
\hline I & Digital presence & $\begin{array}{l}\text { Being able to create digital or cyber-physical models of parts or the complete manufacturing } \\
\text { system to develop a simulation environment for advanced planning, decision support and } \\
\text { validation capability, before any action is implemented physically. }\end{array}$ \\
\hline 2 & Modularity & Being able to create "economies of scale" within the manufacturing system. \\
\hline 3 & Heterogeneity & Being able to create "economies of scope" within the manufacturing system. \\
\hline 4 & Scalability & $\begin{array}{l}\text { Being able to adjust (e.g. increase) production capacity through the manufacturing system } \\
\text { reconfiguration with minimal cost and in minimal time. }\end{array}$ \\
\hline 5 & Context awareness & $\begin{array}{l}\text { Being able to automatically and in real-time collect manufacturing system data via a network of } \\
\text { sensors (e.g. loT), and subsequently conduct real-time processing (event or data-driven) to } \\
\text { provide the proper information to the right people or system and the right time. }\end{array}$ \\
\hline 6 & Autonomy & $\begin{array}{l}\text { Being able to support (autonomous) reasoning, planning and decision-making via hardware, } \\
\text { software, sensors and communication technology to increase a manufacturing system's } \\
\text { productivity and flexibility. }\end{array}$ \\
\hline 7 & Adaptability & $\begin{array}{l}\text { Being able to manage unforeseen events during production as a manufacturing system. } \\
\text { Adaptability may include flexibility and robustness features' capabilities. }\end{array}$ \\
\hline 8 & Robustness & $\begin{array}{l}\text { Being able to cope with problems during production as a manufacturing. Robustness can be } \\
\text { achieved through redundancy. }\end{array}$ \\
\hline 9 & Flexibility & Being able to produce different products on the same manufacturing system. \\
\hline 10 & Fully automated & $\begin{array}{l}\text { Being able to fully control by means of a computer system parts or the complete manufacturing } \\
\text { system. }\end{array}$ \\
\hline II & Asset self-awareness & $\begin{array}{l}\text { Being able to sense a phenomenon or event within itself (the asset), such as its location, condition } \\
\text { or availability within the manufacturing system. }\end{array}$ \\
\hline 12 & Interoperability & $\begin{array}{l}\text { Being able to allow communication through interfaces between the components/sub-systems of a } \\
\text { manufacturing system, allowing it to work with or use parts of another components/sub-systems. }\end{array}$ \\
\hline 13 & Networkability & $\begin{array}{l}\text { Being able to allow information exchange and communication between the components/sub- } \\
\text { systems of a manufacturing system. }\end{array}$ \\
\hline 14 & $\begin{array}{l}\text { Information } \\
\text { appropriateness }\end{array}$ & $\begin{array}{l}\text { Being able to acquire information from one or more sources within the manufacturing system } \\
\text { components and sub-systems, store it and assure its quality, accessibility and understandability, as } \\
\text { well as its provisioning to the right people or system and the right time. }\end{array}$ \\
\hline 15 & Integrability & $\begin{array}{l}\text { Being able to bring together different component sub-systems (e.g. machine tools, robots, } \\
\text { computer systems, humans) of a manufacturing system into one integrated system and ensuring } \\
\text { that all the sub-systems function together as a coordinated whole. }\end{array}$ \\
\hline 16 & Sustainability & $\begin{array}{l}\text { Being able to conduct all manufacturing processes and system operations with minimum } \\
\text { environmental footprint (e.g. resource efficiency). }\end{array}$ \\
\hline $\begin{array}{l}17 \\
18\end{array}$ & $\begin{array}{l}\text { Compositionality } \\
\text { Composability }\end{array}$ & $\begin{array}{l}\text { Being able to provide recombinant components within a manufacturing system that can be } \\
\text { selected and assembled in various combinations to satisfy specific production requirements. }\end{array}$ \\
\hline 19 & Proactivity & $\begin{array}{l}\text { Being able to anticipate (predict), by means of continuous situation-awareness capabilities, events } \\
\text { (e.g. problems) in the production or manufacturing system components (e.g. machine tool) and } \\
\text { react ahead of time (e.g. proactive maintenance). }\end{array}$ \\
\hline 20 & Reliability & $\begin{array}{l}\text { Being able to perform the required manufacturing processes and operations as a "reliable" } \\
\text { manufacturing system under stated conditions, to achieve production objectives. Condition } \\
\text { monitoring and defect diagnosis are enablers to improve the reliability of a manufacturing system. }\end{array}$ \\
\hline 21 & Agility & Being able to respond to external changes (e.g. market changes) that affect production plans. \\
\hline 22 & Responsiveness & Being able to provide a "quick response" to changes in production plans. \\
\hline 23 & Accuracy & $\begin{array}{l}\text { Being able to produce with minimal or zero-waste in all manufacturing processes and operations } \\
\text { (e.g. lean manufacturing). }\end{array}$ \\
\hline 24 & Reusability & $\begin{array}{l}\text { Being able to use existing assets as they are or by modifying them in the manufacturing system in } \\
\text { some form or other to reduce the introduction of new ones. }\end{array}$ \\
\hline 25 & Decentralized & $\begin{array}{l}\text { Being able to allow the components or sub-systems of a manufacturing system to operate on local } \\
\text { information to accomplish global production goals. }\end{array}$ \\
\hline 26 & Distributed & $\begin{array}{l}\text { Being able to produce in dispersed manufacturing facilities that are coordinated using information } \\
\text { and communication technology. }\end{array}$ \\
\hline 27 & Resilience & $\begin{array}{l}\text { Being able to tolerate large perturbations during production and still achieve production goals } \\
\text { (e.g. in terms of product quality, delivery time, production cost). }\end{array}$ \\
\hline
\end{tabular}

loT: Internet of Things.

heterogeneity, interoperability and compositionality; 11 technologies, namely, intelligent control, energy saving/ efficiency, cyber security, CPS/CPPS, visual technology, IoT/IoS, cloud computing/cloud manufacturing, 3D printing/additive manufacturing, smart product/ part/materials, data analytics and IT-based production management; as well as three enabling factors, namely, law and regulations, innovative education and training and data sharing systems, that are required in SM. These characteristics, technologies and enabling factors might also be used to classify a manufacturing system as smart. Additionally, these characteristics and technologies were matched with the design principles of Industry $4.0^{97}$ and the key characteristics of CPSs and 
Table 6. Design principles for SMS readiness for Industry 4.0 scenarios.

\begin{tabular}{|c|c|c|c|c|}
\hline SI no. & $\begin{array}{l}\text { Industry } 4.0 \\
\text { design principles }\end{array}$ & SM characteristics & SM-associated technologies & Selected manifestations \\
\hline I & Interoperability & $\begin{array}{l}\text { Interoperability } \\
\text { Networkability } \\
\text { Distributed } \\
\text { Information appropriateness } \\
\text { Integrability } \\
\text { Sustainability }\end{array}$ & $\begin{array}{l}\text { Cyber security } \\
\text { Interface } \\
\text { IT-based production management }\end{array}$ & $\begin{array}{l}\text { Interoperability frameworks } \\
\text { Interoperability standards } \\
\text { Middleware } \\
\text { Plug-and-play } \\
\text { solutions } \\
\text { loE } \\
\text { M2M }\end{array}$ \\
\hline 2 & Virtualization & $\begin{array}{l}\text { Context awareness } \\
\text { Digital presence } \\
\text { Asset self-awareness }\end{array}$ & $\begin{array}{l}\text { Holograms } \\
\text { VR } \\
\text { AR } \\
\text { CPS/CPPS } \\
\text { Modeling } \\
\text { Simulation } \\
\text { CAM/CAD/CAx }\end{array}$ & $\begin{array}{l}\text { Virtual organization } \\
\text { Virtual factory } \\
\text { Digital factory } \\
\text { Digital manufacturing } \\
\text { Digital services } \\
\text { Digital twin } \\
\text { Product avatar }\end{array}$ \\
\hline 3 & Decentralization & $\begin{array}{l}\text { Modularity } \\
\text { Heterogeneity } \\
\text { Autonomy } \\
\text { Asset self-awareness } \\
\text { Sustainability } \\
\text { Compositionality } \\
\text { Decentralized } \\
\text { Distributed } \\
\text { Resilience }\end{array}$ & $\begin{array}{l}\text { Cyber-physical } \\
\text { infrastructure } \\
\text { Cloud computing/ } \\
\text { cloud manufacturing } \\
\text { 3D printing/additive } \\
\text { manufacturing } \\
\text { GIS }\end{array}$ & $\begin{array}{l}\text { Cloud environments } \\
\text { (public, private, hybrid) } \\
\text { Local production } \\
\text { (produce on-site) } \\
\text { Rapid prototyping }\end{array}$ \\
\hline 4 & Real-time capability & $\begin{array}{l}\text { Context awareness } \\
\text { Asset self-awareness } \\
\text { Fully automated } \\
\text { Sustainability } \\
\text { Proactivity } \\
\text { Reliability } \\
\text { Agility } \\
\text { Responsiveness } \\
\text { Accuracy }\end{array}$ & $\begin{array}{l}\text { Intelligence } \\
\text { Intelligent control } \\
\text { Energy saving/efficiency } \\
\text { Real-time } \\
\text { communication/data } \\
\text { Big data } \\
\text { Data analytics } \\
\text { Predictive analytics } \\
\text { Data visualization } \\
\text { Forecasting } \\
\text { Machine learning } \\
\text { MES } \\
\text { Operations planning } \\
\text { Tracking and tracing } \\
\text { Knowledge } \\
\text { decision-making } \\
\text { techniques } \\
\text { SPC }\end{array}$ & $\begin{array}{l}\text { Sensing enterprise } \\
\text { Proactive enterprise } \\
\text { Smart enterprise } \\
\text { Smart factory } \\
\text { Intelligent products } \\
\text { Intelligent assets } \\
\text { Intelligent services } \\
\text { Intelligent maintenance systems }\end{array}$ \\
\hline 5 & Service orientation & $\begin{array}{l}\text { Modularity } \\
\text { Interoperability } \\
\text { Networkability } \\
\text { Composability }\end{array}$ & $\begin{array}{l}\text { Intelligence } \\
\text { Intelligent control } \\
\text { loT/loS/lloT } \\
\text { Smart sensors } \\
\text { Smart products/parts } \\
\text { RFID } \\
\text { Smart materials }\end{array}$ & $\begin{array}{l}\text { SOA } \\
\text { SOC } \\
\text { Software/platform/ } \\
\text { infrastructure-as-a-service } \\
\text { Servitization paradigm } \\
\text { loS } \\
\text { Digital services } \\
\text { IPSS }\end{array}$ \\
\hline 6 & Modularity & $\begin{array}{l}\text { Modularity } \\
\text { Scalability } \\
\text { Autonomy } \\
\text { Adaptability } \\
\text { Robustness } \\
\text { Flexibility } \\
\text { Sustainability } \\
\text { Composability } \\
\text { Reusability }\end{array}$ & $\begin{array}{l}\text { Advanced manufacturing } \\
\text { ERP } \\
\text { SCM } \\
\text { MES } \\
\text { PLM } \\
\text { CAM/CAD/CAx }\end{array}$ & $\begin{array}{l}\text { Plug-and-produce paradigm } \\
\text { Mass-customization paradigm }\end{array}$ \\
\hline
\end{tabular}

SM: smart manufacturing; loE: Internet of Everything; M2M: machine-to-machine communication; VR: virtual reality; AR: augmented reality; CPS: cyber-physical system; CPPS: cyber-physical production system; CAM: computer-aided manufacturing; CAD: computer-aided design; CAx: computeraided X; 3D: three-dimensional; GIS: Geographic Information Science; MES: manufacturing execution system; SPC: statistical process control; loT: Internet of Things; loS: Internet of Services; IloT: Industrial Internet of Things; RFID: radio-frequency identification; SOA: service-oriented architecture; SOC: service-oriented computing; IPSS: industrial product-service system; ERP: enterprise resource planning; SCM: supply chain management; MES: manufacturing execution system; PLM: product lifecycle management. 
Table 7. The $6 \mathrm{Cs}$ for smart manufacturing systems in cyber-physical environments.

\begin{tabular}{|c|c|c|c|c|}
\hline SI no. & $6 \mathrm{Cs}$ & SM characteristics & SM-associated technologies & Selected manifestations \\
\hline I & Connectivity & $\begin{array}{l}\text { Interoperability } \\
\text { Networkability } \\
\text { Distributed } \\
\text { Information appropriateness } \\
\text { Integrability } \\
\text { Sustainability } \\
\text { Reliability } \\
\text { Agility } \\
\text { Decentralized } \\
\text { Distributed } \\
\text { Resilience }\end{array}$ & $\begin{array}{l}\text { Cyber security } \\
\text { Real-time communication/data } \\
\text { loT/loS/lloT } \\
\text { RFID } \\
\text { Machine learning } \\
\text { Interfaces } \\
\text { IT based on production } \\
\text { management }\end{array}$ & $\begin{array}{l}\text { Pervasive or ubiquitous } \\
\text { computing } \\
\text { AAA paradigm (anywhere, } \\
\text { anytime, anybody/any type/any } \\
\text { device) } \\
\text { IT integration (vertical and } \\
\text { horizontal integration) } \\
\text { Mobile devices }\end{array}$ \\
\hline 2 & Cloud & $\begin{array}{l}\text { Interoperability } \\
\text { Networkability } \\
\text { Modularity } \\
\text { Scalability } \\
\text { Integrability } \\
\text { Compositionality } \\
\text { Composability } \\
\text { Decentralized } \\
\text { Distributed }\end{array}$ & $\begin{array}{l}\text { Energy saving/efficiency } \\
\text { Cloud computing/cloud } \\
\text { manufacturing } \\
\text { IT based on production } \\
\text { management }\end{array}$ & $\begin{array}{l}\text { Cloud-based applications } \\
\text { Cloud manufacturing } \\
\text { Distributed manufacturing }\end{array}$ \\
\hline 3 & Cyber & $\begin{array}{l}\text { Interoperability } \\
\text { Networkability } \\
\text { Context awareness } \\
\text { Digital presence } \\
\text { Asset self-awareness } \\
\text { Integrability } \\
\text { Compositionality } \\
\text { Composability }\end{array}$ & $\begin{array}{l}\text { Cyber security } \\
\text { Holograms } \\
\text { VR } \\
\text { AR } \\
\text { Cyber-physical infrastructure } \\
\text { CPS/CPPS } \\
\text { CAM/CAD/CAx } \\
\text { IT based on production } \\
\text { management }\end{array}$ & $\begin{array}{l}\text { Visual technologies } \\
\text { Sensor networks } \\
\text { Internet communication } \\
\text { Infrastructure } \\
\text { Intelligent, real-time processing } \\
\text { and event management } \\
\text { Big data and data provisioning } \\
\text { Embedded software for logic } \\
\text { Automated operations }\end{array}$ \\
\hline 4 & Content/context & $\begin{array}{l}\text { Context awareness } \\
\text { Asset self-awareness } \\
\text { Fully automated } \\
\text { Information appropriateness } \\
\text { Sustainability } \\
\text { Proactivity } \\
\text { Responsiveness } \\
\text { Accuracy }\end{array}$ & $\begin{array}{l}\text { Intelligence } \\
\text { Intelligent control } \\
\text { Big data } \\
\text { Smart sensors } \\
\text { Smart products/parts } \\
\text { Data analytics } \\
\text { Predictive analytics } \\
\text { Data visualization } \\
\text { Modeling } \\
\text { Simulation } \\
\text { Forecasting } \\
\text { Machine learning } \\
\text { Operation planning } \\
\text { Tracking and tracing } \\
\text { Knowledge decision-making } \\
\text { techniques } \\
\text { SPC }\end{array}$ & $\begin{array}{l}\text { Sensor networks } \\
\text { loT platforms } \\
\text { Data analytics } \\
\text { Data management }\end{array}$ \\
\hline 5 & Community & $\begin{array}{l}\text { Modularity } \\
\text { Heterogeneity } \\
\text { Autonomy } \\
\text { Robustness } \\
\text { Fully automated } \\
\text { Integrability } \\
\text { Compositionality } \\
\text { Composability } \\
\text { Decentralized } \\
\text { Distributed } \\
\text { Resilience }\end{array}$ & $\begin{array}{l}\text { loT/loS/lloT } \\
\text { Smart sensors } \\
\text { Smart products/parts } \\
\text { GIS } \\
\text { ERP } \\
\text { RFID } \\
\text { Machine learning } \\
\text { SCM } \\
\text { MES } \\
\text { PLM } \\
\text { Smart materials } \\
\text { CAM/CAD/CAx }\end{array}$ & $\begin{array}{l}\text { Collaborative virtual factory } \\
\text { Social networks } \\
\text { Grid computing } \\
\text { Distributed manufacturing } \\
\text { IloT } \\
\text { Sharing economy }\end{array}$ \\
\hline
\end{tabular}


Table 7. Continued

\begin{tabular}{|c|c|c|c|c|}
\hline SI no. & $6 \mathrm{Cs}$ & SM characteristics & SM-associated technologies & Selected manifestations \\
\hline 6 & Customization & $\begin{array}{l}\text { Modularity } \\
\text { Heterogeneity } \\
\text { Adaptability } \\
\text { Flexibility } \\
\text { Integrability } \\
\text { Compositionality } \\
\text { Composability } \\
\text { Reusability }\end{array}$ & $\begin{array}{l}\text { Advanced manufacturing } \\
\text { 3D printing/additive } \\
\text { manufacturing } \\
\text { Smart products/parts } \\
\text { ERP } \\
\text { Machine learning } \\
\text { SCM } \\
\text { MES } \\
\text { PLM } \\
\text { CAM/CAD/CAx }\end{array}$ & $\begin{array}{l}\text { Flexible manufacturing systems } \\
\text { Reconfigurable manufacturing } \\
\text { systems } \\
\text { On-demand manufacturing } \\
\text { Customer-centric production }\end{array}$ \\
\hline
\end{tabular}

SM: smart manufacturing; loT: Internet of Things; loS: Internet of Services; IloT: Industrial Internet of Things; RFID: radio-frequency identification; VR: virtual reality; AR: augmented reality; CPS: cyber-physical system; CPPS: cyber-physical production system; CAM: computer-aided manufacturing; CAD: computer-aided design; CAx: computer-aided X; SPC: statistical process control; GIS: Geographic Information Science; ERP: enterprise resource planning; SCM: supply chain management; MES: manufacturing execution system; PLM: product lifecycle management; 3D: threedimensional.

big data analytics. ${ }^{98}$ It was found that all the identified characteristics and technologies match with the design principles of Industry 4.0 and CPS.

In a next step, a very similar approach could be used to classify other popular initiatives such as smart factory, intelligent manufacturing and distributive manufacturing. Based on this clarification, a mapping of the different initiatives and a "degree of similarity" might be derived to identify overlaps and areas where these initiatives complement each other.

In this article, we can also observe that there are a smaller number of clustered characteristics compared to the number of clustered technologies. One possible explanation for this occurrence is that the technologies need certain characteristics as input and it would have been redundant to consider such characteristics separately. For example, scalability, flexibility, adaptability, robustness, autonomy, fully automated and proactivity were clustered in the technology intelligent control. However, we do not have technology/technologies clustered into a characteristic as they depend on later. Furthermore, it was also discussed why advanced manufacturing is a manufacturing system itself and should not be considered as a part of technologies.

Another finding this article addresses is that some of the technologies such as GIS, smart materials, tracking and tracing could be considered as part of both data analytics and smart parts/products/materials. It is the application of the technology which determines the cluster it will belong to. Therefore, the application will vary with the objective of SM.

The resultant list is to be understood as a first step in defining a comprehensive list of commonly agreed upon SM characteristics, technologies and enabling factors. The authors encourage industry and academic experts to provide feedback to further develop this list. This can lead to additional expansion or reduction in the current list. A similar development is expected if an increasing amount of new SM literature, including applications, is published in the future containing additional or more clearly defined characteristics, technologies and enabling factors.

There are several limitations in this article, which need to be mentioned. First, when the identified articles were thoroughly read to prepare a list of characteristics, technologies and enabling factors, it was found that many articles mention SM only once in the title and/or in the keywords. This might lead to the interpretation that the term is strongly associated with positive goals (e.g. federal funding opportunities, "hot topic") and authors would incorporate SM in the title to be more visible. It has to be observed if this changes once $\mathrm{SM}$ is more established and the definition is broadly disseminated among academics and industry.

Furthermore, while extracting the characteristics, technologies and enabling factors from literature sources where they were not directly mentioned and classified as such, the subjective perspective of the authors plays a part in the decision of choosing either technology or characteristic as the defining element. These characteristics and definitions are from a small set of research and there might be some others, which were not reviewed. The clusters in this work are based on the knowledge, expertise, experience and perspective of the authors. Some of the characteristics and technologies were listed in the literature, but definitions were not explicitly provided. Therefore, these characteristics and technologies were defined from other articles and the authors' knowledge. The authors tried to increase the transparency of the clustering by explaining the reasoning of the decisions. Another limitation of this article is that there was only one article covering Industry 4.0 and CPS that was considered by the authors to find the design principles of Industry 4.0 and characteristics of CPS. However, this article should be considered as a first step toward a commonly accepted list of defining characteristics and technologies for SM that eventually leads to a comprehensive SM ontology. Readers are actively encouraged to provide feedback and challenge the selection. 


\section{Acknowledgements}

The authors would like to express their gratitude to the members of IFIP WG 5.1 and 5.7 as well as the SMLC for their valuable input and encouragement at the different stages of this study. Furthermore, the authors thank the participants of the NIST Smart Manufacturing workshop 2016 and 2017 for the inspiration. Finally, the authors would like to thank the reviewers for their valuable comments that helped to significantly improve the article. The article is an enhanced and extended version of the following publication "Mittal, S., Khan, M. \& Wuest, T. (2016). Smart Manufacturing: Characteristics and Technologies. 13th International Conference on Product Lifecycle Management (PLM) 2016, July 1113., 2016, Columbia, SC, USA.”

\section{Declaration of conflicting interests}

The author(s) declared no potential conflicts of interest with respect to the research, authorship and/or publication of this article.

\section{Funding}

The author(s) disclosed receipt of the following financial support for the research, authorship, and/or publication of this article: This work was supported by the J. Wayne \& Kathy Richards Faculty Fellowship in Engineering at WVU.

\section{References}

1. Davis J, Edgar T, Graybill R, et al. Smart manufacturing. Annu Rev Chem Biomol Eng 2015; 6: 141-160.

2. Lightfoot HW, Baines $\mathrm{T}$ and Smart P. Examining the information and communication technologies enabling servitized manufacture. Proc IMechE, Part B: J Engineering Manufacture 2011; 225: 1964-1968.

3. Esmaeilian B, Behdad S and Wang B. The evolution and future of manufacturing: a review. J Manuf Syst 2016; 39: 79-100.

4. Energy-efficient buildings: multi-annual roadmap for the contractual PPP under Horizon 2020. Brussels: European Commission Directorate-General for Research \& Innovation, 2013, http://www.buildup.eu/en/practices/publications/energy-efficient-buildings-multi-annual-roadmapcontractual-ppp-under-horiz-0

5. Jung K, Kulvatunyou B, Choi S, et al. An overview of a smart manufacturing system readiness assessment. In: Proceedings of the international conference on advances in production management systems, Iguassu Falls, Brazil, 37 September 2016, pp.705-712. Berlin: Springer.

6. Teramoto K, Wu D, Ota K, et al. A framework of accuracy assured machining for smart manufacturing. Mem Muroran Inst Tech 2016; 65: 35-39.

7. Anderson A. Report to the President on ensuring American leadership in advanced manufacturing. Executive Office of the President, 2011, https://obama whitehouse.archives.gov/sites/default/files/microsites/ostp/ pcast-advanced-manufacturing-june2011.pdf
8. Tao F, Cheng Y, Zhang L, et al. Advanced manufacturing systems: socialization characteristics and trends. $J$ Intell Manuf 2015; 28: 1-6.

9. Kim DB, Denno PO and Jones AT. A model-based approach to refine process parameters in smart manufacturing. Concurrent Eng 2015; 23: 365-376.

10. Kühnle H and Bitsch G. Foundations \& principles of distributed manufacturing. Berlin: Springer, 2015, pp.55-70.

11. Strozzi F, Colicchia C, Creazza A, et al. Literature review on the "Smart Factory" concept using bibliometric tools. Int J Prod Res 2017; 11: 1-20.

12. Thoben KD, Wiesner S and Wuest T. "Industrie 4.0" and smart manufacturing - a review of research issues and application examples. Int J Autom Technol 2017; 11: 4-16.

13. Harispe S, Ranwez S, Janaqi S, et al. Semantic similarity from natural language and ontology analysis. Synth Lect Hum Lang Technol 2015; 8: 1-254.

14. Rachuri S. Smart manufacturing systems design and analysis. National Institute of Standards and Technology, 2015, https://www.nist.gov/programs-projects/smart-manufactur ing-systems-design-and-analysis-program

15. Trombley D and Rogers E. Benefits and barriers of smart manufacturing. Energy systems laboratory. College Station, TX: Texas A\&M University, 2014.

16. Qu S, Jian R, Chu T, et al. Computational reasoning and learning for smart manufacturing under realistic conditions. In: Proceedings of the international conference on behavioral, economic, and socio-cultural computing, Shanghai, China, 30 October 2014, pp.1-8. New York: IEEE.

17. Jung K, Morris K, Lyons KW, et al. Performance challenges identification method for smart manufacturing systems. Report no. 8108, 27 November 2015. Gaithersburg, MD: National Institute of Standards and Technology.

18. Lee YT, Kumaraguru S, Hatim Q, et al. A classification scheme for smart manufacturing systems' performance metrics. ASTM J Smart Sustain Manuf 2017; 1: 52-74.

19. Kusiak A. A four-part plan for smart manufacturing. ISE Mag 2017; 49: 43-47.

20. Park $\mathbf{J}$ and Lee $\mathbf{J}$. Presentation on Korea smart factory program. In: Proceedings of the international conference on advances in production management systems, Tokyo, Japan, 5-9 September 2015. Berlin: Springer.

21. Davis J. Cyberinfrastructure in chemical and biological process systems: impact and directions. NSF workshop report, Arlington, VA, https://smartmanufacturingcoalition.org/sites/default/files/the_norma_language_applica tion_to_solution_of_strong_nonequilibrium_transfer.pdf (2006, accessed 29 March 2017).

22. Park HS and Tran NH. Autonomy for smart manufacturing. J Korean Soc Precis Eng 2014; 31: 287-295.

23. Smart Process Manufacturing Engineering Virtual Organization Steering Committee. Smart process manufacturing: an operations and technology roadmap, https:// smartmanufacturingcoalition.org/sites/default/files/spm _ _an_operations_and_technology_roadmap.pdf (2009, accessed 29 March 2017).

24. Rathinasabapathy R, Elsass MJ, Josephson JR, et al. A smart manufacturing methodology for real time chemical process diagnosis using causal link assessment. AIChE $J$ 2016; 62: 3420-3431.

25. Kibira D, Morris K and Kumaraguru S. Methods and tools for performance assurance of smart manufacturing systems. J Nat Inst Stand Technol 2015; 8099. 
26. Papazoglou MP, Van Den Heuvel WJ and Mascolo JE. Reference architecture and knowledge-based structures for smart manufacturing networks. IEEE Softw 2015; 32: 61-69.

27. Lu Y, Morris KC and Frechette S. Standards landscape and directions for smart manufacturing systems. In: Proceedings of the IEEE international conference on automation science and engineering, Gothenburg, 24 August 2015, pp.998-1005. New York: IEEE.

28. Kusiak A. Smart manufacturing. Int J Prod Res 2017; 14: $1-10$.

29. Cheng K. Keynote presentation-2: smart tooling, smart machines and smart manufacturing: working towards the Industry 4.0 and beyond. In: Proceedings of the 21 st international conference on automation and computing, Glasgow, Scotland, 11 September 2015, pp.11-12. New York: IEEE.

30. Kang HS, Lee JY, Choi S, et al. Smart manufacturing: past research, present findings, and future directions. Int J Precis Eng Manuf 2016; 3: 111-128.

31. Malik JA. US expects energy savings through smart manufacturing. MRS Bull 2016; 41: 10-11.

32. Choi S, Jung K and Do Noh S. Virtual reality applications in manufacturing industries: past research, present findings, and future directions. Concurr Eng 2015; 23: 40 63.

33. Korambath $\mathrm{P}$, Wang J, Kumar A, et al. A smart manufacturing use case: furnace temperature balancing in steam methane reforming process via Kepler workflows. Procedia Comput Sci 2016; 80: 680-689.

34. Leitão P, Colombo AW and Karnouskos S. Industrial automation based on cyber-physical systems technologies: prototype implementations and challenges. Comput Ind 2016; 81: 11-25.

35. Kulvatunyou B, Ivezic N, Morris KC, et al. Drilling down on smart manufacturing-enabling composable apps. Manuf Lett 2016; 10: 14-17.

36. Lao L, Ellis M and Christofides PD. Smart manufacturing: handling preventive actuator maintenance and economics using model predictive control. AlChE J 2014; 60: 2179-2196.

37. Shin SJ, Woo J and Rachuri S. Predictive analytics model for power consumption in manufacturing. Procedia CIRP 2014; 15: 153-158.

38. Schabus S and Scholz J. Geographic Information Science and technology as key approach to unveil the potential of Industry 4.0: how location and time can support smart manufacturing. In: Proceedings of the 12th international conference on informatics in control, automation and robotics, Colmar, 21 July 2015, pp.463-470. New York: IEEE.

39. Kusiak A. Smart manufacturing must embrace big data. Nature 2017; 544: 23-25.

40. Shao G, Shin SJ and Jain S. Data analytics using simulation for smart manufacturing. In: Proceedings of the winter simulation conference, Savannah, GA, 7 December 2014, pp.2192-2203. New York: IEEE.

41. Bryner M. Smart manufacturing: the next revolution. Chem Eng Prog 2012; 108: 4-12.

42. Choi S, Kim BH and Do Noh S. A diagnosis and evaluation method for strategic planning and systematic design of a virtual factory in smart manufacturing systems. Int $J$ Precis Eng Manuf 2015; 16: 1107-1115.
43. Lee I and Lee K. The Internet of Things (IoT): applications, investments, and challenges for enterprises. Bus Horizons 2015; 58: 431-440.

44. Nezhad MN. Smart manufacturing systems: real-time data analytics. Advances in Embedded Interactive Systems, Technical Report. 2016; 4: 20-26.

45. Wu D, Jennings C, Terpenny $\mathbf{J}$, et al. A comparative study on machine learning algorithms for smart manufacturing: tool wear prediction using random forests. $J$ Manuf Sci Eng 2017; 139: 071018.

46. Sinha $\mathrm{S}$. Advanced/smart manufacturing: from nanoscale to megascale. IEEE Potentials 2016; 35: 7-8.

47. Bostelman R, Falco J, Shah M, et al. Dynamic metrology performance measurement of a six degrees-of-freedom tracking system used in smart manufacturing. In: Proceedings of the Autonomous industrial vehicles: from the laboratory to the factory floor, 2016. West Conshohocken, PA: ASTM International. https://www.astm.org/DIGI TAL_LIBRARY/STP/PAGES/STP159420150056.htm, DOI: $10.1520 /$ STP159420150056.

48. Shafiq SI, Sanin C, Szczerbicki E, et al. Decisional DNA based conceptual framework for smart manufacturing. In: Proceedings of the international conference on information systems architecture and technology, Karpacz, 20-22 September 2015, pp.79-88. Berlin: Springer.

49. Stephen JE. A policymaker's guide to smart manufacturing. Report, Information Technology \& Innovation Foundation, Washington, DC, November 2016.

50. Feeney AB, Frechette SP and Srinivasan V. A portrait of an ISO STEP tolerancing standard as an enabler of smart manufacturing systems. J Comput Inf Sci Eng 2015; 15: 021001.

51. Hudson S. Smart manufacturing and smarter talent acquisition and development: extending Alcoa's talent pipeline into communities. People Strategy 2014; 37: 40-46.

52. Kulvatunyou B, Ivezic N and Srinivasan V. On architecting and composing engineering information services to enable smart manufacturing. J Comput Inf Sci Eng 2016; 16: 031002 .

53. Abowd GD, Ebling M, Hung G, et al. Context-aware computing [guest editors' intro.]. IEEE Pervas Comput 2002; 1: 22-23.

54. Zuehlke D. Smart factory - towards a factory-of-things. Annu Rev Control 2010; 34: 129-138.

55. De Weck OL, Ross AM and Rhodes DH. Investigating relationships and semantic sets amongst system lifecycle properties (ilities). In: Proceedings of the third international engineering systems symposium, 18-20 June 2012. Delft: Delft University of Technology.

56. Stengel R. Robotics and intelligent systems, https:/ www.princeton.edu/ stengel/MAE345Lecture1.pdf (2015, accessed 29 March 2017).

57. Báez-González P, Alejandro J, Carlini MA, et al. Dayahead economic optimization of energy use in an olive mill. Control Eng Pract 2016; 54: 91-103.

58. Matsushima K, Nakahara S, Arima Y, et al. Computer holography: 3D digital art based on high-definition CGH. J Phys Conf Ser 2013; 415: 12-53.

59. Steuer J. Defining virtual reality: dimensions determining telepresence. J Commun 1992; 42: 73-93.

60. Earnshaw RA. Virtual reality systems. Cambridge, MA: Academic press, 2014.

61. Azuma RT. A survey of augmented reality. Teleoperators Virtual Environ 1997; 6: 355-385. 
62. Yu C, Xu X and Lu Y. Computer-integrated manufacturing, cyber-physical systems and cloud manufacturingconcepts and relationships. Manuf Lett 2015; 6: 5-9.

63. Ghahramani Z. Probabilistic machine learning and artificial intelligence. Nature 2015; 521: 452-459.

64. Waller MA and Fawcett SE. Data science, predictive analytics, and big data: a revolution that will transform supply chain design and management. J Bus Logist 2013; 34: 77-84.

65. Fan W and Bifet A. Mining big data: current status, and forecast to the future. ACM SIGKDD Explor Newsletter 2013; 14: 1-5.

66. Chai J, Liu JN and Ngai EW. Application of decisionmaking techniques in supplier selection: a systematic review of literature. Expert Syst Appl 2013; 40: 3872 3885.

67. Lee EA. Cyber physical systems: design challenges. In: Proceedings of the 11th IEEE international symposium on object and component-oriented real-time distributed computing, Orlando, FL, 5-7 May 2008. New York: IEEE.

68. Monostori L Cyber-physical production systems: roots, expectations and R\&D challenges. Procedia CIRP 2014; 17: 9-13.

69. Wang M, Zhong RY, Dai Q, et al. A MPN-based scheduling model for IoT-enabled hybrid flow shop manufacturing. Adv Eng Inf 2016; 30: 728-736.

70. Alberti AM and Singh D. Internet of things: perspectives, challenges and opportunities. In: Proceedings of the international workshop on telecommunications (IWT 2013), INATEL, Brazil, 6-9 May 2013.

71. Klötzer C and Pflaum A. Cyber-physical systems as the technical foundation for problem solutions in manufacturing, logistics and supply chain management. In: Proceedings of the 5th international conference on internet of things, Seoul, Korea, 26-28 October 2015. New York: IEEE.

72. Ning $H$ and Wang Z. Future internet of things architecture: like mankind neural system or social organization framework? IEEE Commun Lett 2011; 15: 461-463.

73. Tao F, Zhang L, Venkatesh VC, et al. A computing and service-oriented manufacturing model. Proc IMechE, Part B: J Engineering Manufacture 2011; 225: 1969-1976.

74. Paunescu D, Stark WJ and Grass RN. Particles with an identity: tracking and tracing in commodity products. Powder Technol 2016; 291: 344-350.

75. Kumar A, Baldea M, Edgar TF, et al. Smart manufacturing approach for efficient operation of industrial steammethane reformers. Indus Eng Chem Res 2015; 54: 4360 4370.

76. Bindel A, Rosamond E, Conway P, et al. Product life cycle information management in the electronics supply chain. Proc IMechE, Part B: J Engineering Manufacture 2012; 226: 1388-1400.

77. Bindel A, Conway PP and West AA. Information structure required for life-cycle monitoring of electronic products. Proc IMechE, Part B: J Engineering Manufacture 2012; 226: 1612-1627.

78. Yuan L, Guo Y, Wei F, et al. Radio frequency identification-enabled monitoring and evaluating in the discrete manufacturing process. Proc IMechE, Part B: J Engineering Manufacture. Epub ahead of print 29 June 2017. DOI: $10.1177 / 0954405415620986$.

79. Rade DA and Steffen V. Introduction to smart materials and structures. In: Junior L, Steffen V and Savi V (eds)
Dynamics of smart systems and structures. Berlin: Springer, 2016, pp.121-134

80. Khan MA, Rozati GL and Wuest T. Sensor triggered replacement of spare parts: customer service process innovation. In: Proceedings of the IFIP international conference international conference on advances in production management systems, Iguassu Falls, Brazil, 3-7 September 2016. Berlin: Springer.

81. Spaggiari A, Castagnetti D, Golinelli N, et al. Smart materials: properties, design and mechatronic applications. Proc IMechE, Part L: J Materials: Design Applications. Epub ahead of print 12 December 2016. DOI: $10.1177 / 1464420716673671$.

82. Nettsträter A, Geißen T, Witthaut $M$, et al. Logistics software systems and functions: an overview of ERP, WMS, TMS and SCM systems. In: Hompel M, Rehof J and Wolf $\mathrm{O}$ (eds) Cloud computing for logistics. Berlin: Springer, 2015, pp.1-11.

83. Chopra S and Meindl P. Supply chain management. Strategy, planning \& operation. In: Boersch $\mathrm{H}$ and Eschen C (eds) Das Summa Summarum des Management. Berlin: Springer, 2007, pp.265-275.

84. Blanc P, Demongodin I and Castagna P. A holonic approach for manufacturing execution system design: an industrial application. Eng Appl Artif Intell 2008; 211: 315-330.

85. Stark J. Product lifecycle management. In: Saaksvuori A and Immonen A (eds) Product lifecycle management. Berlin: Springer, 2015, pp.1-29.

86. Manafi D, Nategh MJ and Parvaz H. Extracting the manufacturing information of machining features for computer-aided process planning systems. Proc IMechE, Part B: J Engineering Manufacture 2016; 15: 1-12.

87. Kocaoğlu B, Gülsün B and Tanyaş M. A SCOR based approach for measuring a benchmarkable supply chain performance. J Intell Manuf 2013; 24: 113-132.

88. Zuñiga R, Seifert M and Thoben KD. Study on the application of DCOR and SCOR models for the sourcing process in the mineral raw material industry supply chain. In: Kreowski H, Scholz-Reiter B and Thoben KD (eds) Dynamics in logistics. Berlin; Heidelberg: Springer, 2013, pp.211-220.

89. Robles T, Alcarria R, Martın D, et al. An IoT based reference architecture for smart water management processes. J Wirel Mob Netw Ubiquit Comput Dependable Appl 2015; 6: 4-23.

90. Chryssolouris G, Mavrikios D, Papakostas N, et al. Digital manufacturing: history, perspectives, and outlook. Proc IMechE, Part B: J Engineering Manufacture 2009; 223: 451-462.

91. Lu Y, Morris KC and Frechette S. Current standards landscape for smart manufacturing systems. Report no. 8107, 23 February 2016. Gaithersburg, MD: National Institute of Standards and Technology.

92. Ma R and Ho YS. Comparison of environmental laws publications in Science Citation Index Expanded and Social Science Index: a bibliometric analysis. Scientometrics 2016; 1-3.

93. Pavlovic A and Fragassa C. Analysis of flexible barriers used as safety protection in woodworking. Int J Qual Res 2016; 10: 71-88.

94. Bruton K, O'Donovan P, McGregor A, et al. Design and development of a software tool to assist ISO 50001 implementation in the manufacturing sector. Proc IMechE, 
Part B: J Engineering Manufacture. Epub ahead of print 26 December 2016. DOI: 10.1177/0954405416683427.

95. Bruton K, Walsh BP, óg Cusack D, et al. Enabling effective operational decision making on a combined heat and power system using the $5 \mathrm{C}$ architecture. Procedia CIRP 2016; 55: 296-301.

96. Blümel E. Global challenges and innovative technologies geared toward new markets: prospects for virtual and augmented reality. Procedia Comput Sci 2013; 25: 4-13.
97. Hermann M, Pentek T and Otto B. Design principles for Industrie 4.0 scenarios. In: Proceedings of the 49th Hawaii international conference on system sciences, Kauai, HI, 5 January 2016, pp.3928-3937. New York: IEEE.

98. Lee J, Bagheri B and Kao HA. Recent advances and trends of cyber-physical systems and big data analytics in industrial informatics. In: Proceedings of the international conference on industrial informatics, Porto Alegre, Brazil, 27-30 July 2014. New York: IEEE. 


\section{Original Papers}

\section{Publication III}

A critical review of smart manufacturing \& Industry 4.0 maturity models: Implications for small and medium-sized enterprises (SMEs)

By

Sameer Mittal, Muztoba Ahmad Khan, David Romero and Thorsten Wuest, October 2018

Mittal, S., Khan, M. A., Romero, D., \& Wuest, T. (2018). A critical review of smart manufacturing \& Industry 4.0 maturity models: Implications for small and medium-sized enterprises (SMEs). Journal of manufacturing systems, 49, 194-214.

2018 Elsevier. Reprint with Right to include in Dissertation. 


\title{
A critical review of smart manufacturing \& Industry 4.0 maturity models: Implications for small and medium-sized enterprises (SMEs)
}

\author{
Sameer Mittal ${ }^{\mathrm{a}}$, Muztoba Ahmad Khan ${ }^{\mathrm{a}}$, David Romero ${ }^{\mathrm{b}}$, Thorsten Wuest ${ }^{\mathrm{a}, *}$ \\ ${ }^{a}$ Department of Industrial and Management Systems Engineering, West Virginia University, Morgantown, WV, USA \\ ${ }^{\mathrm{b}}$ Tecnológico de Monterrey, Mexico City, Mexico
}

\section{A R T I C L E I N F O}

\section{Keywords:}

Smart manufacturing

Industry 4.0

Industrie 4.0

Smart factory

Roadmaps

Maturity models

Frameworks

Readiness assessments

Small and medium-sized enterprises

SMEs

SMM

\begin{abstract}
A B S T R A C T
The objective of this paper is to critically review currently available Smart Manufacturing (SM) and Industry 4.0 maturity models, and analyze their fit recognizing the specific requirements of Small and Medium-sized Enterprises (SMEs). To this end, this paper presents features that are characteristic for SMEs and identify research gaps needed to be addressed to successfully support manufacturing SMEs in their progress towards Industry 4.0. The results of this study show that only a limited number of the SM and Industry 4.0 roadmaps, maturity models, frameworks and readiness assessments that are available today reflect the specific requirements and challenges of SMEs. The main findings include: (1) the current standard starting "level 1" (base level) of most maturity models appears to be disconnected from the real digitization and smart manufacturing maturity level of many SMEs. Therefore, we propose a "level 0 " specifically designed to reflect the 'real - base level' for SMEs; (2) the transition from this new base level, "level 0", to the current standard "level 1", requires significant effort including a mind-set change; (3) maturity models and readiness assessments can be associated with an SM toolkit, and (4) SMEs need to develop their own, unique SM or Industry 4.0 vision and roadmap. This study provides insights that help towards developing a realistic SM (Industry 4.0) maturity model for SMEs that reflects their industrial realities more accurately. With the help of SM maturity models that are more customized to the SME specific requirements, the SMEs' stakeholders will be able to better define their SM (Industry 4.0) vision, roadmap, and strategic projects. It will ultimately lower the entry barrier and reduce the risk of the transition process towards SM and Industry 4.0 and support the critical change in culture. Summarizing, we identified manufacturing SMEs' specific requirements, conducted a literature review of current SM maturity models, and discussed how these maturity models reflect the SME specific requirements.
\end{abstract}

\section{Introduction}

Small and Medium-sized Enterprises (SMEs) are the driving force of many manufacturing economies [1]. As the backbone of the manufacturing industry, SMEs' impact on the Fourth Industrial Revolution is significant. SMEs often face different challenges and barriers than larger companies (from now on, Multi-National Enterprises - MNEs) [2,3]. A recent 2017 study conducted with manufacturing SMEs in West Virginia, USA, confirmed the struggle for SMEs to adopt Smart Manufacturing [4]. According to our literature review, only a few studies specifically focus on supporting SMEs' evolutionary path and paradigmshift towards "Smart Manufacturing (SM)" or "Industry 4.0". Some authors refer to SMEs who successfully managed this transition as 'SME $4.0^{\prime}[5,6]$.
This paper first looks at SME specific requirements prior to conducting a comprehensive literature review of currently available Smart Manufacturing assessment, maturity and readiness models (hereinafter referred to as 'maturity models' for easier reading). Then it discusses the assessment, maturity, and readiness models regarding their 'fit' with the identified SME specific requirements. In the process, it determines and discusses research gaps and finally proposes a possible avenue to address them by creating dedicated maturity models for SMEs.

\subsection{SME requirements}

This section discusses a set of SME specific requirements that differentiate their business from MNEs. To develop such a set of SME specific requirements, Table 1 defines what constitutes an SME.

\footnotetext{
* Corresponding author.

E-mail addresses: samittal@mix.wvu.edu (S. Mittal), mdkhan@mix.wvu.edu (M.A. Khan), david.romero.diaz@gmail.com (D. Romero), thwuest@mail.wvu.edu (T. Wuest).
} 
Table 1

SMEs Category (European Commission [7],).

\begin{tabular}{llll}
\hline Enterprise & $\begin{array}{l}\text { Max. People } \\
\text { Employed }\end{array}$ & $\begin{array}{l}\text { Max. Annual } \\
\text { Turnover }\end{array}$ & $\begin{array}{l}\text { Max. Annual } \\
\text { Balance Sheet Total }\end{array}$ \\
\hline Small & $<50$ & $\leq € 10$ million & $\leq € 10$ million \\
Medium & $<250$ & $\leq € 50$ million & $\leq € 43$ million
\end{tabular}

According to the European Commission [7], SMEs may be defined as the enterprises which employ less than 250 employees and have an annual turnover not exceeding EUR 50 million, and/or an annual balance sheet total not exceeding EUR 43 million (see Table 1). This paper will follow the EC's definition for the remainder of this research work.

The current literature discusses various opportunities and challenges faced by SMEs. Wuest \& Thoben [2] emphasized the importance of information management in manufacturing SMEs. Dyerson et al. [8] performed an empirical analysis of 117 small manufacturing firms in the UK and clustered them based on their degree of IT readiness. Kennedy \& Hyland [9] analyzed data from 632 SMEs (both OECD and non-OECD) and concluded that SMEs are not involved when it comes to the deployment of advanced manufacturing technologies (AMTs). Terziovski [10] studied 600 Australian manufacturing SMEs and found that SMEs lack the innovation culture and strategy to succeed. Kumar et al. [11] compared the various quality management practices in the UK and Australian manufacturing SMEs and found that leadership, fact-based decision-making, networking with government bodies and academic institutions, as well as an ISO 9000 certification are critical success factors for SMEs. Vasudevan \& Chawan [12] conducted interviews with CEOs, managers, and manufacturing consultants to find the importance of knowledge management in Indian manufacturing SMEs. The authors [12] concluded that global awareness on manufacturing, frequent employee interaction, attending workshops or conferences outside India, as well as industry-academia interaction are essential activities that foster knowledge creation. Müller \& Voigst [13] deployed the design interaction strategies for the introduction of Industry 4.0 in German SMEs and interviewed 68 experts including 41 CEOs in firms dealing in (1) mechanical and plant engineering, (2) electrical engineering and (3) automotive suppliers, and concluded that standardization, personnel resources, financial resources, and a belief on digitization are unique constraints for SMEs.

Table 2 presents specific SME features (Column 3). Additionally, it reports on the general peculiarity of the features in MNEs (Column 4) emphasizing the differences between the perspective of the small and large enterprises. It has to be noted that the illustrated differences are generalized. There might be instances where an SME is actually far more advanced in their SM adoptions compared to individual MNEs, e.g., SMEs operating in industries such as aerospace or defense. However, the surveyed literature as well as data collected in a recent study [4] support our generalization. The general features (Column 2) are derived from the literature [2,8-13] and are based on case studies performed with SMEs in different countries. These studies considered the various viewpoints that are relevant to manufacturing enterprises. The similar SME requirements, were grouped and finally eight clusters (finance, technical resource availability, product specialization, standards, organizational culture, employee participation, alliances and collaboration) were formed for a more fluent discussion.

One very important feature of an enterprise is the availability of financial resources. All businesses rely heavily on the access to investments and the return on investment. SMEs are often owned by an individual and several risk factors are involved with the small-scale businesses. For example, lack of collaterals, the informational asymmetries between small businesses and investors, etc [14]. are some of the reasons for capital constrains that SMEs face as compared to the MNEs [15]. Overall, it can be concluded that SMEs are financially constrained.
Table 2

Comparison of SME and MNE based on defining features (based on [2,8-13].

\begin{tabular}{|c|c|c|c|}
\hline \# & Features & SMEs & MNEs \\
\hline 1 & Financial Resources & Low & High \\
\hline 2 & $\begin{array}{l}\text { Use of Advanced } \\
\text { Manufacturing } \\
\text { Technologies (AMTs) }\end{array}$ & Low & (Very) High \\
\hline 3 & $\begin{array}{l}\text { Software Umbrella (incl. } \\
\text { Data Analytics) }\end{array}$ & $\begin{array}{l}\text { Low (Often Tailored } \\
\text { Solutions) }\end{array}$ & $\begin{array}{l}\text { High (With More } \\
\text { Standardized Solutions) }\end{array}$ \\
\hline 4 & Research \& Development & Low & High \\
\hline 5 & $\begin{array}{l}\text { Nature of Product } \\
\text { Specialization }\end{array}$ & High & Low \\
\hline 6 & Standards consideration & Low & High \\
\hline 7 & $\begin{array}{l}\text { Organization culture/ } \\
\text { Leadership flexibility }\end{array}$ & Low & High \\
\hline 8 & $\begin{array}{l}\text { Company } \\
\text { Strategy }\end{array}$ & $\begin{array}{l}\text { Dictated by Instinct Of } \\
\text { Leader (Owner) }\end{array}$ & $\begin{array}{l}\text { Market Research \& } \\
\text { Accurate Analyses }\end{array}$ \\
\hline 9 & $\begin{array}{l}\text { Decision } \\
\text { Making }\end{array}$ & $\begin{array}{l}\text { Restricted to Leader/ } \\
\text { Few Knowledge Carriers }\end{array}$ & $\begin{array}{l}\text { Board of Advisors \& } \\
\text { (Int./Ext.) Consultants }\end{array}$ \\
\hline 10 & $\begin{array}{l}\text { Organizational } \\
\text { Structure }\end{array}$ & $\begin{array}{l}\text { Less Complex } \\
\text { And Informal }\end{array}$ & $\begin{array}{l}\text { Complex } \\
\text { And Formal }\end{array}$ \\
\hline 11 & $\begin{array}{l}\text { Human } \\
\text { Resources Engagement }\end{array}$ & Multiple Domains & Specialized Domains \\
\hline 12 & $\begin{array}{l}\text { Exposure to Human } \\
\text { Resource } \\
\text { Development }\end{array}$ & $\begin{array}{l}\text { High in The Industry/ } \\
\text { Low Outside The Industry }\end{array}$ & $\begin{array}{l}\text { Low Within Industry/ } \\
\text { High Outside the } \\
\text { Industry }\end{array}$ \\
\hline 13 & $\begin{array}{l}\text { Knowledge and } \\
\text { Experience Industry }\end{array}$ & $\begin{array}{l}\text { Focused In A } \\
\text { Specific Area }\end{array}$ & $\begin{array}{l}\text { Spread Around } \\
\text { Different Areas }\end{array}$ \\
\hline 14 & $\begin{array}{l}\text { Alliances with } \\
\text { Universities/ } \\
\text { Research Institutions }\end{array}$ & Low & High \\
\hline 15 & $\begin{array}{l}\text { Important } \\
\text { Activities }\end{array}$ & Outsourced & $\begin{array}{l}\text { Internal to The } \\
\text { Organization }\end{array}$ \\
\hline 16 & $\begin{array}{l}\text { Dependence on } \\
\text { Collaborative Network }\end{array}$ & High & Low \\
\hline 17 & $\begin{array}{l}\text { Customer/Supplier } \\
\text { Relations }\end{array}$ & High (Strong) & Low (Not So Strong) \\
\hline
\end{tabular}

Technology is another prominent feature in the context of SM and Industry 4.0. Adoption of AMTs can improve various strategic domains of manufacturing such as quality, HR policies, etc. [16]. However, a financially constrained SME cannot easily upgrade and adopt AMTs, nor they have the technical resources readily available. As a result, SMEs do not perform well when it comes to research and development. Also, when compared with the MNEs the SMEs lack in the IT integration, and therefore, the software (incl. data analytics tools) used to maintain the SME records are tailored towards resolving the specific issues faced by SMEs.

Due to the limited technical and financial resources, SME's research and development domains are not very advanced, but their hard work leads to highly specialized products that can differentiate SMEs from their competitors [17]. The lack of awareness and resources compared to MNEs make the survival of SMEs difficult [18]. MNEs strictly obey standards such as ISO; however, the presence of these standards in SMEs is rare. It is partly due to the resources required to prepare and pass the certifications [19]. Therefore, SMEs need to consider the industrial standards. Study [20] conducted in electrical engineering and machinery micro firms in Germany showed that SMEs are interested in accessing the knowledge gained by MNEs, but they think that standardization may disclose their essential information to the competitors.

The organization behavior is also a critical aspect of an enterprise. The organizational structure in SMEs is less complicated and informal compared to MNEs. The organizational culture is often not sufficiently flexible to experiment and consider implementation initiatives for cutting-edge technologies [21]; therefore, SMEs are not able to invest comparably in market research and analysis. Consequently, there may be times when SME's decisions are not as informed [22] and are mostly based on a 'gut feeling' of the manager/decision-maker. Gut feeling always involves high levels of uncertainty, and therefore the 
managers/decision-makers in SMEs may not be confident in their decisions. In contrast, decisions in MNEs are based on market research and accurate analyses that are discussed by a board of advisors/consultants [23].

The opportunities and exposure that are received by employees in SMEs and MNEs are also very different. For example, the employees at SMEs are more likely to be 'Jack of all Trades' [24] and less likely to develop high levels of expertise [25] in a particular field as they have day-to-day responsibilities in a variety of areas. Employees of MNEs, on the other hand, are more likely to be highly specialized and thus considered experts in specific areas such as automation technology, and they are aware of the state-of-the-art in their field. SME employees are also more likely to lack the exposure to mentors, workshops, supervised industrial training, etc. [26]. Therefore, there is a lack of employee participation in SMEs.

SMEs may also have a deficit in (national/international) cross-disciplinary networking opportunities. As a result, they are not able to update themselves with the on-going, cutting-edge research and have alliances with universities and research institutes.

The collaboration strategies are also crucial to the success of an organization. However, when it comes to SMEs, they lack alliances with universities and other research institutions. They might be limited to learn from their own experience due to lack of access to shared knowledge. The knowledge and wisdom of SMEs are often focused in a specific domain, whereas in the case of MNEs it is spread across different areas. Thus, SMEs outsource many essential activities. SMEs generally have fewer products to manage, and their collaborative network is not that strong, therefore, they have a particular number of suppliers/vendors [27] and consequently have an extreme dependence on them. MNEs, on the other hand, usually have a vast number of option for suppliers/vendors, and as a result, their reliance on a particular supplier/vendor is comparatively less. Table 2 presents a summary of the above discussion.

Table 3 mentions the SME features, cluster corresponding to each feature and the SME perspective on the features. From the above discussion it can be concluded that among all the clusters (finance, technical resource availability, specialized products, standards, organizational culture, employee participation, alliances, and collaboration), SMEs are already doing well when it comes to producing the specialized products. Therefore, in the current manuscript the overall number of features (17 in total) that can be used to record differences between SMEs and MNEs will be treated as SME specific requirements (16 in total) to assess the SM maturity models. The feature 'specialized products (SP)' was excluded from the requirements list as SMEs are more likely to produced specialized products and thus confirm with the Industry 4.0 notion of batch-size 1 .

\subsection{Smart manufacturing/Industry 4.0 in SMEs}

Modern manufacturing is inherently complex [28]. Current literature presents several studies focusing on how manufacturing SMEs cope, and in many cases struggle with this complexity. Nieuwenhuize [29] analyzed six different Dutch SMEs from the following sectors: (a) sheet metal production, (b) rail-road manufacturing, (c) machine packaging, (d) profile and tube cutting, (e) steel processing, and (f) copper separation, to identify their strategic orientation towards a shift to "smart manufacturing". Based on an SME's level of intention and adoption of SM technologies and practices, Nieuwenhuize [29] categorized SMEs into three segment profiles: (1) dormant, (2) captives and (3) adopters.

SMEs often lack the resources to look at new avenues outside of their core competencies. In most cases, they are not "early adopters," mainly because of the fear of investing in the wrong technologies or adopting inapt practices. However, SMEs have to learn fast about the emerging technologies and digital practices to compete [30] with the MNEs who have already begin their SM journey. Veza et al. [31] used a nine-question survey format, based on a scale from 1 to 4 , to evaluate the Industry 4.0 Maturity Level of Croatian Enterprises under the project INSENT (an acronym for Croatian Model of Innovative Smart Enterprise). According to the survey results, the present level of Industry 4.0 Maturity of Croatian Enterprises is " 2.15 ", implying that the Croatian Enterprises have still not started to deploy the Industry 4.0 technologies. Presently, they are in the second generation of industrialization using electrically powered mass production systems [32]. The survey [31] included 159 companies, among which 69\% were SMEs.

Only two studies mentioned above [29] and [31], were identified during the literature review to have at least a partial focus on SMEs' specific needs. This lack of SME based studies towards SM/Industry 4.0 indicates a research gap within the current scientific body of knowledge. While there are plenty and well-developed studies available on holistic models, including organizational, business, and technological aspects, most are only marginally supporting SMEs towards adopting SM and Industry 4.0. Most of the available academic and consulting studies focus on MNEs and treat SMEs similarly in their evolutionary path towards SM or Industry 4.0. However, given SMEs' distinct differences and requirements, this can be considered challenging. Furthermore, the literature review shows that SMEs are often overwhelmed with decisions (i.e., strategic and operational) about what, why, when, where, who and how they can incorporate the different SM or Industry 4.0 technologies [33,34] into their manufacturing and/or service business and operational models. Table 4 depicts a snapshot of five selected SM technologies. It has to be noted that this does not constitute

Table 3

SME requirements and clusters.

\begin{tabular}{|c|c|c|c|}
\hline \# & Features & Cluster & SME Perspective on Features \\
\hline 1 & Financial resources & Finance (FN) & Require Financial Resources \\
\hline 2 & Use of Advanced Manufacturing Technologies (AMTs) & Technical Resource Availability (TR) & Require Advanced Manufacturing Technologies (AMTs) \\
\hline 3 & Software Umbrella (incl. Data Analytics) & Technical Resource Availability (TR) & Require Advanced Manufacturing Technologies (AMTs) \\
\hline 4 & Research \& development & Technical Resource Availability (TR) & Require Advanced Manufacturing Technologies (AMTs) \\
\hline 5 & Nature of Product Specialization & Product Specialization (SP) & Product Specialization Available \\
\hline 6 & Standards consideration & Standards (ST) & Require Industrial Standards \\
\hline 7 & Organization culture/ Leadership flexibility & Organizational culture (OC) & Require Organizational Culture \\
\hline 8 & Company Strategy & Organizational Culture (OC) & Require Organizational Culture \\
\hline 9 & Decision Making & Organizational Culture (OC) & Require Organizational Culture \\
\hline 10 & Organizational Structure & Organizational Culture (OC) & Require Organizational Culture \\
\hline 11 & Human Resources Engagement & Employee Participation (EP) & Require Employee Participation \\
\hline 12 & Exposure to Human Resource Development & Employee Participation (EP) & Require Employee Participation \\
\hline 13 & Knowledge and Experience Industry & Employee Participation (EP) & Require Employee Participation \\
\hline 14 & Alliances with Universities/ Research Institutions & Alliances (AL) & Require Alliances with Universities/ Research Institutions \\
\hline 15 & Important Activities & Collaboration (CL) & Require Collaboration \\
\hline 16 & Dependence on Collaborative Network & Collaboration (CL) & Require Collaboration \\
\hline 17 & Customer/supplier Relations & Collaboration (CL) & Require Collaboration \\
\hline
\end{tabular}


Table 4

Common Definitions of Selected SM/Indsutry 4.0 Technologies (based on [33]).

\begin{tabular}{|c|c|c|c|}
\hline \# & Technology & Definition & Reference(s) \\
\hline 1 & $\begin{array}{l}\text { Augmented Reality (AR) and Virtual } \\
\text { Reality (VR) }\end{array}$ & $\begin{array}{l}\text { AR/VR creates an artificial (virtual) environment of the real world using various innovative technologies like } \\
\text { mobile devices, wearables, etc. }\end{array}$ & {$[34,40,41,42]$} \\
\hline 2 & Additive Manufacturing & $\begin{array}{l}\text { Additive manufacturing creates complex parts from the ground up, mostly adding one layer at a time, based on a } \\
\text { 3D CAD model. }\end{array}$ & {$[43,44]$} \\
\hline 3 & $\begin{array}{l}\text { Internet of Things } \\
\text { (IoT) }\end{array}$ & $\begin{array}{l}\text { IoT (also referred to as the Internet of Everything or Industrial Internet of Things) describes the connection and } \\
\text { communication of physical 'things' over the internet. }\end{array}$ & {$[42,45]$} \\
\hline 4 & (Big) Data Analytics & $\begin{array}{l}\text { Data sets (or data lakes) are now characterized by their high volume, velocity, and variety nature ( } 3 \mathrm{Vs} \text { ) plus } \\
\text { veracity and value ( } 5 \mathrm{Vs}) \text {. Specific technologies with new analytical methods and tools are required to transform } \\
\text { significantly big volumes of data effectively and efficiently into information and knowledge. }\end{array}$ & [46-49] \\
\hline 5 & Cyber-Physical Systems & $\begin{array}{l}\text { CPS are systems of collaborating computational entities that are in connection with their surrounding physical } \\
\text { world and their on-going processes, providing and using, at the same time, data-accessing and data-processing } \\
\text { services available on the internet. }\end{array}$ & {$[50,51]$} \\
\hline
\end{tabular}

a comprehensive list, but technologies that are commonly used in the SM context. Readers interested in a comprehensive overview of SM related technologies are referred to [33]. Maier \& Student [35] summarize this predicament very well by stating: "SMEs know that something has to be done, but they don't know how and where to start" [35]. A report [36] by WirtschaftsWoche magazine presents that two-thirds of over a thousand surveyed industries in Germany, Austria, and Switzerland are not aware of the basics regarding Industry 4.0 technologies and their enabling business and operating models. Many German SMEs are not yet shifting towards the new Industry 4.0 paradigm $[37,38]$ and on top of that, many SMEs are also ignoring associated trends like digitization (digitalization) and automation [38,39]. The overarching research question of this paper is:

- 'Are the current Smart Manufacturing maturity models a good fit for the specific requirements of manufacturing SMEs?' (RQ1)

Subsequent research questions that we aim to answer are:

- 'What are the research gaps that prevent current Smart Manufacturing maturity models from providing the missing SME specific support?' (RQ2)

- 'How can the current Smart Manufacturing maturity models be adapted to support SMEs' specific requirements in their evolutionary path and the paradigm shift towards SM and Industry 4.0?' (RQ3)

This paper addresses these questions with the help of an in-depth literature review and a subsequent critical review. As a result, the study presents a first overview of the opportunities and challenges for SMEs towards adopting and deploying the technologies and principles of SM and Industry 4.0 by using maturity models.

Some of the standard terms in the international landscape referring to Smart Manufacturing Initiatives include "Smart Manufacturing" (predominantly used in the USA), "Industry 4.0" (predominantly used in Germany/Europe) and "Smart Factory" (predominantly used in Korea/ Asia/Europe) [52]. In this paper, these terms are considered interchangeably despite minor differences in their definitions. These three terms denote the primary objective of helping industries and their manufacturing ecosystems in different countries to connect and adopt novel information and operation technologies, as well as business and operating models, to enable new revenue streams as well as cost and efficiency gains. The findings of this literature review indicate that current reference models and architectures stemming from these SM initiatives are more suitable, helpful, and readily available for MNEs. We suspect that this might also be true for the different SM maturity models that are currently available.

The structure of this paper is as follows. Section 2 illustrates research methodology that involved a literature review and a critical review following the approach of Grant \& Booth [53]. Relevant scientific papers and industry/consulting white papers were identified in established databases and included in the literature review. Section 3 presents in-depth analysis and critical review of the different maturity models available in today's literature that focus on the transition towards SM and Industry 4.0 and also analyzes the fit between specific requirements of SMEs with the state-of-art maturity models for SM/ Industry 4.0. Section 4 presents the research questions on how to support SMEs towards the SM/Industry 4.0 paradigm adoption. Section 5 discusses the strategic rationale to promote SMEs' shift towards value adding SM business and operating models. Finally, Section 6 concludes the paper and includes a brief discussion of the limitations of the conducted research as well as future work that might emerge from this paper's results.

\section{Methodology}

To answer the framed research questions (see Section 1.2) we developed a five-step methodology that will be described in this section. Fig. 1 presents a schematic overview of the research methodology.

Step 1: Manufacturing SME cases from different countries were studied, and the essential enterprise features were identified. Then the viewpoints of both SMEs and MNEs on these features were compared, and this comparison resulted in the framing of the specific requirements of manufacturing SMEs.

Step 2: A comprehensive review of the current literature on Smart Manufacturing and Industry 4.0 maturity models including related terms such as assessment and readiness models, frameworks and roadmaps was conducted. The literature review was followed by a transparent, step-by-step process to identify the relevant literature in the field. The literature review considered the following keywords and searched terms: "Smart Manufacturing" (or "Industry 4.0" or "Smart Factory") and "Roadmap" (or "Model" or "Framework" or "Assessment"). Presented below is the full search string used to identify the relevant literature for this critical review paper:

"Smart Manufacturing" and "Roadmap"; "Smart Manufacturing" and "Model"; "Smart Manufacturing" and "Framework"; "Smart Manufacturing" and "Assessment"; "Industry 4.0" and "Roadmap"; "Industry 4.0" and "Model"; "Industry 4.0" and "Framework"; "Industry 4.0" and "Assessment"; "Smart Factory" and "Roadmap"; "Smart Factory" and "Model"; "Smart Factory" and "Framework"; "Smart Factory" and "Assessment".

These keywords were searched in Google Scholar and Web of Science databases for relevant literature. After analyzing the titles of all resulting papers from initial search, in a first iteration, only 40 potential SME focused papers were identified. However, after critically reading the identified 40 papers entirely in a second iteration, 15 papers relevant to this research were determined. The limited number of relevant papers indicates the novelty of the topic.

This critical review is essential to identify the primary sources that 


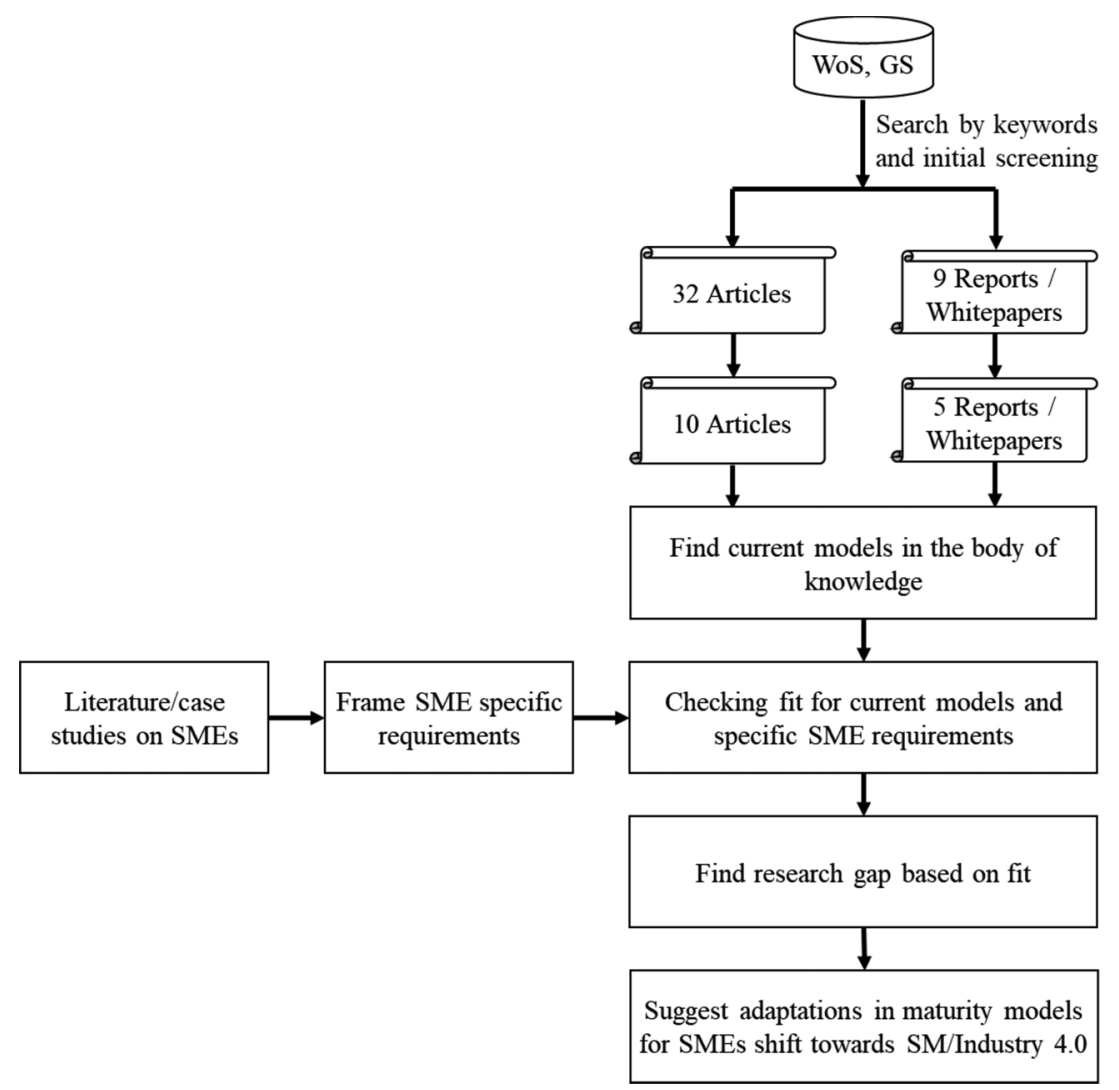

Fig. 1. Schematic for Methodology adopted in this Paper.

cope with the evolution of SMEs towards adopting smart manufacturing. Moreover, as "Smart Manufacturing" and "Smart Factory" are newer terms compared to "Industry 4.0", there were comparably more relevant papers related to the "Industry 4.0" keyword. Of the 15 identified relevant sources, nine were academic peer-reviewed papers and another one was published as a book chapter. However, large consulting firms published the other five of the 15 papers and therefore were considered as white papers. The availability of industrial-backed white papers emphasizes the practical application and relevance of maturity models to drive Smart Manufacturing. This study is aware that the five white papers might introduce a certain bias due to the business interest of the companies publishing them. However, due to the limited amount of available relevant literature and the insights into industrial practice, it was decided to consider the white papers.

Step 3: This step involved verifying the fit for the specific requirements of manufacturing SMEs (step 1) with the current maturity models that can help SMEs to adopt SM/Industry 4.0 (step 2). The verification was performed with the help of a critical discussion of the identified literature focusing on the fit between the previously defined SME requirements and the maturity models present in the literature. The primary contribution and novelty of this research lay in this critical discussion, as the majority of maturity models identified during comprehensive literature review were developed with MNEs in mind, e.g., regarding the required resources for SM/Industry 4.0.

Step 4: This step considered evaluating the research gaps that resist the journey of manufacturing SMEs towards SM/Industry by recognizing how the current maturity models for SM/Industry 4.0 fit the specific requirements of the manufacturing SMEs.

Step 5: Finally, the research gaps were discussed to suggest adaptations in the maturity models that can help manufacturing SMEs in their shift towards SM/Industry 4.0. If a model acknowledges these research gaps, then we additionally discussed how that model will function when it comes to the specific SME requirements.

\section{Literature and Critical Review}

This section presents a critical discussion of the identified maturity models and checks each model's 'fit' with the SME requirements. Before diving into the 15 different maturity models, the previous literature that compared maturity models in the context of digitization, Industry 4.0 and smart manufacturing maybe worth to discuss. It has to be noted that the four papers [54-57] that examined maturity models do i) not cover the topic as comprehensively (include 3, 7, 4 and 7 different models respectively) as this paper does (includes 15 different models), and ii) not include the perspective of a manufacturing SME. Nevertheless, these four papers may be of interest to the reader, hence a summary of them is also presented in this section.

From a series of workshops, De Carolis et al. [54] found that the maturity of technology, information connectivity, process, organization, and personnel capability are the main pillars of smart manufacturing. The workshops considered three maturity models and discussed different aspects regarding the models' objective(s), focus, analysis dimensions, process areas, maturity levels, inspiring frameworks, assessment methods, purpose, survey questions/answers' type and the number of questions. The three models compared in this paper are the DREAMY (Digital REadiness Assessment MaturitY) model [58], SMSRL (Smart Manufacturing Readiness Level) [59], as well as the MOM (Manufacturing Operations Management Capability Maturity Model) [60]. Nevertheless, none of the factors used in the comparison specifically considered an SME perspective.

Gökalp et al. [55] evaluated seven maturity models using six criteria: (i) Fitness for purpose, (ii) Completeness of aspects, (iii) Granularity of dimensions, (iv) Definition of measurement attributes, (v) description of assessment method, and (vi) Objectivity of the assessment method. Gökalp et al. [55] found that none of the models were able to satisfy all criteria. Although [55], considered very comprehensive measures for the evaluation of the models, however, the paper [55] 
does not include the 'fit for SMEs' in their assessment of the maturity models.

Akdil et al. [56], compared four maturity models [61-64] in terms of the maturity/readiness levels and dimensions, and the industry scope. The comparison performed by [56] did not consider SME requirements as well.

Scremin et al. [57] compared seven maturity models [61-67]. These models were compared on the basis of seven criteria: (i) What is the model used for?, (ii) How is the model designed?, (iii) Where do assessment data come from?, (iv) Method of goal benchmarking, (v) Number of Stages, (vi) Existing stage, and the (vii) Tool supported. The comparison by [57], i) considered a maturity model [65] purely for IT and software perspective, ii) recognized two models that were not written in English $[66,67]$ and iii) did not acknowledged the viewpoint of SMEs.

Therefore, it may be observed that the existing comparisons do not help the manufacturing SMEs. As a result, the current paper compared the stand of maturity models, roadmaps and frameworks, based on how these models satisfy the specific requirements of manufacturing SMEs.

There is a limited number of studies available that consider SM/ Industry 4.0 roadmaps, maturity models, frameworks and/or readiness assessments as specifically developed models, methods and/or tools for SMEs [64]. Although the terms "roadmaps," "maturity models," "frameworks" and "readiness assessments" might look similar, they have a slight difference in their definitions.

- Roadmaps are "plans that match short-term and long-term goals with specific technology solutions to help to meet those goals" [68]

- Maturity Models are models that help an individual or entity to reach a more sophisticated maturity level (i.e., ability) in people/culture, processes/structures and/or objects/technologies following a stepby-step continuous improvement process [69].

- Frameworks are collections of coherent procedures, methods, and tools for architecting (i.e., designing and engineering) a system [70].

- Readiness Assessments are evaluation tools to analyze and determine the level of preparedness of the conditions, attitudes, and resources, at all levels of a system, needed for achieving its goal(s) [71].

As previously mentioned, the comprehensive literature search in this study identified fifteen relevant maturity models, which will be discussed in the form of a critical review. Each of the following subsections (3.1.1-3.1.15) focuses on an individual model, and summarizes that model with regard to scope and methodology before critically reflecting on how the respective model corresponds with the previously identified SME requirements. It has to be noted, that due to the different complexity of the different models, their description in the following sub-sections may vary in length in order to capture all relevant details of each model reviewed. After discussing the models individually (from Table 5-15), a summary of the maturity models is presented (Tables 16, 17). Table 16 illustrates how the 15 models reflect various SME requirements. Table 17 gives an overview of the different models concerning the focus area and research gap regarding 'fit for SMEs.'

\subsection{Models towards implementing SM/Industry 4.0}

\subsubsection{A categorical framework of manufacturing for Industry 4.0 and beyond}

Qin et al. [72] state that the available roadmaps for Industry 4.0 are not clear, and the journey towards industrial initiatives (such as Industry 4.0) is a long-term commitment that needs to acknowledge four main viewpoints: (a) factory, (b) business, (c) process and (d) customers, which the current roadmaps fail to do so. Qin et al. [72] cover five maturity levels towards the integration of new manufacturing capabilities: (L1) single-station automated cells, (L2) automated assembly system, (L3) flexible manufacturing system, (L4) computer-
Table 5

Maturity Dimensions and some Exemplary Maturity Items [64].

\begin{tabular}{|c|c|c|}
\hline$\#$ & $\begin{array}{l}\text { Maturity } \\
\text { Dimensions }\end{array}$ & Exemplary Maturity Items \\
\hline 1 & Strategy & $\begin{array}{l}\text { - Implementing Industry } 4.0 \text { roadmap. } \\
\text { - Realizing available resources for digitalization and } \\
\text { smart automation. } \\
\text { - Adaption of business model(s). }\end{array}$ \\
\hline 2 & Leadership & $\begin{array}{l}\text { Willingness of leaders to embrace Industry } 4.0 \\
\text { paradigm. } \\
\text { - } \text { Management of (digital) competences and methods. } \\
\text { Existence of a central coordination for Industry } 4.0 \\
\text { strategy. }\end{array}$ \\
\hline 3 & Customers & $\begin{array}{l}\text { - Utilization of customer data (i.e., analytics). } \\
\text { - Digitalization of sales and services. } \\
\text { - Customer's digital media competence. }\end{array}$ \\
\hline 4 & Products & $\begin{array}{l}\text { - Individualization of products (i.e., personalization). } \\
\text { - Digitalization of products (i.e., product-service } \\
\text { systems). } \\
\text { - Product integration into other systems (i.e., smart } \\
\text { products). }\end{array}$ \\
\hline 5 & Operations & $\begin{array}{l}\text { - Decentralization of processes. } \\
\text { - Modelling and simulation. } \\
\text { - Interdisciplinary and interdepartmental collaboration. }\end{array}$ \\
\hline 6 & Culture & $\begin{array}{l}\text { - Knowledge sharing. } \\
\text { - Open innovation and cross company collaboration. } \\
\text { - Value of Information and Communication Technologies } \\
\text { (ICT) in company. }\end{array}$ \\
\hline 7 & People & $\begin{array}{l}\text { - ICT competences of employees. } \\
\text { - Openness of employees to new technology. } \\
\text { - Autonomy of employees. }\end{array}$ \\
\hline 8 & Governance & $\begin{array}{l}\text { - Labor regulations for Industry } 4.0 \text {. } \\
\text { - Suitability of technological standards. } \\
\text { - Protection of intellectual property. }\end{array}$ \\
\hline 9 & Technology & $\begin{array}{l}\text { - Existence of modern ICT. } \\
\text { - Utilization of mobile devices. } \\
\text { - Utilization of machine-to-machine (M2M) } \\
\text { communication. }\end{array}$ \\
\hline
\end{tabular}

integrated manufacturing (CIM) system, and (L5) reconfigurable manufacturing system.

Fig. 2 presents a manufacturing system and its different maturity levels. Grey arrows represent the current maturity of a manufacturing system, while the white arrows represent specific capability gaps towards a "smart" manufacturing system. Qin et al. [72] propose to address such capability gaps by adopting and implementing Industry 4.0 technologies, as well as digital and smart automation practices.

According to their study [72], the companies can create building blocks to achieve integrated SM systems. Building blocks are the fundamental modular units (i.e., technologies and best practices) that can be grouped to build a coherent (smart) system. The framework considers 'intelligence' and 'automation' at three different capability levels [72]. Automation capabilities are reflected at the (a) machine, (b) process and (c) factory levels; and Intelligence capabilities are reflected at (x) control, (y) integration and (z) intelligence levels. A shop floor with automation capabilities at 'c) factory level' and intelligence capabilities at ' $z$ ) intelligence level' was referred to as "Industry 4.0 ready".

All the manufacturing systems (L1 to L5), and characteristics (such as flexibility, standardization, customization) discussed by [72] fall under the umbrella of AMTs. However, as mentioned in Section 1.1, the AMTs cannot be presumed to be readily available in SMEs. As a result, this roadmap paper caters more towards the needs of MNEs rather than SMEs.

\subsection{2. maturity model for assessing Industry 4.0 readiness and maturity of manufacturing enterprises}

Schumacher et al. [64] suggest a maturity index that can be used to 


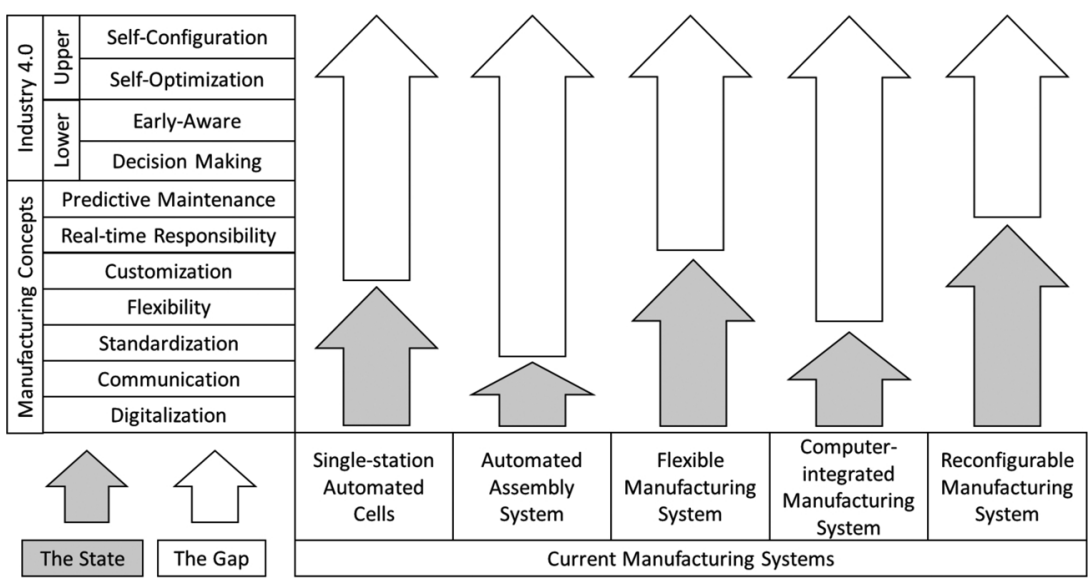

Fig. 2. Research Gap between Current Manufacturing Systems and Industry 4.0 [72].

calculate the readiness level of an SME to adopt Industry 4.0 technologies as well as digital and smart automation practices. The maturity index was computed focusing on various organizational aspects in practice, and the qualitative and quantitative methods were deployed to validate the index empirically. This index is based on a survey of nine dimensions (as mentioned in exemplary maturity items in Table 5): (1) strategy, (2) leadership, (3) customers, (4) products, (5) operations, (6) culture, (7) people, (8) governance and (9) technology. Table 5 presents the maturity dimensions (organizational aspects) used in this index and provided three exemplary maturity items under each dimension.

One may think that SMEs possess traits such as more interaction with customers/vendors and therefore, this model is relevant for SMEs. However, as depicted in Section 1.1, the strategies of SMEs often depend on the leader (owner). Therefore, the adoption of SM/Industry 4.0 depends on her/his understanding of the topic and willingness to pursue the shift. Resistance towards the adoption of advanced technologies and digitalization, lack of employee training, lack of highly centralized processes, not following technological standards and protection of intellectual property rights, lacking digitalized and individualized products, etc. are some items that are included in the maturity items (Table 5) but do not acknowledge the SME requirements.

\subsubsection{Towards Industry 4.0: gap analysis between current automotive MES} and industry standards using model-based requirement engineering

Kannan et al. [73] performed a gap analysis, based on the "MES Product Survey" of MESA International [74], between the current Manufacturing Execution Systems (MES) in the automotive industry and industry standards. The research work [73] assumes that achieving industry standards recognized by the International Society of Automation (ISA), ISA-95 and ISA-88 would help automotive companies in their journey towards Industry 4.0. The model-based requirement approach integrated with gap analysis consists of three phases:

1) Vendor selection phase: Focuses on the selection of the best vendors for parts and/or products based on the services provides by their MES.

2) Requirement modeling phase: Defines requirements for the current automotive MES.

3) Gap analysis phase: Analysis of possible gaps between the services provided by vendors and the MES requirements of the automotive industry.

SMEs deal with a lesser number of vendors/suppliers, and similarly, they have a fewer variety of parts/products as compared to MNEs (see Table 1). Therefore, the requirements of SMEs may vary. Hence, it would be difficult to execute the three phases proposed by [73] in a meaningful and value-adding way. SMEs may not consider following ISA and other standards. Therefore, the process of gap analysis assisted by a model-based requirement engineering as proposed in this model [73] may not adequately reflect SMEs' requirements.

3.1.4. Towards Industry 4.0-standardization as the crucial challenge for highly modular, multi-vendor production systems

Weyer et al. [75] considered open and standardized solutions as an essential factor for the success of Industry 4.0 paradigm adoption in SMEs. The research [75] mentioned 'highly modular' and 'multi-vendor interoperable' production system as the critical enablers that can recognize the diversity of solutions nowadays found in a traditional SME shop floor. A reference smart production line was discussed as a sample. Table 6 summarizes the essential issues [75] in the production line.

The key issues (Table 6) of this model deal with less involvement of human resources and rely on electro-mechanical plug-in systems. However [75], suggest the extreme use of digitalization and AMTs such as smart glasses and tablets, expensive modular infrastructure boxes, etc. As a result, many SMEs may not be financially secure enough (see Section 1.1) to include these technologies in their production systems. Therefore, the proposed model does not correspond entirely with the requirements of SMEs.

3.1.5. An overview of a smart manufacturing system readiness assessment Jung et al. [76] propose a novel Smart Manufacturing System Readiness Assessment (SMSRA). SMSRA model had four dimensions: organizational maturity, information technology maturity, performance management maturity and information connectivity maturity.

1) Organizational maturity refers to how the activities are performed by the manufacturers, whether i) a process formally manages each activity (i.e., automation) or ii) a human is responsible for the process (i.e., mechanization).

2) Information Technology maturity denotes the existence of digital tools and methods. E.g., paper-based layout design is not a part of information technology maturity.

3) Performance maturity addresses the degree to which performance measures are used and monitored.

4) Information Connectivity maturity reflects the sophistication of the methods used to exchange the required information and the degree to which the information is shared/exchanged.

Jung et al. [76] also performed a study based on statistical analysis. This analysis was a part of the SMSRA index to demonstrate the positive correlation with different types of performances that can be evaluated at a discrete level when aiming for new smart capabilities for SMEs manufacturing systems. 
Table 6

Smart Production Line Issues and their Descriptions [75].

\begin{tabular}{|c|c|c|}
\hline \# & Key Issues & Description \\
\hline 1 & $\begin{array}{l}\text { Production Line } \\
\text { and Process }\end{array}$ & $\begin{array}{l}\text { From a production planning and control system (PPCS) traditional paradigm to a product-centric, dynamic, and decentralized } \\
\text { production control where the customized job data is written on the memory of a product and communicated to each } \\
\text { manufacturing cell with the help of an RFID chip. }\end{array}$ \\
\hline 2 & Plug and Produce & $\begin{array}{l}\text { Manufacturing cells (modules) can be easily changed in their order, removed, or added to a production line during the } \\
\text { manufacturing system operation, which gives the ability to the operator to reconfigure the production line (e.g., an automatic } \\
\text { neighborhood detection allows an independent topology derivation, supported by an RFID tag and reader at each module in its } \\
\text { both sides, which deduces its new neighbor modules automatically). }\end{array}$ \\
\hline 3 & $\begin{array}{l}\text { Smart } \\
\text { Infrastructure }\end{array}$ & $\begin{array}{l}\text { Smart (modular) infrastructure box through which each manufacturing cell can be supplied with everything it requires to } \\
\text { perform its functionality, facilitating fast data communications, standardized cabling, and power, and ensuring the safety and } \\
\text { security of the manufacturing systems. }\end{array}$ \\
\hline 4 & $\begin{array}{l}\text { Manual Work } \\
\text { Solution }\end{array}$ & $\begin{array}{l}\text { Support of virtual instructions directly at the point-of-action by tablet, projection mapping or smart glasses to the operator in } \\
\text { his/her manual assembly workstation. }\end{array}$ \\
\hline 5 & $\begin{array}{l}\text { Control } \\
\text { Architectures }\end{array}$ & $\begin{array}{l}\text { Decentralized control architecture based on Service Oriented Architecture paradigm to integrate different software modules } \\
\text { with defined functionalities into a more significant and distributed IT system (e.g., an SOA PLC to allow a top-down } \\
\text { communication from the ERP system via MES and PLC down to the sensor). }\end{array}$ \\
\hline 6 & $\begin{array}{l}\text { Vertical Integration of Superordinate IT } \\
\text { systems }\end{array}$ & $\begin{array}{l}\text { Key technologies for enabling vertical integration are communication standards such as OPC UA, MTConnect, etc. as well as } \\
\text { integrated web services (e.g., an integrated OPC UA server in every vendor-specific module can guarantee a problem-free } \\
\text { interaction of different modules beyond proprietary limits). }\end{array}$ \\
\hline
\end{tabular}

SMEs may not have full access to all four dimensions discussed [76], because they lack in AMTs, information technology, strategies for performance management, and information connectivity (see section 1.1). The lack of automation experience and experts also implies that SMEs might not be able to evaluate their actual manufacturing system readiness. Therefore, this readiness assessment is more oriented towards MNEs.

\subsubsection{Three-stage maturity model in SME's towards Industry 4.0}

Ganzarain \& Errasti [77] considered 'diversification corporate strategy' as the main enabler for Industry 4.0. According to the authors, the SMEs lack the basic prerequisites such as awareness, knowledge, formalized processes, techniques, and tools needed for adopting a diversification strategy. A diversification strategy focuses on new products or introducing an improved version of previously available product to expand the market [78]. Ganzarain \& Errasti [77] followed the three-stage maturity model (proposed by [79]).

a) In stage 1 , an SME develops a specific vision for Industry 4.0 with the help of present capacity and resource analysis.

b) In stage 2, the SME's Industry 4.0 vision is informed by

c) The company's network, processes, product(s) and market dimensions.

d) The requirements and technologies involved in Industry 4.0 environments.

e) And finally, in stage 3 the Industry 4.0 projects are enacted, which results in the formation of risk management policies for the SME management, and the training methods for the SME workforce.

Companies consider the inputs from experts and key partners during the Vision 4.0 development (stage 2) Furthermore, the collaborative diversification method integrates with a generalized maturity model for Industry 4.0 and a synthesis in the form of a diagram as depicted in Table 7. The various levels of the maturity model are:

1) Initial: Company-specific Industry 4.0 vision does not exist

2) Managed: Roadmap for Industry 4.0 vision is available.

3) Defined: Customer segments, value proposition and key resources of SME are defined.

4) Transform: Strategy divided into specific tasks.

5) Detailed Business Model: The entire business model is transformed towards Industry 4.0 .

This model [77] acknowledges an Industry 4.0 tailored vision for SMEs, and therefore SMEs may be able to analyze their financial condition, the technology present in the system, and the current skills of employees. However, performing the self-assessment in absence of clear instructions will not be an easy task as the SMEs may lack the experience, and the expertise needed to analyze their existing capacity and resources to develop their Industry 4.0 vision. Hiring a consultant for this purpose might not be a feasible option given SMEs' financial constraints. Similarly, employee training will need extreme changes in SME strategies; therefore, this approach needs to be improved to be implemented by SMEs.

\subsubsection{IMPULS Industrie 4.0 readiness}

Lichtblau et al. - IMPULS report [61] suggests a readiness model that classifies an SME in six levels of Industry 4.0 readiness from outsider to a beginner (newcomer), passing through intermediate (or learner), to experienced, expert and finally top performer (leader). This

Table 7

Maturity Model to the Industry 4.0 Revolution [77].

\begin{tabular}{|c|c|c|c|}
\hline Maturity & $\begin{array}{l}\text { Vision } \\
\text { ENVISION }\end{array}$ & $\begin{array}{l}\text { Business } \\
\text { ENABLE }\end{array}$ & $\begin{array}{l}\text { Actions } \\
\text { ENACT }\end{array}$ \\
\hline $1 \mathrm{MM}$ & A Company specific Industry 4.0 Vision does not exist & & \\
\hline $2 \mathrm{MM}$ & $\begin{array}{l}\text { Tailored } \\
\text { Industry } 4.0 \text { Vision }\end{array}$ & Customer Segments and Expectation Defined & $\begin{array}{l}\text { Projects Portfolio } \\
\text { without Prioritize }\end{array}$ \\
\hline $3 \mathrm{MM}$ & $\begin{array}{l}\text { Developed its Understanding on Industry } 4.0 \text { with specific } \\
\text { Capabilities and Resources. }\end{array}$ & $\begin{array}{l}\text { Customer Segments and Expectations Defined and } \\
\text { Value Proposition Defined }\end{array}$ & $\begin{array}{l}\text { Projects Evaluated and Resources and } \\
\text { Collaboration Needed Identified }\end{array}$ \\
\hline $4 \mathrm{MM}$ & $\begin{array}{l}\text { Opportunity Map } \\
\text { described in Industry } 4.0\end{array}$ & $\begin{array}{l}\text { Customer Segments and Expectations, } \\
\text { Value Proposition and Technology/Resources } \\
\text { Defined }\end{array}$ & $\begin{array}{l}\text { Actual and Future } \\
\text { Projects Portfolio Detailed }\end{array}$ \\
\hline $5 \mathrm{MM}$ & $\begin{array}{l}\text { Future Challenges } \\
\text { by the Industry } 4.0\end{array}$ & $\begin{array}{l}\text { Future Industry } 4.0 \\
\text { Enabled-Business Models }\end{array}$ & $\begin{array}{l}\text { Projects Portfolio } \\
\text { (Risk) Management }\end{array}$ \\
\hline
\end{tabular}


classification considered 18 items that made the following six dimensions of an Industry 4.0 environment: (1) organizational strategy, which addresses the strategic planning and control of the Industry 4.0 corporate strategy (2) smart factory, which aims for a distributed, highly automated production environment (i.e., digital modelling, equipment infrastructure, data usage, IT systems), (3) smart operation, which aims for an enterprise-wide and cross-enterprise integration of the physical and virtual worlds (i.e. information sharing, cloud usage, IT security, autonomous processes), (4) smart products, which aim to facilitate an automated, flexible, efficient production management, as well as the creation of new data-driven services (i.e., ICT add-on functionalities of products such as automatic identification, localization, self-reporting), (5) data-driven services, which support new operational efficiencies and revenue streams through services (i.e. availability of data-driven services, share of revenues derived from data-driven services, share of data used) and (6) employees, which help to realize digital transformation (i.e., digital skills). Lichtblau et al. - IMPULS [61] also provides an online assessment tool where SMEs may identify their readiness level for Industry $4.0^{1}$.

Lichtblau et al. - IMPULS [61] considers horizontal integration with external customers and suppliers as a part of the technical foundation that supports SMEs. However, the six dimensions considered for an Industry 4.0 environment include AMTs, digitalization, smart products, and employee awareness and training, suitable strategies and organization culture aligning towards Industry 4.0, etc. SMEs will not be able to score well in these dimensions (as discussed in Section 1.1). It may result in the wrong estimation of their readiness. Therefore, by following this model, most of the SMEs will end up being the "outsiders" or at the lowest level of Industry 4.0.

\subsubsection{Industry 4.0: building the digital enterprise}

Geissbauer et al. - PwC [62] propose a readiness assessment model for Industry 4.0, mainly focusing on "digitalization" strategies as the key for Industry 4.0 capabilities. Geissbauer et al. - PwC [62] readiness assessment model is based on four stages: (a) digital novice, (b) vertical integrator, (c) horizontal collaborator and (d) digital champion, and seven dimensions: (1) digital business models and customer access (e.g. from digital solutions and isolated applications to new digital disruptive business models), (2) digitization of product and service offerings (e.g. from online presence to integrated (digital) customer journey management), (3) digitization and integration of vertical and horizontal value chains (e.g. from digitalized and automated sub-processes to fully digitalized, integrated processes), (4) data \& analytics as core capability (e.g. from basic analytical capabilities to predictive analytics), (5) agile IT architecture (e.g. from fragmented IT architecture in-house to a single data lake), (6) compliance security, legal and tax (e.g. from traditional in-house structures to optimizing the value-chain compliance), and (7) organization, employees and digital culture (e.g. from silos to collaboration as a key value driver). Furthermore, the following steps are recommended [62] for digital success: map out your Industry 4.0 strategy, create initial pilot projects, define capabilities you need, become a 'virtuoso' in data analytics, transform into a digital enterprise and actively plan an ecosystem approach.

Geissbauer et al. - PwC [62] assume the presence of digitally integrated supply chains that will require a real-time update of the product with the collaborators, which may not be possible for the SMEs to implement because of the financial constraints. Finding a supplier that is both economical and has installed real-time update technology (like RFID), might be time-consuming and thus it might further complicate the situation for the SMEs, who already have a high dependence on their customers/suppliers. The seven dimensions proposed in this paper will need digitalization, automation, digital organization culture, analytics, etc. to be implemented. As discussed in Section 1.1, these

\footnotetext{
${ }^{1}$ https://www.industrie40-readiness.de/?lang = en
}

facilities are not frequently present in SMEs. Therefore, the digital enterprise model proposed in this report [62] does not consider the SMEs aspect.

\subsubsection{The connected enterprise maturity model}

Rockwell Automation [63] suggested a "connected enterprise maturity model" with technology as its key enabler. Four different dimensions of technology that can help to achieve Industry 4.0 were mentioned: (1) information infrastructure, including hardware and software, (2) controls and devices such as sensors, actuators, motor controls, switches, etc., which feed and receive data, (3) networks that facilitate the exchange of all information, and (4) security policies. Moreover, a fivestage action plan is recommended [63]: (S1) assessment of exiting OT/ IT network (the four dimensions of technology previously mentioned), (S2) secure and upgraded, network and controls (from plant floor to enterprise network), (S3) defined and organized working data capital (from new data capabilities emerging to harness and leverage of data), (S4) analytics (from real-time analytics to proactive and automatic analytics), and collaboration (from the enterprise to the extended enterprise).

According to Rockwell Automation [63], the SMEs will need a formal collaboration with its customers/vendors and this collaboration will require the presence of digitally coordinated enterprises, which may not be possible to achieve for many manufacturing SMEs. The four technology dimensions needed for the connected enterprise maturity model also demand AMTs, information sharing systems, networks, etc. that are not possessed by most SMEs. Therefore, the connected enterprise maturity model might not be able to help SMEs.

3.1.10. Guideline industrie 4.0 - guiding principles for the implementation of industrie 4.0 in small and medium-sized businesses

Anderl et al. - VDMA \& Partners [80] focus on company-specific approaches of Industry 4.0 and present instructions considering the specific nature of German SMEs with the help of a report. The guidelines include business models at five different stages, namely: (1) preparation - knowledge base, (2) analysis - competencies and internal projects, (3) creativity - ideas and business models, (4) evaluation, and (5) implementation - application. In addition, these five stages were suggested to provide a step-by-step journey for the firm's vision of Industry 4.0. The report [80] considered the commitment of senior managers, cross-disciplinary teams, and a toolbox for Industry 4.0 as the essential facilitators/tools. The report [80] also mentioned the technologies of these toolboxes from both the product and the process viewpoints (see Tables 8 and 9).

Anderl et al. - VDMA \& Partners [80] provide a step-by-step method for SMEs to realize its vision of Industry 4.0 using low-priced sensors/ actuators and training employees to make use of these sensors might be feasible for SMEs (as discussed in Section 1.1). Nevertheless, how the SMEs can know about their present situation and which specific tools (sensors/actuators, communication/connectivity, etc.) they can look for installing, are some of the questions that might confuse SMEs and thus make the application of this toolbox challenging. As a result, while some aspects are a good fit, this report does not fulfill all requirements to be considered as the ideal match from an SME standpoint.

\subsubsection{A smartness assessment framework for smart factories using analytic network process}

Lee et al. [81] used Analytic Network Process (ANP) tool and performed a Multiple-Criteria Decision-Making (MCDM) analysis for smart factory based on the study of 20 Korean SMEs. The criteria for assessment considered the existing literature together with the conceptual framework presented in Table 10. These criteria were divided into subcriterions and finally broken into assessment items (see Table 11) with the help of five industrial consultants.

This study was based on the collected data and focused on the processes involved in a traditional value chain. Three categories of 
Table 8

Toolbox Industry 4.0 - Product [80].

\begin{tabular}{|c|c|c|c|c|c|}
\hline $\begin{array}{l}\text { Integration } \\
\text { of sensors / actuators }\end{array}$ & $\begin{array}{l}\text { No Use of } \\
\text { Sensors / Actuators }\end{array}$ & $\begin{array}{l}\text { Sensors / Actuators are } \\
\text { Integrated }\end{array}$ & $\begin{array}{l}\text { Sensor Readings are } \\
\text { Processed } \\
\text { by the } \\
\text { Product }\end{array}$ & $\begin{array}{l}\text { Data is Evaluated for } \\
\text { Analyses } \\
\text { by the } \\
\text { Product }\end{array}$ & $\begin{array}{l}\text { The Product } \\
\text { Independently } \\
\text { Responds } \\
\text { based on } \\
\text { the Gained Data }\end{array}$ \\
\hline $\begin{array}{c}\text { Communication / } \\
\text { Connectivity }\end{array}$ & $\begin{array}{l}\text { The Product } \\
\text { has no Interfaces }\end{array}$ & $\begin{array}{l}\text { The Product } \\
\text { Sends or Receives } \\
\text { I/O Signals }\end{array}$ & $\begin{array}{l}\text { The Product } \\
\text { has Field } \\
\text { Bus Interfaces }\end{array}$ & $\begin{array}{l}\text { The Product } \\
\text { has } \\
\text { Industrial Ethernet } \\
\text { Interfaces }\end{array}$ & $\begin{array}{l}\text { The Product has Access to } \\
\text { the Internet }\end{array}$ \\
\hline $\begin{array}{l}\text { Functionalities for Data } \\
\text { Storage and } \\
\text { Information } \\
\text { Exchange }\end{array}$ & No functionalities & $\begin{array}{l}\text { Possibility of } \\
\text { Individual } \\
\text { Identification }\end{array}$ & $\begin{array}{l}\text { Product } \\
\text { has a } \\
\text { Passive } \\
\text { Data Store }\end{array}$ & $\begin{array}{l}\text { Product } \\
\text { with Data } \\
\text { Storage for Autonomous } \\
\text { Information } \\
\text { Exchange }\end{array}$ & $\begin{array}{l}\text { Data and Information } \\
\text { Exchange as Integral } \\
\text { Part }\end{array}$ \\
\hline Monitoring & $\begin{array}{l}\text { No Monitoring } \\
\text { by the } \\
\text { Product }\end{array}$ & Detection of Failures & $\begin{array}{l}\text { Recording of } \\
\text { Operating Condition } \\
\text { for Diagnostic } \\
\text { Purposes }\end{array}$ & $\begin{array}{l}\text { Prognosis of its Own } \\
\text { Functional Condition }\end{array}$ & $\begin{array}{l}\text { Independently } \\
\text { adopted Control } \\
\text { Measures }\end{array}$ \\
\hline $\begin{array}{l}\text { Product- } \\
\quad \text { related IT } \\
\quad \text { Services }\end{array}$ & No Services & $\begin{array}{l}\text { Services via } \\
\text { Online } \\
\text { Portals }\end{array}$ & $\begin{array}{l}\text { Service Execution } \\
\text { Directly via Product }\end{array}$ & $\begin{array}{l}\text { Independently } \\
\text { Performed services }\end{array}$ & $\begin{array}{l}\text { Complete Integration } \\
\text { into IT Infrastructure }\end{array}$ \\
\hline $\begin{array}{l}\text { Business } \\
\text { Models } \\
\text { around } \\
\text { the Product }\end{array}$ & $\begin{array}{l}\text { Gaining Profits from Selling } \\
\text { Standardized } \\
\text { Products }\end{array}$ & $\begin{array}{l}\text { Sales and } \\
\text { Consulting regarding } \\
\text { the Product }\end{array}$ & $\begin{array}{l}\text { Sales, Consulting } \\
\text { and Adaption of Product to } \\
\text { Meet } \\
\text { Customer } \\
\text { Specifications }\end{array}$ & $\begin{array}{l}\text { Additional Sale of } \\
\text { Product-related } \\
\text { Services }\end{array}$ & $\begin{array}{l}\text { Sale of Product } \\
\text { Functions }\end{array}$ \\
\hline
\end{tabular}

SMEs participated in this research: (1) facility centered, (2) purchase and inventory-centered, and (3) all round groups. Finally, the assessment items were weighed using expert discussions, and these weights were used in ANP to rank the SMEs among three different groups. Lee et al. [81] considered five levels of maturity for classifying a smart factory: (1) checking (factory not linked to an external monitoring system), (2) monitoring (factory can gather data linked to external monitoring system), (3) control (factory can analyze abnormalities from the data), (4) optimization (factory can integrate entire data and optimize itself by interfacing all devices, facilities, internal and external systems), and (5) autonomy (factory can operate and diagnose itself with the help of AI).

This research work [81] involved decision making with the help of ANP. Although it considered collaboration with suppliers, facilities automation, updated information systems, etc., however, it does not suggest how an enterprise can shift towards Smart Factory recognizing the mentioned criteria (Table 11). Therefore, this study may not guide the development of SMEs towards SM/Industry 4.0.

\subsubsection{Industrie 4.0 maturity index (managing the digital transformation of the companies)}

Schuh et al. [82] considered "digitalization" as an enabler for Industry 4.0 in their report and developed a maturity index with the help of a four-stage methodology. The methodology was a result of various workshops and case studies and included four phases. The first phase was based on the discussion of various projects with strategic partners from both industry and academia. In the second phase, a steering committee reviewing and updating the project progress was formed. While in the third phase, the feasibility of projects was validated in a technology-based manufacturing enterprise. The fourth phase was running in parallel with the other three stages and included the verification of findings that are derived during each of the three stages.

The maturity index considered six development stages that are: (1) Computerization, meaning the installation of computers (and information systems) that will support tasks with data processing systems and relieve employees from repetitive manual activities, (2) Connectivity, referring to connecting and structuring these computers and data processing systems with the help of intranet and/or internet to support the core business processes, (3) Visibility, creating a digital shadow of what is happening in real-time at the factory and supporting management decision with data. Visibility can be achieved with the help of Enterprise Information Systems (EIS) such as ERP, PLM and MES, (4) Transparency, allowing to view events and understand the root cause of their happening (e.g. problems), (5) Predictability, building on the understanding of the Transparency stage, and moving forward to plan-and-make decisions on the basis of future scenarios (e.g. forecasting), and (6) Adaptability, including the autonomous response from machines and other systems based on their predictive capacity. It is important to highlight that Computerization and Connectivity stages are more related to the goals of the Industry 3.0 era, whereas the Industry 4.0 journey starts at the Visibility maturity stage. Furthermore, four key areas, each having two sub-dimensions, were assessed at each maturity stage: (a) resources (viz. digital capability and structured communication), (b) information systems (viz. self-learning information processing and information system integration), (c) organization structure (viz. organic internal organization and dynamic collaboration within the value network), and (d) organization culture (viz. willingness to change and social collaboration). The report's objective was to define a maturity index that can evaluate the present Industry 4.0 stage of the organization and find the measures, which can lead them to a higher maturity stage. The idea of a tailored vision of Industry 4.0 for a company was also emphasized.

The two sub-dimensions of the four key areas assume the presence of various high-end technologies (like self-learning information processing, integrated information systems, efficient M2M communication, etc.) and adaptable culture (organizational mindset regarding Industry 4.0), that are required in the digitalization and collaboration of an organization, but the assumed technologies and the mindset might not be available in an SME (see Section 1.1). Therefore, in spite of considering a tailored vision, the assumed technical and the organizational mindsets make this model impractical for SMEs. The model defined in the report [82] can find the present maturity level of the organization and guide it towards its next level of maturity. However, this is not a selfassessment instrument, so any industry using this maturity index may need to develop an understanding of the instrument before filling the survey questions, and finally find the answer(s) with the help of experts (e.g., SMEs may need to hire a consultant). As a result, from the SMEs' viewpoint, this approach might be expensive and time-consuming. 
Table 10

Conceptual Framework for Smart Factory Assessment [81].

\begin{tabular}{|c|c|c|c|c|}
\hline \multicolumn{2}{|c|}{ Management Level } & \multicolumn{3}{|c|}{ Operational Requirements } \\
\hline \multirow{10}{*}{$\begin{array}{l}\text { Vision } \\
\text { Goal } \\
\text { Operations }\end{array}$} & \multirow{9}{*}{$\begin{array}{l}\text { Enterprise Level } \\
\text { Factory Level }\end{array}$} & \multirow{2}{*}{\multicolumn{2}{|c|}{$\begin{array}{l}\text { Leadership and Strategy } \\
\text { Performance Assessment }\end{array}$}} & \multirow{10}{*}{$\begin{array}{l}\text { Manufacturing } \\
\text { Process }\end{array}$} \\
\hline & & & & \\
\hline & & \multicolumn{2}{|c|}{ Information Systems } & \\
\hline & & Product & Production & \\
\hline & & Development & Planning & \\
\hline & & Process & Quality & \\
\hline & & Control & Control & \\
\hline & & Facility & Logistics & \\
\hline & & Management & Management & \\
\hline & Machine Level & \multicolumn{2}{|c|}{ Facility Automation } & \\
\hline
\end{tabular}

\subsubsection{Development of an assessment model for Industry 4.0: industry 4.0} maturity model

Gökalp et al. [55] adopted SPICE (Software Process Improvement and Capability dEtermination) approach for framing a maturity model for Industry 4.0. Five aspect dimensions - (i) asset Management (IT and technologies considering Industry 4.0); (ii) data governance (data gathering, assessment and decision making); (iii) application management (managing interfaces and information flow); (iv) process transformation (mapping of basic processes planning, acquisition, production, sale and distribution with the digital world); and (v) organizational alignment (organizational structure and strategies, and human resource management) were considered. Levels $0-5$, "incomplete," "performed," "managed," "established," "predictable" and "optimizing" were defined based on the different aspect practices (features) (see Table 12).

The model makes sense for SMEs in the respect that it recommends increasing the degree of employee participation and an investment in the employee awareness towards Industry 4.0. But, overall the assessment model proposed by [55] does not consider the perspective of SMEs, because the SMEs may not have an access to the technologies like IoT, wireless networks, IT Security, etc.

\subsubsection{Maturity and readiness model for Industry 4.0 strategy}

Akdil et al. [56] proposed an Industry 4.0 maturity model with four levels of maturity and three broad dimensions. The levels considered are absence (level 0 - Industry 4.0 requirements are not fulfilled at all), existence (level 1 - company's utilization of integration, automation, data collection, digital technologies, interoperability, etc. is at very low level), survived (level 2 - company's utilization of integration, data sharing, interoperability, etc. are at medium level), and maturity (level 3 - company's utilization of integration, data sharing, interoperability, etc. are at a high level). In addition, Akdil et al. [56] recognized various principles and technologies for Industry 4.0 (Table 13). Three dimensions (smart products and services, smart business processes, and strategy and organization) and their corresponding maturity levels (level 0-3) were defined in this model [56] with the help of a set of key characteristics. Finally, a survey-based instrument was used to find the maturity level, and a retail sector demonstration was presented. The demonstration shows the computation of maturity score for each of the three sub-dimensions.

This model provides an index to calculate the readiness for Industry 4.0; however, it does not show a maturity path towards Industry 4.0 as the model is oriented towards the MNEs. Also, the dimensions considered [56] do not show any concern towards the SME requirements discussed in Section 1.1 (see Table 3). Only the organization culture and the readiness towards Industry 4.0 are the factors that show the model's concern towards SMEs. The dimensions related to the various Industry 4.0 principles and technologies (suggested by [56] in (Table 13)) may not be present in SMEs. For example, here the products are expected to be smart (i.e., communicate with each other) and the processes are supposed to be semi- or fully- automated, etc. 
Table 11

Criteria, Sub-Criteria and Corresponding Assessment Items used for ANP [81].

\begin{tabular}{|c|c|c|}
\hline Criteria & Sub-Criteria & Assessment Items \\
\hline Leadership & Leadership \& Strategy & $\begin{array}{l}\text { - CEO leadership } \\
\text { - Strategy and plan for implementing smart factory } \\
\text { - Management of organization and capability of smart factory } \\
\text { - Management of KPIs (key performance indicators) }\end{array}$ \\
\hline \multirow[t]{6}{*}{ Process } & Product Development & $\begin{array}{l}\text { - Procedure of product development } \\
\text { - Product design and evaluation } \\
\text { - Process design and evaluation } \\
\text { - Management of product information } \\
\text { - Management of technical information }\end{array}$ \\
\hline & Production Planning & $\begin{array}{l}\text { - Management of information for production planning } \\
\text { - Demand and order planning } \\
\text { - Sales and operation planning } \\
\text { - Master production scheduling }\end{array}$ \\
\hline & Process Control & $\begin{array}{l}\text { - Development of the detailed job schedule and order } \\
\text { - Management of the production progress } \\
\text { - Management of abnormalities in the manufacturing process }\end{array}$ \\
\hline & Quality Control & $\begin{array}{l}\text { - Management of information for quality control } \\
\text { - Management of documents of standards for quality control } \\
\text { - Management of testing data } \\
\text { - Management of machines and equipment for quality control }\end{array}$ \\
\hline & Facility Management & $\begin{array}{l}\text { - Management of the operation of facilities } \\
\text { - Maintenance of facilities } \\
\text { - Management of spare parts } \\
\text { - Management of molds, jigs, and tools }\end{array}$ \\
\hline & Logistics Management & $\begin{array}{l}\text { - Management of the demand of materials } \\
\text { - Management of orders and lead times } \\
\text { - Management of storing and releasing products in a warehouse } \\
\text { - Management of tracking systems } \\
\text { - Management of peaking and delivering products } \\
\text { - Management of information about delivering and tracking }\end{array}$ \\
\hline System \& Automation & Information System & $\begin{array}{l}\text { - Utilization of ERP and SCM } \\
\text { - Utilization of MES } \\
\text { - Utilization of PLM } \\
\text { - Utilization of FEMS } \\
\text { - Management of information security }\end{array}$ \\
\hline & Facility Automation & $\begin{array}{l}\text { - Automation of manufacturing facilities } \\
\text { - Automation of logistics facilities } \\
\text { - Automation of evaluation and testing facilities } \\
\text { - Automation of information network for facilities } \\
\text { - Management of energy, safety, and environment }\end{array}$ \\
\hline Performance & Performance Assessment & $\begin{array}{l}\text { - Productivity } \\
\text { - Quality } \\
\text { - Cost } \\
\text { - Lead time } \\
\text { - Safety } \\
\text { - Environment }\end{array}$ \\
\hline
\end{tabular}

Table 12

Capability Dimensions and Levels of Industry 4.0 Maturity Model [55].

\begin{tabular}{|c|c|}
\hline Level & Generic aspect Practices/Generic Work Products \\
\hline Level 5: Optimizing & $\begin{array}{l}\text { - End-to-end digital integration of engineering across } \\
\text { the entire value chain } \\
\text { - Innovative business processes } \\
\text { - Continuous adaptation } \\
\text { - Self-optimization }\end{array}$ \\
\hline Level 4: Predictable & $\begin{array}{l}\text { - Horizontal integration through value networks } \\
\text { - Controlled processes and operations } \\
\text { - Big Data Analytics, Machine Learning \& AI }\end{array}$ \\
\hline Level 3: Established & $\begin{array}{l}\text { - Vertical integration and networked manufacturing } \\
\text { systems } \\
\text { - Development of a common language with its own signs } \\
\text { and semantics } \\
\text { - Standardized qualification of processes and operations }\end{array}$ \\
\hline Level 2: Managed & $\begin{array}{l}\text { - Infrastructure of smart technologies is installed and } \\
\text { independently operated } \\
\text { - Physical items are represented by a virtual work }\end{array}$ \\
\hline Level 1: Performed & $\begin{array}{l}\text { - Aspect practices are performed } \\
\text { - Transition attempts to Industry } 4.0\end{array}$ \\
\hline Level 0: Incomplete & $\begin{array}{l}\text { - Aspect practices are not performed } \\
\text { - Basic business operations are carried out }\end{array}$ \\
\hline
\end{tabular}

Table 13

Industry 4.0 Principles and Technologies (Akdil et al., 2018).

\begin{tabular}{ll}
\hline Principles & Technologies \\
\hline - Real time data management & - Adaptive robotics \\
- Collection/Processing/Analysis/ & - Data analytics and Artificial Intelligence \\
$\quad$ Interference & - Simulation \\
- Interoperability & - Embedded Systems \\
- Virtualization & - Cybersecurity \\
- Decentralization & - Cloud \\
- Agility & - Additive Manufacturing \\
- Service Oriented & - Virtualization Technologies \\
- Integrated Business Processes & - Sensors and Actuators \\
& - RFID and RTLS Technologies \\
& - Mobile Technologies
\end{tabular}

Additionally, the incomplete definition of each maturity level under each dimension is another drawback that may confuse SMEs.

\subsubsection{Towards a framework for assessing the maturity of manufacturing companies in Industry 4.0 adoption}

Scremin et al. [57] developed assessment framework "AMM 
Table 14

Industry 4.0 Maturity Assessment Framework [57].

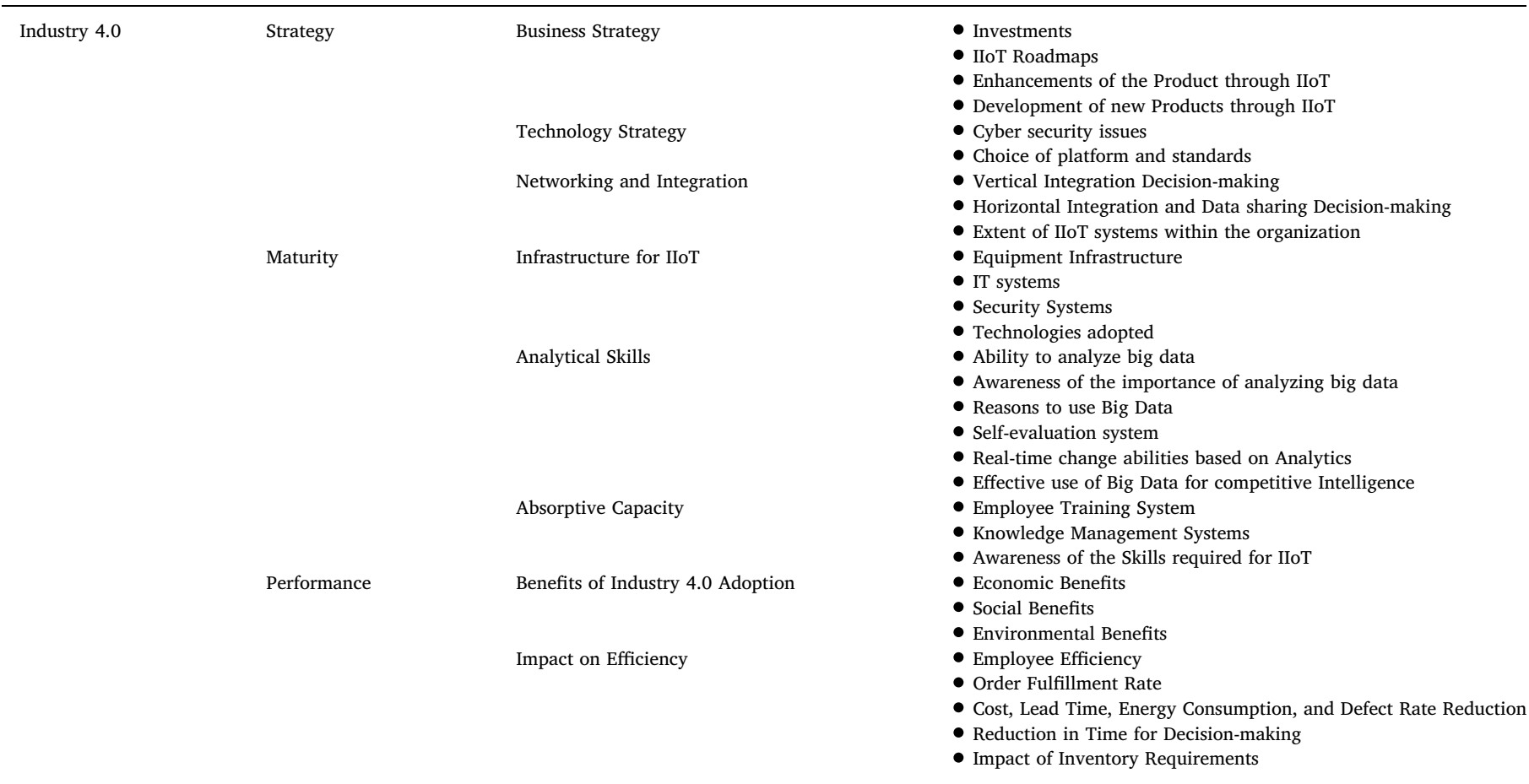

Table 15

Industry 4.0 Roadmaps Corresponding to a Particular Stage [57].

\begin{tabular}{ll}
\hline Stage & Industry 4.0 Roadmaps \\
\hline 0 & No roadmaps developed; and Industry 4.0 is not a part of the business strategy process. \\
1 & No roadmaps developed; and Industry 4.0 (focused on technology development) is a part of company's general strategy. \\
2 & Roadmaps maybe developed but the action plan is not well defined; and Industry 4.0 is a part of the company's business strategy. \\
3 & Roadmaps developed but long-term action plans are still not clear; and Industry 4.0 is a part of company's business strategy. \\
4 & Roadmaps developed with short-term and long-term plans; and Industry 4.0 is a part of company's business strategy. \\
\hline
\end{tabular}

(Adoption Maturity Model)" for the manufacturing companies transitioning towards Industry 4.0. AMM acknowledges 30 maturity items divided along three axes (strategy, maturity, performance) and eight maturity indicators (Table 14). AMM recognized a series of requirements for each of its maturity stages (Table 15) with the help of a crosssectional exploratory research project that employed qualitative methods for data collection.

Developing AMM followed a methodology. At first, a review on Industry 4.0 literature acknowledging the enabling technologies and existing maturity models was performed. This literature review helped in proposing a model consisting of 30 maturity items (Table 14). The maturity items were further distributed among eight maturity indicators and interview questions were linked with the maturity indicators. As a next step, an interview guideline containing these questions was deployed to collect data from ten organizations (five Italian and five Canadian). The collected data helped in elaborating the case studies by understanding organizations' perspective on various aspects (e.g., motivations for adopting, implementation process, major challenges faced, etc.) regarding Industry 4.0. Next step determined the thresholds for each maturity item identified earlier by utilizing the information collected from case studies. These thresholds helped in model validation and case evaluation using indicators (represented using radar charts). The evaluation of individual cases also helped in developing a matrix for cross-case comparative analysis. Finally, the comparison matrix along with the individual maturity assessment was analyzed, to identify archetypes and formulate conclusions on Industry 4.0 adoption.
The objective of AMM was to evaluate the maturity stage of an enterprise that has already started its journey towards Industry 4.0. Therefore, AMM will not be helpful for an organization (including any SME) that is yet to take any step towards Industry 4.0. Although, employee training systems may enhance the skills of SME employees; however, the technologies like Data Analytics, Industrial Internet of Things (IIoT), vertical and horizontal organizational integration, etc. mentioned in the AMM framework are unlikely to be present in a manufacturing SME. Therefore, AMM may not fit a manufacturing SME. Furthermore, the study [57] do not explain the maturity items included in the AMM. The 30 maturity items were developed with the help of a comparison between eight maturity models that included a software maturity model [65] as well. The relevance of a pure software maturity model in a manufacturing scenario has not been discussed [57] as well. Finally, the incomplete explanation of the 30 maturity items and the absence of key characteristics at each stage of the maturity might confuse any organization, which does not have an expert or consultant to implement this model. Therefore, all the drawbacks discussed above makes the deployment of AMM in an SME impractical.

\subsection{Verifying current maturity model fit with manufacturing SME specific requirements}

It is important to understand how the fifteen models discussed above stand regarding the SME requirements described in Section 1.1 (see Table 3). Table 16 compares the Industry 4.0 models in terms of SME requirements, where "+" denotes that the model reinforces the 
Table 16

Comparing Smart Manufacturing/Industry 4.0 Models based on SME Requirements.

\begin{tabular}{|c|c|c|c|c|c|c|c|c|}
\hline \# & Models & FN & TR & ST & OC & EP & AL & CL \\
\hline 1 & A Categorical Framework of Manufacturing for Industry 4.0 and Beyond & & - & & & & & \\
\hline 2 & Maturity Model for Assessing Industry 4.0 Readiness and Maturity of Manufacturing Enterprises & & - & - & - & - & & \\
\hline 3 & $\begin{array}{l}\text { Towards Industry 4.0: Gap Analysis between Current Automotive MES and Industry Standards using Model-Based Requirement } \\
\text { Engineering }\end{array}$ & & & - & & & & - \\
\hline 4 & Towards Industry 4.0-Standardization as the Crucial Challenge for Highly Modular, Multi-vendor Production Systems & & - & & & - & & \\
\hline 5 & An Overview of a Smart Manufacturing System Readiness Assessment & & - & & - & & & \\
\hline 6 & Three Stage Maturity Model in SME's towards Industry 4.0 & + & + & & & + & & \\
\hline 7 & IMPULS Industrie 4.0 Readiness & & - & & - & - & & \\
\hline 8 & Building the Digital Enterprise & & - & & - & - & & - \\
\hline 9 & The Connected Enterprise Maturity Model & & - & & & & & - \\
\hline 10 & Guideline Industrie 4.0 - Guiding Principles for the Implementation of Industrie 4.0 in Small and Medium-sized Businesses & + & + & & & + & & \\
\hline 11 & A Smartness Assessment Framework for Smart Factories Using Analytic Network Process & & - & & - & - & & - \\
\hline 12 & Industrie 4.0 Maturity Index & - & - & & - & & & - \\
\hline 13 & Development of an Assessment Model for Industry 4.0: Industry 4.0-MM & & - & & - & + & & \\
\hline 14 & Maturity and Readiness Model for Industry 4.0 Strategy & & - & & + & & & \\
\hline 15 & Towards a framework for Assessing the Maturity of Manufacturing Companies in Industry 4.0 Adoption & & - & & & + & & \\
\hline
\end{tabular}

SME requirements, and "-" denotes that the specific requirements of the manufacturing SME do not go in harmony with the model. Below is discussed the standing of existing maturity models for each of the clusters formed from the specific SME requirements.

a) Finance (FN): It can be discerned from Table 16, that only three models $[77,80,82]$ recognize the presence of a tailored vision for SM/Industry 4.0 and therefore their approach suits SMEs. The tailored vision considers the unique needs of the organization and thus it may better acknowledge the financial constraints of SMEs.

b) Technical Resource Availability (TR): All models (except [73]) have advocated technology as an essential enabler leading to SM/Industry 4.0. Assuming technology as a vital resource was intuitive as SM/Industry 4.0 has to do with a technological transition. But, SMEs are more into specialized manufacturing, and therefore they might not feel the need of an umbrella of advanced technologies. Only two models $[77,80]$ emphasized on the tailored vision for SM/Industry 4.0 and thought that organizations may approve the technologies that fit their tailored vision. Although [82] considered a tailored vision, it suggests an extreme orientation towards digitalization. Therefore, the model by [82] might not fit an SME's technical requirements.

c) Standards (ST): Only two $[64,73]$ models discussed the importance of maintaining standards. Nevertheless, none of them can positively influence the standardization from the SME viewpoint. The detailed documentation, and the understanding of the appropriate industry standards, which the organization need to follow, may turn out to be a tedious process. Therefore, in the absence of an expert/consultant, the SME may not be able to implement and maintain the industrial standards.

d) Organization Culture (OC): The emphasis on organizational culture has also been considered by eight models [55,56,61,62,64,76, 81,82]. However, only [56] favor the SME perspective as their model acknowledges that the presence of an appropriate organizational culture and the mind-set towards having a belief is the first step on the road for Industry 4.0.

e) Employee Participation (EP): The value of employee participation is recognized in as many as eight models $[55,61,62,64,75,77,80,81]$. However, only four models $[55,57,77,80]$ considered employee participation from the SME viewpoint, because these four models acknowledge that employee training and their exposure to SM/Industry 4.0 are a crucial factor for the enterprise transition towards SM/Industry 4.0.

f) Alliances ( $A L)$ : Another important observation is that an alliance with academic/research institutes is not acknowledged by any of the models in the literature. Alliances with Universities and research institutes, and the exposure received by attending the workshops and skill-oriented seminars might help the SME employees in exchanging their viewpoints and insights with the other participants.

g) Collaboration (CL): SMEs are highly dependent on their suppliers and vendors, and therefore they may have an active collaboration. When it comes to literature as many as five models $[62,63,73,81,82]$ have considered collaboration as a vital factor of SM/ Industry 4.0. But, none of the five models have studied the SME viewpoint as they assume that the enterprise is digitalized, and can get real-time updates from its customers/ vendors. Therefore, the models have not provided any suggestions on how to pursue a healthy collaboration network.

Based on the above discussion, it can be observed that currently there is no model that fulfill all the specific requirements of manufacturing SMEs (thus answering RQ1). Therefore, there is a need for a comprehensive model that can align itself with all the SME specific requirements.

An SME may still follow one of the available models in the literature if the model can fulfill SME's specific requirements. For example, if an SME considers SM/Industry 4.0 but lacks finances, technological resources, and employee participation than they might adopt the maturity model proposed by [80]. However, the objective of this research work is to find ingredients for a general maturity model that can serve all the requirements of an SME.

\section{Critical review: results and framing of research gaps}

Table 17 presents a comprehensive summary of all the fifteen papers discussed in the previous section. The focus and the questions that emerge from the studies supporting SMEs in their evolutionary journey or paradigm shift towards SM/Industry 4.0 are the primary objectives of the table. The table also mentions the methodology applied in the research. These research findings can be used as an input for the development of a Maturity Model for SMEs. In addition, Table 17 shows that there are only a few studies that acknowledge an SME's organizational shift towards SM and/or Industry 4.0. Since all the articles and white-papers studied in this research are published between 2014 and 2018 , it can be inferred that the topic is very current and relevant.

\subsection{Findings}

From Table 17 it can be observed that different methodologies, such as framework, maturity model, readiness assessment, and gap analysis, were used to discuss the enterprise journey towards SM/Industry 4.0. Eight of these articles and reports have acknowledged the use of surveys and pilot studies (viz [56,61-64,76,77,81]. for the validation of maturity models, whereas [57] considered survey interviews as a mean for 


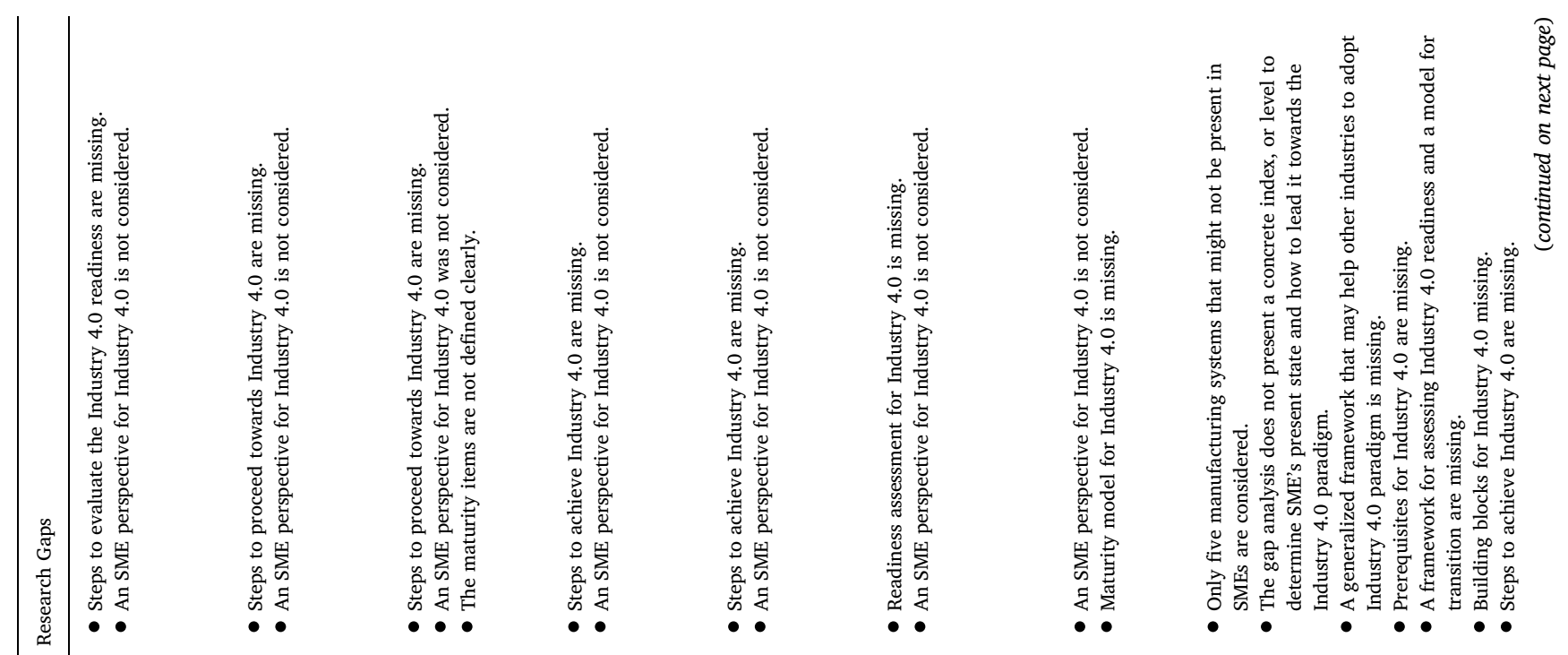

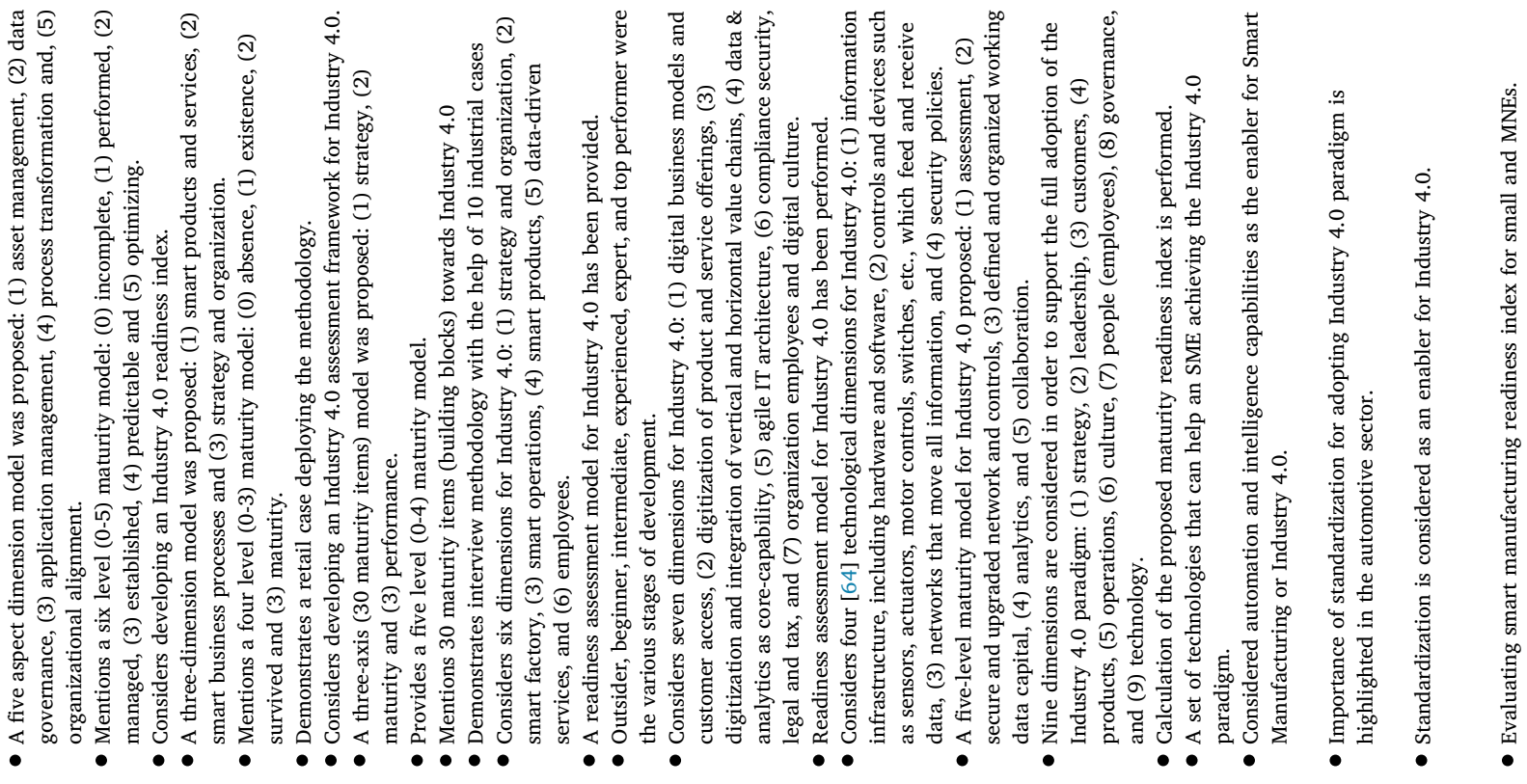

逢
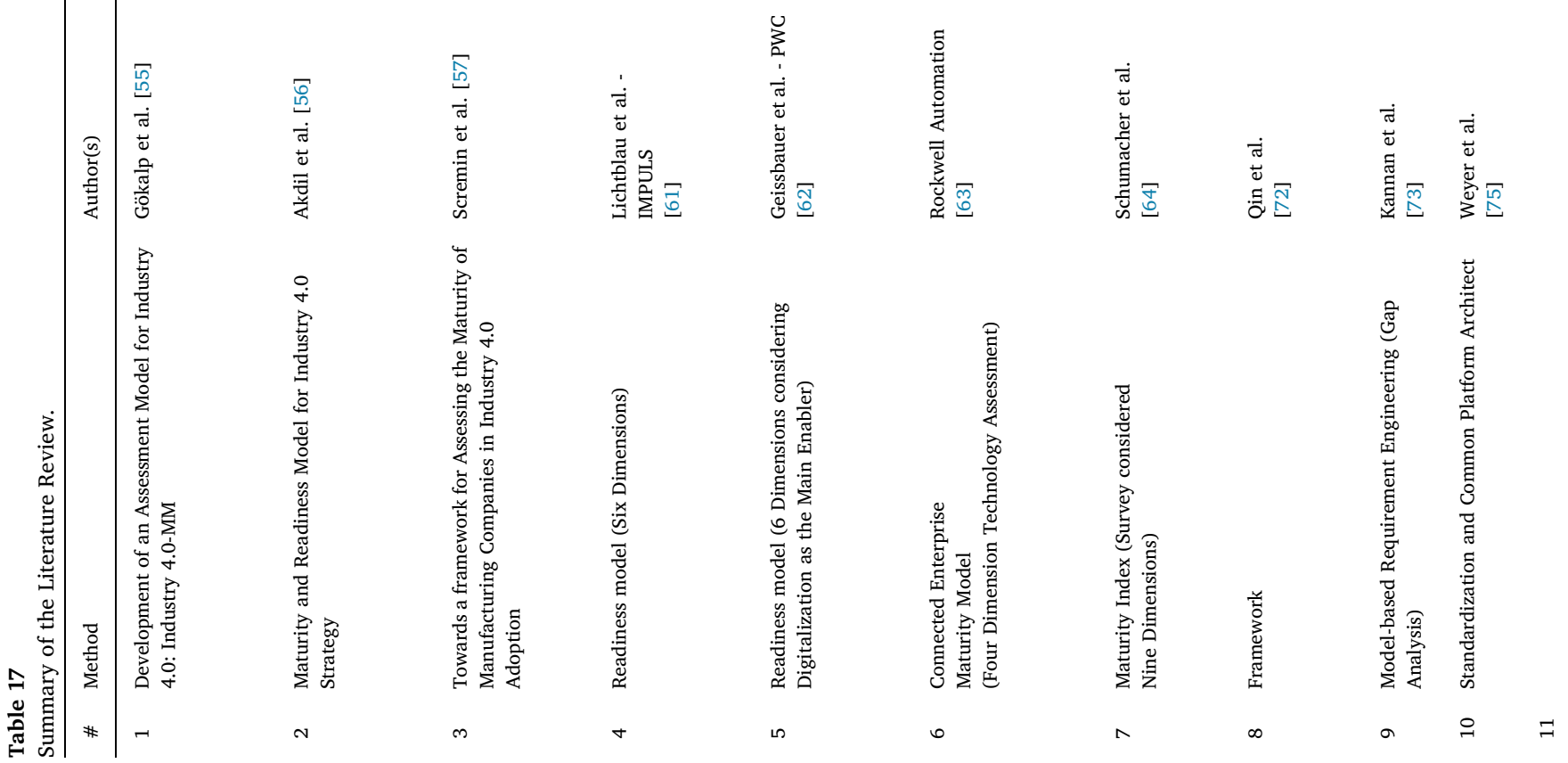
model validation. Anderl et al. - VDMA \& Partners [80] have developed a toolkit (set of technologies, methods, tools and practices- [83]) and suggested to share it with managers with the help of a workshop. Two papers by [72] and [73] have deployed a "Gap Analysis" for the journey towards SM/Industry 4.0. Weyer et al. [75] demonstrated the use of critical technologies for SM/Industry 4.0. Schuh et al. [82] considered workshop and surveys for initial study and validated the results with the help of an industrial case, and Akdil et al. [56] demonstrated the evaluation of maturity readiness index with the help of an example case from the retail industry.

Another observation from the study is that individual researchers have different perspectives towards the understanding of dimensions (e.g. [61,62,64,76]). Jung et al. [76] consider only "organizational maturity" whereas [61] deploy two indices: "strategy and organization" and "people." Similarly [62], apply "organization employees" and "digital culture," but only one index involving "organization, people, and organizational maturity." Schuh et al. [82] mentioned "resources," "information systems," "organization structure" and "organization culture" as the dimensions. Whereas Schumacher et al. [64] mention "strategy," "leadership," "culture," "people" and "governance." Only $[57,80,81]$ mention the prerequisites of Industry 4.0 in the form of technologies, toolbox and building blocks (considered by both $[57,81]$. The report by Lichtblau et al. - IMPULS [61] mentions a stage named: "outsider," where the organization does not have an idea about SM/ Industry 4.0, and it is not proceeding towards SM/Industry 4.0. Also [77], emphasize the enterprise's tailored vision for SM/Industry 4.0. Another significant finding is that some reports have defined the journey towards SM/Industry 4.0 depending on the orientation of their capabilities and strengths with SM/Industry 4.0. For example, the report by [63] emphasizes the importance of automation, control, and operations in general for the shift towards Industry 4.0; whereas [62] considers digitalization as the enabler. It may be happening because in Rockwell Automation [63] core-business has to do with automation and operation technologies, and for PwC [62] core-business involve digitalization and information technologies.

Overall, this study identified several research gaps in the current scientific body of knowledge that prevent maturity models for SM or Industry 4.0 in supporting the case of SMEs. For example, only four (viz $[72,77,80,81]$.) papers considered an 'SME perspective' for SM/Industry 4.0. These papers either mention the steps towards SM or Industry $4.0[63,72,73,75,77]$ or they emphasize on the readiness assessment $[56,57,61,62,64,76]$. Only [82] considers both to be used in unison to provide a comprehensive analysis. Anderl et al. - VDMA \& Partners $[80,81]$ neither consider the steps nor they focus on the readiness index for SM/Industry 4.0 .

\subsection{Gap identification}

In this section, a set of research gaps have been derived (thus answering RQ2) from the critical review conducted. These research gaps, if addressed correctly, might close the currently existing differences (see Table 16) and can provide SMEs with the dearly needed guidance in their Industry 4.0 journey.

Firstly, the roadmaps, frameworks and maturity models identified in the literature have targeted the needs of MNEs. Most of them assume that the companies already have access to necessary resources such as advanced and connected machines, IT integrated systems to mention a few. Therefore, it can be safely assumed that a significant number of MNEs have already started on their journey towards Industry 4.0. SMEs on the other hand often do not have dedicated resources, such as an IT department, connected equipment, etc., and thus have difficulties with the initial steps towards Industry 4.0. A possible case that exemplifies the challenge is the following: Large corporations start from a hypothetical "level 1" or an "initial" stage where the organization has already started implementing and accepting the shift towards SM and/ or Industry 4.0. While at the same time, SMEs may have to start from a 
"level 0" or "novice" (viz. very limited or no adoption of digital and (smart) automation technology as well as restricted connectivity regarding bandwidth, basic cybersecurity, and communication between information systems). In this case (level 0 ), the enterprise is not even aware and confident about launching an SM/Industry 4.0 initiative. Before moving on, it is essential to acknowledge that this generalization is not valid for all SMEs and MNEs across the board. There are several high-tech/technology-based SMEs that are operating at the top of their field and can be seen as role models for other SMEs in the SM or Industry 4.0 context. However, in general, the practical experience and the studies presented by other authors such as [84-89] suggest that the generalization is substantiated and is a suitable foundation for the work presented in the current research.

In that scenario, there are often some significant challenges involved when SMEs want to move from "level 0" to "level 1". Compared to going from "level 1" to "level 2", these challenges may be considered more severe for several reasons, such as building up infrastructure and mind-set (i.e., from virtually 'non-existent' - including the often-accompanying strong initial resistance) vs. upgrading and educating workers. As a result, it is not practical to consider the roadmap of a MNE for an SME, given SMEs' requirements and challenges faced toward digitalization, and (smart) automation. Secondly, a unique method that allows integrating self-assessing approaches for evaluating the current level of Industry 4.0 readiness is needed. And, based on that index, recommendations of specific prerequisites (or building blocks) and/or set(s) of characteristics, technologies and enabling factors [33] for directing the individual manufacturing system towards SM or Industry 4.0 capabilities are still missing. Thirdly, SM or Industry 4.0 have different meanings and implications for separate entities (companies/business-units/ people/etc.) and industries. It applies specifically to SMEs because they focus on a comparatively lesser variety of products and involve fewer processes.

Three main research gaps that pertain to SMEs are identified during this literature review.

Research Gap 1: Differences in the 'starting conditions' between SMEs and MNEs when it comes to Smart Manufacturing and Industry 4.0

The first identified research gap, different starting conditions for SMEs and MNEs consider that the currently available maturity models/ roadmaps/frameworks for SM or Industry 4.0 focus mostly on MNEs. Based on this background, many of the reviewed tools start from a somewhat advanced level (see Table 16) that includes connected machines, sensors, and some form of OT/IT integration. Similarly, the financial situation of SMEs has not been considered by (most of) the models (see Table 16). The models available in the literature also assume that SMEs have an appropriate organizational culture and the required employee skills towards SM/Industry 4.0, which is not the case in reality (see Section 3 - Table 16). Given the fact in many manufacturing SMEs, this assumed starting point might be too advanced for some SMEs. For SMEs, the starting conditions are often entirely different, and this needs to be reflected in the maturity models, etc., to be effective in their goal to support SMEs towards adopting SM and Industry 4.0. A readiness/maturity level below the first tier for MNEs is necessary to reflect this phenomenon accurately.

Following this train of thought a little further, another question remains unanswered: Is the effort necessary to move from the currently missing "level 0" to the next higher level (in particular for SMEs, which face this challenge more often) comparable with the efforts to transitioning from "level 1" to "level 2".

Research Gap 2: Disconnect between Maturity Models and self-assessment readiness tools

The second identified research gap is the disconnection between maturity models and self-assessment readiness-tools. Considering the results of the literature review summarized in Table 17, not all (only [82]) maturity models/roadmaps/frameworks aim at supporting the transition towards SM or Industry 4.0 include a readiness assessment tool. SMEs especially profit from the ease of use and smooth transition between self-assessment to maturity model. Therefore, the current disconnects between the two tools can be considered as another research gap that needs to be discussed in more detail.

Research Gap 3: Support (tailored to SMEs) for next step after maturity and readiness are assessed

The last identified research gap focuses on the next step after the maturity and readiness assessment. Larger manufacturing companies often have strategy departments or even a dedicated Industry 4.0 group that can work with the input provided by the maturity model and/or readiness assessment. SMEs on the other hand, often lack this dedicated $\mathrm{SM} /$ Industry 4.0 strategic resources. Nevertheless, SMEs need to create their own tailored SM and Industry 4.0 vision following the maturity model and/or readiness assessment results. Given the previously discussed features of many SMEs, they might profit from additional compartmentalized input following the maturity/readiness results. Tailored vision can be in the form of matching with predefined toolboxes ('plug and play' solutions) that allow for the modular development of their technical SM strategy.

\section{Discussion of the research gaps}

In this section, the previously identified three main research gaps are critically discussed and answered in more detail, so that the existing maturity models can be adapted in order to guide the SMEs toward the SM/Industry 4.0 paradigm shift (hence answering RQ3). The objective is to establish a solid foundation for selected and targeted follow-up studies based on primary data, e.g., surveys. At this point, the discussion and answers are framed based on the available (extended) literature and the experience of the authors.

\subsection{Research gap 1: different starting conditions for SMEs and MNEs}

The literature review (section 2), found that most maturity models, roadmaps, frameworks, etc. currently available for SM or Industry 4.0 consider mainly the needs and resources of MNEs, e.g., regarding the IT/OT infrastructure. Therefore, the reality of many SMEs today is that their "level 1" or starting point is often a disconnect from the average level of smartness (i.e., digitalization and (smart) automation capabilities). E.g., some of the SMEs may require a Wi-Fi connection on shop floor first before thinking about wireless sensor networks. As a result, SMEs might find it strategically tricky, and of little value to place themselves in one of the first defined levels (i.e., level 1) of existing maturity models. Levels are the various stages that can represent the current state of an organization, in this case, an SME. As a result, if SMEs know they are at a "level 0", they might be able to judiciously invest their available financial resources in technology and in

Table 18

Identified Gaps in terms of various SME requirements.

\begin{tabular}{|c|c|c|c|c|c|c|c|c|}
\hline \# & New Model Considerations & FN & TR & ST & OC & EP & $\mathrm{AL}$ & CL \\
\hline 1 & Different starting conditions for SMEs and MNEs & + & + & & + & + & & \\
\hline 2 & Disconnect between Maturity Models and self-assessment readiness tools & + & & & & & & \\
\hline 3 & Support (tailored to SMEs) for next step after maturity and readiness are assessed & + & + & + & + & + & + & + \\
\hline
\end{tabular}


developing the organizational culture and the employee participation towards SM/Industry 4.0. Therefore, a "level 0" may help to address the SME issues in a better way (see Table 18).

Although [61], suggests a stage "outsider," whereas [55] and [56] consider "level 0 " as incomplete and absence stages respectively, they fail to mention the requirements of "level 0". "Level 0" may be defined as the stage where the organizations are neither aware and nor they have started inclining themselves towards SM or Industry 4.0; e.g., an SME might be involved in the same labor-intensive processes, methods, etc., and do not possess the required expertise and resources (monetary and human) to adopt new Industry 4.0 technologies. An SME might not have something as basic as an intranet facility. An example can be hand-made item produced by a small group of people like a familyowned business. Hence, defining a "level 0" for SMEs is a necessary starting point to elevate their position along both the short- and longterms.

Faller \& Feldmüller [30] presented the case of three SMEs that invented "learning factories" oriented towards Industry 4.0 around the Campus Velbert/Heiligenhaus (CVH). The three SMEs employed different technologies like SAP as ERP system, PLC, MES, HMI, etc. to connect the shop floor and the top floor. But, this paper acknowledges that there are SMEs that do not have the awareness and the resources to become compatible to adapt the Industry 4.0 technologies. Therefore, it may be believed that there is a definite need of specifying a "level 0" for SMEs that may separate their position from the other advanced SMEs.

Big production houses at "level 1" might already have the required resources and skills that can accelerate their SM or Industry 4.0 journey towards "level 2" or from "level 2" to "level 3" or the corresponding higher levels. Whereas, the SMEs at "level 0" still need to address basic requirements, for example, the awareness of current technologies that thus far have not been relevant to their businesses. An SME at "level 0" may need to invest more in purchasing the required technology and set a platform for the employee participation and organization culture (see Table 18). Addressing skill gaps of their employees and access to other resources are relevant, but the overarching mind-set and willingness to change are also severe challenges that define "level 0". For example, a transition from manually maintained records to digital records, be it a proprietary database or a sophisticated ERP/MES solution, requires more resources and significant efforts. However, changing from existing digital records to, e.g., mobile applications may be comparatively easier. There might be SMEs that still maintain the records manually, and from the viewpoint of such SMEs, shifting from "level 1" to "level 2" is less demanding as compared to going from "level 0" to "level 1", especially when taking the 'mind-set' shift into consideration.

\subsection{Research gap 2: disconnect between maturity models and self- assessment readiness tools}

The literature review suggests that most of the maturity models/ roadmaps/frameworks leading towards SM or Industry 4.0 lack a selfassessment readiness tool and, thereby making it harder for SMEs to self-assess its starting point. Similarly, most of the self-assessments, maturity models and roadmaps seem to be separated, independent tools. Only Erol et al. [79] provided an integrated toolkit that is comparatively easier to purchase and install. The authors aim to provide a clear "strategic guideline" to manage the entire digital transformation process; nevertheless, their maturity model does not include a self-assessment tool. Anderl et al. - VDMA \& Partners [80] also provide a toolbox with different phases towards SM or Industry 4.0, but the toolbox did not offer any support in assessing the current state of the company. Similarly, Schuh et al. [82] consider a maturity model integrated with a self-assessment tool, but it does not present an SME perspective. Therefore, there is a need for an integrated maturity model and self-assessment readiness tool for SMEs that can help them to lead towards SM/Industry 4.0.

SMEs will always have budget constraints in their minds, and therefore, it might not be feasible for them to hire a consultant. However, the MNEs might do that. As a result, it is more important for SMEs to have, an easy to interpret maturity model that can include both a readiness assessment tool and a maturity model, which may be applied by an SME manager (see Table 18). The readiness assessment will keep them updated about their present position towards SM or Industry 4.0 , and the maturity model will guide their progress.

\subsection{Research gap 3: support (tailored to SMEs) for next step after maturity} and readiness are assessed

Based on the results of this literature review, only two papers $[64,79]$, have focused on "company-specific SMEs 4.0 vision", and subsequent steps to achieve it. However, they have not demonstrated an example of an industry or SME that can follow such steps towards its tailored vision of SM or Industry 4.0. Showing a systematic methodology leading towards SM or Industry 4.0 may help motivating other SMEs to move towards a company-specific SME 4.0 vision ('successstories'/ test-beds). Each SME has its specific needs and therefore should have its customized version of an SM or Industry 4.0 vision. The tailored vision will also help SMEs in spending on both technical and non-technical resources by focusing on their needs. On the other hand, with the help of readiness assessments, SMEs may be able to assess and get aware about their manufacturing capabilities. Awareness is another crucial factor that can help in developing SMEs 4.0. The SMEs may get aware with the help of the reports provided by other industries and consultants and thus promote an organizational culture towards SM (see Table 18). These reports will include cases that may guide the SMEs towards the required (digital) work culture. Attending workshops and seminars on SM/Industry 4.0 with universities and institutes (see Table 18) will keep them updated with cutting-edge research, and the various industrial standards (like ISOs), they have to follow for product regulation and safety. The awareness developed by workshops and seminars will also help the SMEs to develop digital Industry 4.0 vision and culture. The SMEs have an extreme dependence on their collaborators (see Section 1.1), and a tailored vision towards SM may also help the SMEs in specifying their requirements in-time and thus reducing the demand uncertainties from the collaborator's mind. After attending the workshops, the SMEs might be able to inform their vendor (s) about how the industry standards may be met in the best possible manner, and this may further strengthen their relations with the collaborators (see Table 18).

SMEs often focus on specific domains, and therefore for them, it becomes even more critical to self-assess and document their success stories, lessons learned, for highlighting the successful role models available. Another factor is the trust issue - many SMEs trust their peers to a greater extent as compared to believing the service providers or other entities whom SMEs may perceive as having their agenda and/or self-interest.

With the help of the identified research gaps, it was learned that although there are websites available that aim to help companies to locate/map their current state, they do not allow for an independent assessment. Defining/ customizing items under the dimensions are rather limited, and thus the reflection of individual challenges and requirements is only marginally possible. Only [64] considered items such as customer data, process decentralization, knowledge sharing, etc. and [61] discussed the employee skills, autonomous processes, data analytics, etc. However [64], and [61] lacked a self-assessment tool for companies. Most of the readiness assessment tool (i.e. [31,62,63,76],) have not transparently defined dimensions for evaluating the readiness for Industry 4.0. There are different toolkits available in the market that claim to support organizations to achieve Industry 4.0. Qin et al. [72] mention some of these in the form of technologies. In any case, for the self-assessment of the companies, they need to perform an analysis based on the different characteristics, technologies and enabling factors [33], the work culture, organizational strategies, etc. The presence of 
incomplete toolkits may confuse the SMEs and even create additional strategic and operational difficulties, and the specific technologies that SME may install might be ignored.

\subsection{Summary of discussion}

Section 5 identified and discussed three main research gaps of currently available maturity/readiness/assessment models and their fit for SMEs using a comprehensive literature review. Based on this work, it is believed that the current models are not sufficiently addressing the identified gaps and if more work is done in this direction than the mentioned research gaps (see Section 4.2) might be resolved. Table 18 shows how the research gaps discussed in Section 5.1-5.3 handle the previously introduced SME requirements.

Based on the discussion of answers (to Research Gap 1-3, Section 5.1-5.3), Table 18 has been presented. It might be interesting to consider why only focusing on a tailored vision of SM/Industry 4.0 for SME may not be sufficient for a future maturity model. Even though having a tailored vision serves all the SME requirements, it does not allow an SME to evaluate its strengths and weakness, and therefore an SME should have a tailored vision after assessing its readiness. The presence of a "level 0" and the critical shift from "level 0" to "level 1" are very significant, and they will need a different set of resources like investments, human resources, etc. and therefore for SMEs, it becomes vital to have these two as a separate focus. Similarly, the presence of a self-assessing maturity model is discussed, but it does not recognize integrating the maturity model with a readiness tool (which otherwise may be understood differently). For example, in the case of SMEs they need to assess their present situation with time, and thus readiness tool may not be ignored. Therefore, the urge is to have a maturity model that will firmly stand to recognize all the identified research gaps and convincingly comply with the SME requirements.

As a result of the above discussion we believe a future model that focusses specifically on SME's needs is needed. Such a model should first demonstrate organization's readiness towards SM with the help of the activities performed in the SME, and then show how an SME can create its own tailored vision of SM. A tailored vision will assist in finding the required tools [90] that can strengthen the organizational dimensions [91] of SME, and thus guide it towards SM. For example, an SME currently at "level 0" may be storing data with the help of logbooks/spreadsheets. In order to move towards a SM reality, they need to adopt a more reliable and accessible data storage system, such as a cloud-based system [91].

\section{Conclusions, limitations and future work}

The paper begins with identifying the specific requirements of manufacturing SMEs, and then a critical review of the present literature on SM/Industry 4.0 is done. We defined three guiding research questions that were answered through a comprehensive critical review. Results of the review show that the reports and papers included in the literature mainly consider the challenges and requirements of MNEs, as the identified requirements of SMEs are not fulfilled (see Table 16) by the present models (RQ1). The unfulfilled SME requirements lead to the recognition of important research gaps from the perspective of SMEs' specific needs and realities. As a result, this paper frames three research gaps that need to be answered in order to understand and support SMEs in their successful journey towards SM and/or Industry 4.0 (RQ2). The paper then discusses the research gaps and provide answers based on the available (extended) literature. The authors' industrial experience offered a genuine value to SMEs' digital transformation towards SM and/or Industry 4.0 by supporting the development of a future toolkit and maturity model to answer the research gaps established in this paper. We also discussed how the identified gaps respond to the SMEs requirements. $T$ The main findings of this study are $(R Q 2 / R Q 3)$ :
- A maturity model for SMEs should have a distinctly defined "level 0" (to focus on fundamental needs, e.g., computerization of corebusiness processes and connectivity at shop-floor), which may better explain the state of many SMEs regarding their current digital and (smart) automation capabilities. This suggestion assumes that many MNEs have already started their journey towards SM/Industry 4.0 and a "level 0" allows to reflect the realities of many SMEs and distinguish their needs from those of the larger corporations.

- The transition from "level 0" to "level 1" may include a drastic change in the organizational culture of a company (in this case an SME) as it involves adopting new technologies, organizational culture, and learning skills, etc. Therefore, this shift may probably take longer time, require more resources, and involve more unforeseen problems compared to, e.g., the shift from "level 1" to "level 2" (or a certain level to the corresponding higher level).

- It is essential that a company considers both the present 'state/level' of their organization and the move towards their SM/Industry 4.0 vision with the help of a self-assessment tool. SMEs may not consider hiring a consultant to assess their readiness from time to time in order to guide their journey. As a result, they need a readiness assessment tool complemented and deeply integrated within a corresponding maturity model.

- There is a need for an SME-tailored vision of SM and/or Industry 4.0. A maturity model can reflect this diversity and may be integrated with a self-assessing tool, which may be deployed by an SME manager at various stages in their journey towards SM/ Industry 4.0 .

The major limitation of this paper is that it has been developed mainly based on a literature review without collecting primary research data. Most of the available literature is focused on more mature enterprises as established in the previous section, and thus a certain bias might be included in the analysis. Furthermore, it did not consider any cultural or location-based restrictions or influences at this point. While this might have a considerable impact on the SMEs situation, the current body of knowledge does not allow for a critical and thorough assessment of this issue yet. As mentioned earlier, the study includes five white-papers by consulting companies / technology providers and as such, might be biased to some extent by the self-interest of the authoring companies.

This paper established a solid foundation towards the development of a future SM or Industry 4.0 Maturity Model for SMEs by answering the framed research gaps in this paper. Based on the need identified in the current paper, the plan is to develop an SME centric model in the near future. To design such a SM model for SMEs, the results of this indepth, literature-based analysis may be verified with the help of primary data, e.g., using a survey to SMEs.

\section{Conflict ofinterest}

No conflict of interest.

\section{Acknowledgements}

This work was supported by the J. Wayne \& Kathy Richards Faculty Fellowship in Engineering at WVU. The authors are also thankful to the anonymous referees for their comments that helped to significantly improve the quality of the manuscript.

\section{References}

[1] Schiersch A. Inefficiency in the German mechanical engineering sector. 2009.

[2] Wuest $\mathrm{T}$, Thoben KD. Information management for manufacturing SMEs September IFIP International Conference on Advances in Production Management Systems2011:488-95.

[3] Wadhwa R. Flexibility in manufacturing automation: a living lab case study of Norwegian metal casting SMEs. J Manuf Syst 2012;31:444-54. 
[4] Wuest T, Schmid P, Lego B, Bowen E. Overview of smart manufacturing in West Virginia. WVU bureau of business \& economic research. 2018. Morgantown, WV, USA.

[5] Nagy D. International collaboration tools for Industrial development. 6th CSIR Conference: ideas that work for industrial development, 5-6 october 2017. Pretoria, South Africa: CSIR International Convention Centre; 2017.

[6] EC. SME 4.0 - smart manufacturing and logistics for SMEs in an X-to-order and mass customization environment Retrieved January 2018 from 2018http://www. sme40.eu.

[7] EC (2003). Retrieved April 2018 http://ec.europa.eu/growth/smes/businessfriendly-environment/sme-definition_en.

[8] Dyerson R, Spinelli R, Harindranath G. Revisiting IT readiness: an approach for small firms. Ind Manage Data Syst 2016;116(3):546-63.

[9] Kennedy J, Hyland P. A comparison of manufacturing technology adoption in SMEs and large companies. Proceedings of 16th Annual Conference of Small Enterprise Association of Australia and New Zealand 2003:1-10.

[10] Terziovski M. Innovation practice and its performance implications in small and medium enterprises (SMEs) in the manufacturing Sector: A resource-based View. Strateg Manage J 2010;31(8):892-902.

[11] Kumar M, Khurshid KK, Waddell D. Status of quality management practices in manufacturing SMEs: A comparative study between Australia and the UK. Int J Prod Res 2014;52(21):6482-95.

[12] Vasudevan H, Chawan A. Demystifying knowledge management in Indian manufacturing SMEs. Procedia Eng 2014;97:1724-34.

[13] Müller JM, Voigt KI. Industry 4.0-Integration strategies for small and medium-sized enterprises. International Association for Management of Technology (IAMOT) 2017:1-15.

[14] InfoDev Innovation \& Entrepreneurship. Retrieved May 2018 from http://www. infodev.org/articles/issues-sme-financing.

[15] Jasra JM, Hunjra AI, Rehman AU, Azam RI, Khan MA. Determinants of business success of small and medium enterprises. 2012.

[16] Dangayach GS, Deshmukh SG. Advanced manufacturing technology implementation: evidence from Indian small and medium enterprises (SMEs). Journal Manufacturing Technology Management 2005;16(5):483-96.

[17] Julien PA, Ramangalahy C. Competitive strategy and performance of exporting SMEs: an empirical investigation of the impact of their export information search and competencies. Entrepreneur Theory and Pract 2003;27(3):227-45.

[18] Lee S, Park G, Yoon B, Park J. Open innovation in smes-an intermediated network model. Res Policy 2010;39(2):290-300.

[19] Brown A, Van Der Wiele T, Loughton K. Smaller enterprises' experiences with ISO 9000. Int J Quality \& Reliability Manage 1998;15(3):273-85.

[20] Blind K, Mangelsdorf A. Alliance formation of SMEs: empirical evidence from standardization committees. IEEE Trans Eng Manage 2013;60(1):148-56.

[21] Van de Vrande V, De Jong JP, Vanhaverbeke W, De Rochemont M. Open innovation in SMEs: trends, motives and management challenges. Technovation 2009;29(67):423-37.

[22] Salles M. Decision making in SMEs and information requirements for competitive intelligence. Product Plann Control 2006;17(3):229-37.

[23] Trott P. The role of market research in the development of discontinuous new products. Eur J Innov Manage 2001;4(3):117-26.

[24] Bublitz E, Noseleit F. The skill balancing act: when does broad expertise pay off? Small Bus Econ 2014;42(1):17-32.

[25] Dombrowski U, Crespo I, Zahn T. Adaptive configuration of a lean production system in small and medium-sized enterprises. Prod Eng 2010;4(4):341-8.

[26] McAdam R, Reid R. SME and large organisation perceptions of knowledge management: comparisons and contrasts. J Knowl Manage 2001;5(3):231-41.

[27] Singh RK, Garg SK, Deshmukh SG, Kumar M. Modelling of critical success factors for implementation of AMTs. J Modell Manage 2007;2(3):232-50.

[28] Esmaeilian B, Behdad S, Wang B. The evolution and future of manufacturing: A review. J Manuf Syst 2016;39:79-100.

[29] Nieuwenhuize GB. Smart manufacturing for Dutch SMEs why and how? (Master's thesis). Rotterdam, Netherlands: Rotterdam School of Management - Erasmus University; 2016.

[30] Faller C, Feldmüller D. Industry 4.0 learning factory for regional SMEs. Procedia CIRP 2015;32:88-91.

[31] Veza I, Mladineo M, Peko I. Analysis of the current State of Croatian manufacturing industry with regard to industry 4.0 Retrieved April 2018 from Vodice, Croatia: Croatian Association of Production Engineering; 2015http://bib.irb.hr/prikazi-rad? \&rad $=802656$.

[32] Kagermann H, Helbig J, Hellinger A, Wahlster W. Recommendations for implementing the strategic initiative INDUSTRIE 4.0: securing the future of German manufacturing industry. Forschungsunion: Final Report of the Industrie 4.0 Working Group; 2013.

[33] Mittal S, Khan MA, Romero D, Wuest T. Smart manufacturing: characteristics, technologies and enabling factors. Proceedings of the institution of mechanical engineers, part B: journal of engineering manufacture. 2017:0954405417736547.

[34] Rüßmann M, Lorenz M, Gerbert P, Waldner M, Justus J, Engel P, et al. industry 4.0: The future of productivity and growth in manufacturing industries. Boston consulting group Retrieved April 2018 from 2015http://www.inovasyon.org/pdf/bcg. perspectives_Industry.4.0_2015.pdf.

[35] Maier A, Student D. Industrie 4.0 - der große Selbstbetrug [In German] Retrieved April 2018 from 2015http://www.manager-magazin.de/magazin/artikel/digitalerevolution-industrie-4-0-ueberfordert-deutschen-mittelstand-a-1015724.html.

[36] Eisert R. Mittelständler verpassen die Zukunftstrends [In German] Retrieved April 2018 2014http://www.wiwo.de/unternehmen/mittelstand/industrie-4-0mittelstaendler-verpassen-die-zukunftstrends/10004718.html.
[37] Rickman H. Verschläft der deutsche mittelstand einen megatrend? [In German] Retrieved April 2018 from 2014http://www.focus.de/finanzen/experten/ rickmann/geringer-digitalisierungsgrad-verschlaeft-der-deutsche-mittelstandeinen-megatrend_id_3973075.html.

[38] Sommer L. Industrial revolution - industry 4.0: are German manufacturing SMEs the first victims of this revolution? Journal Industrial Engineering Management 2015;8(5):1512-32.

[39] Knop C. Dem deutschen Mittelstand ist die Digitalisierung egal [In German] Retrieved April 2018 from 2014http://www.faz.net/aktuell/wirtschaft/ wirtschaftspolitik/deutsche-betriebe-investieren-kaum-in-digitalen-ausbau13146623.html.

[40] Kolberg D, Zühlke D. Lean automation enabled by industry 4.0 technologies. IFACPapersOnLine 2015;48(3):1870-5.

[41] Tzong-Ming C, Tu TH. A fast parametric deformation mechanism for virtual reality applications. Comput Ind Eng 2009;57(2):520-38.

[42] Wu HK, Lee SWY, Chang HY, Liang JC. Current Status, opportunities and challenges of augmented reality in education. Comput Educ 2013;62:41-9.

[43] Huang SH, Liu P, Mokasdar A, Hou L. Additive manufacturing and its societal impact: a literature review. Int J Adv Manuf Technol 2013;67:1191-203.

[44] Chan S, Lu Y, Wang Y. Data-driven cost estimation for additive manufacturing in cyber-manufacturing. J Manuf Syst 2018;46:115-26.

[45] Wu D, Liu S, Zhang L, Terpenny J, Gao R, Kurfess T, et al. A fog computing-based framework for process monitoring and prognosis in cyber-manufacturing. J Manuf Syst 2017;43(1):25-34.

[46] De Mauro A, Greco M, Grimaldi M. What is Big data? A consensual definition and a review of key research topics. Am Inst Phys (AIP) Conf Proc 2015;1644(1):97-104.

[47] Addo-Tenkorang R, Helo PT. Big data applications in Operations/Supply-Chain management: A literature review. Comput Ind Eng 2016;101:528-43.

[48] Tao F, Qi Q, Liu A, Kusiak A. Data-driven smart manufacturing. J Manuf Syst 2018. (in press).

[49] Lenz J, Wuest T, Westkaemper E. Holistic approach to machine tool data analytics. J Manuf Syst 2018.

[50] Monostori L. Cyber-physical production systems: roots, expectations and R\&D challenges. Procedia CIRP 2014;17:9-13.

[51] Zhong H, Nof SY. The dynamic lines of collaboration model: collaborative disruption response in cyber-physical systems. Comput Ind Eng 2015;87:370-82.

[52] Thoben KD, Wiesner S, Wuest T. "industrie 4.0" and smart manufacturing-a review of research issues and application examples. Int J Autom Technol 2017;11(1).

[53] Grant MJ, Booth A. A typology of reviews: an analysis of 14 review types and associated methodologies. Health Inf Lib J 2009;26(2):91-108.

[54] De Carolis A, Macchi M, Kulvatunyou B, Brundage MP, Terzi S. Maturity models and tools for enabling smart manufacturing systems: comparison and reflections for future developments. IFIP International Conference on Product Lifecycle Management 2017:23-35.

[55] Gökalp E, Şener U, Eren PE. Development of an assessment model for industry 4.0: industry 4.0-MM. International Conference on Software Process Improvement and Capability Determination 2017:128-42.

[56] Akdil KY, Ustundag A, Cevikcan E. Maturity and readiness model for industry 4.0 strategy. Industry 4.0: managing the digital transformation. Cham: Springer; 2018. p. 61-94.

[57] Scremin L, Armellini F, Brun A, Solar-Pelletier L, Beaudry C. Towards a framework for assessing the maturity of manufacturing companies in industry 4.0 adoption. Analyzing the Impacts of Industry 4.0 in Modern Business Environments 2018:224-54.

[58] De Carolis A, Macchi M, Negri E, Terzi S. A maturity model for assessing the digital readiness of manufacturing companies. IFIP International Conference on Advances in Production Management Systems 2017:13-20.

[59] Jung K, Choi S, Kulvatunyou B, Cho H, Morris K. A reference activity model for smart factory design and improvement. Product Plan Control 2017;28(2):108-22.

[60] Brandl D. MESA MOM capability maturity model version 1.0. 2016.

[61] Lichtblau K, Stich V, Bertenrath R, Blum M, Bleider M, Millack A, et al. IMPULSindustrie 4.0-readiness. Impuls-stiftung des VDMA, Aachen-köln Retrieved April 2018 from 2015http://www.impuls-stiftung.de/documents/3581372/4875835/ Industrie + 4.0 + Readniness + IMPULS + Studie + Oktober + 2015.pdf/447a61879759-4f25-b186-b0f5eac69974.

[62] Geissbauer R, Vedso J, Schrauf S. industry 4.0: building the digital Enterprise: 2016 global industry 4.0 survey Retrieved April 2018 from Munich: PricewaterhouseCoopers; 2016https://www.pwc.com/gx/en/industries/industries4.0/landing-page/industry-4.0-building-your-digital-enterprise-april-2016.pdf.

[63] Rockwell Automation. The connected enterprise maturity model Retrieved April 2018 from Rockwell Automation; 2014http://literature.rockwellautomation.com/ idc/groups/literature/documents/wp/cie-wp002_en-p.pdf.

[64] Schumacher A, Erol S, Sihn W. A maturity model for assessing industry 4.0 readiness and maturity of manufacturing enterprises. Procedia CIRP 2016;52:161-6.

[65] Leyh C, Bley K, Schäffer T, Forstenhäusler S. SIMMI 4.0-a maturity model for classifying the enterprise-wide it and software landscape focusing on industry 4.0 September Computer Science and Information Systems (FedCSIS), 2016 Federated Conference on IEEE. 2016. p. 1297-302.

[66] Beaudoin J, Lefebvre G, Normand M, Gouri V, Skerlj A, Pellerin R, et al. Prendre part à la révolution manufacturière? Du Rattrapage Technologique à L'Industrie 4.0 Chez Les PME 2016.

[67] Jodlbauer H, Schagerl M. Reifegradmodell industrie 4.0-ein vorgehensmodell zur identifikation von industrie 4.0 potentialen. Informatik; 2016. 2016.

[68] Garcia ML, Bray OH. Fundamentals of technology roadmapping (No. SAND—970665. NM (United States): ). Sandia National Labs, Albuquerque; 1997.

[69] Mettler T. Maturity assessment models: A design science research approach. Int J 
Soc Syst Sci 2011;3(1-2):81-98.

[70] Storey MA. Theories, methods and tools in program comprehension: past, presen and future May Program Comprehension, 2005. IWPC 2005. Proceedings. 13th International Workshop on IEEE. 2005. p. 181-91.

[71] Benedict N, Smithburger P, Donihi AC, Empey P, Kobulinsky L, Seybert A, et al. Blended simulation progress testing for assessment of practice readiness. Am J Pharm Educ 2017;81(1):14.

[72] Qin J, Liu Y, Grosvenor R. A categorical framework of manufacturing for industry 4.0 and beyond. Procedia CIRP 2016:52:173-8.

[73] Kannan SM, Suri K, Cadavid J, Barosan I, Brand MVD, Alferez M, et al. Towards industry 4.0: Gap analysis between current automotive MES and industry standards using model-based requirement engineering arXiv preprint arXiv:1704.02824 2017.

[74] CGI. MES product survey. MESA Int 2015;16(1):1-768.

[75] Weyer S, Schmitt M, Ohmer M, Gorecky D. Towards industry 4.0: standardization as the crucial challenge for highly modular, multi-vendor production systems. IFACPapersOnLine 2015;48(3):579-84.

[76] Jung K, Kulvatunyou B, Choi S, Brundage MP. An overview of a smart manufacturing system readiness assessment. IFIP International Conference on Advances in Production Management Systems 2016:705-12.

[77] Ganzarain J, Errasti N. Three stage maturity model in SME's toward industry 4.0. J Ind Eng Manage 2016;9(5):1119-28.

[78] Ansoff HI. Strategies for diversification. Harvard Bus Rev 1957;35(5):113-24.

[79] Erol S, Schumacher A, Sihn W. Strategic guidance towards industry 4.0: A Threestage process model. International Conference on Competitive Manufacturing (COMA) 2016

[80] Anderl R, Picard A, Wang Y, Fleischer J, Dosch S, Klee B, et al. Guideline industrie 4.0-guiding principles for the implementation of industrie 4.0 in small and medium sized businesses. VDMA Forum Industrie 2015;Vol. 4. ISBN: 978-3-8163-0687-0.
[81] Lee J, Jun S, Chang TW, Park J. A smartness assessment framework for smart factories using analytic network process. Sustainability 2017;9(5):794-808.

[82] Schuh G, Anderl R, Gausemeier J, Hompel M, Wahlster W. Industrie 4.0 maturity index. Retrieved April 2018 from 2017http://www.acatech.de/fileadmin/user upload/Baumstruktur_nach_Website/Acatech/root/de/Publikationen/ Projektberichte/acatech_STUDIE_Maturity_Index_eng_WEB.pdf.

[83] Odedairo BO, Bell D. Framework for introducing and implementing value methods: a novel toolkit for small and medium scale industries in developing nations. Int $\mathrm{J}$ Basic Appl Sci IJBAS 2010;9(10):130-46. (Next to Schuh).

[84] Buonanno G, Faverio P, Pigni F, Ravarini A, Sciuto D, Tagliavini M. Factors affecting ERP system adoption: A comparative analysis between SMEs and large companies. J Enterprise Inf Manage 2005;18(4):384-426.

[85] Arendt L. Barriers to ICT adoption in SMEs: how to Bridge the digital divide? J Syst Inf Technol 2008;10(2):93-108.

[86] Wielicki T, Arendt L. A knowledge-driven shift in perception of ICT implementation barriers: comparative study of US and European SMEs. J Inf Sci 2010;36(2):162-74.

[87] Mutula SM. Digital divide and SMEs. Digital economies: SMEs and E-readiness. IG Global; 2010. p. 54-7.

[88] Lenny Koh SC, Simpson M. Change and uncertainty in SME manufacturing en vironments using ERP. J Manuf Technol Manage 2005;16(6):629-53.

[89] Quinton S, Simkin L. The digital journey: reflected learnings and emerging challenges. Int J Manage Rev 2016:1-18. https://doi.org/10.1111/ijmr.12104.

[90] Mittal S, Romero D, Wuest T. Towards a smart manufacturing toolkit for SMEs July (Accepted). IFIP International Conference on Product Lifecycle Management. 2018.

[91] Mittal S, Romero D, Wuest T. Towards a smart manufacturing maturity model for SMEs (SM 3 E) August IFIP International Conference on Advances in Production Management Systems2018:155-63. 


\title{
Original Papers
}

\section{Publication IV}

\section{Towards a Smart Manufacturing Toolkit for SMEs}

\author{
By
}

Sameer Mittal, David Romero and Thorsten Wuest, July 2018

Mittal, S., Romero, D., \& Wuest, T. (2018, July). Towards a smart manufacturing toolkit for SMEs. In IFIP International Conference on Product Lifecycle Management (pp. 476-487). Springer, Cham.

2018 Springer Nature. Print rights of the final author's accepted manuscript. 


\title{
Towards a Smart Manufacturing Toolkit for SMEs
}

\author{
Sameer Mittal ${ }^{1}$, David Romero ${ }^{2}$, Thorsten Wuest ${ }^{1}$ (corr. author) \\ ${ }^{1}$ Industrial and Management Systems Engineering, Benjamin M. Statler College of \\ Engineering and Mineral Resources, West Virginia University, Morgantown, WV, USA \\ samittal@mix.wvu.edu, thwuest@mail.wvu.edu \\ ${ }^{2}$ Tecnológico de Monterrey, Mexico \\ david.romero.diaz@gmail.com
}

\begin{abstract}
Technology, human and financial capitals will always be a significant constraint for manufacturing Small and Medium-sized Enterprises (SMEs). Keeping that in mind, this paper introduces a modular Smart Manufacturing (SM) Toolkit for SMEs as a set of technologies, methods, tools, and practices that can help manufacturing enterprises to increase their SM capabilities. The modular SM toolkit is composed of seven individual specialized toolboxes, which cover both technical and business management aspects of a successful digital transformation in a manufacturing SME. In addition, the various SME functions that can be supported with each individual toolbox are presented as well. The paper concludes with two short demonstration case studies as a means of an early validation mechanism for the SM toolkit in refinement.
\end{abstract}

Keywords: Digitalization, SMEs, Industry 4.0, Smart Manufacturing, Intelligent Manufacturing, Toolboxes, Toolkit.

\section{Introduction}

The goal of a Smart Manufacturing (SM) initiative is to optimize a production system with the help of a set of digital practices, technologies and other enabling factors that support the operations of a manufacturing enterprise [1] [2]. The discretion of practices, technologies and enabling factors that may be deployed by a manufacturing enterprise will depend on the degree of digitalization of its industrial sector (i.e., push-adoption) and/or self-conviction in pursuit of a new (digital) competitive advantage (i.e., pulladoption). In this sense, it is important to emphasize that developing an SM system represents both a technological and managerial challenge [3]. Therefore, shifting towards an SM practice should be both profitable and sustainable for a manufacturing enterprise. Although, the scientific literature has suggested a number of assessments, frameworks, maturity models and roadmaps for supporting the digital transformation of manufacturing enterprises towards the development of SM capabilities, the body of knowledge is lacking methods, tools and support systems for Small and Medium-sized Enterprises (SMEs).

According to Esmaelian, et al. [4]: "Manufacturing is continuously evolving from concept development to methods and tools available for the production of goods for use or sale. Traditionally, manufacturing refers to an industrial production process through which raw materials are transformed into finished products to be sold in the market. However, these days manufacturing is considered to be an integrated concept at all levels from machines to production systems to an entire business level operation". 
The evolution in the definition of "manufacturing" [4] has led to the establishment of new requirements for the development of manufacturing toolkits as a set of methods, tools, and practices. Different manufacturing initiatives, such as lean manufacturing [5] and digital manufacturing [6] have developed their own toolkits over the years that may help manufacturing enterprises in their shift towards more efficient production operations. These toolkits include a diverse range of items from cutting-edge CAx technologies, working tools, managerial principles, training methods, organizational practices, etc. However, when it comes to the recent SM initiative [1] [2], there is a void, or at least a very limited number, of toolkits aimed at supporting manufacturing enterprises (i.e., SMEs), in adopting the new 'smart' ways of production operations. Therefore, there is a need for systematizing the currently available SM methods, tools and practices in a modular toolkit providing a step-by-step and building-block approach for SMEs to develop SM capabilities in their own individual manufacturing systems.

This paper discusses the importance of SM toolkits for SMEs in the context of the Fourth Industrial Revolution or Industry 4.0. Section 2 focuses on available toolkits in the scientific body of knowledge. Section 3 proposes a modular SM toolkit that aims to help SMEs to develop SM capabilities. Following, two case studies validating the proposed toolkit are discussed in Section 4. Section 5 presents conclusions and further research work.

\section{Literature Review}

Toolkits may be considered as the set of organized working methods, physical and software tools, and managerial practices [7]. Every toolkit has its own objective. When it comes to manufacturing, there are a few toolkits available that may be considered as precursors for the development of an SM toolkit.

[5] categorized different lean tools and methods under five families to develop a modular toolkit: (a) JIT (pull-system, takt-time and Kanban systems), (b) TPM (OEE, SMED and 5S), (c) Automation (poka-yoke, andon and full work systems), (d) VSM (current state map, future state map and flow diagrams), and (e) Kaizen (brainstorming, continuous flow, five whys, Pareto-chart and Gantt-chart). The selection of the best lean toolkits for manufacturing SMEs has also been discussed in the literature [8], emphasizing the toolkits specific SME characteristics.

A target toolset, or toolkit, for digital manufacturing has been suggested by [6], considering five families: (a) manufacturing design and production simulation tools focus on value addition and waste reduction - e.g.: manufacturing planning, layout planning, process simulation and lean manufacturing, (b) production automation tools, e.g.: CNC machining, remote monitoring, PLC programming, machine vision, RFID and barcode technology, (c) robotic tools - which can be an alternative for human labour with a positive effect on production rate and quality, e.g.: office programming, material handling, welding and trimming, (d) additive manufacturing tools - for cost-reduction - e.g.: pre-moulding, prototyping and 3D-printing, and (e) digital scanning and measuring (metrology) - for economical design and process innovation, e.g.: 3D-laser scanning, reverse engineering and quality assurance.

[9] mentioned the following tools, or toolkit, for e-manufacturing: (a) predictive intelligence (e.g.: agents, algorithms, software), (b) scalable platform, (c) information compatibility between devices and business, (d) data-to-information-to-knowledge 
transformation tools, (e) synchronization systems for dynamic decision-making (e.g., CRM, SCM, B2B e-commerce systems), (f) tether-free communication systems, (g) employee education and training, and (h) flexible enterprise culture.

Similarly, a toolset or toolkit for small-scale intelligent manufacturing systems has been proposed by [3], where three broad categories were defined: (a) ICT as the use of information and communication technology for production management, e.g.: agent technology, cloud computing, mobile technology and remote monitoring, (b) artificial intelligence (AI) techniques in manufacturing as well as technologies like CAD, CNC machines, robots and virtual reality, and (c) others technologies like rapid prototyping, 3D measurements \& inspection, reverse engineering and reconfigurable machine tools.

An Industry 4.0 toolbox has been proposed by [10], for both product and process levels, including six distinct toolboxes each. At the product level: (a) sensor and actuator integration, (b) communication/connectivity, (c) functionality of data storage and information exchange, (d) monitoring, (e) product related IT services, and (f) business models. Similarly, at the process level: (a) data processing, (b) Machine-toMachine (M2M) communication, (c) company-wide networking with production, (d) ICT-infrastructure, (e) man-machine interfaces (HMIs), and (f) efficiency with small batches.

ICT has been considered as a fundamental technology in the aforementioned toolkits [3, 5, 6 and 8], but an operationalization perspective has been only offered by the Industry 4.0 toolbox [10]. The need of ICT, data and other application technologies such as CAD, CAM and recently 3D-printing, are the other vital factors that can be observed. Business models, charts, brainstorming, employee education, training, and skills enhancement programs are other organizational practices that were contemplated. Therefore, the available scientific literature presents several (general) toolboxes from both a technical and a managerial perspective. However, based on the literature review conducted in SCOPUS and Web of Science databases, there are a limited number of SM toolkits. Although there is an Industry 4.0 toolkit [10] available, this covers only the technical perspective (i.e., product and process families) and neglects the managerial view (i.e., employees' skills enhancement and business model aspects).

Due to the imminent pressure by OEMs to digitalize their whole value chains, SMEs need more than ever support in their digital transformation. A possible way to effectively support SMEs is by providing them with a modular SM toolkit, which can help them to follow a step-by-step and building-block approach for the needed actions to adopt SM technologies and business practices, and deliver both short-term and long-term results to themselves and their value chains. The short-term benefits/results should motivate SMEs to lower the entry barrier and start their digitalization journey towards new SM capabilities, whereas the long-term benefits should bring new competitive advantages to the manufacturing enterprise.

\section{Towards a Smart Manufacturing Toolkit for SMEs}

[6] proposed a Digital Manufacturing (DM) toolkit for SMEs. DM allows SMEs to virtually prototype and test multiple products and process designs; thus reducing design risks and ultimately costs. Whereas, $S M$ will allow/enable SMEs to connect all their manufacturing resources with each other and with their products in order to optimize 
their operations. Therefore, there is a need to provide a specific SM toolkit for manufacturing SMEs, which is currently not available in literature.

Table 1 presents a set of toolboxes that integrate and conform the proposed modular SM toolkit for SMEs. The proposed SM toolkit has been developed with the help of a literature review, discussions with experts from academia based in India, Mexico, and the United States, and further refined with the help of SME managers. As a result, some of the toolboxes, which were already partially available in the literature, were refined. Others, not available yet, were developed as part of this research work. Table 1 presents a list of toolboxes and their corresponding features, various technologies, methods, tools and practices that are considered under the proposed SM toolkit and the enterprise functions that the toolboxes serve (see also Tables 2 to 9).

Table 1: SM Toolkit: Features, Examples and Corresponding SME Functions

\begin{tabular}{|c|c|c|c|}
\hline Toolboxes & Features & Examples & SME Functions \\
\hline $\begin{array}{l}\text { Manufacturing/ } \\
\text { Fabrication } \\
\text { Tools } \\
\end{array}$ & $\begin{array}{l}\text { - Used for } \\
\text { manufacturing. } \\
\text { - Human involved }\end{array}$ & $\begin{array}{l}\text { - Lathe, Casting, } \\
\text { Carpentry, Mill, } \\
\text { Welding, etc. }\end{array}$ & - Manufacturing/Production \\
\hline $\begin{array}{l}\text { Design and } \\
\text { Simulation } \\
\text { Tools } \\
\text { [3] [6] } \\
\end{array}$ & $\begin{array}{l}\text { Deployed during } \\
\text { design phase \& } \\
\text { simulating } \\
\text { production }\end{array}$ & $\begin{array}{l}\text { - Process Simulation, } \\
\text { CAD, G-codes, } \\
\text { 3D-printing, etc. }\end{array}$ & $\begin{array}{l}\text { - Product Design } \\
\text { - Process Planning } \\
\text { - Operation(s) Times Estimation } \\
\text { - Manufacturing/Production }\end{array}$ \\
\hline $\begin{array}{l}\text { Robotics and } \\
\text { Automation } \\
\text { Tools } \\
{[6]}\end{array}$ & $\begin{array}{l}\text { Tools that can } \\
\text { perform } \\
\text { repetitive work. } \\
\text { - Automated and } \\
\text { modular } \\
\end{array}$ & $\begin{array}{l}\text { - Material Handling, } \\
\text { Conveyor Belts, } \\
\text { AS/RS, etc. } \\
\text { - Scanners/Printers, } \\
\text { etc. }\end{array}$ & $\begin{array}{l}\text { - } \text { Part/Product/Transportation/ } \\
\text { - Storage } \\
\text { - } \text { Quality Control and Inspection } \\
\text { - Reverse Engineering } \\
\text { - } \text { Manufacturing/Production }\end{array}$ \\
\hline $\begin{array}{c}\text { Sensors and } \\
\text { Connectivity } \\
\text { Tools } \\
\text { [3] [9] }\end{array}$ & $\begin{array}{l}\text { - Convert outputs } \\
\text { to readable } \\
\text { formats. } \\
\text { - Support } \\
\text { communication. }\end{array}$ & $\begin{array}{l}\text { Microcontrollers, } \\
\text { Boards, Sensors, } \\
\text { Actuators, Wi-Fi, } \\
\text { M2M, Digital } \\
\text { Readouts, Mobile } \\
\text { Apps, etc. }\end{array}$ & $\begin{array}{l}\text { - Quality Control } \\
\text { - Repair and Maintenance } \\
\text { - IT } \\
\text { - Dispatching } \\
\text { - Safety }\end{array}$ \\
\hline $\begin{array}{c}\text { Cloud/Storage } \\
\text { Tools }\end{array}$ & $\begin{array}{l}\text { - Provide space } \\
\text { for data storage. } \\
\text { - Stored data is } \\
\text { shareable by } \\
\text { host. }\end{array}$ & $\begin{array}{l}\text { Google Drive, } \\
\text { Microsoft } \\
\text { OneDrive, MS } \\
\text { Azure etc. } \\
\text { - External Hard-/ } \\
\text { Optical-Drives, etc. }\end{array}$ & $\begin{array}{l}\text { - IT } \\
\text { - Supply Chain Management } \\
\text { - Storing Investments, } \\
\text { Expenses, Sales, Payrolls, Tax } \\
\text { and Compliance, etc. }\end{array}$ \\
\hline $\begin{array}{c}\text { Data Analytics } \\
\text { Tools }\end{array}$ & $\begin{array}{l}\text { - Support data } \\
\text { analytics. }\end{array}$ & $\begin{array}{l}\text { Data Analytics, AI, } \\
\text { Optimization, } \\
\text { Statistics, Machine } \\
\text { Vision, etc. }\end{array}$ & $\begin{array}{l}\text { - Decision Making } \\
\text { - Purchasing \& Sales } \\
\text { - Evaluation Methods/Products/ } \\
\text { - Process/Employees } \\
\text { - Production Planning } \\
\text { - Statistical Quality Control } \\
\text { - Data Management } \\
\text { - Product Development } \\
\end{array}$ \\
\hline $\begin{array}{c}\text { Business } \\
\text { Management } \\
\text { Tools/Principles } \\
\text { [3] [8] }\end{array}$ & $\begin{array}{l}\text { Support } \\
\text { development of } \\
\text { business models, } \\
\text { awareness and } \\
\text { organizational } \\
\text { culture. }\end{array}$ & $\begin{array}{l}\text { - Collaboration, } \\
\text { - Attending } \\
\text { workshops, } \\
\text { - Reading reports, } \\
\text { Lean Practices, etc. }\end{array}$ & $\begin{array}{l}\text { - Employee Relations } \\
\text { - Employee Development } \\
\text { - Realizing organizational short- } \\
\text { term and long-term goals } \\
\text { - Change Management } \\
\text { Strategies } \\
\text { - Strategic Planning } \\
\text { - Deploying Standards } \\
\end{array}$ \\
\hline
\end{tabular}


A modular SM toolkit for SMEs must be a stepwise and building-block instrument, always considering a continuous improvement process and various maturity levels towards developing new SM capabilities. The proposed levels are: (a) novice, when a manufacturing SME is not aware of the benefits of adopting SM technologies, (b) beginner, when an SME is informed about the benefits of adopting SM technologies and has taken the first step towards the adoption of one or more SM technologies, (c) learner, when an SME has already started its 'digitalization journey' towards SM practices, (d) intermediate, when an SME has spent sufficient time, effort and resources in practicing the SM paradigm and has develop new SM capabilities, and (e) expert, when an SME has realized new competitive advantages through its SM capabilities.

Tables 2 to 9 present seven toolboxes as key components of the modular SM toolkit for SMEs composed by various technologies, methods, tools, and practices (from Table 1), which act as enablers for the progress of a manufacturing SME through the different maturity levels to achieve new, value-adding SM capabilities. Some toolboxes may require inputs from other toolboxes for their functioning. Therefore, in Tables' column three, those inputs of other toolboxes are specified.

Toolbox 1 - Fabrication/Manufacturing Tools (FMTs): This toolbox involves production processes where humans are directly involved in the operation of different machinery tools. It might even be considered as the traditional form of manufacturing. This research work assumes the presence of manufacturing machine tools such as lathe, mill, etc. at the SME. Table 2 shows the evolution of manufacturing systems based on the inputs (enablers) required to move forward to the next SM maturity level [11] [12] when developing SM manufacturing/fabrication capabilities. [11] and [12] consider the following inputs as enablers to develop new SM capabilities in a manufacturing/ fabrication system (see Table 2). The novice level requires working dextrously with raw materials that require only hand-tools for their transformation into products, whereas at the beginner level, power-tools such pneumatic and/or electric energy machines are now needed to work more efficiently with (new) raw materials. At the learner level, numerical control machines take the stage at the shopfloor for enabling larger production volumes (of parts/products), and for the later introduction of the first manufacturing information systems (e.g. CAD in Toolbox 2) \& MES) at the intermediate level. As both learner and intermediate stage need to mention the number of parts and products, the data analytics (see Toolbox 6) may be used as well. Finally, at the expert level, an SME starts to be concerned with the sustainability of its production resources, once it has managed to effectively achieving its production objectives.

Table 2: Fabrication/Manufacturing Toolbox (FMTs) and Maturity Levels

\begin{tabular}{|c|c|c|}
\hline Inputs Required & Levels & Toolbox \\
\hline Raw Materials & Novice & FMTs \\
\hline Energy & Beginner & FMTs \\
\hline Parts & Learner & FMTs, DATs \\
\hline Orders & Intermediate & FMTs, DATs, DSTs \\
\hline Sustainable Resources & Expert & FMTs \\
\hline
\end{tabular}

Toolbox 2 - Design and Simulation Tools (DSTs): This toolbox considers the use of simulations of how actual production process should work. It involves the digital imitation of the manufacturing process environment. DST might be used during the 
design and ramp-up phase of a production line (see Table 3). The design and simulation process begins with paper-based designs, next level is when a design environment and model are present, a more sophisticated level involves software that can actually simulate how a product/part will behave in real-world, subsequently prototypes deploying 3D-printing (see Toolbox 3) may be produced using the design in the next level, and finally an interface is available for both producers and customers to actually interact with the product/part.

Table 3: Design and Simulation Toolbox (DSTs) and Maturity Levels

\begin{tabular}{|c|c|c|}
\hline Inputs Required & Levels & Toolbox \\
\hline Paper-based design & Novice & CSTs \\
\hline $\begin{array}{c}\text { Environment \& Model } \\
\text { (Design Environment) }\end{array}$ & Beginner & DSTs \\
\hline Simulation Software & Learner & DSTs \\
\hline 3D Prototypes & Intermediate & RATs \\
\hline Interface (Configurators) & Expert & SCTs \\
\hline
\end{tabular}

Toolbox 3 - Robotics and Automation Tools (RATs): This toolbox will support the elimination of strenuous and repetitive work by means of automation. Robots and other automation tools will be able to perform repetitive tasks more efficiently as compared to humans. Robots and other automation solutions will need to be installed as part of the manufacturing systems. RATs are the first step towards production automation. Since RATs need a separate investment, SMEs may consider purchasing them on the basis of their critical operations. Therefore, they can be classified in different levels that may require new hardware acquisitions during the SM maturity journey (see Table 4). The novice level of this toolbox requires manually-operated machines, whereas the beginner level involves non-programmable machines, which can be controlled by changing their basic parameters like speed, direction, etc. Moreover, at the learner level, programmable machines are introduced, while at the intermediate level, collaborative robots mimic human-motions and learn with experience. Finally, at expert level, the collaborative robots operate by deploying AI. Different families of RATs based on their functions have also been considered (see Table 5).

Table 4: Robotics and Automation Tools (RATs) and Maturity Levels

\begin{tabular}{|c|c|c|}
\hline Inputs Required & Levels & Toolbox \\
\hline Manually-Operated Machines & Novice & RATs \\
\hline Non-Programmable Machines & Beginner & RATs \\
\hline Programmable Machines & Learner & RATs \\
\hline Collaborative Robot (mimic human) & Intermediate & RATs \\
\hline Collaborative Robot (based on AI) & Expert & RATs \\
\hline
\end{tabular}

Table 5: Robotics and Automation Tools Families and Functions (RATs)

\begin{tabular}{|c|l|}
\hline Family & \multicolumn{1}{c|}{ Function } \\
\hline Quality \& Inspection & They are used for maintaining quality in the manufacturing systems. \\
\hline Pick-n-Place & They are used for inter- and intra-departmental transportation. \\
\hline
\end{tabular}

Toolbox 4 - Sensors and Connectivity Tools (SCTs): This toolbox includes sensors that can convert manufacturing processes outputs into readable formats. Their installation in machine tools helps to measure the required data for a better production 
management. Thus, helping in networking and sharing the data/information needed for a smart production planning and control [13]. The first level of this toolbox requires a source in the form of a physical body like raw materials (see FMT) or tools (see RBT), the second level requires sensors that can sit on the source, in the third level, the sensors will be able to convert the signals in readable formats, at the fourth level, the data can be stored, and finally at the expert level the user is able to operate with the help of an interface (see Table 6).

Table 6: Sensors and Connectivity Toolbox (SCTs) and Maturity Levels

\begin{tabular}{|c|c|c|}
\hline Inputs Required & Levels & Toolbox \\
\hline Source & Novice & FMTs, RBTs \\
\hline Sensors & Beginner & SCTs \\
\hline Signals and Converters & Learner & SCTs \\
\hline Storage & Intermediate & CSTs \\
\hline Interface & Expert & SCTs \\
\hline
\end{tabular}

Toolbox 5 - Cloud/Storage Tools (CSTs): This toolbox enables to store and share data. Nowadays, there is an abundance of online/cloud platforms that provide various facilities for data storage and sharing. For SMEs, the CST toolbox (see Table 7) begins with registering data by manually entering it in paper-based logbooks or spreadsheets to store data, in the second level, data storage is made in built-in hard drives (HDs), whereas in the third level, data store is made in shared HDs (i.e., flash drives, intranet, etc.), finally as data increases, massive data storage may be required based on cloud and/or fog solutions corresponding to the fourth and fifth maturity levels respectively. The difference between these two levels is minor as both fog and cloud have similar resources and services. But fog is able to reduce network congestion and latency [14].

Table 7: Cloud/Storage Toolbox (CSTs) and Maturity Levels

\begin{tabular}{|c|c|c|}
\hline Inputs Required & Levels & Toolbox \\
\hline $\begin{array}{c}\text { Registers, Logbooks, } \\
\text { Spreadsheets }\end{array}$ & Novice & CSTs \\
\hline Built-in HDs & Beginner & CSTs \\
\hline Shared HDs & Learner & CSTs \\
\hline Cloud & Intermediate & CSTs \\
\hline Fog & Expert & CSTs \\
\hline
\end{tabular}

Toolbox 6 - Data Analytics Tools (DATs): This toolbox contains methods for data analytics. It includes a large family of statistical methods, optimization techniques, heuristics, etc. There are five main levels of data analytics [15]. During the first level, data collection is done by the input sources mentioned in Table 7; in the beginner level, data is cleaned; in the learner level, the meaningful data from various sources is combined; at the next level, data is reduced with the help of various rules; and finally data is transformed or normalized to avoid, e.g., redundancies (Table 8).

Table 8: Data Analytics Toolbox and Maturity Levels (DATs) [15]

\begin{tabular}{|c|c|c|}
\hline Inputs Required (Processes) & Levels & Toolbox \\
\hline Data collection & Novice & CSTs \\
\hline Data cleaning & Beginner & DATs \\
\hline Data integration & Learner & DATs \\
\hline Data reduction & Intermediate & DATs \\
\hline Data transformation & Expert & DATs \\
\hline
\end{tabular}


Toolbox 7 - Business Management Tools (BMTs): This toolbox involves a lot more than technology. For example, it deals with practices that manufacturing SMEs need to develop and follow as part of a new SM culture. This toolkit considers managerial oriented aspects towards an SM culture such as employees' skills enhancement, lean culture, employee/employer shared mind-sets, positive organizational culture, keeping the organization updated about the latest trends in SM with the help of workshops, seminars and reading grey papers. Since this toolbox motivates the SME at all levels towards an SM culture and practice, therefore, this toolbox is one of the most essential and might be considered as a foundation for successfully developing SM capabilities. This toolbox considers also the five maturity levels defined for each of the business principles included, since the adoption of new business practices comes together with the adoption of the other technology-based SM toolboxes and vice versa. Selected BMT tools have been described in Table 9.

Table 9: Business Management Toolbox (BMTs) [Adapted from 16]

\begin{tabular}{|c|l|}
\hline Principle/Practices & \multicolumn{1}{c|}{ Description } \\
\hline Lean Thinking & Eliminating all forms of waste in a production process. \\
\hline Organizational Culture & System where employees share the same set of beliefs and values. \\
\hline Employee Involvement & $\begin{array}{l}\text { Activity where employees (not involved in R\&D) can share their } \\
\text { ideas, knowledge and play a role in organisation's decisions. }\end{array}$ \\
\hline Customer Involvement & Products are designed based on customer voice/feedbacks. \\
\hline Collaboration & Products are designed considering supplier feedbacks. \\
\hline
\end{tabular}

As observed from Tables 2 to 9, a combination of different tools from several toolboxes might be required before the stepwise deployment of a particular toolbox. Implementing IoT technology requires sensors and actuators to be installed, Wi-Fi connectivity, data storage, and data analysis. Therefore, it will need to integrate SCTs, CSTs and DATs toolboxes.

\section{Demonstration Case Studies}

In addition to introducing the toolboxes as a means of integrating the proposed modular SM toolkit, it is important to identify the issues faced by SMEs during their adoption as well as how the proposed toolboxes may be deployed. As a result, this paper presents two short cases studies, where we present a stepwise deployment of the SM toolkit.

Digital Read Outs in Lathes and Mills: Two seasoned analogue lathe and mill machines had been lacking the needed accuracy on the shop floor. Job accuracy was mainly dependent on the skill and the experience of their individual operators. Considering budget constraints, the SME owner installed digital readouts (DROs). The DROs deployment made possible to ensure that the actual displacement with reference point is shown on the screen and the operator was no longer expected to set the zero for DROs repeatedly. The DROs may be considered as a part of the SCTs toolbox. Since a screen was attached to the lathe and mill itself (see Fig. 1), therefore, the wireless connectivity was not required in this case. Table 10 presents the various levels for installing the DROs in lathe and mill machine tools and shows how the toolbox helped the lathe and mill to shift from a "novice" to a "learner" - in the SCT toolbox levels. 

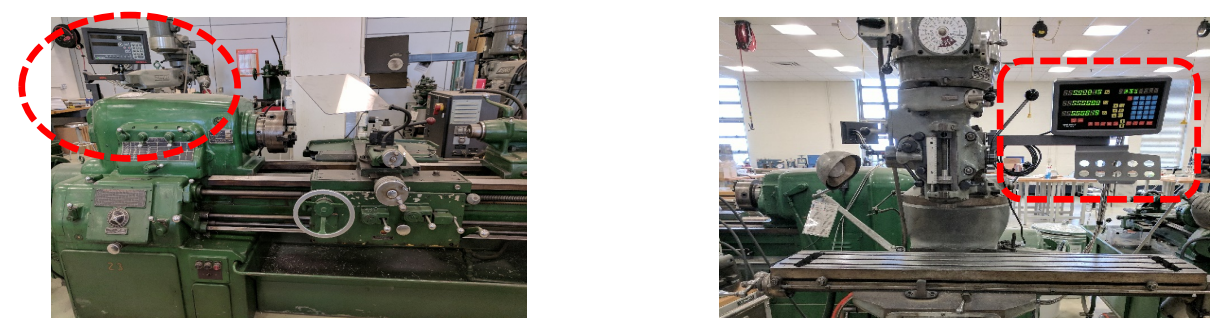

Figure 1. Smart Lathe (left) and Smart Mill (right) after DROs Installantion

Table 10: SCTs Toolbox for DRO Installation in Lathe and Mill Machine Tools

\begin{tabular}{|c|c|c|}
\hline Inputs Required & Levels Went Through & Toolboxes Required \\
\hline Lathe/Mill & Novice & FMTs \\
\hline DRO Sensors & Beginner & SCTs \\
\hline Signals, Converters & Learner & SCTs \\
\hline
\end{tabular}

Visual Inspection in Garment Industry: The SME was facing problems with manual inspections. The defects identification in the garment varied based on the subjective judgement of the worker the hour of the day. As a result, to improve the consistency in identifying defects and quality problems, an installation of a fabric inspection machine was suggested. For this improvement project, the RATs toolbox would be used and it will help the SME to make the cloth inspection more consistent. The fabric inspection machine will have a light box installed under the platform for inspecting the garment, also allowing the worker to adjust the speed of roll. Since the visual inspection machine will be operated by a human, therefore, it can be considered that the inspection process in the Garment industry shifted from a "novice" to a "beginner" (see Table 11). Additionally, if a digital fabric inspection machine is installed the fibre defects can be detected with the help of the sensors [17].

Table 11: RATs Toolbox for Visual Inspection Installation in Garment Industry

\begin{tabular}{|c|c|c|}
\hline Inputs Required & Levels Went Through & Toolboxes Required \\
\hline Manually-Operated Machines & Novice & RATs \\
\hline Non-Programmable Machines & Beginner & RATs \\
\hline
\end{tabular}

\section{Conclusions and Further Research}

This paper presents a modular SM toolkit for SMEs consisting of seven individual toolboxes. Six toolboxes are technical in nature (fabrication/manufacturing; design and simulation; robotics and automation; sensors and connectivity; cloud/storage; data analytics), while one is managerial-oriented (business management). Moreover, the robotics toolbox has been accompanied with a robotics tools' families and functions sub-toolbox.

The technically oriented toolboxes have been complemented by selected business management tools via the seventh business management toolbox (see Table 9). The reason for this seventh toolbox is that to deploy successfully the SM toolkit, a change in the SMEs mind-set is required as well as a change in their organizational culture and other management aspects. Therefore, the proposed SM toolkit includes both technical 
and business management toolboxes. The stepwise and building-block approach of the SM toolkit is matched with SME specific requirements for its easy adoption by SMEs.

Although, the application of selected toolboxes (i.e. [3], [5], [6], [8] and 10]) has been demonstrated in an industrial setting, their full evaluation is a long-term commitment. Hence, the full validation of the proposed modular SM toolkit for SMEs is part of our planned future work. Our future work will additionally include the deployment of all presented SM toolboxes in more SMEs and the development of a corresponding SM maturity model for SMEs $\left(\mathrm{SM}^{3} \mathrm{E}\right)$ creating a comprehensive support system for SMEs.

\section{References}

1. Kusiak, A.: Smart Manufacturing. Int'1. J. of Production Research, pp. 1-10 (2017)

2. Mittal, S., Khan, M.A., Romero, D., Wuest, T.: Smart Manufacturing: Characteristics, Technologies and Enabling Factors. Part B: Journal of Engineering Manufacture (2017)

3. Huang, T.: Development of Small-Scale Intelligent Manufacturing Systems (SIMS): A Case Study at Stella Polaris AS, Master Thesis, Artic University of Norway (2016)

4. Esmaeilian, B., Sara, B., Ben W.: The Evolution and Future of Manufacturing: A Review. Journal of Manufacturing Systems, 39: 79-100 (2016)

5. Belekoukias, I., Garza-Reyes, J.A., Kumar, V.: The Impact of Lean Methods and Tools on the Operational Performance of Manufacturing Organisations. Int'l. J. of Production Research, 52(18):5346-5366 (2014)

6. Kaartinen, H., Pieskä, S., Vähäsöyrinki, J.: Digital Manufacturing Toolbox for Supporting the Manufacturing SMEs. $7^{\text {th }}$ IEEE Int'1. C. Cognitive Infocommunications, 71-76 (2016)

7. Odedairo, B.O., Bell, D.: Framework for Introducing and Implementing Value Methods: A Novel Toolkit for Small \& Medium Scale Industries in Developing Nations. Int'1. J. of Basic \& Applied Sciences, 9(10):130-146 (2010)

8. Alaskari, O., Ahmad, M. M., Pinedo-Cuenca, R.: Development of a Methodology to Assist Manufacturing SMEs in the Selection of Appropriate Lean Tools. International Journal of Lean Six Sigma, 7(1):62-84 (2016)

9. Lee, J.: e-Manufacturing: Fundamental, Tools, and Transformation. Robotics \& ComputerIntegrated Manufacturing, 19(6):501-507 (2003)

10. Anderl, R., Picard, A., Wang, Y., Fleischer, J., Dosch, S., Klee, B. and Bauer, J.: Guideline Industrie 4.0: Guiding Principles for the Implementation of Industrie 4.0 in Small and Medium Sized Businesses. VDMA Forum Industrie, Vol. 4 (2015)

11. Cusumano, M.A.: Shifting Economies: From Craft Production to Flexible Systems and Software Factories. Research Policy, 21(5):453-480 (1992)

12. Bi, Z., Da Xu, L., Wang, C.: Internet of Things for Enterprise Systems of Modern Manufacturing. IEEE Transactions on Industrial Informatics, 10(2):1537-1546 (2014)

13. Nelles, J., Kuz, S., Mertens, A., and Schlick, C. M.: Human-Centered Design of Assistance Systems for Production Planning and Control: The Role of the Human in Industry 4.0. In Industrial Technology (ICIT), IEEE Int'1. Conference: 2099-2104 (2016)

14. Osanaiye, O., et al.: From Cloud to Fog Computing: A Review and a Conceptual Live VM Migration Framework. IEEE Access, 5: 8284-8300 (2017)

15. Han, J., Pei, J., Kamber, M.: Data Mining: Concepts and Techniques. Elsevier (2011)

16. Vrande, V., De Jong, J., Vanhaverbeke, W., De Rochemont, M.: Open Innovation in SMEs: Trends, Motives and Management Challenges. Technovation, 29(6-7):423-437 (2009)

17. Li, Y., Ai, J. and Sun, C.: Online Fabric Defect Inspection using Smart Visual Sensors. Sensors, 13(4):4659-4673 (2013) 


\section{Original Papers}

\section{Publication V}

Towards a Smart Manufacturing Maturity Model for SMEs $\left(\mathrm{SM}^{3} \mathrm{E}\right)$

By

Sameer Mittal, David Romero and Thorsten Wuest, August 2018

Mittal, S., Romero, D., \& Wuest, T. (2018, August). Towards a Smart Manufacturing Maturity Model for SMEs (SM 3 E). In IFIP International Conference on Advances in Production Management Systems (pp. 155-163). Springer, Cham.

2018 Springer Nature. Print rights for final author's accepted manuscript. 


\title{
Towards a Smart Manufacturing Maturity Model for SMEs $\left(\mathbf{S M}^{3} \mathbf{E}\right)$
}

\author{
Sameer Mittal ${ }^{1}$, David Romero ${ }^{2}$, Thorsten Wuest ${ }^{1}$ (corr. author) \\ ${ }^{1}$ Industrial and Management Systems Engineering, Benjamin M. Statler College of \\ Engineering and Mineral Resources, West Virginia University, Morgantown, WV, USA \\ samittal@mix.wvu.edu, thwuestemail.wvu.edu \\ ${ }^{2}$ Tecnológico de Monterrey, Mexico \\ david.romero.diaz@gmail.com
}

\begin{abstract}
This paper proposes a new Smart Manufacturing Maturity Model for small and medium-sized Enterprises $\left(\mathrm{SM}^{3} \mathrm{E}\right)$. The $\mathrm{SM}^{3} \mathrm{E}$ maturity model supports SMEs during the challenging digital transformation journey and paradigm shift towards Smart Manufacturing and Industry 4.0 on three-axis: (i) organizational dimensions, (ii) toolboxes, and (iii) maturity levels. The $\mathrm{SM}^{3} \mathrm{E}$ maturity model development was based on a literature and critical review as well as interviews conducted during industrial visits. During these visits, SME specific requirements were collected, assessed and taken into account during the development of the $\mathrm{SM}^{3} \mathrm{E}$ maturity model. Overall, an analysis of maturity levels, based on the working methods and toolboxes of our $\mathrm{SM}^{3} \mathrm{E}$ maturity model will help SMEs to progress towards Smart Manufacturing and Industry 4.0.
\end{abstract}

Keywords: Digitalization, SMEs, Industry 4.0, Smart Manufacturing, Intelligent Manufacturing, Maturity Model, Working Methods, Toolboxes, Toolkit.

\section{Introduction}

Small and Medium-sized Enterprises (SMEs), especially those in the manufacturing sector, have always been considered as the backbone of the economy [1-4] for both developed and developing countries. However, their perspective has not always been taken into account when it comes to the framing of appropriate Industry 4.0 policies. Similarly is the case for the guidelines of Smart Manufacturing Initiatives in countries such as the U.S. (i.e., Smart Manufacturing), Germany (i.e., Industrie 4.0) and South Korea (i.e., Smart Factory) where specific directions for SMEs are missing [5-6]. These SM Initiatives aim at accelerating the growth of the economy by capitalizing on the new digital engines of growth (e.g., connectivity, intelligence, and flexible automation) offered by the Fourth Industrial Revolution (4IR). Nevertheless, by not considering the perspective of SMEs, their confined growth might have adverse effects on the overall growth of the economy and creation of true smart global value chains.

Maturity models are capable of identifying a set of "conditions when the examined objects reach the best (perfect) state for their intended purpose" [7]. Although literature shows several SM/Industry 4.0 maturity models for large enterprises [e.g., 8-16], it fails to present an SME perspective. The organizational dimensions and maturity levels for large enterprises need to be altered to reflect the different requirements of SMEs. Thus far, there are no "self-assessment methods" for SMEs, which support their digital transformation. Therefore, SMEs are often forced to either hire external experts (e.g., 
consultants or service providers), and thus straining their already limited resources, or slow down their activities to ramp-up their Smart Manufacturing (SM) journey.

This paper is divided into five sections. Section 1 presents the overall research problem. Section 2 identifies the research gap based on current literature and critical review augmented by interviews conducted during industrial visits to SMEs. Section 3 introduces our $\mathrm{SM}^{3} \mathrm{E}$ maturity model, a three-axis model composed by organizational dimensions, toolboxes and maturity levels. Section 4 presents an exemplary application of the $\mathrm{SM}^{3} \mathrm{E}$ maturity model's 'cloud/storage toolbox' towards the development of the SM capability 'data-driven decision making'. Section 5 concludes the paper with a summary of the results, limitations and an outlook on future work.

\section{Literature Review}

The most popular, based on citations, maturity models in the literature [8-16] do not sufficiently reflected an SME specific perspective and their unique requirements when it comes to adopting the SM/Industry 4.0 paradigm. Table 1 depicts nine current maturity models that mainly cater for large enterprises and do not represent SMEs' specific requirements. Only [10] has partially considered an SME perspective, but falls short in clearly defining 'organizational dimensions', thus making its utilization unrealistic for SMEs. Hence, organizational dimensions represent the organizational areas and/or enterprise functions of an organization, and the maturity levels provide a stepwise approach towards "maturity" in each of these organizational dimensions [17].

Table 1. Maturity Models' Dimensions and Levels

\begin{tabular}{|c|c|c|c|}
\hline Paper & Organizational Dimensions & Maturity Levels & SME Persp. \\
\hline$[8]$ & $\begin{array}{l}\text { Nine dimensions: strategy, leadership, } \\
\text { customers, products, operations, culture, } \\
\text { people, governance, and technology. }\end{array}$ & Not defined. & Not considered \\
\hline [9] & $\begin{array}{l}\text { Four dimensions: organizational maturity, } \\
\text { information technology maturity, } \\
\text { performance management maturity, and } \\
\text { information connectivity maturity. }\end{array}$ & $\begin{array}{l}\text { Activity maturing scoring scale } \\
\text { based on a task-score of } 0 \text { to } 9 \text { : } \\
\text { not performed }(0) \text {, initial (1), } \\
\text { managed (3), defined (5), } \\
\text { qualitative ( } 7) \text {, optimizing (9) }\end{array}$ & Not considered \\
\hline$[10]$ & Not defined. & $\begin{array}{l}\text { Three stage maturity model: } \\
\text { initial, managed, and defined. }\end{array}$ & Considered \\
\hline$[11]$ & $\begin{array}{l}\text { Six dimensions: strategy and organization, } \\
\text { smart factory, smart operations, smart } \\
\text { products, data-driven services, and } \\
\text { employees. }\end{array}$ & $\begin{array}{l}\text { Six stage maturity model: } \\
\text { outsider, beginner, } \\
\text { intermediate, experienced, } \\
\text { expert, top performer }\end{array}$ & Not considered \\
\hline [12] & $\begin{array}{l}\text { Seven dimensions: digital business models } \\
\text { and customer access, digitization of product } \\
\text { and service offerings, digitization and } \\
\text { integration of vertical and horizontal value } \\
\text { chains, data \& analytics as core-capability, } \\
\text { agile IT architecture, compliance security, } \\
\text { legal and tax, and organization employees } \\
\text { and digital culture. }\end{array}$ & $\begin{array}{l}\text { Four stage maturity model: } \\
\text { digital novice, vertical } \\
\text { integration, horizontal } \\
\text { collaborator, and digital } \\
\text { champion. }\end{array}$ & Not considered \\
\hline [13] & $\begin{array}{l}\text { Four dimensions: resources, information } \\
\text { systems, organization structure and } \\
\text { organizational culture. }\end{array}$ & $\begin{array}{l}\text { Six stage maturity model: } \\
\text { computerization, connectivity, } \\
\text { visibility, transparency, } \\
\text { predictability, and adaptability. }\end{array}$ & Not considered \\
\hline
\end{tabular}




\begin{tabular}{|c|l|l|l|}
\hline$[14]$ & $\begin{array}{l}\text { Four dimensions: information infrastructure, } \\
\text { (incl. hard- / software), controls \& devices } \\
\text { (e.g., sensors, actuators, motor controls, } \\
\text { switches, and feed \& receive data), networks } \\
\text { (enabling information exchange), and } \\
\text { security policies. }\end{array}$ & $\begin{array}{l}\text { Five stage maturity model: } \\
\text { assessment, secure and } \\
\text { upgraded network and controls, } \\
\text { defined and organized working } \\
\text { data capital, analytics, and } \\
\text { collaboration. }\end{array}$ & Not considered \\
\hline$[15]$ & $\begin{array}{l}\text { Five dimensions: asset management, data } \\
\text { governance, application management, } \\
\text { process transformation, and organizational } \\
\text { alignment. }\end{array}$ & $\begin{array}{l}\text { Six level (0-5) maturity model: } \\
\text { incomplete, performed, } \\
\text { managed, established, } \\
\text { predictable, and optimizing. }\end{array}$ & Not considered \\
\hline$[16]$ & $\begin{array}{l}\text { Three dimensions: smart products and } \\
\text { services, smart business processes, and } \\
\text { strategy and organization. }\end{array}$ & $\begin{array}{l}\text { Four level (0-3) maturity } \\
\text { model: absence, existence, } \\
\text { survived, and maturity. }\end{array}$ & Not considered \\
\hline
\end{tabular}

\section{Towards a Smart Manufacturing Maturity Model for SMEs}

Maturity models often define each of their levels in terms of components and subcomponents, and the validity of these elements is mainly confirmed with the help of industrial surveys [18]. This makes maturity models a viable option to support manufacturing SMEs towards successfully realizing SM/Industry 4.0 capabilities.

Our proposed $S M^{3} E$ maturity model is a three-axis model (see Fig. 1), addresses five key organizational areas and/or enterprise functions of an SME, from now on referred to as organizational dimensions (X-axis), includes a modular toolkit composed of seven individual complementary toolboxes (Y-axis), which supports a stepwise approach through five maturity levels (Z-axis).

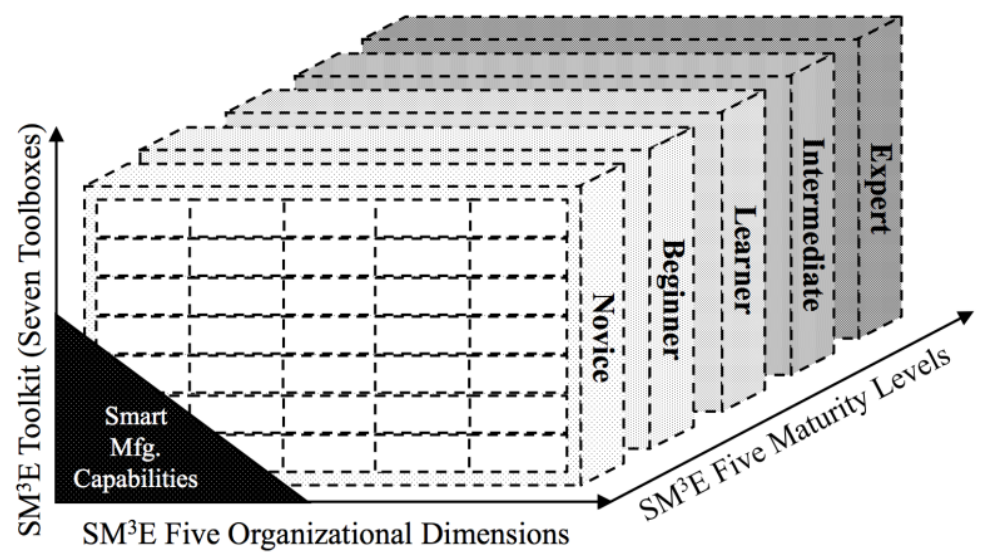

Fig. 1. The Smart Manufacturing Maturity Model for SMEs $\left(\mathrm{SM}^{3} \mathrm{E}\right)$

By adopting our $S M^{3} E$ maturity model, an SME will be able to assess and place itself in one of five maturity levels for each of its five key organizational dimensions. Thus, the SME would be able to identify the input and/or support required to reach the next level of maturity in an organization dimension, which can be provided by dedicated toolboxes. A toolbox enables an SME to perform more sophisticated activities in the respective dimension(s). The next sub-sections detail each of the three-axes of the $S M^{3} E$ maturity model: organizational dimensions, maturity levels and toolboxes. 


\subsection{SM${ }^{3}$ E Organizational Dimensions}

SM is about the connectivity, virtualization, and data utilization of manufacturing systems and beyond. The main focus is on manufacturing operations' performance. However, there are other organizational dimensions, beyond the purely technical ones, that have not yet been included in current maturity models. An example of such nontechnical organizational dimensions is "finance". In order to truly support a holistic digital transformation of an enterprise those have to be reflected in the maturity model as well. Hence, in order to provide the best possible support to an SME that is willing to start its SM journey, the SME must be holistically informed about all the benefits of achieving the highest maturity level of the respective organizational dimensions. This information will build confidence and motivate the SME to move towards the development of SM/Industry 4.0 capabilities. SMEs have to balance different factors stemming from the evolution of manufacturing systems [19]. We took this into careful consideration when designing the organizational dimensions and sub-dimensions included in the $\mathrm{SM}^{3} \mathrm{E}$ maturity model (see Table 2). They all were selected based on the alignment with an SME perspective and their specific requirements and are aimed to "mimic" the typical organization structure and basic enterprise functions of a small business for easier adoption by SME managers during the SM journey.

Table 2. Organizational Dimensions and Sub-dimensions of $\mathrm{SM}^{3} \mathrm{E}$ Maturity Model

\begin{tabular}{|c|c|c|c|c|c|}
\hline Dim. & Finance & People & Strategy & Process & Product \\
\hline $\begin{array}{l}\text { Sub- } \\
\text { dim. }\end{array}$ & $\begin{array}{l}\text { - Cost-Benefit } \\
\text { Analysis } \\
\text { - Budgeting and } \\
\text { Costs Control } \\
\text { - Investments } \\
\text { Risk and } \\
\text { Returns } \\
\text { Management }\end{array}$ & $\begin{array}{l}\text { - Leadership } \\
\text { - Customer } \\
\text { Feedback } \\
\text { - Safety and } \\
\text { Ergonomics } \\
\text { - Training and } \\
\text { Education }\end{array}$ & $\begin{array}{l}\text { - Knowledge } \\
\text { Management } \\
\text { - Decision Support/ } \\
\text { Decision Making } \\
\text { - Standards } \\
\text { - Legal/Tax Policies } \\
\text { - Sustainability } \\
\text { Guidelines } \\
\text { - Government } \\
\text { Regulations }\end{array}$ & $\begin{array}{l}\text { - Quality Control } \\
\text { - Job Scheduling } \\
\text { - Repair and } \\
\text { Maintenance } \\
\text { - Machines } \\
\text { Operation } \\
\text { - Flexibility }\end{array}$ & $\begin{array}{l}\text { - Logistics } \\
\text { - New Product } \\
\text { Development } \\
\text { - Packaging } \\
\text { - Modularity } \\
\text { - Time to Market }\end{array}$ \\
\hline
\end{tabular}

Dimension 1: Finance. This dimension is focussing on how the SME is managing its economics (i.e., financial accounting). Existing data is often managed in the form of balance sheets, income statements, cash flow statements, and investment portfolios. Cost-benefit analysis, budgeting, and costs control, as well as investments risk and return management, are the SME's primary concerns (sub-dimensions). In this sense, an accounting computer-based information system can provide a transparent and secure method (data) to help SMEs to manage their SM project.

Dimension 2: People. This dimension considers different organizational and cultural aspects such as an encouraging "leadership" and vision towards SM/Industry 4.0 [8] [20]. An organizational culture that is prepared to learn and evolve as well as to look ahead is positive for employee motivation [9] [11] [13] [15], and "customer feedback" in product development [8]. However, there may be some additional subdimensions that organizations need to consider, such as employees "safety and ergonomics" practices in order to have more productive employees and avoid medical expenditure due to occupational accidents. Here, data exists in the form of payroll- 
sheets (e.g., number of employees) and work schedules-sheets (e.g., workhours, shifts), which can help SMEs to better manage the personnel involved in their SM project. Moreover, allowing employees to attend workshops and seminars will help them to embrace new working methods and technologies, and up-skill/re-skill themselves (i.e., training and education) for the new Industry 4.0 workplace.

Dimension 3: Strategy. This dimension has been previously discussed in the literature [8] [16]. However, this dimension might overwhelm SMEs since they are more likely to focus on tactics and operations to run their daily business. When it comes to the SM journey, the most important 'strategy' for an SME, currently missing in literature, is how to utilize its data strategically (i.e., data/information/knowledge management). Unlike many large enterprises, SMEs do not have an enormous amount of data readily available. However, SMEs have the versatile expertise of their employees, who often work in different domains and if their experience is augmented by supporting data (i.e., other computer-based enterprise information systems), the SME might be able to make better decisions. Similarly, "decision-making" should involve employees from different areas, rather than just relying on the instinct and limited market research of the SME managers. Moreover, SMEs are not always fully aware of the "industrial standards" they need to obey - e.g., new "legal \& tax policies", "sustainability guidelines", and "government regulations" that might benefit their growth (i.e., incentives). Therefore, 'strategy' is another important dimension of our $S M^{3} E$ model, where data occurs in the form of targets, performance metrics, ranks, etc.

Dimension 4: Process. The steps involved in the transformation of a product from raw material to final product fall under the 'process' organizational dimension. This dimension has been considered by [20] as a key element for measuring the potential of an SME for becoming a smart factory. The key aspects (or sub-dimensions) of this organizational dimension are: "quality control", "job scheduling", "repair and maintenance", "machines operation", and "flexibility" [21]. Furthermore, data exists in the form of process parameters, machine downtimes, etc., documented in manuals and spreadsheets. Therefore, it is important to provide clear instructions to support employees in the execution of the key business processes of a manufacturing SME (i.e., sales, manufacturing, and delivery).

Dimension 5: Product. This organizational dimension includes the business activities (or sub-dimensions) of "logistics", "new product development", "packaging", "product modularity", and "time to market" [21]. In this case, data exists in the form of product specifications, the number of products, etc. The 'product' organizational dimension considers product logistics inside and outside the shopfloor environment, the development of new products, and making the product(s) available by reducing the time-to-market.

\section{2 $\mathrm{SM}^{3} \mathrm{E}$ Maturity Levels}

The $\mathrm{SM}^{3} \mathrm{E}$ model acknowledges the common number of levels in maturity models (e.g., CMMI), and considers the following five levels: (i) Novice represents organizations, largely unaware of the SM/Industry 4.0 paradigm, (ii) Beginner signifies a recent awareness and basic notion of the SM/Industry 4.0 paradigm, (iii) Learner stands for 
an SME that has started to experiment with SM/Industry 4.0 technologies, (iv) Intermediate implies successful pilot projects with SM/Industry 4.0 technologies in different organizational domains, finally (v) Expert embodies an SME deploying $\mathrm{SM} /$ Industry 4.0 technologies in a strategic way, and therefore it might be referred to as an "SME 4.0".

\section{3 $\mathrm{SM}^{3} \mathrm{E}$ Toolkit (Toolboxes)}

A toolkit is a set of methods, tools, and practices that can lead towards a final goal [22]. The $S M^{3} E$ maturity model toolkit is composed of seven toolboxes: (i) manufacturing/ fabrication toolbox, (ii) design and simulation toolbox, (iii) robotics and automation toolbox, (iv) sensors and connectivity toolbox, (v) cloud/storage toolbox, (vi) data analytics toolbox, and (vii) business management toolbox (please read [22] for details on the SM toolkit). The rationale behind these seven toolboxes is to include various technologies, skills and business practices that can serve both the technical and managerial aspects required in an SME to adopt the SM/Industry 4.0 paradigm.

\section{Exemplary Usage of the $\mathrm{SM}^{3} \mathrm{E}$ Cloud/Storage Toolbox}

Due to pages length limitation, only the application/usage of the $S M^{3} E$ maturity model's cloud/storage toolbox will be detailed in this paper as an example. The toolbox focuses on "data/information storage support" as an enabler for "data-driven decision making", and it needs different "input requirements" depending on its maturity level like registers, logbooks and spreadsheets (novice), built-in hard drives (beginner), shared hard drives (HDs) (learners), cloud computing (intermediate), and fog computing (expert) in order to create a "data-rich environment" to successfully support decisionmaking in an SM environment (see Table 3).

Table 3. SM르 Maturity Model's Cloud/Storage Toolbox

\begin{tabular}{|c|c|c|c|c|c|}
\hline Dimension & Novice & Beginner & Learner & Intermediate & Expert \\
\hline Finance & $\begin{array}{c}\text { Store financial } \\
\text { data using } \\
\text { spreadsheets }\end{array}$ & $\begin{array}{c}\text { Store financial } \\
\text { data using hard } \\
\text { drives }\end{array}$ & $\begin{array}{c}\text { Store financial } \\
\text { data using } \\
\text { shared HDs }\end{array}$ & $\begin{array}{c}\text { Store financial } \\
\text { data using cloud }\end{array}$ & $\begin{array}{c}\text { Store financial } \\
\text { data using fog }\end{array}$ \\
\hline Ptrategy & $\begin{array}{c}\text { Store people's } \\
\text { data using } \\
\text { spreadsheets }\end{array}$ & $\begin{array}{c}\text { Store people's } \\
\text { data using hard } \\
\text { drives }\end{array}$ & $\begin{array}{c}\text { Store people's } \\
\text { data using } \\
\text { shared HDs }\end{array}$ & $\begin{array}{c}\text { Store people's } \\
\text { data using cloud }\end{array}$ & $\begin{array}{c}\text { Store people's } \\
\text { data using fog }\end{array}$ \\
\hline Process & $\begin{array}{c}\text { Store process } \\
\text { data using } \\
\text { spreadsheets }\end{array}$ & $\begin{array}{c}\text { Store process } \\
\text { data using hard } \\
\text { drives }\end{array}$ & $\begin{array}{c}\text { Store process } \\
\text { data using } \\
\text { shared HDs }\end{array}$ & $\begin{array}{c}\text { Store process } \\
\text { data using cloud }\end{array}$ & $\begin{array}{c}\text { Store process } \\
\text { data using fog }\end{array}$ \\
\hline Product & $\begin{array}{c}\text { Store product } \\
\text { data using } \\
\text { spreadsheets }\end{array}$ & $\begin{array}{c}\text { Store product } \\
\text { data using hard } \\
\text { drives }\end{array}$ & $\begin{array}{c}\text { Store product } \\
\text { data using } \\
\text { shared HDs }\end{array}$ & $\begin{array}{c}\text { Store product } \\
\text { data using cloud }\end{array}$ & $\begin{array}{c}\text { Store product } \\
\text { data using fog }\end{array}$ \\
\hline
\end{tabular}

Table 3 illustrates that not all organizational dimensions, in this case 'strategy', are affected by the cloud/storage toolbox. Additionally, some toolboxes may depend on other toolboxes/toolbox to perform their function. For example, the data stored in Table 3 have to be analyzed with the help of data analytics toolbox to truly create a "datadriven decision making" capability. The first level (novice) of data analytics toolbox is 
data collection, which is performed by the cloud/storage toolbox. The other maturity levels are data cleaning (beginner), data integration (learner), data reduction (intermediate) and data transformation (expert) respectively. These maturity levels are performed utilizing various statistical, optimization, machine learning, and artificial intelligence techniques. In case an SME uses only registers, logbooks and spreadsheets for their data collection, they can only support some short-term decision making processes, like planning for the number of products to be manufactured, the scheduling of workers shifts, etc. They will not be able to know the exact position of their product within the supply chain (i.e., traceability). On the other hand, if they can store data in the cloud (intermediate level), they might be able to get the shared and updated data from their customers, and therefore, they might be able to make better medium- and long-term decisions on the number of products to be produced and the scheduling of workers shifts. Similarly, they may now have the capability to know the location of their products across the supply chain. As an SME shifts towards the 'expert' maturity level, its overall awareness of its operational system increases. Thus, leading to a better, more mature, "data-driven decision making" capability.

\section{Results, Limitations and Future Work}

This paper introduced our new $S M^{3} E$ maturity model composed of five organizational dimensions, seven toolboxes and five maturity levels aimed at support manufacturing SMEs in their digital transformation towards SM/Industry 4.0.

An exemplary case based on the $S M^{3} E$ maturity model's cloud/storage toolbox was presented to showcase how data is stored and utilized based on the different organizational dimensions and maturity levels. This includes the use of different technologies from the toolboxes in order to create a "data-driven decision making" capability for the SME. Furthermore, it was illustrated how the different $S M^{3} E$ maturity model's toolboxes work together, in this case, to enhance the "data-driven decision making" capability in the discussion, i.e., the data analytics toolbox with the cloud/storage toolbox.

The limitation of this paper is that it presents only one (digital) capability: "datadriven decision making", which can be performed by deploying in this case the cloud/ storage toolbox in combination with the data analytical toolbox.

Future work will focus on the refinement and validation with SMEs of the proposed $S M^{3} E$ maturity model, and the later development of the adoption guidelines.

\section{References}

1. Husin, M.A., Ibrahim, M.D.: The Role of Accounting Services and Impact on SMEs Performance in Manufacturing Sector from East Coast Region of Malaysia: A Conceptual Paper. Procedia-Social and Behavioral Sciences, 115:54-67 (2014)

2. Tuyon, J., et al.: The Role of Microfinance in Development of Micro Enterprises in Malaysia. Business \& Management Quarterly Review, 2(3):47-57 (2011)

3. Jankowska, B., Götz, M., Główka, C.: Intra-Cluster Cooperation Enhancing SMEs' Competitiveness - The Role of Cluster Organisations in Poland. Investigaciones Regionales 39:195-214 (2017) 
4. Schiersch, A.: Inefficiency in the German Mechanical Engineering Sector. DIW Berlin, Discussion Paper No. 1949 (2009)

5. Maier, A., Student, D.: Industrie 4.0 - Der Große Selbstbetrug [In German] (2015) http://www.manager-magazin.de/magazin/artikel/digitale-revolution-industrie-4-0ueberfordert-deutschen-mittelstand-a-1015724.html

6. Balasingham, K.: Industry 4.0: Securing the Future for German Manufacturing Companies. Master's Thesis, University of Twente (2016)

7. Wendler, R.: The Maturity of Maturity Model Research: A Systematic Mapping Study. Information and Software Technology, 54(12):1317-1339 (2012)

8. Schumacher, A., Erol, S., Sihn, W.: A Maturity Model for Assessing Industry 4.0 Readiness and Maturity of Manufacturing Enterprises. Procedia CIRP, 52:161-166 (2016)

9. Jung, K., et al.: An Overview of a Smart Manufacturing System Readiness Assessment. In: Int'l. Conf. on Advances in Production Management Systems, pp. 705-712, Springer (2016)

10. Ganzarain, J., Errasti, N.: Three Stage Maturity Model in SME's toward Industry 4.0. J. of Industrial Engineering and Management, 9(5): 1119-1128 (2016)

11. Lichtblau, K., et al.: IMPULS-Industrie 4.0-Readiness. Impuls-Stiftung des VDMA, Aachen-Köln (2015) - http://www.impuls stiftung.de/documents/3581372/4875835/ Industrie+4.0+Readniness+IMPULS+Studie+Oktober+2015.pdf/447a6187-9759-4f25b186-b0f5eac69974

12. Geissbauer, R., Vedso, J., Schrauf, S.: Industry 4.0: Building the Digital Enterprise. Global Industry 4.0 Survey. PricewaterhouseCoopers (PwC), Munich (2016) - https://www. pwc.com/gx/en/industries/industries-4.0/landing-page/industry-4.0-building-your-digitalenterprise-april-2016.pdf

13. Schuh, G., Anderl, R., Gausemeier, J., Hompel, M., Wahlster, W.: Industrie 4.0 Maturity Index (2017) - http://www.acatech.de/fileadmin/user_upload/Baumstruktur_nach_Website/ Acatech/root/de/Publikationen/Projektbeichte/acatech_STUDIE_Maturity_Index_eng_WE B.pdf

14. Rockwell Automation: The Connected Enterprise Maturity Model (2014) - http:// literature. rockwellautomation.com/idc/groups/literature/documents/wp/cie-wp002_-en-p.pdf

15. Gökalp, E., Şener, U., Eren, P.E.: Development of an Assessment Model for Industry 4.0: Industry 4.0-MM. In: Int'l. Conf. on Software Process Improvement and Capability Determination, pp. 128-142, Springer (2017)

16. Akdil, K.Y., Ustundag, A., Cevikcan, E.: Maturity and Readiness Model for Industry 4.0 Strategy. In Industry 4.0: Managing The Digital Transformation, pp. 61-94, Springer (2018)

17. Pöppelbuß, J., Röglinger, M.: What Makes a Useful Maturity Model? A Framework of General Design Principles for Maturity Models and its Demonstration in Business Process Management. In: 19th European Conf. on Information Systems, Paper No. 28 (2011)

18. Lasrado, L.A., Vatrapu, R., Andersen, K.N.: Maturity Models Development in is Research: A Literature Review. In: IRIS Selected Papers of the Information Systems Research Seminar in Scandinavia, Vol. 6 (2015)

19. Tao, F., Cheng, Y., Zhang, L., Nee, A.Y.: Advanced Manufacturing Systems: Socialization Characteristics and Trends. Journal of Intelligent Manufacturing, 28(5):1079-1094 (2017)

20. Lee, J., Jun, S., Chang, T.W., Park, J.: A Smartness Assessment Framework for Smart Factories Using Analytic Network Process. Sustainability, 9(5): 794-808 (2017)

21. Weyer, S., Schmitt, M., Ohmer, M., Gorecky, D.: Towards Industry 4.0: Standardization as the Crucial Challenge for Highly Modular, Multi-Vendor Production Systems. IFACPapersOnLine, 48(3):579-584 (2015)

22. Mittal, S., Romero, D., Wuest, T.: Towards a Smart Manufacturing Toolkit for SMEs. In: Proceedings of the 15th International Conference on Product Lifecycle Management (2018) 


\section{Original Papers}

\section{Publication VI}

\section{Building Blocks for Adopting Smart Manufacturing}

By

Sameer Mittal, David Romero, Muztoba Ahmad Khan and Thorsten Wuest, June 2019

Mittal, S., Khan, M. A., Romero, D. \& Wuest, T. (2019, June). Building blocks for adopting smart manufacturing. In Procedia Manufacturing Vol. 34 (pp. 978-985).

2019 Elsevier. Open Access Permission. 
Publication VI (to be published)

\title{
Building Blocks for Adopting Smart Manufacturing
}

\author{
Sameer Mittal ${ }^{\mathrm{a}}$, Muztoba Ahmad Khan ${ }^{\mathrm{a}}$, David Romero ${ }^{\mathrm{b}}$, Thorsten Wuest ${ }^{\mathrm{a}, *}$ \\ ${ }^{a}$ Industrial and Management Systems Engineering Department, West Virginia University, Morgantown, WV 26506, United States. \\ ${ }^{b}$ Tecnologico de Monterrey, Mexico City, Mexico
}

* Corresponding author. Tel.: +1 (304) 293-9439. E-mail address: thwuest@mail.wvu.edu

\begin{abstract}
Smart Manufacturing (SM) enables companies to perform processes more effectively and efficiently, ensuring faster demand fulfillment on the one hand, and a reduction of production costs on the other hand. Thus, SM can provide a competitive edge for manufacturers that successfully adopt it. In the process of adopting SM, building blocks play a critical role and can be seen as prerequisites. Managers of manufacturing companies are interested in learning what building blocks are relevant and can help make their operations smarter and more competitive. Our paper is a first attempt to answer this question through presenting the most frequently used building blocks for SM adoption. In order to achieve this objective, we conducted a systematic mapping review to identify both building blocks as well as current methods for adopting SM. In a next step, we matched the building blocks with the adoption methods. This matching of building blocks with the adoption methods helped in determining whether a building block actually recommended in the methods for adopting SM. We found that intelligent control, data analytics, IT-based production management systems (e.g., ERP, CAx, etc.), smart products/parts/materials, interoperability, data sharing systems and standards are the most commonly used building blocks for manufacturers that are aligned towards adopting SM. As a consequence, the future manufacturing workforce needs to be prepared to understand analytics, sensors, etc. The results also showed that, although building blocks such as blockchain, robots, visual technology, and 3D printing may find their application in specific manufacturing sectors, overall, they are less commonly associated with SM adoption compared to the other building blocks.
\end{abstract}

(C) 2019 The Authors. Published by Elsevier B.V.

This is an open access article under the CC BY-NC-ND license (http://creativecommons.org/licenses/by-nc-nd/3.0/)

Peer-review under responsibility of the Scientific Committee of NAMRI/SME.

Keywords: Smart Manufacturing; Building Blocks; Industry 4.0; Intelligent Control; Data Analytics; Additive Manufacturing; IoT

\section{Introduction}

The efficient processes of Smart Manufacturing (SM) systems are able to scale themselves depending on the demand, making SM highly responsive to the change in demands [1]. The connected systems in SM minimizes the chances of miscommunication by ensuring that all employees are aware about: What is required? Where it is required? How much is required? What are the individual responsibilities? and Which machines will be deployed to serve these requirements? Machine downtime is reduced with the help of predictive maintenance, and the product designs are directed with the help of advanced simulated designs. Waste reduction, employee safety, identifying new business opportunities and markets, etc. are some of the other benefits of SM.
Moreover, various governments have launched their own initiatives to transform their manufacturing industries. For example, the governments of Germany, the U.S., and South Korea have started assisting and informing their respective manufacturing industry through initiatives such as Industry 4.0 (Germany), Smart Manufacturing (U.S.A.), and Smart Factory (South Korea) - from here on, we refer to these initiatives as Smart Manufacturing (SM). These initiatives are supposed to assist manufacturing companies in form of a smoother transformation towards SM. However, many manufacturers still lack a solid understanding of the prerequisites for, e.g., exploiting available data and aligning themselves towards adopting SM. 
Experienced researchers [2] have suggested technologies such as the Internet of Things (IoT), Additive Manufacturing (AM), machine learning, Cyber-Physical Systems (CPS), etc. to be the main building blocks of SM. A current article in the Huffington post [3] mentioned that 3D Printing, IoT, nanotechnology, cloud computing, next-level robotics, and augmented reality are the technologies that transformed the manufacturing industry in 2016. Similarly, Forbes [4] suggested that advanced analytics, cloud computing, advanced modelling and simulation, IoT platforms, optimization, and predictive analytics are the most invested technologies in the manufacturing industry. According to this article [4], the market for Artificial Intelligence (AI) will grow from $\$ 8 \mathrm{~B}$ in 2016 to $\$ 72 \mathrm{~B}$ in 2021 . Similarly, the market for blockchain, 3D Printing, advanced robotics, IoT, and advanced analytics are also estimated to grow significantly between 2016 to 2021 .

These overwhelming findings might entice the manufacturers to invest in some or all of those SM building blocks. During our literature review, we found that there are different terms used for the components of an SM system, e.g., technologies, standards, characteristics, etc. Therefore, in order to align the different perspectives, in this paper, we will use the term 'building blocks' as a generic term encompassing all different variations used previously. However, the question remains, whether the building blocks suggested in the above paragraph are really the relevant and essential ones that manufacturers should prioritize investing in? Although, the adoption of building blocks will depend on the nature of the industry and the kind of processes that the company plans to improve [5], the literature suggested that there are a number of common building blocks that might help industries across the board, irrespective of the specific nature of their work. These building blocks are expected to facilitate the transition of manufacturing companies by making the individual departments more efficient and workers more productive.

Hence, the objective of the current research work is to inform industry managers about the essential building blocks that should be considered when adopting SM. Utilization of building blocks is also important because it will help the manufacturers to compete with the other players in the market, some of whom might have already started their journey towards SM. Highlighting the above objective; we define the research question of our study as follows:

RQ: What are the most frequently used building blocks to adopt SM?

In order to address this research question, the rest of the paper is organized as follows. Section 2 presents the detailed methodology for identifying the relevant articles regarding the SM building blocks, and the articles concerning adoption of SM in manufacturing industries. The following, Section 3 presents a literature review on the building blocks identified and the methods suggested for adopting SM. In Section 4, the results and the answers to the posed research question have been discussed, and finally, the Section 5 presents the conclusions, limitations, and the future work of the current research.

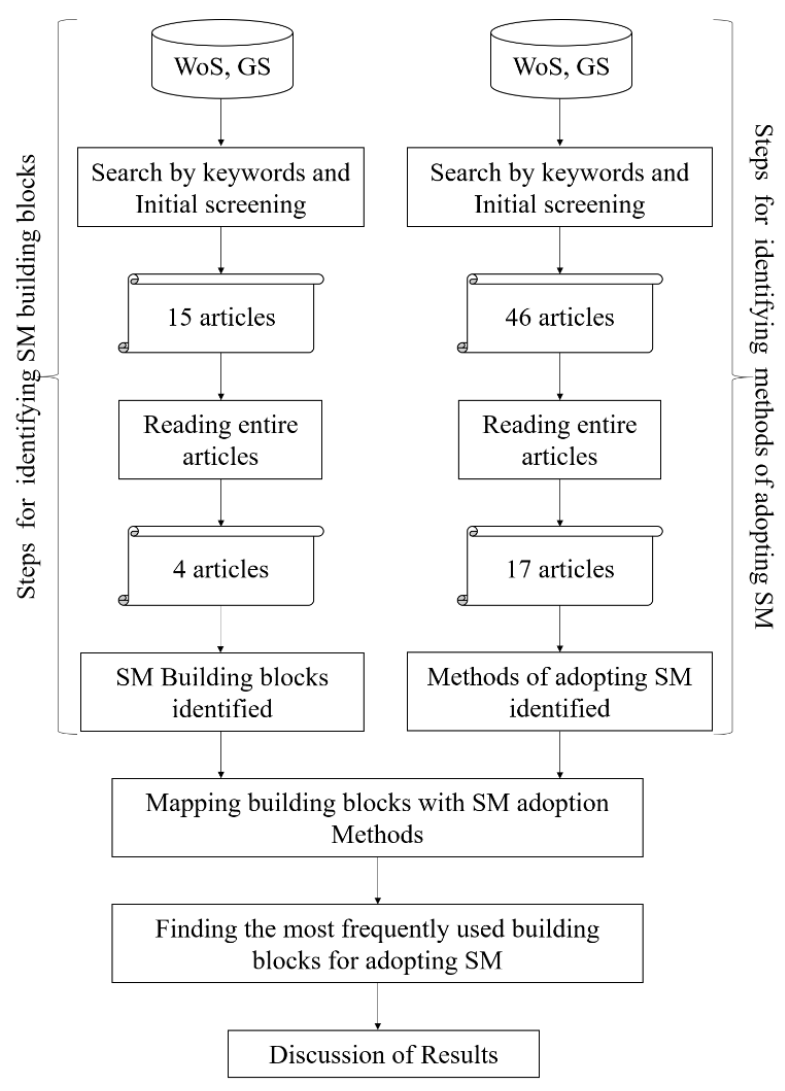

Fig. 1. A schematic for the methodology deployed in the paper.

\section{Research Methodology}

Systematic mapping studies can unbiasedly categorize and summarize the information concerning a research question [6]. Therefore, we chose the approach of systematic mapping study for our current research work. Our study follows the principle guidelines provided by other studies [6,7]. Fig. 1 depicts the general setup of our study and provides a detailed overview of the methodology. In the following, we illustrate the main steps of our methodology expanding on Fig. 1:

\section{Step 1: Identifying the building blocks for SM.}

In this step, we identified the building blocks related to SM with the help of keywords searched in the following databases: Web of Science and Google Scholar. "Smart Manufacturing" and "Building Blocks" became a natural choice for keywords in the search, since the building blocks for SM were to be identified. Furthermore, we limited our search results by considering only review articles, assuming that they will acknowledge the building blocks determined by the other articles. Therefore, we used the following search string: "smart manufacturing" and "building blocks" and "review".

The above search criterion was complemented by an initial screening criterion. For the initial screening, the title and abstracts of the articles were read, and the articles that did not presented a review of SM building blocks were removed. Finally, it was found that only fifteen articles presented a comprehensive review on the building blocks for SM. 
At this stage, we applied a second search criterion. In case an article considered just a single building block for SM adoption, we excluded it (for example, in case interoperability was referred to as the building block for SM, and then the review was performed on interoperability). Including such articles would have repeated the building blocks that have already been covered in the review articles. At this stage, our database was left with six review articles. Then, all the articles were read carefully, and it was found that some articles did not present their methodology in a clear manner, and hence, these articles were also not considered. Finally, we identified four review articles focused on building blocks for SM.

\section{Step 2: Identifying the methods for adopting SM.}

In order to find methods supporting the adoption of SM, a combination of keywords was used. "Industry 4.0" and "smart factory" are similar to SM, and similarly, models, framework, roadmap, and architecture are similar to "methods". Therefore, the following combinations of keywords were utilized for our database search:

"Smart Manufacturing" and "Methods"; "Smart
Manufacturing" and "Models"; "Smart Manufacturing" and
"Framework"; "Smart Manufacturing" and "Roadmap";
"Smart Manufacturing" and "Architecture"; "Industry 4.0"
and "Methods"; "Industry 4.0" and "Models"; "Industry
4.0" and "Framework"; "Industry 4.0" and "Roadmap";
"Industry 4.0" and "Architecture"; "Smart Factory" and
"Methods"; "Smart Factory" and "Models"; "Smart
Factory" and "Framework"; "Smart Factory" and
"Roadmap"; "Smart Factory" and "Architecture"

For the screening purpose, the title and abstracts of the papers were read to make sure that these papers present sequential steps towards achieving SM / Industry 4.0 / Smart Factory only. As a result, the articles that did not show the steps or were aligned towards only a specific building block (e.g., methodology towards adopting CPS) were not considered. At this stage, there were 46 articles. Finally, these articles were read to identify if there were specific items (e.g., utilization of M2M communication [8]) that needed to be present or activities (e.g., analytic studies conducted for pricing [9]) that were required to be performed at different stages, during the manufacturing industry's journey towards SM. If these items were present in an article, then only the article was considered to provide a method for adopting SM. In other words, only the papers that showed steps towards adopting SM were considered. Finally, it was found that only 17 articles suggested methods for adopting SM following our selection criteria.
Step 3: Mapping building blocks with the methods of adopting SM.

The various building blocks (identified in Step 1) associated with SM were searched in the articles that presented methods of adopting SM (identified in Step 2). Different authors have used different terminologies for different keywords, as a result, the similar terms corresponding to a building block were also searched. The context of the keyword was read to confirm whether the building block has been adopted from the perspective of achieving SM. Only in such cases, a building block was considered to be present in the method of adopting SM. Mapping helped in identifying the most frequently used building blocks for adopting SM.

\section{Step 4: Present results and Discussion.}

Finally, during this step the results and conclusions were drawn to find the possible answer to the research question of the current study.

\section{Literature Review}

This section presents a literature review of the building blocks (Section 3.1) and the adoption methods (Section 3.2) corresponding to SM.

\subsection{Building Blocks of SM}

The current research deals with the building blocks that are required for SM. Review studies and surveys [10,11,12,13] mention a list of building blocks. The review articles that identify the building blocks of SM are discussed below and summarized in Table 1.

Mittal et al. [10] identified five characteristics, eleven technologies, and three enabling factors that are associated with an SM system. A characteristic was defined [10] as a property peculiar to an element, which can be varied to make those elements look similar or different. Technology was considered [10] as a practical application of science, and the enabling factors are the standards and managerial practices that an industry needs to follow.

Ghobakhloo [11] did a systematic- and content-centric review of literature and identified twelve design principles and fourteen technology trends. According to [11], the design principles provide appropriate procedures for developing solutions towards knowledge. Whereas, the technology trends refer to the advanced digital technological innovations.

$\mathrm{Xu}$ et al. [12] considered selected technologies for Industry 4.0 with the help of a literature review.

Table 1: Details of review articles focussed on SM/Industry 4.0

\begin{tabular}{|ccccc|}
\hline$\#$ & Article & \# of articles reviewed & Review approach & Term(s) used synonymously for building blocks \\
\hline 1 & {$[10]$} & 67 & Systematic literature review & Characteristics, technologies and enabling factors \\
2 & {$[11]$} & 178 & Systematic- and content-centric review & Key design principles and technology trends \\
3 & {$[12]$} & $60+$ & Literature review & Technologies \\
4 & {$[13]$} & 110 & Qualitative and segmentation methods & Technology tools \\
\hline
\end{tabular}


Saucedo-Martinez et al. [13] developed categories for Industry 4.0 technologies with the help of qualitative and segmentation methods. The categories were decided in a way that all the reviewed items belong to a single category and the possible connection between the categories can be avoided.

Table 1 illustrates the article reference, the number of articles they reviewed, the approach taken for the review, and the synonymous terms used for "building blocks". It can be observed (see Table 1), that there are different terms (as a result, in the current research, "building block" is used as a generalized term) for denoting the building blocks among which technology was the most popular. The number of articles reviewed, the review approaches deployed, and the years of publication minimized the probability of excluding a building block that has been already established in the literature.

Table 2 mentions the building blocks that were proposed in the review papers $[10,11,12,13]$. It can be observed that most of the building blocks (e.g., IoT, data analytics, cloud computing, cyber-security, integration, etc.) that were defined by the review papers are repeated, and similarly, some building blocks (e.g., integration, vertical integration, and horizontal integration) were found to be similar. The review performed by [10] handled this case of similarity by considering the principle of semantic similarity. According to the principle of semantic similarity [14] the distance between two terms depends on the likeliness of their meaning/semantic content. Thus, [10] clustered various similar terms under the same heading (see Appendix A). As a result, to avoid missing a search term used by a methodology to adopt SM (Step 3), the current research utilized the search list prepared by [10] (see Appendix A). an outcome of the other building blocks of SM [15]. As these three design principles [11] were not found relevant from a manufacturer's perspective, therefore, they are not considered as building blocks in the current study.

\subsection{Methods for adopting SM}

For the process of identifying the methods for adopting SM, it was important to understand the perspective reflected in the literature and to lay a strong foundation for the research question. During the current research, various methods with a focus on adopting SM were identified. During the search for relevant articles, the authors made sure that selected articles do not focus exclusively on any single one of the identified building blocks; otherwise, the results of the current study would have been biased. Literature suggests adopting SM by using frameworks, maturity models, readiness assessments, and roadmaps. These terms are similar, but they have some differences as well [16]. Frameworks include the coherent procedures for designing a system [17]. Maturity models follow continuous improvement step-by-step process to reach to a more sophisticated stage [18]. Readiness assessments evaluate the preparedness of capabilities towards a particular goal [19], whereas roadmaps show procedures to achieve shortand long-term goals with the help of a specific technology [20].

The current paper considered the assessment items or the activities, in the steps towards adopting SM to identify if a building block was present in the adoption methods. It can be observed that the majority of the SM adoption methods were

Table 2: Building blocks corresponding to the reviewed articles on SM.

\begin{tabular}{|c|c|c|}
\hline \# & Article & Proposed building blocks \\
\hline 1 & {$[10]$} & $\begin{array}{l}\text { Characteristics: compositionality, context awareness, heterogeneity, interoperability, modularity. } \\
\text { Technologies: 3D printing/AM, cloud manufacturing, CPS/CPPS, cyber security, data analytics, energy saving/efficiency, intelligent control, } \\
\text { IoT/IoS, IT-based production management, smart product/part/material, visual technology. } \\
\text { Enabling Factors: laws and regulations, innovative education and training, data sharing systems and standards. }\end{array}$ \\
\hline 2 & [11] & $\begin{array}{l}\text { Design Principles: IoT (Internet of Things), IoS (Internet of Service), IoP (Internet of People), IoD (Internet of Data), cloud computing, big } \\
\text { data analytics, blockchain, cybersecurity, augmented reality, automation and industrial robots, additive manufacturing, simulation and } \\
\text { modelling, cyber-physical systems (CPS), semantic technologies. } \\
\text { Technology Trends: service orientation, smart product, smart factory, interoperability, modularity, decentralization, virtualization, real-time } \\
\text { capability, vertical integration, horizontal integration, product personalization, Corporate Social Responsibility (CSR). }\end{array}$ \\
\hline 3 & [12] & Technologies: CPS, IoT, cloud computing, blockchain, industrial information integration and other related technologies. \\
\hline 4 & [13] & $\begin{array}{l}\text { Categories: big data and analytics, autonomous robots, simulation, horizontal and vertical integration, Industrial Internet of Things (IIoT), } \\
\text { cyber-security, augmented reality, cloud (for sharing). }\end{array}$ \\
\hline
\end{tabular}

There are building blocks that are presented by other reviews $[11,12,13]$, but are not present in [10]. Such building blocks have been highlighted in bold in Table 2. Some of these building blocks can also be clustered into the existing list by [10]. However, other building blocks cannot be included in the existing clusters (presented in bold and italics in Table 2) following the principle of semantic similarity. As a result, two new technological clusters (i.e., blockchain and robots) were added to the existing list of technology clusters in [10] (an updated list of clusters with building blocks is presented in Appendix A, where the newly added building blocks and clusters are highlighted in bold). With time, more researches have considered blockchain and robots as building blocks for $\mathrm{SM}$, and therefore, they are the new items in the technology cluster. Corporate Social Responsibility (CSR) are the ethics that industries should follow but they do not contribute towards the industry adopting SM, and product personalization is published as a conference paper or a white paper (and one study was published as a book chapter) (see Table 3 ).

Therefore, it can be safely assumed that adoption of SM in manufacturing is still at a very early stage, and this is also a reason why there are very few articles comprehensively reporting on successful cases available for this topic. Similarly, it can also be observed that all SM adoption methods were not supported by the demonstration/evaluation cases. However, ten out of seventeen methods have been already demonstrated and/or evaluated in real manufacturing applications, therefore, studying these approaches might be beneficial when studying the adoption of SM in manufacturing companies. Additionally, the methods of adopting SM that we selected have all been published between 2015-2018, thus it is ensured that only recently published adoption methods are included. 
Table 3: Methods for adopting SM in manufacturing.

\begin{tabular}{|c|c|c|c|c|}
\hline \# & $\begin{array}{l}\text { Adopting } \\
\text { SM }\end{array}$ & Methodology & Type of article & Case Study \\
\hline 1 & [8] & Maturity Model & Conference paper & $\checkmark$ \\
\hline 2 & [9] & Maturity Model & Conference paper & $\checkmark$ \\
\hline 3 & [21] & Framework & Conference paper & \\
\hline 4 & [22] & $\begin{array}{l}\text { Model-based } \\
\text { requirement } \\
\text { engineering }\end{array}$ & Conference paper & $\checkmark$ \\
\hline 5 & [23] & Roadmap & Conference paper & $\checkmark$ \\
\hline 6 & [24] & Architecture & Conference paper & $\checkmark$ \\
\hline 7 & [25] & Roadmap & Conference paper & \\
\hline 8 & [26] & $\begin{array}{c}\text { Readiness } \\
\text { Model }\end{array}$ & White paper & $\checkmark$ \\
\hline 9 & [27] & Roadmap & Conference paper & \\
\hline 10 & [28] & Roadmap & White paper & \\
\hline 11 & [29] & Roadmap & White paper & \\
\hline 12 & [30] & $\begin{array}{l}\text { Multi-criteria } \\
\text { Decision } \\
\text { Making }\end{array}$ & Conference paper & $\checkmark$ \\
\hline 13 & [31] & Roadmap & White paper & $\checkmark$ \\
\hline 14 & [32] & Maturity Model & Conference paper & \\
\hline 15 & [33] & Maturity Model & Book chapter & $\checkmark$ \\
\hline 16 & [34] & Maturity Model & Conference paper & $\checkmark$ \\
\hline 17 & [35] & Maturity Model & White paper & \\
\hline
\end{tabular}

\section{Results and Discussion}

Fig. 2 depicts how frequently the SM building blocks were deployed by the identified methods of SM adoption. While there are 17 methods, only 16 considered a single individual building block (intelligent control (I) ), thus determining the scale of Fig. 2. The most interesting results from the Fig. 2 have been selected and discussed in greater detail below. Roman numerals (I - VII) have been put at the end of selected building blocks during the discussion below and in Fig. 2 (e.g., Intelligent control (I)) to facilitate readability.

Intelligent control (I) comprises algorithms that can improve the system performance [10]. For example, the system knows when it needs to stop, or change its actions based on the requirements. During the current study, it was found that the adoption methods emphasized on responsiveness, scalability, etc. (the intelligent control cluster). These aspects are not very new for the manufacturing industries. However, it is surprising to see that all articles that included case studies had demonstrations and/or evaluations for intelligent control. For example, the use of autonomously guided work pieces [26].

Manufacturing companies' hesitation towards data sharing and following standards (for e.g., ISO 50001) (II) are often discussed. However, in the current study, it is interesting to find that all ten SM adoption methods with cases were considering use of data sharing systems or following the standards. This might be the case due to the reason that, for most of the cases the data sharing was within the company or between the sister companies.

Interoperability (III) was the building block used for fifteen times for SM adoption. This cluster included systemintegrability, networkability, connectivity, etc. The cases in this cluster were demonstrated and/or evaluated considering the aspect of connectivity.

Technologies such as blockchain (IV) and 3D Printing (IV) are in their early stage when it comes to value-adding, regular applications in manufacturing. This might be the reason why these were the least frequently utilized building blocks in the adoption methods. Blockchain in manufacturing was found to be not deployed at all as of yet. Robotics (IV) and $3 D$ Printing

Frequently Used Building Blocks for Smart Manufacturing

$\begin{array}{llllllllll}0 & 2 & 4 & 6 & 8 & 10 & 12 & 14 & 16\end{array}$

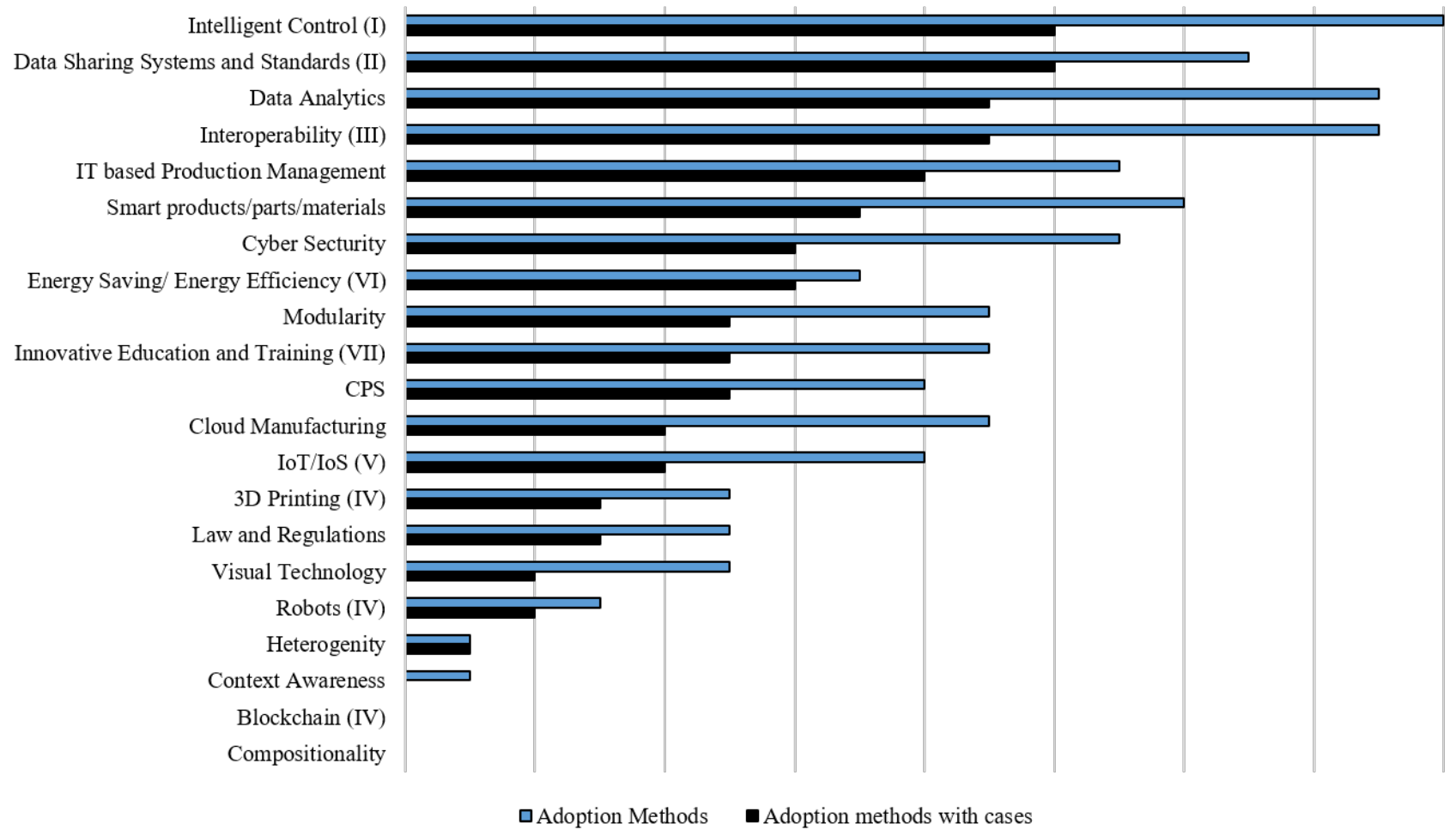

Fig. 2. Clustered bar chart showing frequently used building blocks for smart manufacturing adoption.

The building blocks with unexpected results have been shown with roman numerals, for e.g. Intelligent Control (I) and are discussed in this section. 
(IV) are oriented towards the advanced level of manufacturing, and their practical applications are still limited to perform specific tasks (e.g., transportation, prototyping) in the manufacturing industries. As a result, robotics and 3D printing were rarely suggested by the adoption methods. Another reason why these otherwise popular methods (i.e., blockchain, 3D Printing, robotics) are not included might be the differentiation of SM, focusing on manufacturing data utilization, and Advanced Manufacturing, focusing on manufacturing process technologies.

It was surprising to see that the $\operatorname{IoT} / \operatorname{IoS}(\mathrm{V})$ building block has been acknowledged only in eight out of the seventeen SM adoption methods. It may have happened for a few reasons. Firstly, there is a separate building block (smart parts/products/ materials) that considered the use of sensors, RFID, etc. in manufacturing, therefore, it reduced the number of times IoT/IoS might have been used. Secondly, the IoT/IoS building block mostly has applications in logistics and smart home devices [36], but the current research only considers deployment of IoT/IoS from the perspective of manufacturing operations.

Another surprising finding was related to the energy saving/ energy efficiency (VI) building block. It can be observed that six out of seven articles that involved a case study, recognized the energy saving/energy efficient building block. We believe this is grounded in the fact that energy was considered mostly as an assessment item, e.g., energy consumption reduction [33].

It was also surprising to find that the building block innovative education and training (VII) was considered only by nine of the seventeen adoption methods. This shows that either the studies were considered purely from the technical perspective or employee education and training is assumed to already be present and sufficient in the manufacturing organizations.

\section{Conclusion}

This article adds to the body of knowledge by identifying the most frequently used building blocks for SM adoption. Thus, guiding manufacturers in their journey to be efficient and cut down the cost of production. In this regard, twenty-one SM building blocks and seventeen methods for SM adoption were identified. Finally, the building blocks were mapped through the method of adoption. This approach is referred to as systematic mapping review. Our results aim to inform and support industrial managers in their quest by providing them with information about the most frequently used SM building blocks, which they might want to consider in their journey towards SM. The main findings of the study are:

Intelligent control, data analytics, smart products/parts/ materials, and IT-based production management systems are the most frequently deployed building blocks for SM. Therefore, in the future, possessing only in-depth knowledge of the manufacturing processes might not be sufficient for a manufacturing/production engineer any longer, rather this knowledge needs to be supported with the understanding of algorithms, sensors, and statistical analysis that can bring smartness at the different levels (parts, machines, departments, etc.) of a SM system.
Although blockchains, robots, and 3D Printing are considered among the most promising building blocks of SM, we found in our study that these building blocks are still too advanced to be considered as the most frequently utilized building blocks by manufacturers. For now, their applications are restricted to some specific areas of manufacturing. Similarly, IoT/IoS is often regarded as the core or fundamental technology for SM systems, but their use up until today seems to be restricted to mostly logistics and smart home applications.

We found that interoperability as a building block for SM has been highly regarded in the literature. Similarly, the study showed that the SM adoption in manufacturing industries show a very high inclination towards data sharing within the company and following common industrial standards.

SM adoption is a rising trend, and therefore, in the future, more studies are expected to consider this aspect. The present study had only seventeen articles to work with and it should be considered as an initial study towards finding the most frequently used building blocks for SM. In the future, these findings should be supported by empirical data, such as surveys involving manufacturing practitioners, service providers, academics, and consultants. Furthermore, the current study used only "building blocks" as a search term; but there might be other similar keywords that are used in literature, and from this perspective some other or additional building blocks of SM might emerge. Therefore, future studies should also consider using search terms that are similar to building blocks.

\section{Acknowledgements}

This work was supported by the J. Wayne \& Kathy Richards Faculty Fellowship in Engineering at West Virginia University. The authors thank the reviewers for their constructive feedback that helped to improve the manuscript significantly.

\section{Appendix A.}

Appendix A is attached in the last page.

\section{References}

[1] Davis J, Edgar T, Porter J, Bernaden J, Sarli M. Smart manufacturing, manufacturing intelligence and demand-dynamic performance. Computers \& Chemical Engineering 2012;47:145-56.

[2] Ahuett-Garza H, Kurfess T. A brief discussion on the trends of habilitating technologies for Industry 4.0 and Smart manufacturing. Manufacturing Letters 2018;15,60-63.

[3] Onibalusi, S. Six technologies transforming the manufacturing industry in 2016. Huffingtonpost 2017. Accessed online November 12, 2018 at https://www.huffingtonpost.com/william-morrow/6-technologiestransformi_b_10405528.html

[4] Columbus, L. The future of manufacturing technologies, 2018. Forbes 2018. Accessed online November 12, 2018 at https://www.forbes.com/sites/louiscolumbus/2018/04/15/the-future-ofmanufacturing-technologies-2018/\#692731aa2995

[5] Závadská Z, Závadský J. Quality managers and their future technological expectations related to Industry 4.0. Total Quality Management \& Business Excellence 2018;1-25.

[6] Fernandez A, Insfran E, Abrahão S. Usability evaluation methods for the web: A systematic mapping study. Information and Software Technology 2011;53(8):789-817. 
[7] Dicheva D, Dichev C, Agre G, Angelova G. Gamification in education: A systematic mapping study. Journal of Educational Technology \& Society 2015;18(3).

[8] Schumacher A, Erol S, Sihn W. A maturity model for assessing Industry 4.0 readiness and maturity of manufacturing enterprises. Procedia CIRP 2016;52:161-6.

[9] Akdil KY, Ustundag A, Cevikcan E. Maturity and readiness model for Industry 4.0 strategy. In: Industry 4.0: Managing The Digital Transformation 2018;61-94.

[10] Mittal S, Khan MA, Romero D, Wuest T. Smart manufacturing: characteristics, technologies and enabling factors. Proceedings of the Institution of Mechanical Engineers, Part B: Journal of Engineering Manufacture 2017.

[11] Ghobakhloo M. The future of manufacturing industry: A strategic roadmap toward Industry 4.0. Journal of Manufacturing Technology Management 2018;29(6):910-36.

[12] Xu LD, Xu EL, Li L. Industry 4.0: state of the art and future trends. International Journal of Production Research 2018;56(8):2941-62.

[13] Saucedo-Martínez JA, Pérez-Lara M, Marmolejo-Saucedo JA, SalaisFierro TE, Vasant P. Industry 4.0 framework for management and operations: A review. Journal of Ambient Intelligence and Humanized Computing 2017;1-3.

[14] Harispe S, Ranwez S, Janaqi S, Montmain J. Semantic similarity from natural language and ontology analysis. Synthesis Lectures on Human Language Technologies 2015;8(1):1-254.

[15] Thoben KD, Wiesner S, Wuest T. "Industrie 4.0" and smart manufacturing-a review of research issues and application examples. Int. J. Autom. Technol. 2017;11(1).

[16] Mittal S, Khan MA, Romero D, Wuest T. A critical review of smart manufacturing \& Industry 4.0 maturity models: Implications for small and medium-sized enterprises (SMEs). Journal of Manufacturing Systems 2018;49:194-214.

[17] Storey MA. Theories, methods and tools in program comprehension: Past, present and future. In: Program Comprehension Proceedings 2005; 181191.

[18] Mettler T. Maturity assessment models: a design science research approach. International Journal of Society Systems Science 2011;3(1/2):81-98.

[19] Benedict N, Smithburger P, Donihi AC, Empey P, Kobulinsky L, Seybert A, Waters T, Drab S, Lutz J, Farkas D, Meyer S. Blended simulation progress testing for assessment of practice readiness. American Journal of Pharmaceutical Education 2017;81(1):14.

[20] Garcia ML, Bray OH. Fundamentals of technology roadmapping. Sandia National Laboratories 1997.

[21] Qin J, Liu Y, Grosvenor R. A categorical framework of manufacturing for industry 4.0 and beyond. Procedia CIRP 2016;52:173-8.

[22] Kannan SM, Suri K, Cadavid J, Barosan I, van Den Brand M, Alferez M, Gerard S. Towards Industry 4.0: gap analysis between current automotive MES and industry standards using model-based requirement engineering. In: Software Architecture Workshops IEEE International Conference 2017;29-35.

[23] Weyer S, Schmitt M, Ohmer M, Gorecky D. Towards Industry 4.0standardization as the crucial challenge for highly modular, multi-vendor production systems. Ifac-Papersonline 2015;48(3):579-84.
[24] Jung K, Kulvatunyou B, Choi S, Brundage MP. An overview of a smart manufacturing system readiness assessment. In: IFIP International Conference on Advances in Production Management Systems 2016;705712 .

[25] Ganzarain J, Errasti N. Three stage maturity model in SME's toward industry 4.0. Journal of Industrial Engineering and Management 2016;9(5):1119-28.

[26] Lichtblau K. Industrie 4.0-Readiness. Impuls-Stiftung 2015. Accessed online November 10, 2018 at http://www.impulsstiftung.de/documents/3581372/4875835/Industrie+4.0+Readniness+IMP ULS+Studie+Oktober+2015.pdf/447a6187-9759-4f25-b186b0f5eac69974

[27] Geissbauer R, Vedso J, Schrauf S. Industry 4.0: Building the digital enterprise 2016. Accessed online November 10, 2018 at https://www. pwc. com/gx/en/industries/industries-4.0/landing-page/industry-4.0-buildingyour-digital-enterprise-april-2016. pdf. 2016.

[28] Automation R. The connected enterprise maturity model. Rockwell Automation. 2014. Accessed online November, 102018 at http://iterature.rockwellautomation.com/idc/groups/literature/documents/ wp/cie-wp002_-en-p.pdf

[29] Anderl R, Picard A, Wang Y, Fleischer J, Dosch S, Klee B, Bauer J. Guideline Industrie 4.0-Guiding principles for the implementation of Industrie 4.0 in small and medium sized businesses. In: VDMA Forum Industrie 2015 (Vol. 4). ISBN: 978-3-8163-0687-0.

[30] Lee J, Jun S, Chang TW, Park J. A smartness assessment framework for smart factories using analytic network process. Sustainability 2017;9(5):794

[31] Schuh G, Anderl R, Gausemeier J, ten Hompel M, Wahlster W. Industrie 4.0 maturity index: Managing the digital transformation of companies (acatech study) Herbert Utz Verlag, Munich 2017. Accessed online November $\quad 10, \quad 2018 \quad$ at http://www.acatech.de/fileadmin/user_upload/Baumstruktur_nach Websit e/Acatech/root/de/Publikationen/Projektberichte/acatech_STUDIE_Matur ity Index eng WEB.pdf

[32] Gökalp E, Şener U, Eren PE. Development of an assessment model for Industry 4.0: Industry 4.0-MM. In: International Conference on Software Process Improvement and Capability Determination 2017;128-142.

[33] Scremin L, Armellini F, Brun A, Solar-Pelletier L, Beaudry C. Towards a framework for assessing the maturity of manufacturing companies in Industry 4.0 adoption. In: Analyzing the Impacts of Industry 4.0 in Modern Business Environments 2018;224-254.

[34] Mittal S, Romero D, Wuest T. Towards a smart manufacturing maturity model for SMEs $\left(\mathrm{SM}^{3} \mathrm{E}\right)$. In: IFIP International Conference on Advances in Production Management Systems 2018;155-163.

[35] The singapore smart industry readiness index- catalysing the transformation of manufacturing 2017. Accessed online November, 12 2018 at https://www.edb.gov.sg/en/news-and-resources/news/advancedmanufacturing-release.html

[36] Khan R, Khan SU, Zaheer R, Khan S. Future internet: the internet of things architecture, possible applications and key challenges. In: 10th International Conference on Frontiers of Information Technology 2012;257-260. 


\section{Appendix A.}

The clusters corresponding to the characteristics, technologies and enabling factors associated with Smart Manufacturing [10], (the new building blocks are shown in bold).

\begin{tabular}{|c|c|c|c|}
\hline Clusters & Name of Characteristics & Name of Technologies & Name of Enabling Factor \\
\hline Compositionality & Compositionality & & \\
\hline Context Awareness & $\begin{array}{l}\text { Digital Presence, Context Awareness, } \\
\text { Asset, Self-awareness }\end{array}$ & & \\
\hline Heterogeneity & Heterogeneity & & \\
\hline Interoperability & $\begin{array}{l}\text { Interoperability, Networkability, } \\
\text { Information Appropriateness, } \\
\text { Integrability, Decentralized, Distributed }\end{array}$ & & \\
\hline Modularity & Composability, Modularity & & \\
\hline 3-D Printing / AM & & 3- D Printing / Additive Manufacturing & \\
\hline Cloud Manufacturing & & $\begin{array}{l}\text { Real-time Communication / Data, } \\
\text { Cloud Computing / Cloud } \\
\text { Manufacturing }\end{array}$ & \\
\hline CPS / CPPS & & $\begin{array}{l}\text { Cyber-Physical Infrastructure, CPS } \\
\text { (Cyber-Physical Systems) / CPPS } \\
\text { (Cyber-Physical Production Systems) }\end{array}$ & \\
\hline Cyber Security & & Cyber Security & \\
\hline Data Analytics & & $\begin{array}{l}\text { Big Data, Data Analytics / Big Data } \\
\text { Analytics, Predictive Analytics, Data } \\
\text { Visualization, Modeling, GIS, } \\
\text { Simulation, Forecasting, Machine } \\
\text { learning, Knowledge Decision Making } \\
\text { Techniques, Statistical Process } \\
\text { Control, Semantic Technologies }\end{array}$ & \\
\hline Energy saving / efficiency & Sustainability & Energy Saving / Efficiency & \\
\hline Intelligent Control & $\begin{array}{l}\text { Scalability, Autonomy, Adaptability, } \\
\text { Robustness, Flexibility, Fully } \\
\text { Automated, Proactivity, Reliability, } \\
\text { Agility, Responsiveness, Accuracy }\end{array}$ & Intelligent, Intelligent Control & \\
\hline IoT/ IoS & & IoT / IoS / IIoT/ IoP/ IoD & \\
\hline $\begin{array}{l}\text { IT based Production } \\
\text { Management }\end{array}$ & & $\begin{array}{l}\text { ERP, SCM, MES, PLM, Interface } \\
\text { (SCOR, DCOR, MESA, ISA 95/88), } \\
\text { CAM, CAD, CAx, Operations } \\
\text { Planning, IT based Production } \\
\text { Management, Service orientation } \\
\text { architecture (SOA) }\end{array}$ & \\
\hline $\begin{array}{l}\text { Smart Product / Part / } \\
\text { Material }\end{array}$ & Reusability, Resilience & $\begin{array}{l}\text { Smart Sensors, Smart Product / Part, } \\
\text { RFID, Smart Materials, Tracking and } \\
\text { Tracing }\end{array}$ & \\
\hline Visual Technology & & $\begin{array}{l}\text { Holograms, VR (Virtual Reality), AR } \\
\text { (Augmented Reality) }\end{array}$ & \\
\hline Blockchain & & Blockchain & \\
\hline Robots & & Autonomous and Industrial Robots & \\
\hline Law and regulations & & & Law and regulations \\
\hline $\begin{array}{l}\text { Innovative education and } \\
\text { training }\end{array}$ & & & $\begin{array}{l}\text { Innovative education and } \\
\text { training, Knowledge } \\
\text { workers }\end{array}$ \\
\hline $\begin{array}{l}\text { Data sharing systems and } \\
\text { standards }\end{array}$ & & & $\begin{array}{l}\text { Data sharing systems and } \\
\text { standards, Enterprise } \\
\text { Integration, MTConnect, } \\
\text { STEP AP 242, CMSD }\end{array}$ \\
\hline
\end{tabular}




\title{
Original Papers
}

\section{Publication VII}

\section{A Smart Manufacturing Adoption Framework for SMEs}

By

Sameer Mittal, Muztoba Ahmad Khan, Jayant Kishor Purohit, Karan Menon, David Romero and Thorsten Wuest, XXXX

\author{
Currently Under Review
}




\title{
A Smart Manufacturing Adoption Framework for SMEs
}

\author{
Sameer Mittal ${ }^{1}$, Muztoba Ahmad Khan ${ }^{1}$, Jayant Kishor Purohit ${ }^{2}$, Karan Menon $^{3}$, \\ David Romero ${ }^{4}$, Thorsten Wuest ${ }^{1 *}$ (corr. author) \\ ${ }^{1}$ Industrial and Management Systems Engineering, Benjamin M. Statler College of Engineering \\ and Mineral Resources, \\ West Virginia University, Morgantown, WV, USA \\ samittal@mix.wvu.edu,mdkhan@mix.wvu.edu,thwuest@mail.wvu.edu \\ ${ }^{2}$ Poornima University, Jaipur, India \\ jayant.purohit@poornima.edu.in \\ ${ }^{3}$ Unit of Information and Knowledge Management, Tampere University, Tampere, Finland \\ karan.menon@tuni.fi \\ ${ }^{4}$ Tecnológico de Monterrey, Monterrey, México \\ david.romero.diaz@gmail.com
}

\begin{abstract}
Smart Manufacturing (SM) a revolutionary paradigm that aims to improve production systems' performance in terms of quality, time, cost, and flexibility, as well as human and machine decision-making capabilities. Most large enterprises have already taken first steps towards adopting SM. Small and Medium-sized Enterprises (SMEs) on the other hand, are struggling with developing a SM adoption roadmap. Our research builds on the real and perceived needs and challenges faced by manufacturing SMEs and advances the field by developing and evaluating an SME-specific 'SM adoption framework'. We have employed a multiple case study approach to acknowledge the lessons learned by selected early-adopter SMEs that have recently implemented and deployed SM tools and practices. We propose an SM adoption framework with five vital steps that SMEs interested in SM should follow: (i) identify manufacturing data available within the SME, (ii) readiness assessment of the SME data-hierarchy steps, (iii) developing SM awareness of SME leadership and staff, (iv) develop a SM tailored vision for the SMEs, and (v) identify appropriate SM tools and practices necessary to realize the tailored SM vision. Moreover, the results of the case study analysis enabled us to formulate many generalisations.
\end{abstract}

Keywords: Smart Manufacturing, Industry 4.0, SMEs, Case Studies, Adoption Framework, Readiness Assessment.

\section{Introduction}

Smart Manufacturing (SM) is the integration of Information Technology (IT) and data with different manufacturing technologies, processes, and resources (i.e., Operational Technology (OT)) (Marr 2015). Various international governments (e.g., SM - USA, Industrie 4.0 - Germany, Smart Factory - South Korea) have proposed similar SM initiatives to facilitate the development of their own manufacturing industries (Thoben et al., 2017; Srai et al. 2016). As a result, these titles were used synonymously in this paper. Moreover, customized product developments, efficient production planning of manufacturing resources, precise control of manufacturing 
processes, automatic manufacturing processes monitoring, proactive maintenance, and quality control are some of the benefits of SM (Tao et al. 2018; Zheng et al. 2018). All these benefits result in an overall improvement of a production system performance, including humans and machines decision-making capabilities (Wang et al. 2018). The objective of SM is to use real-time transmission and analysis of data to create a positive impact on all aspects of operations performed across the factory (O’Donovan et al. 2015; Qi and Tao 2018; Bryner 2012). Although data has always been there in the manufacturing enterprises, its importance has been just realized in recent times only (Tao et al. 2018). Therefore, industries need a practical framework that can assist them with the typical stages of data-driven decision-making i.e., data generation, data storage, data transmission and data analysis (Tao et al. 2018).

SMEs act as suppliers of many large enterprises and thus play a vital role in many value creation processes along the supply chain (Müller, Buliga and Voigt 2018). They are also regarded as the backbone of most economies (Jankowska, Götz and Główka 2017; Sommer 2015; Husin and Ibrahim 2014; Schiersch 2009). However, they often lack behind when it comes to innovation and competitiveness and thus can impede the overall growth of their national economies (Nkwe 2012; Kongolo 2010; Lukács 2005). Hence, SM is an initiative that can help SMEs by providing them with a competitive edge and making them more efficient players in their supply chains.

Nowadays affordable smart sensors and wireless networks can capture SMEs products' lifecycle data (Chiang and Lee 2017; Kusiak 2017; Wang et al. 2012; Zhong et al. 2017; Zhong 2018). Analysis of data does not require supercomputers anymore (Marr 2015; Syafrudin et al. 2019), and economical cloud and fog computing make data easily approachable (Marr 2015), e.g.: cloud computing services provided by Amazon and Alibaba (Tao et al. 2018). IIoT platforms are used for data transmission, storage and analysis (Menon et al. 2018), and IoT sensors and laser scanners have been employed by SMEs for efficient production planning (Zhong, Wu and Wang 2017). The 3D-printers have been successfully integrated with the SMEs business models (Rayna and Striukova 2016). Similarly, there are other tools that can cater to the specific needs of SMEs (Strozzi et al. 2017), e.g.: ERP packages (Ruivo et al. 2013; Ruivo, Oliveira and Neto 2015), software packages (Gershwin 2018), smart sensor kits, and wireless networks (Liao et al. 2017). Thus, the rate at which the data for every conceivable process is collected (or can be collected), provides further opportunities to fine-tune the existing manufacturing practices at SMEs (Marr 2015). Therefore, we may conclude that the accessibility to smart technologies at affordable prices has positively influenced the operations of manufacturing systems and has facilitated the adoption of SM from an SME perspective (Ahuett-Garza and Kurfess 2018; Gershwin 2018). As a result, the first pieces of evidence of unique benefits for SMEs, which have already begun their SM journey, have been started to be documented in the scientific literature (Müller, Buliga and Voigt 2018; Frank, Dalenogare and Ayala 2019).

An analysis of the scientific literature has also shown that research in production management has shifted towards data-driven models (Kuo and Kusiak 2018), and aspects of data analytics techniques (such as unsupervised learning, association rules, and time-series analysis (Packianather et al. 2017), have been developed to assist manufacturing SMEs. There are economic and flexible ways of collecting, storing, processing and analysing data that can benefit 
manufacturing SMEs (Tao et al. 2018). In this regard, Mittal, Romero, and Wuest (2018a) have proposed an SM toolkit that can help SMEs in taking advantage of modular and economic SM capabilities. The toolkit focuses on technical and managerial aspects of the SM paradigm to align the SMEs towards performing data-supported activities (Mittal, Romero and Wuest 2018b). Literature also presents the industrial applications of the SM tools and practices (Mittal, Romero and Wuest 2018a; Závadská and Závadský 2018; Črešnar, Protcan and Nedelko 2018; Kusiak 2018). Since SMEs lay foundation of economies, therefore, for an economy to be successful it becomes vital to support SMEs with the right set of tools and practices (Issa, Lucke and Bauernhans1 2017). However, a framework suggesting how these SM tools and practices can be selected from an SME's perspective has been missing.

Other studies in the scientific literature present an overview of how smart manufacturing paradigm was adopted in the manufacturing enterprises or a quantitative overview of how well the enterprise is equipped to adopt smart manufacturing (for e.g. Zhong, Wu and Wang 2017), Lee (2014), Schumacher, Erol and Sihn (2016), Hemann, Pentek and Otto (2016), Zezulka et al. (2016); Müller and Voigt (2017), and Bagheri et al. (2015)). However, our study was different from the other studies and presented an in-depth analysis of the SMEs' experiences during smart manufacturing paradigm adoption. We found only one study (Mosterman and Zander 2016) that performed an indepth multiple case study research from 'smart perspective'. However, this study identifies the various smart manufacturing/ Industry 4.0 technologies present in the construction industry.

Literature shows that the existing approaches towards the SM paradigm adoption focus on large enterprises (Mittal et al. 2018; Davis et al. 2012; Arnold, Kiel and Voigt 2016; Radziwon et al. 2014; Müller, Buliga and Voigt 2018) and managing SMEs is entirely different as compared to managing large enterprises (Coetzer et al. 2019). To address this research gap, we propose an SM paradigm adoption framework designed specifically for SMEs and their unique characteristics and requirements. We will develop our SM adoption framework through a case study approach, based on real use cases of SMEs that have recently adopted SM tools and practices. Therefore, the objective of our research is:

To develop and evaluate an SME-centric SM adoption framework that provides manufacturing SMEs with the appropriate, easy-to-use tools and guidance to support their SM journey. The SME-centric SM adoption framework will build on previously identified $S M E$-specific requirements and potential barriers, such as ease-of-use, fast deployment, assessment of the present situation, development of an SM tailored vision, and clear recommendations of SM tools and practices.

This paper is divided into six sections. Section 1 presents an introduction to the research objective. Section 2 presents a literature review and throws light on the background of adopting the SM paradigm in SMEs. Section 3 proposes a framework to guide SMEs towards SM adoption, and Section 4 explains the research methodology for our study. Section 5 presents the results and discussion of the two SMEs case studies that have recently adopted SM tools and practices and were used to enrich and validate the proposed adoption framework (in Section 3). Finally, the section 6 presents the conclusions, limitations and the future work of the paper. 


\section{Theoretical Background}

\subsection{Defining What is an SME?}

European Commission (EC 2003) classified SMEs under different groups based on their income, number of employees, and annual balance sheet total. SMEs were considered as the enterprises that employ less than 250 employees and have an annual turnover less than EUR 50 million, and/or annual balance sheet total less than EUR 43 million (see Table 1).

Table 1: SMEs Category (EC 2003)

\begin{tabular}{|c|c|c|c|}
\hline Enterprise & $\begin{array}{c}\text { Max. People } \\
\text { Employed }\end{array}$ & $\begin{array}{c}\text { Max. Annual } \\
\text { Turnover }\end{array}$ & $\begin{array}{c}\text { Max. Annual } \\
\text { Balance Sheet Total }\end{array}$ \\
\hline Small & $<50$ & $\leq € 10$ million & $\leq € 10$ million \\
\hline Medium & $<250$ & $\leq € 50$ million & $\leq € 43$ million \\
\hline
\end{tabular}

Even though some enterprises satisfy the above definition/criteria for being classified as an SME, they often have access to significant additional resources. Therefore, such SMEs do not face the unique set of challenges that are faced by 'genuine' SMEs. The genuine SMEs do not have close financial, operational, or governance relationship with the other enterprises (EC 2006). As a result, SMEs are also categorized as autonomous, linked, or partner with a large enterprise (EC 2006). The autonomous SMEs are entirely independent and have a minority partnership of less than $25 \%$. Similarly, partner SMEs have a minority partnership between $25 \%$ and $50 \%$, and the linked SMES have a minority partnership of $50 \%$ or more. For our research, we consider the 'autonomous SMEs' (EC 2006) only.

\subsection{Smart Manufacturing}

The physical tools (e.g., machine tools) in an SM context are equipped with electronic sensors and communication networks (Taylor, Baron and Schmidt 2015), and there are SMEs that have used ICTs to improve their communication across the enterprise (Carayannis et al. 2006). Centobelli, Cerchione and Espostio(2017) found that aligning tools and practices helped SMEs in developing knowledge. Similarly, Shashi et al. (2019) identified that leanness and innovativeness can positively affect the environmental and the financial performance of the SMEs. Manufacturing enterprises can become more competitive by employing SM technologies and practices, and analysing data from design, production, sourcing, and inventory activities (Ahuett-Garza and Kurfess 2018). SM can scale its production based on demands, and without compromising in the time for order fulfilment (Davis et al. 2012). Similarly, connected enterprises can inform their employees about the overall production requirements, and their individual responsibilities, to reduce waste, minimize miscommunication, increase employees' safety and ergonomics, and identify new business opportunities and markets, which are the other benefits of SM (Mittal et al., 2019). Thus, acknowledging the technical, managerial and operational aspects of SM will make SMEs more aware regarding their own organizational dimensions like finance, product, process and people. This awareness will result into an informed decision making. Moreover, the success of any initiative in an SME depends on its owner/manager's understanding of the initiative related to technical, managerial, and operational aspects (White 2009; Carson and Gilmore 2000). As a 
result, Sections 2.2.1 and 2.2.2 present the background of technical, managerial and operational aspects for the adoption of the SM paradigm in an SME. Section 2.2.3 presents the current methods for adopting SM in SMEs.

\subsubsection{Technical Aspects of Smart Manufacturing}

Technical aspects include the hardware and software tools, and instruments associated with technology. New technologies, or technological advances, are beneficial for manufacturing enterprises as they provide advantages such as reduced production costs, improved product quality, reduced delivery times, and reduced inventory levels (Skinner 1984; Mellor, Hao and Zhang 2014). Therefore, manufacturing enterprises that adopt new technologies and learn new (digital) capabilities and skills are more prosperous than those who do not (Boothby, Dufour and Tang 2010). CPS (Cyber-Physical Systems), IIoT (Industrial Internet of Things), data analytics, AR (Augmented Reality), VR (Virtual Reality), autonomous and collaborative robots, 3D-printing, IT-based production management, intelligent products, simulation, energy-saving, and real-time communication are a few examples of technologies that are frequently associated with SM (Mittal et al. 2017; Saucedo-Martinez et al. 2017; Ghobakhloo 2018; Xu, Xu and Li 2018; Chiarello et al. 2018). The industrial applications of these technologies from an SME point of view are also present in the literature (viz. Mittal, Romero and Wuest 2018a; Závadská and Závadský 2018). Table 2 presents selected technical aspects of SM and their applications.

Table 2: Selected Technologies of SM and their Applications (Based on Mittal, Romero and Wuest 2018a; Závadská and Závadský 2018; Chiarello et al. 2018)

\begin{tabular}{|l|l|}
\hline \multicolumn{1}{|c|}{ Technologies } & \multicolumn{1}{c|}{ Applications } \\
\hline CPS (Cyber-Physical Systems) & $\begin{array}{l}\text { Production, logistics \& warehouse operations, } \\
\text { production planning, etc. }\end{array}$ \\
\hline IIoT (Industrial Internet of Things) & $\begin{array}{l}\text { Transportation, smart homes, real-time communication, } \\
\text { etc. }\end{array}$ \\
\hline (Big) Data Analytics & $\begin{array}{l}\text { Data management, decision-making, purchasing, sales, } \\
\text { etc. }\end{array}$ \\
\hline $\begin{array}{l}\text { AR (Augmented Reality), VR (Virtual } \\
\text { Reality) }\end{array}$ & Product development, manufacturing, maintenance, etc. \\
\hline Autonomous \& collaborative Robots & Manufacturing, transportation, inspection, etc. \\
\hline 3D-Printing & $\begin{array}{l}\text { Product development, prototype production and } \\
\text { assessment, manufacturing, etc. }\end{array}$ \\
\hline
\end{tabular}

\subsubsection{Managerial \& Operational Aspects of Smart Manufacturing}

Although SM is often understood as the implementation of technologies, however, technologies can generally not be adopted independently. It is also important to understand the circumstances of technologies being adopted, the extend of the technology adoption, as well as, the system, process or the activity that needs to be made 'smart'. These objectives are realized by acknowledging the managerial and operational aspects of SM. Managerial and operational aspects are the practices followed by an organisation. They include items like business models, lean thinking, organisational culture, and six-sigma (Črešnar, Protcan and Nedelko 2018; Mittal, Romero and Wuest 2018a; Van de Vrande et al. 2009). When integrated with smart manufacturing 
technologies, manufacturing data related to delays in production, defects, and rejections may be collected and analyzed (Davies, Coole and Smith 2017; Gupta, Modgil and Gunasekaran 2019) to make better decisions, therefore, lean and six-sigma practices have been considered under smart manufacturing. The managerial and operations aspects help in performing functions like strategic planning, employee development, and continuous improvement. Table 3 presents selected managerial aspects of SM and their applications.

Table 3: Selected Managerial and Operational Aspects of SM and their Applications (Based on Črešnar, Protcan and Nedelko 2018; Mittal, Romero and Wuest 2018a;

Van de Vrande et al. 2009)

\begin{tabular}{|l|l|}
\hline \multicolumn{1}{|c|}{$\begin{array}{c}\text { Managerial \& Operational } \\
\text { Aspects }\end{array}$} & \multicolumn{1}{c|}{ Applications } \\
\hline Business Models & $\begin{array}{l}\text { Shows how the business earns profits, streamline the } \\
\text { activities, responsibilities. }\end{array}$ \\
\hline Lean Thinking & Eliminates wastes from the production system. \\
\hline Six-Sigma & Identify errors and defects for process improvement. \\
\hline Organisational Culture & All employees share the same set of beliefs and values. \\
\hline Skill Development & Employees/managers learn new skills. \\
\hline
\end{tabular}

The literature presents several approaches for SM adoption in the form of frameworks, maturity models, roadmaps, and readiness assessment methods. Although these approaches appear to be similar, however, they are slightly different (Mittal et al. 2018). Frameworks - consist of guidelines for designing a system (Storey 2005). Maturity models - suggest steps to reach a more sophisticated stage (Mettler 2011). A readiness assessment - can evaluate the preparedness of capabilities towards a goal (Benedict et al. 2017). Roadmaps - are procedures to attain technical short-term and long-term goals (Garcia and Bray 1997).

\subsection{Smart Manufacturing Adoption in SMEs}

We previously performed a critical review addressing SM paradigm adoption in SMEs (Mittal et al. 2018). In this review, the specific requirements of manufacturing SMEs (i.e. financial resources, advanced manufacturing technologies, industrial standards, organizational culture, employee participation, alliances with the universities and the research institutions, and the collaborations with customers and suppliers) were mapped with the fifteen existing methods (viz., Rockwell Automation 2014; Anderl et al. 2015; Lichtblau et al. 2015; Weyer et al. 2015; Ganzarain and Errasti 2016; Geissbauer, Vedso and Schrauf 2016; Jung et al. 2016; Qin, Liu and Grosvenor 2016; Schumacher, Erol and Sihn, 2016; Gökalp, Şener and Eren 2017; Kannan et al. 2017; Lee et al. 2017; Schuh et al. 2017; Akdil, Ustundag and Cevikcan 2018; Scremin et al. 2018) for adopting SM paradigm in SMEs. It was identified that the existing methods do not cater to the specific requirements of the manufacturing SMEs and the existing methods should define a 'level 0' to relate with the reality of many SMEs. The methods referred above assume the presence of financial and technical resources, advanced enterprise information systems, supportive employees' skills, and favourable organisational culture in the SMEs (Mittal et al. 2018). However, some SMEs still follow traditional manufacturing practices like high involvement of human labour, use of old machinery, the absence of computers and internet and lack of mindset to adopt new technologies 
(Müller, Buliga and Voigt 2018). As a result, SMEs think that they are ill-equipped to adopt the SM paradigm (Moeuf et al. 2018), and for them, SM adoption is still a dream (Radziwon et al., 2014). Therefore, it was suggested that SM paradigm adoption framework should define a 'level 0 ' to associate with the reality of many SMEs (Mittal et al. 2018). Existing methods also need to integrate readiness assessment, maturity model and tools to realize the tailored vision of an SME. These findings are in tandem with other studies that found SMEs are unable to associate themselves with the SM vision (Brozzi et al. 2018), and their owners/managers are uncertain about the benefits and outcomes of adopting the SM paradigm (Schumacher, Erol and Sihn, 2016; Chiarello et al. 2018). Therefore, it was suggested that SM paradigm adoption framework should define a 'level 0' to associate with the reality of many SMEs (Mittal et al. 2018).

\section{Smart Manufacturing Framework for SMEs}

Figure 1 summarizes the proposed SM adoption framework for SMEs. The framework consists of four steps that can be employed by SMEs. These steps are assisted by the SM maturity model for SMEs (Mittal, Romero and Wuest 2018b) (see Appendix I). Below is presented the description of the steps for adopting the SM paradigm in SMEs.

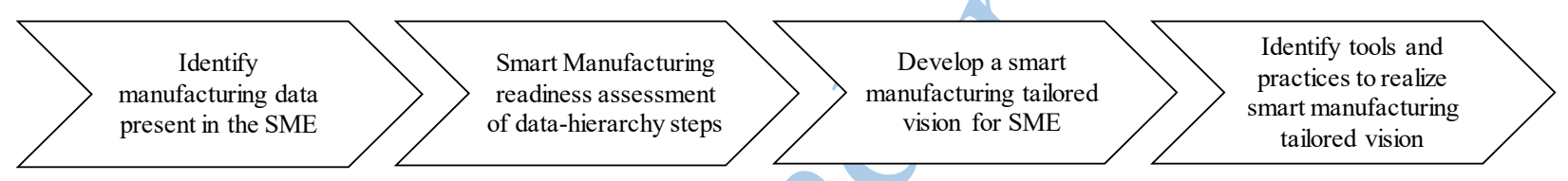

Figure 1: Smart Manufacturing Adoption Framework for SMEs.

Step 1: Identify Manufacturing Data Present in the SMEs

Scientific literature shows the infusion of IT and advanced manufacturing technologies (e.g., OT) from the perspective of SMEs (Dangayach and Deshmukh 2005; Fink and Disterer 2006; Raymond 2005). However, to adopt the SM paradigm, data should be integrated with IT and manufacturing technologies (Marr 2015). Decision making using manufacturing data leads to more accurate judgments and results in closely coordinated production plans, operations and supply chains (Tao et al., 2018). Therefore, the first step towards adopting the SM paradigm is to identify the manufacturing data present/available in the SME. Table 4 presents a set of examples of manufacturing datasets, and its corresponding SME organisational dimension (Mittal, Romero and Wuest 2018b; Kuo and Kusiak 2018; Tao et al. 2018; Dalenogare et al. 2018).

Table 4: Organisational Dimensions and the Manufacturing Data related to these Dimensions.

\begin{tabular}{|c|l|}
\hline $\begin{array}{c}\text { Organisational } \\
\text { Dimension }\end{array}$ & \multicolumn{1}{c|}{ Exemplary Manufacturing Data } \\
\hline Finance & $\begin{array}{l}\text { Equipment cost data, raw material cost data, transportation cost data, } \\
\text { energy consumption cost data, worker cost data, transaction cost data, } \\
\text { recycling cost data. }\end{array}$ \\
\hline People & $\begin{array}{l}\text { Number of hours data, number of employees/workers data, worker } \\
\text { schedule data, human factors data, human ergonomic data, user } \\
\text { behaviour data. }\end{array}$ \\
\hline
\end{tabular}




\begin{tabular}{|c|l|}
\hline $\begin{array}{c}\text { Organisational } \\
\text { Dimension }\end{array}$ & \multicolumn{1}{c|}{ Exemplary Manufacturing Data } \\
\hline Strategy & $\begin{array}{l}\text { Policies, targets, ranks, performance, metrics, lean manufacturing data, } \\
\text { kaizen data, (i.e., strategic management data). }\end{array}$ \\
\hline \multirow{2}{*}{ Process } & $\begin{array}{l}\text { Production process data, process parameters data, machine downtimes } \\
\text { data, process planning data, process control data, equipment status } \\
\text { data, equipment parameters data, energy consumption data, material } \\
\text { characteristics data, facility layout data, quality control data, process } \\
\text { modularity data, sustainable manufacturing data, maintenance data. }\end{array}$ \\
\hline Product & $\begin{array}{l}\text { Product development data, product design data, order data, order } \\
\text { quantity data, inventory management data, sales data, delivery time } \\
\text { data, position of the product, product real-time performance data, } \\
\text { supply chain data, product modularity data, product lifecycle data. }\end{array}$ \\
\hline
\end{tabular}

Step 2: Smart Manufacturing Readiness Assessment of the Data-Hierarchy Steps

A readiness assessment can help in determining the present financial and technical conditions of an SME, and the employees' skills available at the enterprise (Ganzarain and Errasti 2016). Therefore, there is a need to integrate a 'readiness assessment' with a 'maturity model' (Mittal, Romero and Wuest 2018b). Data generation, data transmission, data storage, and data analysis (including data processing, and data visualization) are the broad steps in a data-hierarchy (Tao et al. 2018). Once the manufacturing data present in the organisation and the toolbox involved are identified, we can assess the readiness of the data-hierarchy step (see Appendix II). For example, based on the energy consumption cost data, it can be identified that the SME is at the beginning level of 'Fabrication/Manufacturing Toolbox', during the data generation stage (see Table 5).

Table 5: Assessing Readiness among the Data-Hierarchy Steps

\begin{tabular}{|c|c|c|c|c|c|c|c|}
\hline $\begin{array}{c}\text { Organisational } \\
\text { Dimension }\end{array}$ & Related Data Generated & \multicolumn{6}{|c|}{ Readiness } \\
\hline \multirow{2}{*}{ Finance } & \multirow{2}{*}{ Energy consumption cost data } & & $\mathrm{N}$ & $\mathrm{B}$ & $\mathrm{L}$ & $\mathrm{I}$ & $\mathrm{E}$ \\
\hline & & FMT & & & & & \\
\hline
\end{tabular}

Step 3: Develop a Smart Manufacturing Tailored Vision for SMEs

The SM vision of large enterprises will not fit with the needs of the SMEs, and therefore, this step focuses on the significance of creating an SM tailored vision for SMEs (Mittal et al. 2018; Schuh et al. 2017). The SME tailored vision may be identified by SME's understanding of their market niche, and by assisting their shift from data generation to data transmission (or a higher level of the data-hierarchy). The objective of a tailored vision is to shift the SMEs towards a data-driven decision-making culture. The SM toolboxes can assist SMEs towards an SM tailored vision as they emphasize digitalization, advanced manufacturing, and data analytics capabilities.

Step 4: Identify Tools and Practices to realize Smart Manufacturing Tailored Vision 
An SM tailored vision is realized by acknowledging data with the help of tools and practices. In this regard we have employed the smart manufacturing toolkit proposed by Mittal, Romero, and Wuest (2018a) (see Appendix I). Where, the FMT, DST and RAT toolboxes are the sources of data generation. The SCT toolbox facilitates data transmission. At times, sensors and converters are inbuilt in the tools/machines, and thus, they do not require external sources for data transmission (communication). The CST toolbox is for data sharing and analysis (at times), and finally, the Data Analytics Toolbox (DAT) performs analytics and visualization. DST and RAT tools depending on their inbuilt capabilities may also assist in data transmission, data storage, and data analysis. The BMT was defined from a managerial perspective and consists of practices like lean thinking (Yadav et al. 2018) and organisational culture (Brettel, Chomik and Flatten 2015; O'Regan, Ghobadian and Sims 2006). Thus, BMT can positively affect the operational performance of SMEs. Although, the BMT may not be directly related with data, however, it may be combined with the other toolboxes for various data-hierarchy steps, e.g., digital lean, lean automation (Kolberg, Knobloch and Zühlke 2017; Fettermann et al. 2018; Tortorella and Fettermann 2018; Mayr et al. 2018; Romero et al. 2018). The data-hierarchy steps served by the SM toolboxes for data analysis are shown in Table 6. The manufacturing enterprises do not need to follow the sequence of levels within the same SM toolbox. For example, an organisation may look forward to shifting from storing data in spreadsheets to the cloud.

Table 6: Smart Manufacturing Toolboxes corresponding to the Data-Hierarchy Steps

\begin{tabular}{|l|c|c|c|c|}
\hline \multirow{2}{*}{\multicolumn{1}{c}{ Smart Manufacturing Toolboxes }} & \multicolumn{3}{c|}{ Data-Hierarchy Steps } \\
\cline { 2 - 5 } & $\begin{array}{c}\text { Data } \\
\text { Generation }\end{array}$ & $\begin{array}{c}\text { Data } \\
\text { Transmission }\end{array}$ & $\begin{array}{c}\text { Data } \\
\text { Storage }\end{array}$ & $\begin{array}{c}\text { Data } \\
\text { Analysis }\end{array}$ \\
\hline Fabrication/Manufacturing Toolbox (FMT) & $\bullet$ & & & \\
\hline Design \& Simulation Toolbox (DST) & $\bullet$ & $\bullet$ & $\bullet$ & $\bullet$ \\
\hline Robotics \& Automation Toolbox (RAT) & $\bullet$ & $\bullet$ & $\bullet$ & $\bullet$ \\
\hline Sensors \& Connectivity Toolbox (SCT) & & $\bullet$ & & \\
\hline Cloud/Storage Toolbox (CST) & & & $\bullet$ & $\bullet$ \\
\hline Data Analytics Toolbox (DAT) & & & & $\bullet$ \\
\hline Business Management Toolbox (BMT) & $\bullet$ & $\bullet$ & $\bullet$ & $\bullet$ \\
\hline
\end{tabular}

\section{Research Methodology}

The methodology we followed during our research has been depicted in Figure 3. The three broad steps of our research methodology have been discussed below.

\subsection{Development of the Framework}

The first step of our research methodology was to develop theory. Our theory was developed in the form of a framework in section 3 (see Figure 3). This framework consists of four steps that were used to support SMEs in their SM paradigm adoption journey. 


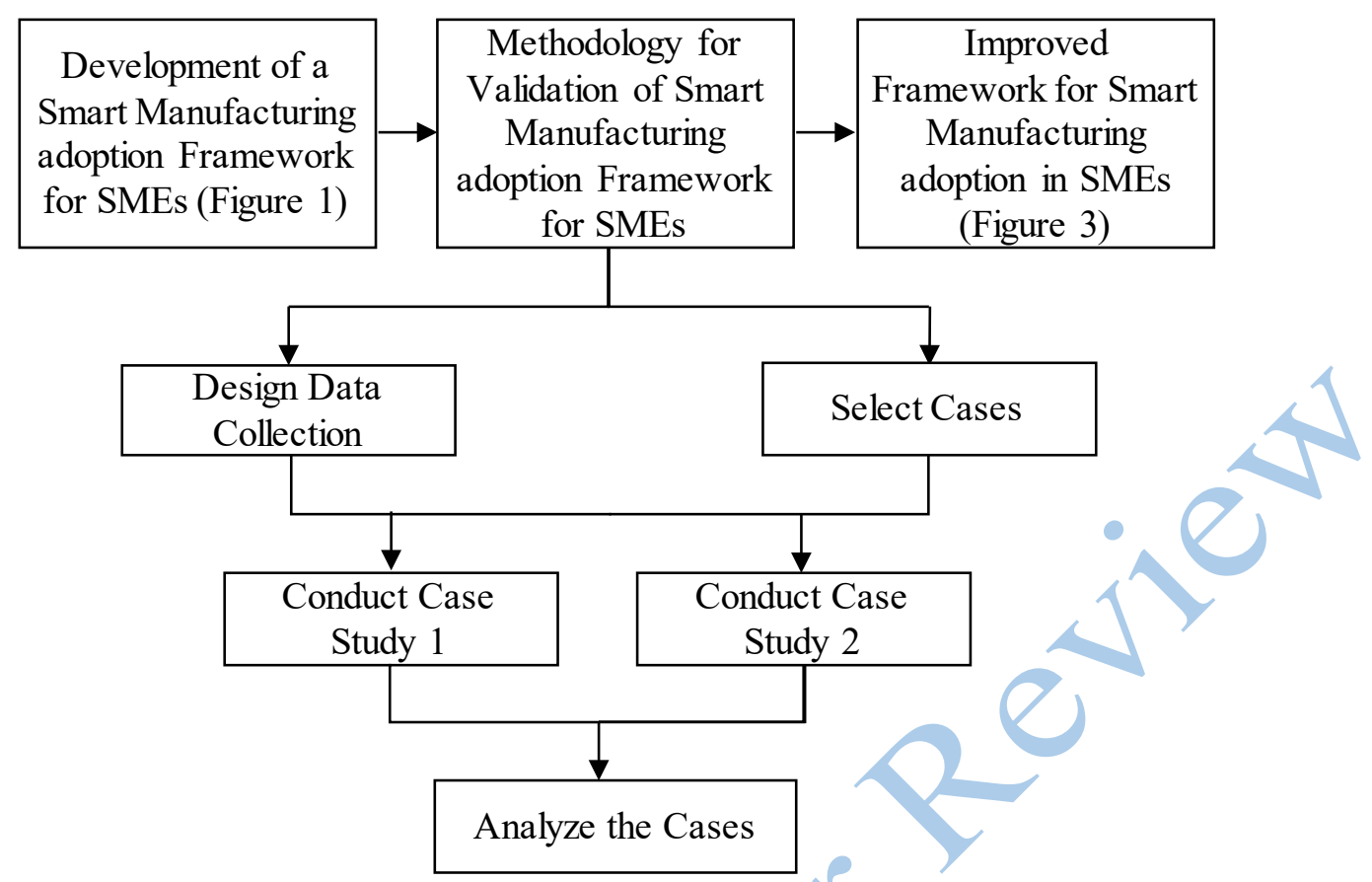

Figure 2: Research Methodology

\subsection{Methodology for Validation of the Framework}

We used multiple case study research to validate the developed framework. Multiple case study research focuses on in-depth analysis of the context dependent knowledge and provides interesting results from the practical viewpoint (Flyvbjerg 2006). The practical viewpoint can describe the complicated issues faced in real-life environments and otherwise may not be acknowledged with the help of survey or experimental research (Zainal 2007). A multiple case studies approach considers multiple sources that lead to the same results and therefore it is a powerful method to develop, test, and refine new theories (Miles, Huberman and Saldaña 1994). It has already refined many of the breakthrough concepts like lean production and manufacturing strategy in operations management (Voss, Nikos and Mark 2002). The multiple case studies throw light on 'why a decision or set of decisions were taken, how they were adopted, and with what result' (Schramm 1971; Yin 2003). The multiple investigators during case study research analyse data from different perspectives and thus increase the chances of capitalizing on novel insights (Eisenhardt 1989). We followed the previous research works (Benbasat, Goldstein and Mead 1987; Meredith 1998; Yin 2003) and found that a multiple case studies research approach is the most appropriate for our study for the following three reasons. Firstly, the SM paradigm adoption is rare in large enterprises and almost absent in SMEs (Davis et al. 2012). Thus, a contemporary topic has been studied in the context of real-life. Secondly, we look at answering the question of 'how an SM paradigm adoption framework for SMEs can be developed', and to evaluate the proposed SM adoption framework (i.e., theory testing, according to Handfield and Melnyk [1998]). Thirdly, the investigation team had no control over the actual behavioural events that accompanied the research objective. For performing the multiple case study research, a design for the data collection was prepared and in parallel the cases for our study were selected. These steps led to conducting individual study of the cases and finally the two cases were analyzed. Below we discuss these steps in detail. 


\section{Design Data Collection}

The boundaries set for data collection were regarding the activities performed and the procedure(s) the SMEs followed to select the SM tools and practices. We also discussed the issues and advantages considered by the SMEs during the selection of SM tools and practices. Data collection was designed with the help of a semi-structured interview (see Appendix III) with the SME owners/managers to understand the various aspects considered by the SME owners/managers before pursuing the adoption of the SM paradigm. A case study protocol was prepared to collect data from the manufacturing SMEs. The interview (see Appendix III) with the SME owners/managers led to the understanding of the technical, managerial, and operational aspects that both SMEs considered before pursuing the adoption of the SM paradigm. The discussion of these aspects helped to generalize the findings to theoretical propositions, and to validate the proposed SM adoption framework.

\section{Select Cases}

The manufacturing SMEs are the unit of analysis for this study because the purpose is to learn from the experiences of manufacturing SMEs that have already adopted SM tools and practices. Retrospective cases can reflect their success or failure, thus, facilitating more controlled case selection (Voss, Nikos and Mark 2002). Therefore, the two cases selected during our research were SMEs that took their first steps towards SM and became the pioneers in their own fields. Since we analyzed the experience of smart manufacturing adoption in SMEs from a technical perspective, therefore we looked for SMEs that have successfully adopted SM. However, there are not many SMEs that have successfully adopted smart manufacturing paradigm. The sharing of the experiences involved an in-depth analysis of their present practices, and not a quantifiable overview because we were studying 'how' the smart manufacturing paradigm was adopted in the two SMEs cases. Table 7 presents the background dimensions of the two SME cases considered during our study.

Table 7: SMEs Profile and Background

\begin{tabular}{|l|l|l|}
\hline Background Dimensions & \multicolumn{1}{|c|}{ Case A } & \multicolumn{1}{c|}{ Case B } \\
\hline Industry & Jewelry Manufacturing & $\begin{array}{l}\text { Modular Kitchen } \\
\text { Manufacturing }\end{array}$ \\
\hline Ownership & Private & Private \\
\hline Company Started & 2003 & 2004 \\
\hline Number of Employees & 95 & 87 \\
\hline Manufacturing Location & Western India & North-central India \\
\hline Customer Location & Western India & North-central India \\
\hline Turnover & $\sim € 1.5$ million & $\sim € 2$ million \\
\hline $\begin{array}{l}\text { Market (Target } \\
\text { customers) }\end{array}$ & $\begin{array}{l}\text { Higher-class Indians (including } \\
\text { NRIs) }\end{array}$ & $\begin{array}{l}\text { Middle- and higher-class } \\
\text { Indians }\end{array}$ \\
\hline Type of Production & Customized/Batch production & Customized production \\
\hline Type of Industry & Autonomous SME & Autonomous SME \\
\hline Nature of Industry & $\begin{array}{l}\text { Engineering-to-Order, Make-to- } \\
\text { Stock }\end{array}$ & Engineering-to-Order \\
\hline
\end{tabular}




\begin{tabular}{|l|l|l|}
\hline Background Dimensions & \multicolumn{1}{|c|}{ Case A } & \multicolumn{1}{c|}{ Case B } \\
\hline Interview Participants & Owner (Production Head) & $\begin{array}{l}\text { Production manager } \\
\text { (Production Head) }\end{array}$ \\
\hline Interviews & Telephone interview & Telephone interview \\
\hline Sight-Seeing & Yes & Yes \\
\hline Operations Performed & $\begin{array}{l}\text { Sales, purchase, design, } \\
\text { production }\end{array}$ & $\begin{array}{l}\text { Sales, purchase, design, } \\
\text { production, site-installation }\end{array}$ \\
\hline
\end{tabular}

Company A used to make jewelry with the help of hand-made molds. However, later they started using a CAD design jewelry software to produce 3-D printed molds to be used during the process of jewelry manufacturing. They became the market leaders in providing customized jewelry designs in Western India within two years of adopting SM tools and practices. Company B dominated the modular kitchen market within three years of adopting SM tools and practices. They initially used hand drawn engineering drawings to design modular kitchens. However, they started using a tab-based interface, where customer can configure the modular kitchen themselves. The tab-based interface then automatically generates the required CAD drawings, reducing the change in medium and is all digital.

In both cases, the adoption of SM tools and practices provided a competitive edge and assisted the SMEs to become market leaders. The cases we selected were diverse- as they were from two different industries, extreme- as they brought major changes in their processes, and influentialbecause their experiences and successful journey motivate other SMEs. Therefore, we considered the case selection strategy mentioned in the research (Seawright and Gerring 2008; Yin 2003). Moreover, these SMEs adopted the SM paradigm in less than three years, and thus minimized the chances of miscommunication, which might happen due to the change in personnel and recalling the past adoption processes.

\section{Conduct Case Study}

During the case study, the members of the research team visited the SMEs and collected the documents shared by the SMEs (e.g., the catalogues, presentations, process charts, etc.). We interviewed only the personnel (the SM owner and/or manager) involved during the adoption of SM tools and practices. The interviewees also had a detailed understanding of all the production related activities in the SMEs. They were also approachable and willing to share their insights gained during SM paradigm adoption. Furthermore, our study highlighted the typical issues faced by the manufacturing SMEs, and how the adoption of the SM paradigm assisted the SMEs in overcoming those issues. Finally, the responses from the SMEs were categorized under fourteen different topics (see Appendix IV). The semi-structured nature of the case study research questions also led to additional questions that prompted a follow-up of the interviewee answers.

\section{Analyze the Cases}

To analyze the cases the interview with the SME manager/owner was recorded with the help of audio tapes and was later manually coded into fourteen different categories based on the similarities between the answers. Three coauthors independently went through these responses and 
presented their analysis of the individual cases. The three coauthors also went through the case analysis prepared by the other two coauthors and the final cross-case comparative analysis of the two SMEs cases was prepared.

A multiple case study approach should satisfy the four scientifically design tests, namely: construct validity, internal validity, external validity, and reliability test during the different phases of research (Yin, 2002). During the composition phase, the interviewees from both SMEs reviewed the case analysis prepared by the authors, thus the construct of the study was validated. Since the study was not causal in nature, therefore, internal validity was not required (Yin, 2002). Similarly, external validity, which helps in generalization, was checked with the help of literal and theoretical replication during the research design phase. Reliability test was performed as different people from the research team went through the same procedure and ended up with similar results. The transcripts obtained during the case analysis were in the form of audio files, notes taken during the interviews, and the documents received. All the data obtained from these sources and the on-site visit by team member(s), together formed the final data. Thus, the multiple sources of evidence for obtaining data and their convergence towards similar results guaranteed triangulation (Yin, 2002).

\subsection{Improving the Framework}

In the next step the relevant statements and the analysis pertaining to the main theoretical propositions (for each case) were prepared in detail and then the report was prepared (presented in the section 5 of the current manuscript). When the data pattern from the two SMEs cases showed similar results (literal replication) or showed contrasting results for known reasons (theoretical replication) (Miles, Huberman and Saldaña 1994; Yin, 2002; Voss et al., 2002) the theoretical proposition was validated. The insights shared by the SMEs also resulted into the modification of new theory by including another step that helped SME cases in adopting SM paradigm (see Figure 3). The summary of case analysis has been presented in Appendix IV.

\section{Results and Discussion}

Below is presented the result and discussion of the response by the SMEs' owner/manager to the semi-structured questions mentioned in Appendix III.

\section{i) Identify Manufacturing Data Generated in the SMEs}

Based on the site visits, the discussion with the interviewed participants, and the process flowcharts shared by the SMEs, we observed that sales, purchase, design, and production were the operations that took place in their businesses. Additionally, Company B was also doing site visits and kitchen installations. Similarly, both SMEs used different design tools from the design and simulation toolbox. It was also found that both the interviewee from the company A and B were utterly aware of their company's business processes.

Both SME cases generated manufacturing data through various activities; however, data transmission and data storage in both SMEs were the results of the design and simulation toolbox (see Appendix V). In addition, Company B also stored orders management and inventory control 
data with the help of an ERP system. We found that various forms of data generated during different activities were not transmitted stored and analyzed. As a result, the business decisions were based on the SME owner/manager's intuitions, and less supported by data analytics. Therefore, considering only the operations performed in the SMEs might not be enough to realize their actual complete picture, however, identifying the manufacturing data present might make SMEs' situation more evident.

\section{ii) Smart Manufacturing Readiness Assessment of the Data-hierarchy steps}

Studied SMEs were not aware of any readiness assessment tool that could guide them towards an assessment of its data management capabilities. The owner of Company A felt that their manufacturing practices were not productive when compared to the other jewelry firms situated globally: '...if you google, you find that there are other businesses, doing similar stuff more productively...'. Similarly, Company B compared its operations with a popular furniture store and found that its operations are behind: '...our operations required a major refinement, compared to our competitor furniture store...'. Therefore, both case companies compared themselves (a kind of benchmarking exercise) with other similar businesses to assess their present situation. The benchmarking exercise can be replaced with a readiness assessment tool comparing the datarelated activities performed in the SMEs with the typical data-related activities that SMEs should perform. Based on the activities performed in the past, the SM readiness of both cases was at 'Level 0', except for the fabrication/manufacturing toolbox. Thus, signifying the importance of the 'Level 0', with which manufacturing SMEs can relate with (Mittal, Romero and Wuest 2018a). When the readiness of the present business activities was assessed (see Appendix V), it was found that both SMEs were performing data generation, data transmission, and data storage activities at higher maturity levels (with the help of the 'Design \& Simulation Toolbox'), however, data analysis activities were absent (performed at 'Novice Level'). Therefore, the SME cases were able to establish the need for readiness assessment among the data-hierarchy steps.

The advantages of using 3D-printed molds already motivated Company A to accept a product configurator in the future: '... as we were successful in changing from hand-made molds to 3Dprinted molds, shifting to an online interface seems rather easy...'. However, the company A showed resistance towards the use of data analysis tools '...numbers are all that we have, and I do not see if there is any other analytics that we can perform with these numbers... '. Similarly, the results shown using the configurator, motivated the management of Company B to further improve their business by updating the actual position of their products in the ERP system '...the product configurator has shown amazing results... and we can visualize the positive effects of integrating it to our ERP system...' '. Company B was also confident that they were performing analysis in the best possible manner: '...this is the best analysis...'.

Thus, it can be concluded that both SMEs agreed to the fact that their future SM visions were easy to achieve, as they already faced significant challenges during their initial transition. Their opinions regarding improving their present data analytics skills ('Level 0') showed that they were reserved in shifting beyond this level. These results prove that SMEs transition from 'Level 0' to 'Level 1' or a higher level is more challenging as compared to their transition from 'Level 1' to a higher level (Mittal et al. 2018). The comments made by the SMEs owners/managers showed that 
all the tools considered by SMEs were covered under the umbrella of SM toolkit. We summarize the similarities and differences of SM practices for both SMEs and their feedback (regarding the SM adoption framework for SMEs) in Appendix IV.

iii) Develop Awareness about Smart Manufacturing

The SMEs followed different ways of developing SM awareness. The owner of Company A visited a 'Jewellers Symposium' in Dubai and was informed about the new measures that might be taken in their business. After attending the symposium, he was confident to include 3D-printed molds in their production process: '...visiting Jeweller's Symposium in Dubai motivated me to include 3Dprinted molds during production...' . Similarly, for Company B, the production manager learned about the concept of a product configurator, from an online product configurator used by a popular furniture outlet '...one day my wife told me about the concept of customized furniture used by one of my competitors...'.

The initially proposed SM adoption framework (see Section 3) did not realize the importance of developing SM awareness. However, after discussion with the SME owners/managers, it was observed that their awareness plays a very vital role in the adoption of the SM paradigm. If the SME owners/managers were not aware of the detailed activities performed in their SMEs, it would not have been possible to acknowledge the available options. Therefore, this finding confirms that SMEs' success depends on its owner/manager's detailed understanding of the technical, managerial and operational aspects (White 2009; Carson and Gilmore 2000) of his/her organisation.

iv) Develop a Smart Manufacturing Tailored Vision for SMEs

For Company A, the objective was to increase its clientele, and therefore, it also considered the use of sensors inside jewelry. However, such jewelry is used for attractive displays (effect Jewelry) or for tracking a person, and these were not the requirements of their customers. Previously, the mould for a jewel was designed manually, and creating precise molds for complicated designs was a time-consuming process: '...the most difficult part was to create a mould for complex jewel designs manually...'. Later, to increase the variety of jewel designs, they considered using 3Dprinted molds: '...effect jewelry, lifesaving jewelry are too fancy for our customers...we wanted to focus on a variety of designs... 3D-printed molds provided design variety...'. In the future, they plan to expand by providing an online interface where young customers can create customized jewelry designs. More CAD designers and 3D printers will serve the increased clientele: '...ebusiness has affected all industries... the new age customers will look to purchase their preferred designs online as well...'

Similarly, Company B considered various options towards their concern of getting a higher number of ECNs (engineering change notes). Their first option was to design parts in CAD and produce these parts using $\mathrm{CNC}$. The second option was to have a user interaction design configurator, and the third option was to reduce the number of ECNs by employing lean practices and ISO regulations. The product configurator can design as well as produce the engineering drawings, guiding the production with the existing machines. Therefore, the second option was 
chosen: '...we wanted to reduce ECNs... considered use of CAD and CNC or a product configurator and consultant suggested following lean practices and ISO regulations... '. Initially, the online product configurator option was considered. However, the expected customers for the modular kitchen were from all age groups, and an online product configurator would have been limited to the 'tech-savvy internet' customers only. Similarly, not every Indian house is connected to the internet. Therefore, a tablet-based product configurator was developed for the salespeople to guide the customers: '...internet connectivity and the reluctance of old-age customers with the use of online product configurators... convinced us for tablet based-interfaces... '. A third-party web interface design firm created the interface. The people from sales, design, and production provided inputs while the interface was designed: '... a web interface design company created the interface...the managers from sales, design, and production often visited the design firm to discuss the requirements...'. In the future, Company $\mathrm{B}$ is looking towards upgrading its ERP system, which will help them in tracking the position of the product in real-time. Integrating the ERP system with the product configurator would also be able to give a more appropriate price and delivery time to their customers: '...we plan to invest in our ERP system to check inventory status and provide a price and date for order supply...'. The ERP system will be complemented by sensors and connectivity that would be able to scan the product and update its position on the system as it goes through the production process.

The SM visions of both SMEs show that they were tailored towards a goal and were based on the understanding of their markets. Therefore, the above argument showed why establishing a tailored vision is necessary for manufacturing SMEs.

\section{v) Identify Tools and Practices to realize Smart Manufacturing Tailored Vision}

The employment of SM tools and practices will depend on the tailored SM vision that SMEs have in mind. This section discusses why the SMEs did or did not consider the various SM tools and practices during their SM journey.

\section{Fabrication/Manufacturing Toolbox + Robotics \& Automation Toolbox:}

Initially, the SME owner of the jewelry considered investing in machines that reduced the time taken during the finishing phase of the jewelry (i.e., filing, polishing, and plating). However, for introducing these machines, a major investment and a significant change in the organisational culture, as well as upskilling its workers were needed. Therefore, the Fabrication/Manufacturing Toolbox (FMT), and the Robotics \& Automation Toolbox (RAT) were not used in their SM journey: '.. time for finishing can be improved with the help of automated machines, but that would have required a major change in our organisational culture, upskilling our workers, and of course a big investment... '. Besides, the finishing time for jewelry was reduced, thanks to the use of 3D-printed molds that provided very precise and accurate jewels.

Similarly, the manager of Company B considered using CNC machines for designing the various parts of a modular kitchen. However, the use of CNC machines would have required employees who can design and generate the CNC codes, and looking at their ECN (120), redesigning and generating would have involved learning a new set of skills and would have resulted into employee 
resistance: '...CNC machines were an option, but we did not have the skills required to design and generate CNC codes ...'.

\section{Design \& Simulation Toolbox:}

Company A faced issues while identifying apt personnel. Finally, they invested in CAD training of a new jewelry designer (who first prepared concept jewelry design by hands, and then prepared the required mould by hands). At present, their demand in customized designed has increased to the extent that they hired two more CAD designers:' ...finding appropriate employees is always a difficult task.... we found engineers who could use CAD, and some designers who hand drew....the need was to have someone who designed Jewelry in CAD....therefore, we hired and invested in our designer to learn advanced CAD...'. '... due to increasing demand, now we have hired other designers as well...finding break-even point and when to invest in technology was also difficult...we waited for three months to invest in 3D-printing...'. The other changes in Company A's business model included finding a raw material supplier (to produce 3D-printed molds) and identifying the break-even point. Other issues were regarding the identification of the best time to invest in technology, because with time the technology cost will get reduced, however, they knew that early adopters are the ones that create a true competitive advantage. Finally, they decided to invest in 3D-printing after waiting for three months. They got the raw material from the same company, where they purchased their 3D-printers. However, their customers showed a positive response for the new designs, and therefore the Company B was able to reach their break-even point within eight months, whereas the break-even point was calculated as ten months: '...besides learning $C A D$, we invested in purchasing the raw material for prototyping from the same company where we purchased $3 D$ printers...our estimation showed that we could reach the break-even point in ten months, but due to increased demand we got there in eight months...'. The owner of Company A believed that they did not face major issues with the organisational change because the employee responsibilities did not change with the introduction of 3D-printed molds: '...you face little resistance when employees do not go through a change in their nature of the work...'. The use of 3D-printed molds required only two process changes, firstly, the concept (hand-drawn design of jewel) was to be drawn in CAD, and, secondly, they use 3D-printed wax molds (instead of the existing molds) during production. These wax molds result in more precise jewelry compared to before. As a result, the Company A was more efficient and reduced the time required during finishing process (i.e., filing, polishing and plating operations): '...investment was worth... with new technology the jewels produced are more precise and reduced the finishing time...'.

Company B was confident that investing in a product configurator might have helped them in reducing the number of ECNs they were getting: '...we had a feeling that a product configurator should help in minimizing the ECNs...'. They required a visual tool that also showed the specifications of the final product and use of a tablet-based product configurator was the best option. Using a virtual reality tool for customers would have required customer to reach their store and would have been expensive. The product configurator led to the use of CAD designs instead of the hand-drawn engineering drawings: '...virtual reality was an expensive option that would have needed customers to visit our stores... with the product configurator, the only change was to use CAD design as engineering drawing...'. 
Similarly, using CAD for production needed automated machines and skilled employees who can design and generate G-codes. All this would have required considerable investment and changes in the production practices: '...use of CAD drawings for production was difficult...purchasing automated and semi-automated machines would have required more investment and major changes during manufacturing, finding a skilled designer was another issue...'. These examples show that manufacturing SMEs preferred changes in design and sales practices.

Sensors \& Connectivity Toolbox, Cloud/Storage Toolbox, Data Analytics Toolbox:

Company B already implemented the product configurator/interface (a common tool for both Design \& Simulation toolbox and Sensors \& Connectivity Toolbox - see Appendix I, Table 1), whereas, Company A considered it as a future option (see Heading iv - developing a tailored SM vision). Company B also considered the use of the Sensors \& Connectivity Toolbox to be able to update the position of products and inventory within its ERP system. Use of data analysis was still unknown to both SMEs.

Data storage is also a significant step towards SM. However, Company A was least concerned regarding data storage. The only data they stored in MS-Excel was regarding the orders and the financial transactions. They used a storage device (e.g., removable flash drive) when they transferred the G-code generated by CAD to the 3D-printer. Although the Company B had an ERP system where the demands and initial payment (token amount) were well received from the customer end, however, the updates on the status of the products were still missing. Thus, highlighting that the ERP system acknowledged the 'finance' and the 'product' organisational dimensions only. We observed that workers manually typed the inventory/product updates, which were not accurate and utilized much time. To make the system more effective, and facilitate the real-time updates of the product, the sensors and connectivity tools are now planned to be installed in the future. The incomplete use of ERP system demonstrates an example where SMEs have the capability, but they are not utilizing the capability to its full potential.

It was seen that the data transmission, data storage and (elementary) data analysis were happening around the design and simulation toolbox. The SMEs employed design data for strategic decisions, like process planning, scheduling, and inventory. However, they were unable to perform sophisticated analysis on the available data. For example, maintenance was performed on a need basis, leading to a high downtime of machines, decreasing the production rate, and increasing the idle time for workers. Both SMEs were satisfied with the kind of data analysis they performed. However, if they even planned to perform more sophisticated data analysis, hiring a data analyst would have been expensive. Therefore, SMEs interested in data analysis should consider outsourcing it to consultancies or collaborating with the other researchers and academicians.

\section{Business Management Toolbox}

Various managerial practices were tried by both SMEs to improve their businesses. The jewelry manufacturer tried increasing the variety of jewelry designs by collaborating with other jewelry manufacturers; however, this collaboration did not work, because even the collaborator jewelry manufacturers were facing similar issues while producing complicated designs: '... we tried joining hands with other jewellers' manufacturers, but, they were also not producing the complicated 
designs...'. The Company B tried reducing the wastage by following lean philosophies and ISO certification practices (with the guidance of consultants) and changing the existing production layout. However, these changes did not affect the number of ECNs: '...we introduced lean and ISO practices, changed existing layouts; however, it did not make any difference...'.

Although SM can provide a competitive edge to the SMEs, initially SM adoption did not work for the two SMEs. For example, Company A tried collaborating with other jewelry manufacturers that had different designs to offer. Similarly, Company B followed lean and ISO practices to reduce the number of ECNs. However, with time they realized that these solutions were not representing the actual problems (e.g., offering customer-specific designs for the Company A, and reducing the miscommunication between the customer, sales, design, and production for the Company B). Company A knew that effect jewelry would not have interested more customers and, similarly, for Company B an online product configurator might have helped only the tech-savvy customers. Therefore, these pieces of evidence prove that chances of SM success will also depend on the identification of the actual problem and the understanding of their market.

Both SMEs followed an Engineer-to-Order (ETO) approach for production and adopted SM tools and practices in their shift from the use of hand-drawn engineering drawings to CAD drawings. Thus, modifying the operations during design and sales phases. Therefore, both cases show that 'hard manufacturing' operational practices were not changed during the shift towards SM. The analysis of both cases also highlights that SMEs based on ETO production policies will hesitate in modifying their existing 'hard manufacturing' practices. As demonstrated, Design and Simulation Toolbox does not/least affect the 'hard manufacturing' practices. Therefore, this toolbox will be more frequently used by ETO companies. Literature shows that sensors and connectivity tools can upgrade a stand-alone machine (Mittal, Romero and Wuest 2018a) without affecting the "hard manufacturing' practices. Therefore, this toolbox will also be preferred by enterprises. The SMEs cases showed that they were least concerned to improve the 'people' organisational dimension, and therefore, they did not have plans to improve the employee skills or make them more productive. As a result, the data collected for people was only dealing with the number of hours they worked. Although, Company A did consider the importance of learning CAD and therefore, its designer was made to learn CAD, however, it was the best option they had. Therefore, in general, SMEs hesitate from employee/worker training, and their participation in discussions.

From our discussion with the SMEs' owner/manager, we found that they have a basic understanding of the terms 'smart manufacturing', 'data analysis', and 'digitalization'. They also related 'smart manufacturing' with the use of smartphones and the internet. According to them, SM made their business more efficient, for example, now they were able to order through e-mails as compared to ordering through phone-calls. Similarly, for them 'digitalization' is the use of computers and design software, whereas, 'data analysis' involved working with MS-Excel functions (e.g., sorting), and doing analytics using arithmetic formulas.

Both SMEs reduced the processing time needed to meet the customer requirements. For Company A, preparing 3D-printed molds took less time as compared to the time taken to make hand-made molds. As 3-D printed molds were more accurate, they also reduced the required time for finishing the jewelry. Whereas, the Company B was able to reduce the time for customer requirements to 
feasibility analysis from five days to one day and designing BOM (Bill-of-Materials) for them became even more comfortable. Also, the percentage of sales orders the Company A was able to complete on time increased from $10 \%$ to $70 \%$. Similarly, when company B analysed their past orders, they started ordering eight standard size components (instead of ordering three standard size components) and thus reduced the production time and wastage. Thus, demonstrating how SM can make an enterprise more efficient. Moreover, the use of simple arithmetic functions can assist its shift in production policy from ETO to ATO. The visits and the discussion with the SMEs showed that various forms of data related to different organisational dimensions (i.e., finance, people, strategy, process, and product) are generated in the SMEs, however, when it comes to decision making, only the financial (cost) analysis is performed. Therefore, to appeal to the SME owners/managers, there is a need to convert the data related to other organisational dimensions as cost data. For example, the data related to the number of hours should be converted as cost/hour, this will inform the SME owner/manager about the downtime cost (of a machine), which an organisation must pay when a worker is going through his learning curve. The comparison of downtime cost with the cost of worker training will help the SME owner/manager to decide if worker training is required.

The data analysis performed on the two SMEs that recently adopted SM tools and practices established the suggest SM adoption framework (see Figure 3). We included an additional step to develop SM awareness in the SM adoption framework, and since the proposed framework helped the SMEs in their steps towards SM, therefore, the framework was established. We also found that the SM toolboxes for data generation were always at a higher level as compared to that for data transmission (see Appendix V). Similarly, the SM toolbox for data transmission was at a higher level as compared to the toolbox for data storage and data analysis. Thus, reflecting that for effective use of a toolbox, its preceding toolbox (in the data- hierarchy) should be at the same or higher level (see Appendix V). The application of 3D-prototyping and product configurator also show that tools from an SM toolbox (Mittal, Romero and Wuest 2018a) may not be used in the sequence (novice to expert). For example, the use of MS-Excel and an ERP system in Company $\mathrm{B}$ also showed that Company B did not use any hard drives in between.

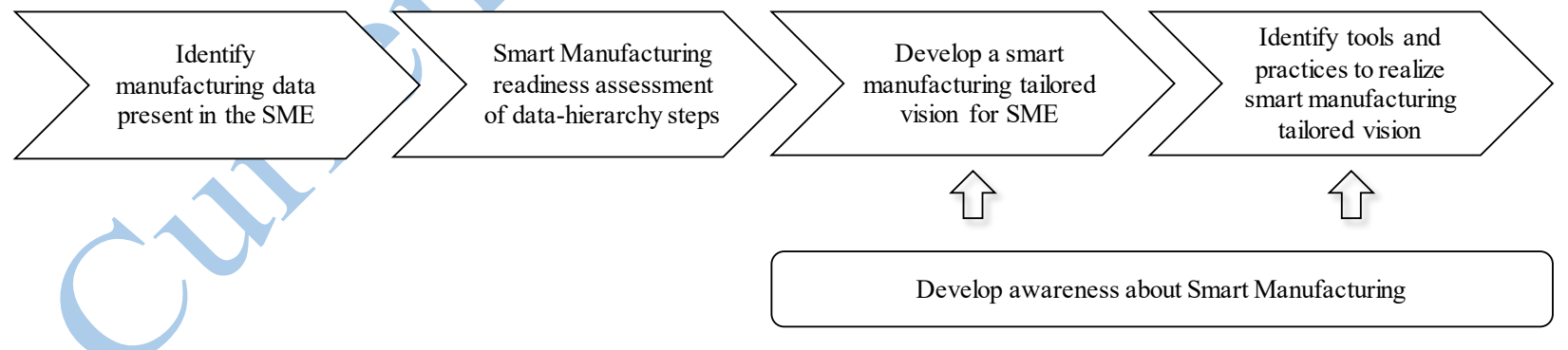

Figure 3: Smart Manufacturing Adoption Framework for SMEs

\section{Conclusions}

Adopting the SM paradigm provides SMEs with a competitive edge and is a necessary step to be considered as collaborators in digital supply networks. Our research caters towards the pressing need of manufacturing SMEs for targeted support by proposing a novel SM paradigm adoption 
framework. We established the proposed SM adoption framework with the help of a multiple case study research approach. The concepts of literal replication (and theoretical replication) were satisfied during the in-depth analysis of the SMEs that have recently adopted SM tools and practices (Miles, Huberman and Saldaña 1994; Yin 2003; Voss, Nikos and Mark 2002). The perspective of SMEs also led to the addition of a new step in the adoption framework. Following are the analytical generalization resulting from the lessons learned from the experiences of SMEs cases:

- The necessary steps that helped the SMEs cases in their journey towards adopting SM are: (i) identifying the manufacturing data present in the SME, (ii) assessing SM readiness of the SME among the data-hierarchy steps, (iii) developing an SM tailored vision for SMEs, and (iv) identifying the appropriate tools and practices that will lead towards the SM tailored vision.

- SMEs that work on ETO production principles may avoid modifying their 'hardmanufacturing' practices, and, therefore, design and simulation toolbox can be the most preferred toolbox for SM paradigm adoption. As sensors and connectivity toolbox will least affect the existing hard manufacturing practices followed in the organisation, therefore, SMEs may prefer sensors and connectivity toolbox over other toolboxes. Similarly, since business and management tools require a significant effort to modify the existing organisational culture and practices, therefore, they may be less preferred.

- In general, SMEs are not aware of the potential of data analytics. Despite the ample amount of data available and stored by them, SMEs may not be doing data analysis, and thus, the SMEs keep themselves away from the advantages of data-driven decision making. Similarly, SMEs may underutilize the available resources.

- SMEs may be prepared for initiatives that help them to improve their customer-facing products and services. For example, the features related to finance and product organisational dimensions may lead to better customer experiences. However, process, strategy, and employee may be the least acknowledged organisation dimension. Therefore, SMEs may deprive-themselves of the benefits they might have with automation, improving employee skills and education.

- Similarly, the short-term and the long-term profits can convince the SME managers/owners towards the SM paradigm shift. Since SMEs mostly use the financial data for decision making, and data related to other organisational dimensions is ignored, therefore, to appeal to the owner/manager of an SME the data corresponding to other SME organisational dimensions should be presented as cost.

- We know that SMEs' inclination towards SM may depend on the awareness of the owner/manager, and similarly, SMEs' generally believe in mimicking the successful business models. Therefore, it is the responsibility of academicians and researchers to organise workshops, seminars, training sessions, and share stories of successful enterprises to inform the SME owners/managers about the developments in their fields.

Overall, all the options considered by the SMEs, for the future were covered under the umbrella of SM toolkit (Mittal, Romero and Wuest 2018a). Therefore, the SM toolkit can be employed by SMEs to identify the set of required technical tools and managerial practices to achieve their 
tailored vision. The cases also demonstrated that SMEs are ready to invest in SM. Although, the SMEs cases transformed themselves towards SM, however, the transformation was only technical and involved the least number of people. It shows SMEs' fear regarding changing their organisational culture. For example, in developing countries like India, the workers do not sign any bonds with the organisations (SMEs). Thus, any change in organisational culture is a threat, and SMEs are afraid of losing skilled employees. So, investing in worker training and education further increases the risk of losing their investments.

\subsection{Limitations and Future Work}

Multiple cases can enhance the validity of a study and our study employed two cases and established the proposed framework by generalizing the theoretical propositions (not the population as in case of the statistical research) (Zhang et al. 2005; Lee 1989; Yin 2003). We completed the study in a relatively short period, resulting in comparably small documents and systematic handling of data (Yin 2003) and it was not an ethnography (Fetterman 1989) or a participant-observation study (Jorgensen 1989). Therefore, our study was able to overshadow the complaints during case study research (Yin 2003). Our study interviewed only the owner (for Company A) and the manager (for Company B), and therefore, single informant bias was a concern. The socio-cultural and political issues can also influence the SM paradigm adoption in SMEs, however, our study only considers the technical, managerial and operational aspects of adopting SM in SMEs.

The future work will be to apply the proposed framework to several other manufacturing SMEs and present the discussion, and findings. The SME cases in our study showed that SMEs learn by mimicking business models of other successful enterprises. The future work will also demonstrate the enterprises that have already adopted SM tools and practices, and highlight the advantages and issues faced by these SM SMEs. Similarly, the cases in our research prepared their production policies based on ETO production principles. Therefore, future work will be to discuss how this framework works with SMEs that use production policies like MTS, MTO, ATO, and CTO for their production. In future, the SMEs cases from developed and developing countries should be compared to study the effect of socio-cultural and political issues during SM paradigm adoption in SMEs. This framework can be extended to a self-evaluation tool to be used by the SME owners and managers. The tool can also be further tailored and refined to the needs of the specific manufacturing sectors. Data generated by the specific manufacturing sectors can be used to assess the present readiness of an SME. Then the experts from the manufacturing sector can be consulted to decide if the amount to be subsidized for a loan is acceptable to realize the SME's vision. Thus, the use of the smart manufacturing adoption framework will mitigate the government's risk of financial investment during the technology adoption in an SME.

\section{Acknowledgments}

Our manuscript is a result of a previous article: 'Towards a Smart Manufacturing Maturity Model for SMEs $\left(\mathrm{SM}^{3} \mathrm{E}\right)$ ', i.e., Mittal, Romero and Wuest 2018b, presented in Advances in Production Management Systems (APMS), August 26-30, 2018, Seoul, South Korea. The author(s) would like

to thank the managers of enterprises visited in India and West Virginia that helped in the 
development of this manuscript. The authors are also thankful to the anonymous referees for their comments that helped in significantly improving the quality of the manuscript.

\section{Declaration of Conflicting Interests}

The author(s) declared no potential conflicts of interest concerning the research, authorship, or publication of this article.

\section{References}

1. Ahuett-Garza, Horacio, and Thomas Kurfess. 2018. "A brief discussion on the trends of habilitating technologies for Industry 4.0 and Smart manufacturing." Manufacturing Letters 15: 60-63.

2. Akdil, Kartal Yagiz, Alp Ustundag, and Emre Cervical. 2018. "Maturity and readiness model for Industry 4.0 strategy." In Industry 4.0: Managing the Digital Transformation, edited by Alp Ustundag, and Emre Cervical, 61-94. Springer, Cham. DOI: 10.1007/978-3-319-57870-5_4.

3. Anderl, R., A. Picard, Y. Wang, J. Fleischer, S. Dosch, B. Klee, and J. Bauer. 2015. "Guideline Industrie 4.0Guiding principles for the implementation of Industrie 4.0 in small and medium sized businesses." In VDMA Forum Industrie, vol. 4.

4. Arnold, Christian, Daniel Kiel, and Kai-Ingo Voigt. 2016. "How the industrial internet of things changes business models in different manufacturing industries." International Journal of Innovation Management 20 (8), 1640015.

5. Benbasat, I., Goldstein, D.K., Mead, M. 1987. The case research strategy in studies of information systems. MIS Quarterly 11 (3): 369-386.

6. Benedict, Neal, Pamela Smithburger, Amy Calabrese Donihi, Philip Empey, Lawrence Kobulinsky, Amy Seybert, Thomas Waters et al. 2017. "Blended simulation progress testing for assessment of practice readiness." American journal of pharmaceutical education 81 (1): 14.

7. Brettel, Malte, Christoph Chomik, and Tessa Christina Flatten. 2015. "How organizational culture influences innovativeness, proactiveness, and risk-taking: Fostering entrepreneurial orientation in SMEs." Journal of Small Business Management 53 (4): 868-885.

8. Brozzi, R., R. D. D’Amico, G. Pasetti Monizza, C. Marcher, M. Riedl, and D. Matt. 2018. "Design of Selfassessment Tools to Measure Industry 4.0 Readiness. A Methodological Approach for Craftsmanship SMEs." In IFIP International Conference on Product Lifecycle Management, edited by Paolo Chiaber, Abdelaziz Bouras, Frédéric Noël, and José Ríos, 566-578. Springer, Cham. DOI: 10.1007/978-3-030-01614-2_52.

9. Bryner, Michelle. 2012. "Smart manufacturing: The next revolution." Chemical Engineering Progress 108 (10): 4-12.

10. Boothby, Daniel, Anik Dufour, and Jianmin Tang. 2010. "Technology adoption, training and productivity performance." Research Policy 39 (5): 650-661.

11. Carayannis, Elias G., Denisa Popescu, Caroline Sipp, and McDonald Stewart. 2006. "Technological learning for entrepreneurial development (TL4ED) in the knowledge economy (KE): case studies and lessons learned." Technovation 26(4): 419-443.

12. Carson, David, and Audrey Gilmore. 2000. "SME marketing management competencies." International Business Review 9 (3): 363-382.

13. Centobelli, Piera, Roberto Cerchione, and Emilio Esposito. 2017. "Knowledge management systems: the hallmark of SMEs." Knowledge Management Research \& Practice 15(2): 294-304.

14. Chiang, Yachi, and Dasheng Lee. 2017. "Smart manufacturing with the internet of makers." Journal of the Chinese Institute of Engineers 40 (7): 585-592.

15. Chiarello, Filippo, Leonello Trivelli, Andrea Bonaccorsi, and Gualtiero Fantoni. 2018. "Extracting and mapping industry 4.0 technologies using wikipedia." Computers in Industry 100: 244-257.

16. Črešnar, Rok, Protcan, Vojko and Nedelko, Zlatko 2018. "Management Tools for Supporting the Transition of Manufacturing Organizations to Industry 4.0: The Case of Slovenia". IACSC 2018 - IACLPM 2018 joint $\begin{array}{llllll}\text { conference } & \text { proceedings. } & \text { Retrieved } & \text { in } & \text { Jan } & \\ \end{array}$ 
https://www.researchgate.net/publication/329103952_Management Tools_for_Supporting the Transition of Manufacturing_Organizations to Industry 40 The Case of Slovenia

17. Coetzer, Alan, Chutarat Inma, Paul Poisat, Janice Redmond, and Craig Standing. 2019. "Does job embeddedness predict turnover intentions in SMEs?" International Journal of Productivity and Performance Management 68 (2): 340-361.

18. Davies, Robert, Tim Coole, and Alistair, Smith. 2017. "Review of socio-technical considerations to ensure successful implementation of Industry 4.0." Procedia Manufacturing 11: 1288-1295.

19. Dalenogare, Lucas Santos, Guilherme Brittes Benitez, Néstor Fabián Ayala, and Alejandro Germán Frank. 2018. "The expected contribution of Industry 4.0 technologies for industrial performance." International Journal of Production Economics 204: 383-394.

20. Dangayach, G. S., and S. G. Deshmukh. 2005. "Advanced manufacturing technology implementation: evidence from Indian small and medium enterprises (SMEs)." Journal of Manufacturing Technology Management 16 (5): 483-496.

21. Davis, Jim, Thomas Edgar, James Porter, John Bernaden, and Michael Sarli. 2012. "Smart manufacturing, manufacturing intelligence and demand-dynamic performance." Computers \& Chemical Engineering 47: 145156.

22. EC (European Commission) 2003. Retrieved in April 2018 from http://ec.europa.eu/growth/smes/businessfriendly-environment/sme-definition en

23. EC (European Commission) 2006. Retrieved in October 2018 from http://ec.europa.eu/regional_policy/sources/conferences/state aid/sme/smedefinitionguide en.pdf

24. Eisenhardt, Kathleen M. 1989. Building theories from case study research. Academy of management review 14 (4): 532-550.

25. Fetterman, David M. 1989. Applied social research methods series: Vol. 17. Ethnography: Step by step.

26. Fettermann, Diego Castro, Caroline Gobbo Sá Cavalcante, Tatiana Domingues de Almeida, and Guilherme Luz Tortorella. 2018. "How does Industry 4.0 contribute to operations management?" Journal of Industrial and Production Engineering 35 (4): 255-268.

27. Fink, Dieter, and Georg Disterer. 2006. "International case studies: to what extent is ICT infused into the operations of SMEs?" Journal of Enterprise Information Management 19 (6): 608-624.

28. Frank, Alejandro Germán, Lucas Santos Dalenogare, and Néstor Fabián Ayala. 2019. "Industry 4.0 technologies: Implementation patterns in manufacturing companies." International Journal of Production Economics 210: 1526.

29. Flyvbjerg, Bent. 2006. Five misunderstandings about case-study research. Qualitative inquiry 12 (2): 219-245.

30. Ganzarain, Jaione, and Nekane Errasti. 2016. "Three stage maturity model in SME's toward industry 4.0." Journal of Industrial Engineering and Management 9 (5): 1119-1128.

31. Garcia, Marie L., and Olin H. Bray. 1997. Fundamentals of technology roadmapping. No. SAND-97-0665. Sandia National Labs., Álbuquerque, NM (United States).

32. Geissbauer, Reinhard, Jesper Vedso, and Stefan Schrauf. 2016. "Industry 4.0: Building the digital enterprise." Retrieved in October 2018 from https://www. pwc. com/gx/en/industries/industries-4.0/landingpage/industry-4.0-building-your-digital-enterprise-april-2016. pdf

33. Gershwin, Stanley B. 2018. "The future of manufacturing systems engineering." International Journal of Production Research 56 (1-2): 224-237.

34. Ghobakhloo, Morteza. 2018. "The future of manufacturing industry: A strategic roadmap toward Industry 4.0." Journal of Manufacturing Technology Management 29 (6): 910-936.

35. Gökalp, Ebru, Şener, Umut and Eren, P. Erhan. 2017. "Development of an assessment model for industry 4.0: industry 4.0-MM." In International Conference on Software Process Improvement and Capability Determination, edited by Antonia Mas, Antoni Mesquida, Rory V. O'Connor, Terry Rout and Alec Dorling, 128-142. Springer, Cham.

36. Gupta, Shivam, Sachin Modgil, and Angappa Gunasekaran. 2019. "Big data in lean six sigma: a review and further research directions." International Journal of Production Research: 1-23.

37. Handfield, Robert B., and Melnyk, Steven A. 1998. "The scientific theory-building process: a primer using the case of TQM." Journal of operations management 16 (4): 321-339. 
38. Hermann, M., Pentek, T. and Otto, B. 2016. Design principles for industrie 4.0 scenarios. In 2016 49th Hawaii international conference on system sciences (HICSS) (pp. 3928-3937). IEEE.

39. Husin, Mohd Azian, and Mohamed Dahlan Ibrahim. 2014. "The role of accounting services and impact on small medium enterprises (SMEs) performance in manufacturing sector from East Coast Region of Malaysia: A conceptual paper." Procedia-Social and Behavioral Sciences 115: 54-67.

40. Issa, Ahmad, Lucke, Dominik, amd Bauernhansl, Thomas. 2017. "Mobilizing SMEs towards Industrie 4.0enabled smart products". Procedia CIRP 63: 670-674.

41. Jankowska, Barbara, Marta Götz, and Cezary Główka. 2017. "Intra-cluster cooperation enhancing SMEs' competitiveness-the role of cluster organisations in Poland." Investigaciones Regionales- Journal of Regional Research 39: 195-214.

42. Jorgensen, Danny L. 1989. "The methodology of participant observation." Thousand Oaks: SAGE, 12-26.

43. Jung, Kiwook, Boonserm Kulvatunyou, Sangsu Choi, and Michael P. Brundage. 2016. "An overview of a smart manufacturing system readiness assessment." In IFIP International Conference on Advances in Production Management Systems, edited by Irenilza Nääs, Oduvaldo Vendrametto, João Mendes Reis, Rodrigo Franco Gonçalves, Márcia Terra Silva, Gregor von Cieminski and Dimitris Kiritsis, 705-712. Springer, Cham.

44. Kannan, S. Manoj, Kunal Suri, Juan Cadavid, Ion Barosan, Mark Van Den Brand, Mauricio Alferez, and Sebastien Gerard. 2017. "Towards industry 4.0: Gap analysis between current automotive MES and industry standards using model-based requirement engineering." In 2017 IEEE International Conference on Software Architecture Workshops (ICSAW), 29-35.

45. Kolberg, Dennis, Joshua Knobloch, and Detlef Zühlke. 2017. "Towards a lean automation interface for workstations." International Journal of Production Research 55 (10): 2845-2856.

46. Kongolo, Mukole. 2010. "Job creation versus job shedding and the role of SMEs in economic development." African Journal of Business Management 4 (11): 2288-2295.

47. Kuo, Yong-Hong, and Andrew Kusiak. 2018. "From data to big data in production research: the past and future trends." International Journal of Production Research: 1-26. DOI: 10.1080/00207543.2018.1443230

48. Kusiak, Andrew. "Smart manufacturing must embrace big data." 2017. Nature News 544 (7648): 23-25.

49. Kusiak, Andrew. 2018. "Smart manufacturing." International Journal of Production Research 56 (1-2): 508-517.

50. Lee, Allen S. 1989. "A scientific methodology for MIS case studies." MIS Quarterly: 33-50.

51. Lee, Jay, Hung-An Kao, and Shanhu Yang. 2014. "Service innovation and smart analytics for industry 4.0 and big data environment." Procedia CIRP 16: 3-8.

52. Lee, Jeongcheol, Sungbum Jun, Tai-Woo Chang, and Jinwoo Park. 2017. "A smartness assessment framework for smart factories using analytic network process." Sustainability 9 (5): 794.

53. Liao, Yongxin, Fernando Deschamps, Eduardo de Freitas Rocha Loures, and Luiz Felipe Pierin Ramos. 2017. "Past, present and future of Industry 4.0-a systematic literature review and research agenda proposal." International Journal of Production Research 55 (12): 3609-3629.

54. Lichtblau, K., Volker Stich, R. Bertenrath, M. Blum, M. Bleider, A. Millack, K. Schmitt, E. Schmitz, and M. Schröter. 2015. "IMPULS-industrie 4.0-readiness." Impuls-Stiftung des VDMA, Aachen-Köln. Retrieved in October 2018 from http://www.impuls stiftung.de/documents/3581372/4875835/ Industrie+4.0+Readniness+IMPULS+Studie+Oktober+2015.pdf/447a6187-9759-4f25-b186-b0f5eac69974

55. Lukács, Edit. 2005. "The economic role of SMEs in world economy, especially in Europe." European Integration Studies 4 (1): 3-12.

56. Marr, Bernard. 2015. Big Data: Using SMART big data, analytics and metrics to make better decisions and improve performance. John Wiley \& Sons.

57. Mayr, Andreas, M. Weigelt, A. Kühl, S. Grimm, A. Erll, M. Potzel, and J. Franke. 2018. "Lean 4.0-A conceptual conjunction of lean management and Industry 4.0." Procedia CIRP 72: 622-628.

58. Mellor, Stephen, Liang Hao, and David Zhang. 2014. "Additive manufacturing: A framework for implementation." International Journal of Production Economics 149: 194-201.

59. Menon, Karan, Hannu Kärkkäinen, Thorsten Wuest, and Jayesh Prakash Gupta. 2019. "Industrial internet platforms: A conceptual evaluation from a product lifecycle management perspective." Proceedings of the Institution of Mechanical Engineers, Part B: Journal of Engineering Manufacture 233 (5): 1390-1401. 
60. Mettler, Tobias. 2011. "Maturity assessment models: a design science research approach." International Journal of Society Systems Science 3 (1/2): 81-98.

61. Miles, Matthew B., Huberman, A. Michael, and Saldaña, Johnny. 1994. Qualitative data analysis: An expanded sourcebook. Sage.

62. Mittal, Sameer, Muztoba Ahmad Khan, David Romero, and Thorsten Wuest. 2017. "Smart manufacturing: characteristics, technologies and enabling factors. " Proceedings of the Institution of Mechanical Engineers, Part B: Journal of Engineering Manufacture 233 (5): 1342-1361.

63. Mittal, Sameer, Muztoba Ahmad Khan, David Romero, and Thorsten Wuest. 2018. "A critical review of smart manufacturing \& Industry 4.0 maturity models: Implications for small and medium-sized enterprises (SMEs)." Journal of Manufacturing Systems 49: 194-214.

64. Mittal, Sameer, David Romero, and Thorsten Wuest. 2018a. "Towards a smart manufacturing toolkit for SMEs." In IFIP International Conference on Product Lifecycle Management, edited by Paolo Chiaber, Abdelaziz Bouras, Frédéric Noël, and José Ríos, 476-487. Springer, Cham.

65. Mittal, Sameer, David Romero, and Thorsten Wuest. 2018b. "Towards a Smart Manufacturing Maturity Model for SMEs (SM 3 E)." In IFIP International Conference on Advances in Production Management Systems, edited by Ilkyeong Moon, Gyu M. Lee, Jinwoo Park, Dimitris Kiritsis and Gregor von Cieminski, 155-163. Springer, Cham.

66. Mittal, Sameer, David Romero, and Thorsten Wuest. 2019. "Building blocks for adopting smart manufacturing." Procedia Manufacturing Vol. 34, 978-985.

67. Meredith, Jack. 1998. "Building operations management theory through case and field research." Journal of Operations Management 16 (4): 441-454.

68. Moeuf, Alexandre, Robert Pellerin, Samir Lamouri, Simon Tamayo-Giraldo, and Rodolphe Barbaray. 2018. "The industrial management of SMEs in the era of Industry 4.0." International Journal of Production Research 56 (3): $1118-1136$.

69. Müller, Julian Marius, Oana Buliga, and Kai-Ingo Voigt. 2018. "Fortune favors the prepared: How SMEs approach business model innovations in Industry 4.0." Technological Forecasting and Social Change 132: 2-17.

70. Nkwe, Nugi. "Role of SMES in Botswana. 2012." American International Journal of contemporary research 2 (8): 29-37.

71. O’Donovan, Peter, Kevin Leahy, Ken Bruton, and Dominic TJ O'Sullivan. 2015. "An industrial big data pipeline for data-driven analytics maintenance applications in large-scale smart manufacturing facilities." Journal of Big Data 2-25. DOI 10.1186/s40537-015-0034-z

72. O'Regan, Nicholas, Abby Ghobadian, and Martin Sims. 2006. "Fast tracking innovation in manufacturing SMEs." Technovation 26 (2): 251-261.

73. Packianather, Michael S., Alan Davies, Sam Harraden, Sajith Soman, and John White. 2017. "Data mining techniques applied to a manufacturing SME." Procedia CIRP 62: 123-128.

74. Qi, Qinglin, and Fei Tao. 2018. "Digital twin and big data towards smart manufacturing and industry 4.0: 360degree comparison." IEEE Access 6: 3585-3593.

75. Qin, Jian, Ying Liu, and Roger Grosvenor. 2016. "A categorical framework of manufacturing for industry 4.0 and beyond." Procedia CIRP 52: 173-178.

76. Radziwon, Agnieszka, Arne Bilberg, Marcel Bogers, and Erik Skov Madsen. 2014. "The smart factory: exploring adaptive and flexible manufacturing solutions." Procedia Engineering 69: 1184-1190.

77. Rayna, T., \& Striukova, L. 2016. "From rapid prototyping to home fabrication: How 3D printing is changing business model innovation". Technological Forecasting and Social Change, 102, 214-224.

78. Raymond, Louis. 2005. "Operations management and advanced manufacturing technologies in SMEs: a contingency approach." Journal of Manufacturing Technology Management 16 (8): 936-955.

79. Automation, Rockwell. 2014. "The connected enterprise maturity model." Retrieved in October 2018 from http:// literature. rockwellautomation.com/idc/groups/literature/documents/wp/cie-wp002_en-p.pdf

80. Romero, David, Paolo Gaiardelli, Daryl Powell, Thorsten Wuest, and Matthias Thürer. 2018. "Digital Lean Cyber-Physical Production Systems: The Emergence of Digital Lean Manufacturing and the Significance of Digital Waste." In IFIP International Conference on Advances in Production Management Systems, edited by Ilkyeong Moon, Gyu M. Lee, Jinwoo Park, Dimitris Kiritsis and Gregor von Cieminski, 11-20. Springer, Cham. 
81. Ruivo, Pedro, Björn Johansson, Tiago Oliveira, and Miguel Neto. 2013. "Commercial ERP systems and user productivity: A study across European SMEs." Procedia Technology 9: 84-93.

82. Ruivo, Pedro, Tiago Oliveira, and Miguel Neto. 2015. "Using resource-based view theory to assess the value of ERP commercial-packages in SMEs." Computers in Industry 73: 105-116.

83. Saucedo-Martínez, Jania Astrid, Magdiel Pérez-Lara, José Antonio Marmolejo-Saucedo, Tomás Eloy SalaisFierro, and Pandian Vasant. 2018. "Industry 4.0 framework for management and operations: a review." Journal of Ambient Intelligence and Humanized Computing 9: 789-801. DOI: 10.1007/s12652-017-0533-1

84. Schiersch, Alexander. 2009. "Inefficiency in the German mechanical engineering sector."

85. Schramm, Wilbur. 1971. "Notes on Case Studies of Instructional Media Projects."

86. Schuh, Günther, Reiner Anderl, Jürgen Gausemeier, Michael ten Hompel, and Wolfgang Wahlster. 2017. "Industrie 4.0 Maturity Index." Managing the Digital Transformation of Companies. Munich: Herbert Utz. Retrieved in October 2018 from http://www.acatech.de/fileadmin/user_upload/Baumstruktur_nach_Website/Acatech/root/de/Publikationen/Proj ektbeichte/acatech_STUDIE_Maturity_Index_eng_WEB.pdf

87. Schumacher, Andreas, Selim Erol, and Wilfried Sihn. 2016. "A maturity model for assessing Industry 4.0 readiness and maturity of manufacturing enterprises." Procedia CIRP 52: 161-166. DOI: 10.1016/j.procir.2016.07.040

88. Scremin, Luca, Fabiano Armellini, Alessandro Brun, Laurence Solar-Pelletier, and Catherine Beaudry. 2018. "Towards a framework for assessing the maturity of manufacturing companies in industry 4.0 adoption." In Analyzing the Impacts of Industry 4.0 in Modern Business Environments, 224-254. IGI Global. DOI: 10.4018/978-1-5225-3468-6.ch012

89. Seawright, Jason, and John Gerring. 2008. "Case selection techniques in case study research: A menu of qualitative and quantitative options." Political Research Quarterly 61 (2): 294-308.

90. Shashi, Centobelli, Piera, Roberto Cerchione, and Rajwinder Singh. "The impact of leanness and innovativeness on environmental and financial performance: Insights from Indian SMEs." International Journal of Production Economics 212 (2019): 111-124.

91. Skinner, Wickham. 1984. "Operations technology: blind spot in strategic management." Interfaces 14 (1): 116125.

92. Sommer, Lutz. 2015. "Industrial revolution-industry 4.0: Are German manufacturing SMEs the first victims of this revolution?" Journal of Industrial Engineering and Management 8 (5): 1512-1532.

93. Srai, Jagjit Singh, Mukesh Kumar, Gary Graham, Wendy Phillips, James Tooze, Simon Ford, Paul Beecher et al. 2016. "Distributed manufacturing: scope, challenges and opportunities." International Journal of Production Research 54 (23): 6917-6935.

94. Strozzi, Fernanda, Claudia Colicchia, Alessandro Creazza, and Carlo Noè. 2017. "Literature review on the 'Smart Factory'concept using bibliometric tools." International Journal of Production Research 55 (22): 6572-6591.

95. Storey, M-A. 2005. "Theories, methods and tools in program comprehension: Past, present and future." In 13th International Workshop on Program Comprehension (IWPC'05), 181-191. DOI: 10.1109/WPC.2005.38

96. Syafrudin, Muhammad, Norma Fitriyani, Ganjar Alfian, and Jongtae Rhee. 2019. "An Affordable Fast Early Warning System for Edge Computing in Assembly Line." Applied Sciences 9 (1): 84. DOI:10.3390/app9010084

97. Tao, Fei, Qinglin Qi, Ang Liu, and Andrew Kusiak. 2018. "Data-driven smart manufacturing." Journal of Manufacturing Systems 48: 157-169.

98. Taylor, Robin, David Baron, and Daniel Schmidt. 2015. "The world in 2025-predictions for the next ten years." In 2015 10th International Microsystems, Packaging, Assembly and Circuits Technology Conference (IMPACT), 192-195. DOI: 10.1109/IMPACT.2015.7365193

99. Thoben, Klaus-Dieter, Stefan Wiesner, and Thorsten Wuest. 2017. "“Industrie 4.0" and smart manufacturing-a review of research issues and application examples." International Journal of Automation Technology 11 (1): 416.

100.Tortorella, Guilherme Luz, and Diego Fettermann. 2018. "Implementation of Industry 4.0 and lean production in Brazilian manufacturing companies." International Journal of Production Research 56 (8): 2975-2987. 
101.Van de Vrande, Vareska, Jeroen PJ De Jong, Wim Vanhaverbeke, and Maurice De Rochemont. 2009. "Open innovation in SMEs: Trends, motives and management challenges." Technovation 29 (6-7): 423-437.

102.Voss, Chris. 2010. "Case research in operations management." In Researching operations management, 176-209. Routledge.

103.Wang, M. L., Ting Qu, Ray Y. Zhong, Q. Y. Dai, X. W. Zhang, and J. B. He. 2012. "A radio frequency identification-enabled real-time manufacturing execution system for one-of-a-kind production manufacturing: a case study in mould industry." International Journal of Computer Integrated Manufacturing 25 (1): 20-34.

104.Wang, Jinjiang, Yulin Ma, Laibin Zhang, Robert X. Gao, and Dazhong Wu. 2018. "Deep learning for smart manufacturing: Methods and applications." Journal of Manufacturing Systems 48: 144-156. DOI: 10.1016/j.jmsy.2018.01.003

105. Weyer, Stephan, Mathias Schmitt, Moritz Ohmer, and Dominic Gorecky. 2015. "Towards Industry 4.0Standardization as the crucial challenge for highly modular, multi-vendor production systems." IfacPapersonline 48 (3): 579-584.

106. White, Garry. 2009. "Strategic, tactical, \& operational management security model." Journal of Computer Information Systems 49 (3): 71-75.

107.Xu, Li Da, Eric L. Xu, and Ling Li. 2018. "Industry 4.0: state of the art and future trends." International Journal of Production Research 56 (8): 2941-2962.

108. Yadav, Vinod, Rakesh Jain, Murari Lal Mittal, Avinash Panwar, and Andrew Lyons. 2019. "The impact of lean practices on the operational performance of SMEs in India." Industrial Management \& Data Systems 119 (2): 317-330.

109. Yin, Robert K. 2003. "Case study research design and methods third edition." Applied Social Research Methods Series 5.

110.Zainal, Zaidah. 2007. "Case study as a research method". Jurnal Kemanusiaan, 5 (1).

111.Závadská, Zuzana, and Ján Závadský. 2018. "Quality managers and their future technological expectations related to Industry 4.0." Total Quality Management \& Business Excellence, 1-25. DOI: 10.1080/14783363.2018.1444474

112.Zezulka, František, Petr Marcon, I. Vesely, and Ondrej Sajdl. 2016. "Industry 4.0-An Introduction in the phenomenon." IFAC-PapersOnLine 49(25): 8-12.

113.Zhang, Zhe, Matthew KO Lee, Pei Huang, Liang Zhang, and Xiaoyuan Huang. 2005. "A framework of ERP systems implementation success in China: An empirical study." International Journal of Production Economics 98 (1): 56-80.

114.Zheng, Pai, Zhiqian Sang, Ray Y. Zhong, Yongkui Liu, Chao Liu, Khamdi Mubarok, Shiqiang Yu, and Xun Xu. 2018. "Smart manufacturing systems for Industry 4.0: Conceptual framework, scenarios, and future perspectives." Frontiers of Mechanical Engineering 13 (2): 137-150.

115.Zhong, Ray Y., Xu, X., and Wang, L. 2017. "IoT-enabled smart factory visibility and traceability using laserscanners". Procedia Manufacturing, 10, 1-14.

116.Zhong, Ray Y., Chen Xu, Chao Chen, and George Q. Huang. 2017. "Big Data Analytics for Physical Internetbased intelligent manufacturing shop floors." International Journal of Production Research 55 (9): 2610-2621.

117.Zhong, Ray Y. 2018. "Analysis of RFID datasets for smart manufacturing shop floors." In 2018 IEEE 15th International Conference on Networking, Sensing and Control (ICNSC), 1-4. IEEE. DOI: 10.1109/ICNSC.2018.8361321.

\section{Appendix I: Smart Manufacturing Maturity Model for SMEs}

Below is presented the description of the SM maturity model.

\section{Smart Manufacturing Maturity Model for SMEs (SM3E)}

The Smart Manufacturing Maturity Model for SMEs (SM $\left.{ }^{3} \mathrm{E}\right)$ (Mittal, Romero and Wuest 2018b) (see Figure 1) is a three-dimensional structure, suggesting seven toolboxes to be utilised at five maturity levels to serve the five SME 
organisational dimensions. The sub-headings i), ii) \& iii) highlights the SM toolkit, maturity levels, and organisational dimensions.

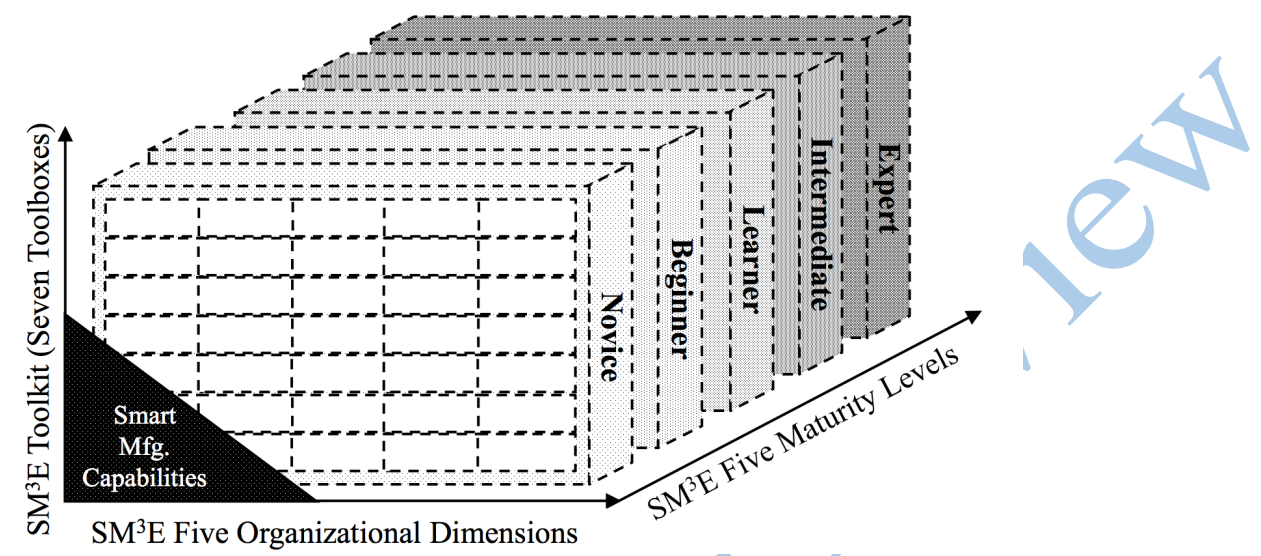

Figure 1: The Smart Manufacturing Maturity Model for SMEs (SM³ E) (Mittal, Romero and Wuest 2018b)

\section{i) Smart Manufacturing Toolkit for SMEs}

SM toolkit will increase the SM capabilities of manufacturing SMEs with the help of technologies, methods, tools, and practices (Mittal, Romero and Wuest 2018a). The SM toolkit comprises of seven toolboxes (see Figure 2). The toolboxes 1-6 focus on the technical aspects of SM, whereas, the toolbox seven focus on the operational and managerial aspects of SM.

- Toolbox 1: Fabrication/Manufacturing Toolbox (FMT) - This toolbox focuses on the evolution of manufacturing. The various inputs required are raw materials, energy, parts, order or sustainable resources.

- Toolbox 2: Design and Simulation Toolbox (DST) - This toolbox focuses on simulating the production processes. The various inputs required are hand-based designs, design environment, simulation software, 3D prototypes and customer interface.

- Toolbox 3: Robotics and Automation Toolbox (RAT) - This toolbox focuses on replacing the repetitive and strenuous and repetitive human work with the robots and automation tools. The various inputs required are manually-operated machines, non-programmable machines, programmable machines, collaborative robots (that mimic human), and collaborative robot (based on $\mathrm{AI}$ ).

- Toolbox 4: Sensors and Connectivity Toolbox (SCT) - This toolbox focuses on converting the manufacturing outputs to a readable format. The various inputs required are source, sensors, signals and converters, storage device, interface.

- Toolbox 5: Cloud/Storage Toolbox (CST) - This toolbox focuses on enabling efficient data storage and sharing in the SMEs. The various inputs required are registers, log books, built-in HDs, shared HDs, cloud, and fog.

- Toolbox 6: Data Analytics Toolbox (DAT) - This toolbox focuses on assisting data analytics. The various inputs required are data collection, data cleaning, data integration, data reduction, and data transformation.

- Toolbox 7: Business Management Toolbox (BMT) - This toolbox focuses on improving culture in the SMEs. The various inputs required here are practices such as lean thinking, positive organisation culture, and customer involvement. 


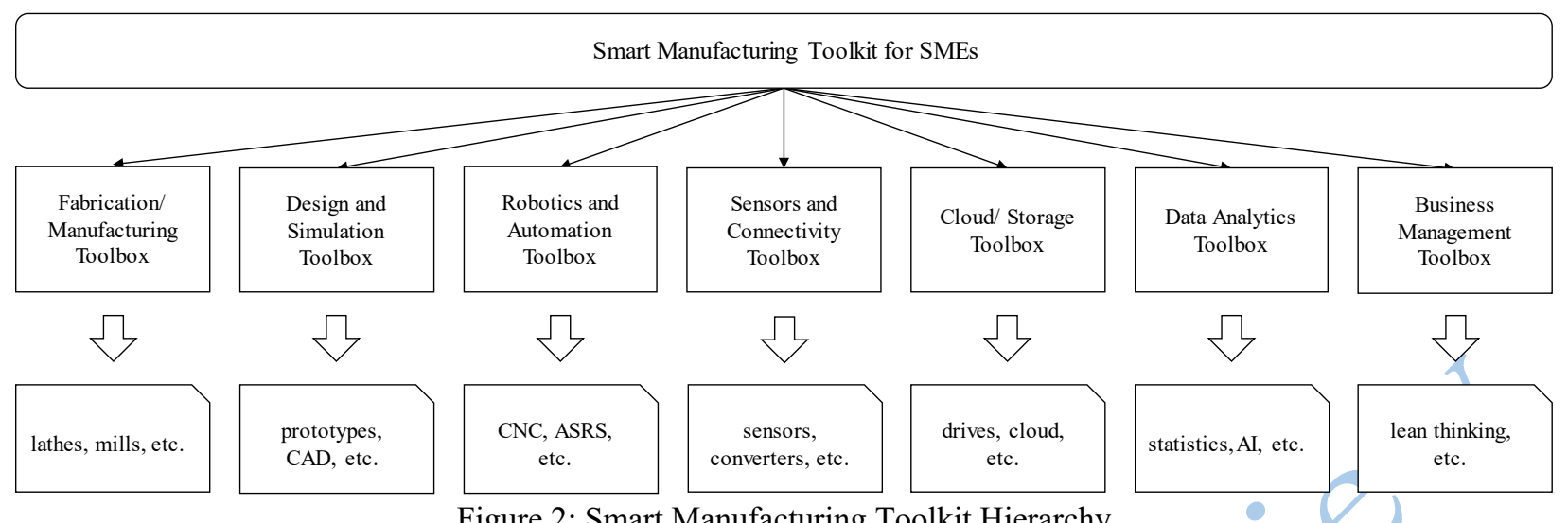

Figure 2: Smart Manufacturing Toolkit Hierarchy

ii) Smart Manufacturing Maturity Levels

Inspired by the standard number of levels in maturity models (e.g., CMMI), the $\mathrm{SM}^{3} \mathrm{E}$ defined five maturity levels. Below we present the definitions of these five levels:

- Level 1: Novice - SMEs that are unaware of the SM/Industry 4.0 paradigm.

- Level 2: Beginner - SMEs that have recently developed awareness and a basic understanding of SM/Industry 4.0 paradigm

- Level 3: Learner - SMEs that have initiated experimenting with SM/Industry 4.0 technologies.

- Level 4: Intermediate - SMEs that have successfully implemented SM/Industry 4.0 pilot projects.

- Level 5: Expert - SMEs that have strategically deployed SM/Industry 4.0 technologies.

The SM toolboxes are installed stepwise and have additional value adding-capabilities with each level within the same toolbox. Table 1 (see below) depicts how SM toolboxes and maturity levels interact with each other.

Table 1: Smart Manufacturing Toolkit for SMEs (Mittal, Romero and Wuest 2018a)

\begin{tabular}{|c|c|c|c|c|c|c|}
\hline $\begin{array}{c}\text { Maturity } \\
\text { Levels }\end{array}$ & $\begin{array}{c}\text { Fabrication/ } \\
\text { Manufacturing } \\
\text { Toolbox } \\
\text { (FMT) }\end{array}$ & $\begin{array}{c}\text { Design \& } \\
\text { Simulation } \\
\text { Toolbox } \\
\text { (DST) }\end{array}$ & $\begin{array}{c}\text { Robotics \& } \\
\text { Automation } \\
\text { Toolbox } \\
\text { (RAT) }\end{array}$ & $\begin{array}{c}\text { Sensors \& } \\
\text { Connectivity } \\
\text { Toolbox } \\
\text { (SCT) }\end{array}$ & $\begin{array}{c}\text { Cloud/ } \\
\text { Storage } \\
\text { Toolbox } \\
\text { (CST) }\end{array}$ & $\begin{array}{c}\text { Data Analytics } \\
\text { Toolbox (DAT) }\end{array}$ \\
\hline Novice & $\begin{array}{c}\text { Raw } \\
\text { Materials }\end{array}$ & $\begin{array}{c}\text { Hand-based } \\
\text { Design }\end{array}$ & $\begin{array}{c}\text { Manually- } \\
\text { Operated } \\
\text { Machines }\end{array}$ & Source & $\begin{array}{c}\text { Registers, } \\
\text { Log books, } \\
\text { Spreadsheets }\end{array}$ & $\begin{array}{c}\text { Data } \\
\text { Collection }\end{array}$ \\
\hline Beginner & Energy & $\begin{array}{c}\text { Environment } \\
\text { \& Model } \\
\text { (Design } \\
\text { Environment) }\end{array}$ & $\begin{array}{c}\text { Non- } \\
\text { Programmable } \\
\text { Machines }\end{array}$ & Sensors & Built-in HDs & $\begin{array}{c}\text { Data } \\
\text { Cleaning }\end{array}$ \\
\hline Interme- \\
diate
\end{tabular}

iii) Smart Manufacturing Organisational Dimension

The organisational dimensions were defined with the help of an extensive literature review and its focus was on those 'dimensions' with more relevance from a manufacturing SME's perspective. During the industrial visits prior to this 
study, the SME managers and/or owners were found to be too concerned regarding 'finance,' and therefore, this dimension was also included as an organisational dimension. SM enables data-driven decision making, and organisational dimensions may be related to different data (Mittal, Romero and Wuest 2018b).

- Dimension 1: Finance - To understand the data related to economics, e.g., equipment cost data, raw material cost data.

- Dimension 2: People - To understand the data related to the personnel involved, e.g., number of employee data, worker schedule data.

- Dimension 3: Strategy - To understand the data related to the decision-making process, e.g., targets, performance metrics.

- Dimension 4: Process - To understand the data related to the transformation of raw materials into the final products, e.g., quality control data, process parameters data.

- Dimension 5: Product - To understand the product logistics data, when the product gets inside the shop and goes outside the shop floor operations, e.g., product development data, product design data.

Various data-related activities are performed accordingly to a specific toolbox and maturity level, and an organisational dimension. Appendix II shows the typical data-driven activities corresponding to the seven toolboxes. Below are the four steps towards adopting an SM paradigm in SMEs:

\section{Appendix II: Exemplary Use of Toolboxes}

Table 1: Different Forms of Data Embraced by the Fabrication/Manufacturing Toolbox

\begin{tabular}{|c|c|c|c|c|c|}
\hline Dimension & Novice & Beginner & Learner & Intermediate & Expert \\
\hline Finance & $\begin{array}{l}\text { cost data based on } \\
\text { raw material }\end{array}$ & $\begin{array}{l}\text { cost data based on } \\
\text { energy consumption }\end{array}$ & $\begin{array}{l}\text { cost data based on } \\
\text { parts (assembly) of } \\
\text { products }\end{array}$ & $\begin{array}{l}\text { cost data based on } \\
\text { order (cad design) of } \\
\text { products }\end{array}$ & $\begin{array}{l}\text { cost data based on } \\
\text { sustainable } \\
\text { production }\end{array}$ \\
\hline Product & $\begin{array}{l}\text { product data based on } \\
\text { raw material }\end{array}$ & $\begin{array}{l}\text { product data based on } \\
\text { energy consumption }\end{array}$ & $\begin{array}{l}\text { product data based on } \\
\text { parts (assembly) of } \\
\text { products }\end{array}$ & $\begin{array}{l}\text { product data based on } \\
\text { order (cad design) of } \\
\text { products }\end{array}$ & $\begin{array}{c}\text { product data based on } \\
\text { sustainable } \\
\text { production }\end{array}$ \\
\hline
\end{tabular}

Table 2: Different Forms of Data Embraced by the Design \& Simulation Toolbox

\begin{tabular}{|c|c|c|c|c|c|}
\hline Dimension & Novice & Beginner & Learner & Intermediate & Expert \\
\hline Finance & $\begin{array}{c}\text { cost data based on } \\
\text { paper-based designs }\end{array}$ & $\begin{array}{c}\text { cost data based on the } \\
\text { design (model) }\end{array}$ & $\begin{array}{c}\text { cost data based on } \\
\text { simulation }\end{array}$ & $\begin{array}{c}\text { cost data based on } \\
\text { prototyping }\end{array}$ & $\begin{array}{c}\text { cost data based on the } \\
\text { customer design } \\
\text { interface }\end{array}$ \\
\hline People & $\begin{array}{c}\text { people's data based } \\
\text { on paper-based } \\
\text { designs }\end{array}$ & $\begin{array}{c}\text { people's data based } \\
\text { on the design (model) }\end{array}$ & $\begin{array}{c}\text { people's data based on } \\
\text { simulation }\end{array}$ & $\begin{array}{c}\text { people's data based } \\
\text { on prototyping }\end{array}$ & $\begin{array}{c}\text { people's data based } \\
\text { on the customer } \\
\text { design interface }\end{array}$ \\
\hline Strategy & - & - & - & - & - \\
\hline Process & $\begin{array}{c}\text { process data based on } \\
\text { paper-based designs }\end{array}$ & $\begin{array}{c}\text { process data based on } \\
\text { the design (model) }\end{array}$ & $\begin{array}{c}\text { process data based on } \\
\text { simulation }\end{array}$ & $\begin{array}{c}\text { process data based on } \\
\text { prototyping }\end{array}$ & $\begin{array}{c}\text { process data based on } \\
\text { the customer design } \\
\text { interface }\end{array}$ \\
\hline Product & $\begin{array}{c}\text { product data based on } \\
\text { paper-based designs }\end{array}$ & $\begin{array}{c}\text { product data based on } \\
\text { the design (model) }\end{array}$ & $\begin{array}{c}\text { product data based on } \\
\text { simulation }\end{array}$ & $\begin{array}{c}\text { product data based on } \\
\text { prototyping }\end{array}$ & $\begin{array}{c}\text { product data based on } \\
\text { the customer design } \\
\text { interface }\end{array}$ \\
\hline
\end{tabular}


Table 3: Different Forms of Data Embraced by the Robotics \& Automation Toolbox

\begin{tabular}{|c|c|c|c|c|c|}
\hline Finance & $\begin{array}{c}\text { cost data based on } \\
\text { manually-operated } \\
\text { machines }\end{array}$ & $\begin{array}{l}\text { cost data based on } \\
\text { non-programmable } \\
\text { machines }\end{array}$ & $\begin{array}{l}\text { cost data based on } \\
\text { programmable } \\
\text { machines }\end{array}$ & $\begin{array}{l}\text { cost data based on a } \\
\text { collaborative robot } \\
\text { (mimic human) }\end{array}$ & $\begin{array}{l}\text { cost data based on a } \\
\text { collaborative robot } \\
\text { (based on } \mathrm{AI})\end{array}$ \\
\hline People & $\begin{array}{l}\text { people's data based } \\
\text { on the manually- } \\
\text { operated machines }\end{array}$ & $\begin{array}{c}\text { people's data based } \\
\text { on the non- } \\
\text { programmable } \\
\text { machines }\end{array}$ & $\begin{array}{c}\text { people's data based } \\
\text { on the programmable } \\
\text { machines }\end{array}$ & $\begin{array}{l}\text { people's data based } \\
\text { on the collaborative } \\
\text { robot (mimic human) }\end{array}$ & $\begin{array}{l}\text { people's data based } \\
\text { on the collaborative } \\
\text { robot (based on AI) }\end{array}$ \\
\hline Strategy & - & - & - & - & - \\
\hline Process & $\begin{array}{c}\text { process data based on } \\
\text { the manually-operated } \\
\text { machines }\end{array}$ & $\begin{array}{c}\text { process data based on } \\
\text { the non- } \\
\text { programmable } \\
\text { machines }\end{array}$ & $\begin{array}{c}\text { process data based } \\
\text { on the programmable } \\
\text { machines }\end{array}$ & $\begin{array}{l}\text { process data based on } \\
\text { the collaborative } \\
\text { robot (mimic human) }\end{array}$ & $\begin{array}{l}\text { process data based on } \\
\text { the collaborative } \\
\text { robot (based on } \mathrm{AI} \text { ) }\end{array}$ \\
\hline
\end{tabular}

Table 4: Different Forms of Data Embraced by the Sensors \& Connectivity Toolbox

\begin{tabular}{|c|c|c|c|c|c|}
\hline Dimension & Novice & Beginner & Learner & Intermediate & Expert \\
\hline Finance & $\begin{array}{c}\text { manually collect cost } \\
\text { data }\end{array}$ & $\begin{array}{c}\text { sensors collect cost } \\
\text { data }\end{array}$ & $\begin{array}{c}\text { signals collect cost } \\
\text { data }\end{array}$ & $\begin{array}{c}\text { digitally stored cost } \\
\text { data }\end{array}$ & $\begin{array}{c}\text { cost data based on } \\
\text { customer design } \\
\text { interface }\end{array}$ \\
\hline Ptrategy & $\begin{array}{c}\text { manually collect } \\
\text { people's data }\end{array}$ & $\begin{array}{c}\text { sensors collect } \\
\text { people's data }\end{array}$ & $\begin{array}{c}\text { signals collect } \\
\text { people's data }\end{array}$ & $\begin{array}{c}\text { digitally store people's data based } \\
\text { people's data } \\
\text { on the customer } \\
\text { design interface }\end{array}$ \\
\hline Process & $\begin{array}{c}\text { manually collect } \\
\text { process data }\end{array}$ & $\begin{array}{c}\text { sensors collect } \\
\text { process data }\end{array}$ & $\begin{array}{c}\text { signals collect } \\
\text { product data }\end{array}$ & $\begin{array}{c}\text { digitally store process } \\
\text { data }\end{array}$ & $\begin{array}{c}\text { process data based on } \\
\text { the customer design } \\
\text { interface }\end{array}$ \\
\hline Product & $\begin{array}{c}\text { manually collect } \\
\text { product data }\end{array}$ & $\begin{array}{c}\text { sensors collect } \\
\text { product data }\end{array}$ & $\begin{array}{c}\text { signals collect } \\
\text { product data }\end{array}$ & $\begin{array}{c}\text { digitally store product } \\
\text { data }\end{array}$ & $\begin{array}{c}\text { product data based on } \\
\text { the customer design } \\
\text { interface }\end{array}$ \\
\hline
\end{tabular}


Table 5: Different Forms of Data Embraced by the Cloud/Storage Toolbox

\begin{tabular}{|c|c|c|c|c|c|}
\hline Dimension & Novice & Beginner & Learner & Intermediate & Expert \\
\hline Finance & $\begin{array}{c}\text { store financial data } \\
\text { using spreadsheets }\end{array}$ & $\begin{array}{c}\text { store financial data } \\
\text { using hard drives } \\
\text { (HDs) }\end{array}$ & $\begin{array}{c}\text { store financial data } \\
\text { using shared HDs }\end{array}$ & $\begin{array}{c}\text { store financial data } \\
\text { using cloud }\end{array}$ & $\begin{array}{c}\text { store financial data } \\
\text { using fog }\end{array}$ \\
\hline People & $\begin{array}{c}\text { store people's data } \\
\text { using spreadsheets }\end{array}$ & $\begin{array}{c}\text { store people's data } \\
\text { using HDs }\end{array}$ & $\begin{array}{c}\text { store people's data } \\
\text { using shared HDs }\end{array}$ & $\begin{array}{c}\text { store people's data } \\
\text { using cloud }\end{array}$ & store people's data \\
\hline Strategy & - & - & - & - & using fog \\
\hline Process & $\begin{array}{c}\text { store process data } \\
\text { using spreadsheets }\end{array}$ & $\begin{array}{c}\text { store process data } \\
\text { using HDs }\end{array}$ & $\begin{array}{c}\text { store process data } \\
\text { using shared HDs }\end{array}$ & $\begin{array}{c}\text { store process data } \\
\text { using cloud }\end{array}$ & $\begin{array}{c}\text { store process data } \\
\text { using fog }\end{array}$ \\
\hline Product & $\begin{array}{c}\text { store product data } \\
\text { using spreadsheets }\end{array}$ & $\begin{array}{c}\text { store product data } \\
\text { using HDs }\end{array}$ & $\begin{array}{c}\text { store product data } \\
\text { using shared HDs }\end{array}$ & $\begin{array}{c}\text { store product data } \\
\text { using cloud }\end{array}$ & $\begin{array}{c}\text { store product data } \\
\text { using fog }\end{array}$ \\
\hline
\end{tabular}

Table 6: Different Forms of Data Embraced by the Data Analytics Toolbox

\begin{tabular}{|c|c|c|c|c|c|}
\hline Dimension & Novice & Beginner & Learner & Intermediate & Expert \\
\hline Finance & $\begin{array}{l}\text { collect and analyse } \\
\text { financial data }\end{array}$ & $\begin{array}{l}\text { clean and analyse } \\
\text { financial data }\end{array}$ & $\begin{array}{c}\text { integrate and } \\
\text { analyse financial } \\
\text { data }\end{array}$ & $\begin{array}{l}\text { reduce and analyse } \\
\text { financial data }\end{array}$ & $\begin{array}{l}\text { transform and analyse } \\
\text { financial data }\end{array}$ \\
\hline People & $\begin{array}{l}\text { collect and analyse } \\
\text { people's data }\end{array}$ & $\begin{array}{l}\text { clean and analyse } \\
\text { people's data }\end{array}$ & $\begin{array}{l}\text { integrate and } \\
\text { analyse people's } \\
\text { data }\end{array}$ & $\begin{array}{l}\text { reduce and analyse } \\
\text { people's data }\end{array}$ & $\begin{array}{l}\text { transform and analyse } \\
\text { people's data }\end{array}$ \\
\hline Strategy & $\begin{array}{l}\text { make strategies } \\
\text { based on the } \\
\text { collected and then } \\
\text { analysed data }\end{array}$ & $\begin{array}{l}\text { make strategies } \\
\text { based on the } \\
\text { cleaned and then } \\
\text { analysed data }\end{array}$ & $\begin{array}{l}\text { make strategies } \\
\text { based on the } \\
\text { integrated and then } \\
\text { analysed data }\end{array}$ & $\begin{array}{l}\text { make strategies based } \\
\text { on the reduced and } \\
\text { then analysed data }\end{array}$ & $\begin{array}{c}\text { make strategies based } \\
\text { on the transformed } \\
\text { and then analysed } \\
\text { data }\end{array}$ \\
\hline Process & $\begin{array}{l}\text { collect and analyse } \\
\text { process data }\end{array}$ & $\begin{array}{l}\text { clean and analyse } \\
\text { process data }\end{array}$ & $\begin{array}{c}\text { integrate and } \\
\text { analyse process } \\
\text { data }\end{array}$ & $\begin{array}{l}\text { reduce and analyse } \\
\text { process data }\end{array}$ & $\begin{array}{c}\text { integrate and } \\
\text { transform data based } \\
\text { on process }\end{array}$ \\
\hline Product & $\begin{array}{c}\text { collect and analyse } \\
\text { product data }\end{array}$ & $\begin{array}{c}\text { clean and analyse } \\
\text { product data }\end{array}$ & $\begin{array}{c}\text { integrate and } \\
\text { analyse product } \\
\text { data }\end{array}$ & $\begin{array}{l}\text { reduce and analyse } \\
\text { product data }\end{array}$ & $\begin{array}{c}\text { integrate and } \\
\text { transform data based } \\
\text { on product }\end{array}$ \\
\hline
\end{tabular}

Table 7: Various Practices Corresponding to the Business Management Toolbox (No Form of Data is Generated)

\begin{tabular}{|c|l|l|l|}
\hline Dimension & \multicolumn{1}{|c|}{ Novice } & Beginner & Learner \\
\hline Finance & e.g. lean accounting & Intermediate & \\
\hline People & e.g. attending workshops, seminars; positive mindset towards SM/Industry 4.0; organisational culture \\
\hline Strategy & e.g. design thinking method; lean training games \\
\hline Process & e.g. lean visual management; digital lean; lean automation \\
\hline Product & e.g. digital lean; lean automation \\
\hline
\end{tabular}




\section{Appendix III: Semi-Structured Questionnaire Employed during our Research}

1. What are the business operations currently performed in your organisation?

2. What data-related activities are performed in your key business operations?

3. Where do you think you stand currently when it comes to digitalization and data analytics?

4. What comes in your mind regarding SM?

5. How you performed your operations earlier?

6. How did you get aware of the new technology and what was the main motivation for adopting the new technology?

7. What were the other options considered (before adopting the new technology)?

8. Did you use the help of external consultants in the process?

9. Why the solution you implemented was the most feasible option?

10. Please explain the technicalities/ of the new technology adoption, (any additional documents may be provided at this stage)?

11. What kind of technical/managerial difficulties were observed? How did you overcome them?

12. What were/would have been the main obstacles in the process of adopting:

- Manufacturing tools

- Design \& simulation tools

- Advanced manufacturing tools

- Sensors and connectivity tools

- Data storage tools (information systems)

- Data analytics tools

- Business and management tools

13. How your business model has been affected because of the new technology adoption?

14. What were the main benefits of the process observed so far? What kind of improvements have you been able to observe (for e.g., in the context of customer interaction, use of data)?

15. What are the future options you will consider (suggested with the help of a framework and their own)?

16. How difficult it will be to shift towards the future option, as compared to the difficulties faced during your transformation in the past? 
Appendix IV: Summary of the Data Analysis

\begin{tabular}{|c|c|c|c|c|c|c|}
\hline $\begin{array}{l}\text { Interview } \\
\text { Questions }\end{array}$ & Points Discussed & Case A & Case B & $\begin{array}{c}\text { Answer } \\
\text { Similarities }\end{array}$ & Answer Differences & $\begin{array}{c}\text { Feedback } \\
\text { Regarding the } \\
\text { Adoption } \\
\text { Framework }\end{array}$ \\
\hline 1 & $\begin{array}{l}\text { Business } \\
\text { Operations }\end{array}$ & $\begin{array}{l}\text { Sales, purchase, } \\
\text { design, } \\
\text { production }\end{array}$ & $\begin{array}{l}\text { Sales, purchase, } \\
\text { design, production, } \\
\text { site-installation }\end{array}$ & $\begin{array}{c}\text { Sales, design, } \\
\text { production } \\
\text { were common; } \\
\text { - 'Hard } \\
\text { manufacturing } \\
\text { ' operations } \\
\text { were not } \\
\text { modified }\end{array}$ & $\begin{array}{c}\text { Site installation; } \\
\text { Different design } \\
\text { tools used (from } \\
\text { design and } \\
\text { simulation } \\
\text { toolbox) }\end{array}$ & 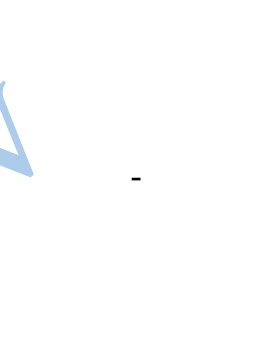 \\
\hline 2 & $\begin{array}{l}\text { Manufacturing } \\
\text { Data Present }\end{array}$ & $\begin{array}{c}\text { See } \\
\text { Appendix V }\end{array}$ & $\begin{array}{c}\text { See } \\
\text { Appendix V }\end{array}$ & $\begin{array}{c}\text { - } \quad \text { Mostly around } \\
\text { design } \\
\text { - } \quad \text { Data generated } \\
\text { not going } \\
\text { through next } \\
\text { levels of data- } \\
\text { hierarchy steps }\end{array}$ & - & $\begin{array}{l}\text { Manufacturing } \\
\text { data present shall } \\
\text { be identified }\end{array}$ \\
\hline 3 & $\begin{array}{l}\text { Readiness } \\
\text { Assessment }\end{array}$ & $\begin{array}{l}\text { Used } \\
\text { comparison }\end{array}$ & Used comparison & $\begin{array}{l}\text { SMEs compared } \\
\text { themselves with } \\
\text { other enterprises } \\
\text { (benchmarking) }\end{array}$ & - & $\begin{array}{l}\text { Readiness } \\
\text { assessment } \\
\text { required }\end{array}$ \\
\hline 11,16 & $\begin{array}{l}\text { The transition } \\
\text { from 'Level 0' to } \\
\text { a higher level }\end{array}$ & $\begin{array}{l}\text { 'Level 0' to } \\
\text { 'Level } 1 \text { ' is the } \\
\text { most challenging } \\
\text { phase }\end{array}$ & $\begin{array}{l}\text { 'Level 0' to 'Level } \\
1 \text { ' is the most } \\
\text { challenging phase }\end{array}$ & $\begin{array}{l}\text { For SMEs } \\
\text { transition from } \\
\text { 'Level 0' to a } \\
\text { higher level is the } \\
\text { most difficult part }\end{array}$ & - & $\begin{array}{l}\text { Acknowledge } \\
\text { difficulties faced } \\
\text { during an SME's } \\
\text { transition from } \\
\text { 'Level 0' to a } \\
\text { higher level }\end{array}$ \\
\hline 4,6 & SM Awareness & $\begin{array}{l}\text { Attending } \\
\text { Jewelry } \\
\text { Symposium }\end{array}$ & $\begin{array}{l}\text { Through popular } \\
\text { furniture store } \\
\text { website }\end{array}$ & & $\begin{array}{l}\text { Different ways to } \\
\text { get aware of SM }\end{array}$ & $\begin{array}{c}\text { Developing SM } \\
\text { awareness is a } \\
\text { very significant } \\
\text { step towards SM } \\
\text { adoption } \\
\end{array}$ \\
\hline 6 & SM Vision & $\begin{array}{c}\text { Increasing } \\
\text { clientele by } \\
\text { providing more } \\
\text { variety of } \\
\text { designs } \\
\end{array}$ & Reducing ECNs & Had a goal in mind & - & $\begin{array}{l}\text { Developing a } \\
\text { tailored vision of } \\
\text { SM involved a } \\
\text { goal }\end{array}$ \\
\hline
\end{tabular}




\begin{tabular}{|c|c|c|c|c|c|c|}
\hline $\begin{array}{l}\text { Interview } \\
\text { Questions }\end{array}$ & Points Discussed & Case A & Case B & $\begin{array}{c}\text { Answer } \\
\text { Similarities }\end{array}$ & Answer Differences & $\begin{array}{c}\text { Feedback } \\
\text { Regarding the } \\
\text { Adoption } \\
\text { Framework } \\
\end{array}$ \\
\hline $\begin{array}{l}5,7,8,9 \\
10,11,12 \\
13,14,15 \\
16\end{array}$ & $\begin{array}{l}\text { SM Tools and } \\
\text { Practices } \\
\text { Considered }\end{array}$ & $\begin{array}{c}\text { Design } \\
\text { tools, } \\
\text { employee } \\
\text { skills, } \\
\text { collaboratio } \\
\mathrm{n} \text { with other } \\
\text { jewelry } \\
\text { manufacture } \\
\mathrm{r} ; \\
\text { Design tools } \\
\text { (future) }\end{array}$ & $\begin{array}{l}\text { - Design tools, } \\
\text { lean practices; } \\
\text { ERP, sensors, } \\
\text { internet } \\
\text { connectivity } \\
\text { (future) }\end{array}$ & $\begin{array}{c}\text { Design tools are } \\
\text { the most preferred } \\
\text { options }\end{array}$ & $\begin{array}{c}\text { Advanced } \\
\text { manufacturing tools, } \\
\text { data analytics, tools } \\
\text { not considered }\end{array}$ & $\begin{array}{l}\text { Identification } \\
\text { of SM tools } \\
\text { and practices } \\
\text { is also very } \\
\text { important } \\
\text { ETO } \\
\text { companies } \\
\text { preferred } \\
\text { design tools } \\
\text { as the first } \\
\text { option }\end{array}$ \\
\hline $\begin{array}{c}5,7,8,9, \\
10,11,12, \\
14,15,16\end{array}$ & $\begin{array}{l}\text { Fabrication/ } \\
\text { Manufacturing } \\
\text { Toolbox }\end{array}$ & $\begin{array}{l}\text { Based on orders } \\
\text { and assembly }\end{array}$ & $\begin{array}{l}\text { Based on orders } \\
\text { and assembly }\end{array}$ & $\begin{array}{l}\text { Change in 'hard } \\
\text { manufacturing' } \\
\text { practices, will need } \\
\text { new organisational } \\
\text { culture, worker } \\
\text { skills, etc. }\end{array}$ & - & Not preferred \\
\hline $\begin{array}{l}5,7,8,9, \\
10,11,12, \\
14,15,16\end{array}$ & $\begin{array}{c}\text { Design and } \\
\text { Simulation } \\
\text { Toolbox }\end{array}$ & $\begin{array}{l}\text { 3D-printing, } \\
\text { configurator } \\
\text { (interface) } \\
\text { (future) }\end{array}$ & $\begin{array}{l}\text { Product } \\
\text { Configurator } \\
\text { (interface) }\end{array}$ & $\begin{array}{l}\text { Only interfered the } \\
\text { design phase }\end{array}$ & - & Most preferred \\
\hline $\begin{array}{l}5,7,8,9, \\
10,11,12, \\
14,15,16\end{array}$ & $\begin{array}{c}\text { Robotics and } \\
\text { Automation } \\
\text { Toolbox }\end{array}$ & & $\mathrm{CNC}$ & $\begin{array}{l}\text { Change in 'hard } \\
\text { manufacturing' } \\
\text { practices, will need } \\
\text { investment, new } \\
\text { organisational } \\
\text { culture, worker } \\
\text { skills, etc. }\end{array}$ & - & Not preferred \\
\hline $\begin{array}{c}5,7,8,9, \\
10,11,12, \\
14,15,16\end{array}$ & $\begin{array}{l}\text { Sensors and } \\
\text { Connectivity } \\
\text { Toolbox }\end{array}$ & $\begin{array}{l}\text { Product } \\
\text { configurator } \\
\text { (interface) }\end{array}$ & 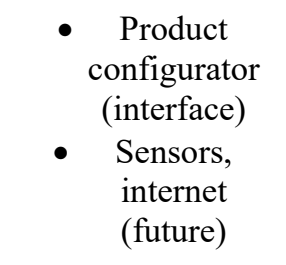 & $\begin{array}{l}\text { Upgrading the } \\
\text { existing 'stand- } \\
\text { alone' machines } \\
\text { avoided }\end{array}$ & - & Less preferred \\
\hline $\begin{array}{c}5,7,8,9 \\
10,11,12, \\
14,15,16\end{array}$ & $\begin{array}{l}\text { Cloud/Storage } \\
\text { Toolbox }\end{array}$ & $\begin{array}{l}\text { MS-Excel, hard- } \\
\text { drive (flash, pen } \\
\text { drive) }\end{array}$ & $\begin{array}{l}\text { Transferred from } \\
\text { MS excel to ERP } \\
\text { (not used to its full } \\
\text { potential) }\end{array}$ & $\begin{array}{l}\text { Only finance } \\
\text { related data was } \\
\text { saved }\end{array}$ & $\begin{array}{l}\text { Case A transferred } \\
\text { design files from } \\
\text { computer to printer } \\
\text { using flash }\end{array}$ & Less preferred \\
\hline $\begin{array}{c}5,7,8,9, \\
10,11,12, \\
14,15,16\end{array}$ & $\begin{array}{c}\text { Data Analytics } \\
\text { Toolbox }\end{array}$ & MS-Excel & MS-Excel & $\begin{array}{l}\text { Only financial data } \\
\text { analysed }\end{array}$ & $\begin{array}{l}\text { Case B used MS- } \\
\text { Excel functions }\end{array}$ & Unknown \\
\hline
\end{tabular}




\begin{tabular}{|c|c|c|c|c|c|c|}
\hline $\begin{array}{c}\text { Interview } \\
\text { Questions }\end{array}$ & Points Discussed & Case A & Case B & $\begin{array}{c}\text { Answer } \\
\text { Similarities }\end{array}$ & Answer Differences & $\begin{array}{c}\text { Feedback } \\
\text { Regarding the } \\
\text { Adoption } \\
\text { Framework }\end{array}$ \\
\hline $8,13,16$ & $\begin{array}{c}\text { Musiness } \\
\text { Tonagement } \\
\text { Toolbox }\end{array}$ & $\begin{array}{c}\text { Collaboration, } \\
\text { employee } \\
\text { training }\end{array}$ & $\begin{array}{c}\text { Lean practices, ISO } \\
\text { certification, layout } \\
\text { changes }\end{array}$ & $\begin{array}{c}\text { Resistance } \\
\text { towards employee } \\
\text { skill enhancement } \\
\text { and change in } \\
\text { organisational } \\
\text { culture }\end{array}$ \\
\hline
\end{tabular}

Appendix V: Manufacturing Data present and the SM Readiness

- Jewelry Manufacturing- J

- Modular Kitchen Manufacturing- K

Table 1: Smart Manufacturing Readiness with Data Generation

\begin{tabular}{|c|c|c|c|c|c|c|c|c|}
\hline $\begin{array}{c}\text { Organisational } \\
\text { Dimension }\end{array}$ & $\begin{array}{c}\text { Related data generated } \\
\text { equipment cost data }(J)(K) \text {, raw material cost data } \\
(J)(K) \text {, transportation cost data }(J)(K) \text {, energy cost } \\
\text { data }(J)(K) \text {, assembly cost data }(J)(K) \text {, worker cost } \\
\text { data }(J)(K)\end{array}$ & \multicolumn{7}{|c|}{ Smart Manufacturing Readiness } \\
\hline \multirow{4}{*}{ Finance } & \multirow{4}{*}{$\begin{array}{l}\text { equipment cost data }(\mathrm{J})(\mathrm{K}) \text {, raw material cost data } \\
(\mathrm{J})(\mathrm{K}) \text {, transportation cost data }(\mathrm{J})(\mathrm{K}) \text {, energy cost } \\
\text { data }(\mathrm{J})(\mathrm{K}) \text {, assembly cost data }(\mathrm{J})(\mathrm{K}) \text {, worker cost } \\
\text { data }(\mathrm{J})(\mathrm{K})\end{array}$} & $\gamma$ & $\mathrm{N}$ & $\mathrm{B}$ & $\bar{L}$ & I & & $\bar{E}$ \\
\hline & & FMT & & & & $(\mathrm{J})(\mathrm{K}$ & & \\
\hline & & DST & & & & (J) & & (K) \\
\hline & & RAT & (J) & $(\mathrm{K})$ & & & & \\
\hline & \multirow{5}{*}{$\begin{array}{l}\text { number of hours data }(\mathrm{J})(\mathrm{K}) \text {, number of } \\
\text { employees/workers data }(\mathrm{K}) \text {, worker schedule data } \\
\text { (K) }\end{array}$} & & & & & & & \\
\hline \multirow{4}{*}{ People } & & & \multicolumn{2}{|c|}{$\mathrm{N}$} & \multirow{2}{*}{$\frac{\mathrm{B}}{(\mathrm{I})(\mathrm{K})}$} & $\mathrm{L}$ & $\mathrm{I}$ & $\mathrm{E}$ \\
\hline & & FMT & & & & & & \\
\hline & & DST & \multicolumn{2}{|c|}{$(\mathrm{J})$} & $(\mathrm{K})$ & & & \\
\hline & & RAT & \multicolumn{2}{|c|}{$(\mathrm{J})(\mathrm{K})$} & & & & \\
\hline Strategy & $1-$ & \multirow{2}{*}{\multicolumn{7}{|c|}{ - }} \\
\hline & & & & & & & & \\
\hline \multirow{4}{*}{ Process } & \multirow{4}{*}{$\begin{array}{l}\text { production process data }(\mathrm{K}) \text {, process parameters data } \\
(\mathrm{J})(\mathrm{K}) \text {, process planning data }(\mathrm{K}) \text {, process control } \\
\text { data }(\mathrm{K})\end{array}$} & & $\mathrm{N}$ & B & & $\mathrm{L}$ & I & $\mathrm{E}$ \\
\hline & & FMT & & $(\mathrm{J})$ & & K) & & \\
\hline & & DST & & $(\mathrm{J})(\mathrm{K}$ & & & & \\
\hline & & RAT & $(\mathrm{J})$ & $(\mathrm{K})$ & & & & \\
\hline \multirow{4}{*}{ Product } & \multirow{4}{*}{$\begin{array}{l}\text { product design data }(\mathrm{J})(\mathrm{K}) \text {, product specifications } \\
(\mathrm{J})(\mathrm{K}) \text {, order data }(\mathrm{J})(\mathrm{K}) \text {, inventory management data } \\
(\mathrm{J})(\mathrm{K}) \text {, sales data }(\mathrm{J})(\mathrm{K}) \text {, delivery time data }(\mathrm{J})(\mathrm{K})\end{array}$} & & N & & I & & & \\
\hline & & FMT & $\mathrm{N}$ & B & $\mathrm{L}$ & $\frac{1}{(1)}$ & & $\frac{\mathrm{E}}{(V)}$ \\
\hline & & DST & & & & $\frac{(J)}{(J)}$ & & $\frac{(\mathrm{K})}{(\mathrm{K})}$ \\
\hline & & RAT & (J) & $(\mathrm{K})$ & & & & (II) \\
\hline
\end{tabular}

Table 2: Smart Manufacturing Readiness with Data Transmission

\begin{tabular}{|c|c|c|c|c|c|c|c|}
\hline $\begin{array}{c}\text { Organisational } \\
\text { Dimension }\end{array}$ & Related data transmitted & \multicolumn{6}{|c|}{ Smart Manufacturing Readiness } \\
\hline \multirow{4}{*}{ Finance } & \multirow{4}{*}{$\begin{array}{l}\text { equipment cost data }(J)(K) \text {, raw material cost data } \\
(J)(K) \text {, transportation cost data }(K) \text {, energy cost } \\
\text { data }(J)(K) \text {, worker cost data }(J)(K)\end{array}$} & & $\mathrm{N}$ & B & $\mathrm{L}$ & I & $E$ \\
\hline & & DST & & $(\mathrm{J})(\mathrm{K})$ & & & \\
\hline & & RAT & $(J)(K)$ & & & & \\
\hline & & $\mathrm{SCT}$ & $(\mathrm{J})(\mathrm{K})$ & & & & \\
\hline
\end{tabular}




\begin{tabular}{|c|c|c|c|c|c|c|c|}
\hline $\begin{array}{c}\text { Organisational } \\
\text { Dimension }\end{array}$ & Related data transmitted & \multicolumn{6}{|c|}{ Smart Manufacturing Readiness } \\
\hline \multirow{4}{*}{ People } & \multirow{4}{*}{$\begin{array}{l}\text { number of hours data }(\mathrm{J})(\mathrm{K}) \text {, worker schedule data } \\
\qquad(\mathrm{K})\end{array}$} & & $\mathrm{N}$ & $\mathrm{B}$ & $\mathrm{L}$ & I & $\mathrm{E}$ \\
\hline & & DST & & $(\mathrm{J})(\mathrm{K})$ & & & \\
\hline & & RAT & $(\mathrm{J})(\mathrm{K})$ & & & & \\
\hline & & SCT & $(\mathrm{J})(\mathrm{K})$ & & & & \\
\hline Strategy & - & & & - & & & \\
\hline & & & & & & & \\
\hline \multirow{4}{*}{ Process } & \multirow{4}{*}{$\begin{array}{l}\text { production process data }(K) \text {, process parameters } \\
\text { data }(J)(K) \text {, process planning data }(K)\end{array}$} & & $\mathrm{N}$ & $\mathrm{B}$ & L & $\bar{I}$ & $\bar{E}$ \\
\hline & & DST & & $(\mathrm{J})(\mathrm{K})$ & 2 & & \\
\hline & & RAT & $(\mathrm{J})(\mathrm{K})$ & & $\overline{7}$ & & \\
\hline & & SCT & $(\mathrm{J})(\mathrm{K})$ & & & & \\
\hline & & & & & & & \\
\hline \multirow{4}{*}{ Product } & \multirow{4}{*}{$\begin{array}{c}\text { product design data }(\mathrm{J})(\mathrm{K}) \text {, product specifications } \\
(\mathrm{J})(\mathrm{K}) \text {, inventory management data }(\mathrm{K}) \text {, delivery } \\
\text { time data }(\mathrm{K})\end{array}$} & & $\mathrm{N} 4$ & $\mathrm{~B}$ & $\overline{\mathrm{L}}$ & $\overline{\mathrm{I}}$ & $\overline{\mathrm{E}}$ \\
\hline & & DST & 8 & $(\mathrm{~J})(\mathrm{K})$ & & & \\
\hline & & RAT & $(\mathrm{J})(\mathrm{K})$ & & & & \\
\hline & & SCT & $(\mathrm{J})(\mathrm{K})$ & & & & \\
\hline
\end{tabular}

Table 3: Smart Manufacturing Readiness with Data Saving

\begin{tabular}{|c|c|c|c|c|c|c|c|}
\hline $\begin{array}{c}\text { Organisational } \\
\text { Dimension }\end{array}$ & Related data saved & Sm & rt Manu & facturi & g R & adinc & \\
\hline \multirow{4}{*}{ Finance } & \multirow{4}{*}{$\begin{array}{c}\text { equipment cost data }(\mathrm{J})(\mathrm{K}) \text {, raw material cost data } \\
(\mathrm{J})(\mathrm{K}) \text {, transportation cost data }(\mathrm{K}) \text {, energy cost } \\
\text { data }(\mathrm{J})(\mathrm{K}) \text {, worker cost data }(\mathrm{J})(\mathrm{K})\end{array}$} & & $\mathrm{N}$ & $\mathrm{B}$ & $\mathrm{L}$ & I & $E$ \\
\hline & & DST & $(\mathrm{J})$ & $(\mathrm{K})$ & & & \\
\hline & & RAT & $(\mathrm{J})(\mathrm{K})$ & & & & \\
\hline & & CST & $(\mathrm{J})$ & & & $(\mathrm{K})$ & \\
\hline \multirow{4}{*}{ People } & \multirow{4}{*}{$\begin{array}{l}\text { number of hours data }(\mathrm{J})(\mathrm{K}) \text {, worker schedule data } \\
\qquad(\mathrm{K})\end{array}$} & & $\mathrm{N}$ & $\mathrm{B}$ & $\overline{\mathrm{I}}$ & $\mathrm{T}$ & $\mathrm{F}$ \\
\hline & & DST & & $(\mathrm{J})(\mathrm{K})$ & & & \\
\hline & & RAT & $(\mathrm{J})(\mathrm{K})$ & & & & \\
\hline & & CST & $(\mathrm{J})(\mathrm{K})$ & & & & \\
\hline Strategy & 0 & & & - & & & \\
\hline & & & & & & & \\
\hline \multirow{4}{*}{ Process } & \multirow{4}{*}{$\begin{array}{l}\text { production process data }(K) \text {, process parameters } \\
\text { data }(J)(K) \text {, process planning data }(K)\end{array}$} & & $\mathrm{N}$ & B & $\mathrm{L}$ & $\mathrm{I}$ & $E$ \\
\hline & & DST & & $(\mathrm{J})(\mathrm{K})$ & & & \\
\hline & & RAT & $(\mathrm{J})(\mathrm{K})$ & & & & \\
\hline & & CST & $(\mathrm{J})(\mathrm{K})$ & & & & \\
\hline & & & & & & & \\
\hline \multirow{4}{*}{ Product } & \multirow{4}{*}{$\begin{array}{l}\text { product design data }(\mathrm{J})(\mathrm{K}) \text {, product specifications } \\
(\mathrm{J})(\mathrm{K}) \text {, inventory management data }(\mathrm{K}) \text {, delivery } \\
\text { time data }(\mathrm{K})\end{array}$} & & $\mathrm{N}$ & B & $\mathrm{L}$ & I & $E$ \\
\hline & & DST & & $(\mathrm{J})(\mathrm{K})$ & & & \\
\hline & & RAT & $(\mathrm{J})(\mathrm{K})$ & & & & \\
\hline & & CST & $(\mathrm{J})(\mathrm{K})$ & & & & \\
\hline
\end{tabular}

Table 4: Smart Manufacturing Readiness with Data Analysis 


\begin{tabular}{|c|c|c|c|c|c|c|c|}
\hline $\begin{array}{c}\text { Organisational } \\
\text { Dimension }\end{array}$ & Related data analysed & \multicolumn{6}{|c|}{ Smart Manufacturing Readiness } \\
\hline \multirow{5}{*}{ Finance } & \multirow{5}{*}{$\begin{array}{l}\text { equipment cost data }(J)(K) \text {, raw material cost data } \\
(J)(K) \text {, energy cost data }(J)(K) \text {; worker cost data } \\
(J)(K)\end{array}$} & & $\mathrm{N}$ & B & $\mathrm{L}$ & I & $\mathrm{E}$ \\
\hline & & DST & & $(\mathrm{J})(\mathrm{K})$ & & & \\
\hline & & RAT & $(\mathrm{J})(\mathrm{K})$ & & & & \\
\hline & & CST & $(\mathrm{J})(\mathrm{K})$ & & & & \\
\hline & & DAT & & $(\mathrm{J})(\mathrm{K})$ & & & \\
\hline People & - & & & - & & 2 & \\
\hline \multirow{5}{*}{ Strategy } & \multirow{5}{*}{ policies $(\mathrm{J})(\mathrm{K})$} & & $\mathrm{N}$ & B & \multicolumn{2}{|c|}{\begin{tabular}{l|l}
$\mathrm{L}$ & $\mathrm{I}$
\end{tabular}} & $\mathrm{E}$ \\
\hline & & DST & & $\frac{\mathrm{D}}{(\mathrm{J})(\mathrm{K})}$ & $\left.\right|^{L}$ & & E \\
\hline & & RAT & $(\mathrm{J})(\mathrm{K})$ & & B & & \\
\hline & & CST & $(\mathrm{J})(\mathrm{K})$ & & & & \\
\hline & & DAT & $(\mathrm{J})(\mathrm{K})$ & & & & \\
\hline Process & - & $=$ & $\square$ & - & & & \\
\hline 110ess & & & & & & & \\
\hline \multirow{5}{*}{ Product } & \multirow{5}{*}{ product specifications $(\mathrm{K})$} & & $\mathrm{N}$ & B & $\mathrm{L}$ & I & $\mathrm{E}$ \\
\hline & & DST & & $(\mathrm{J})$ & & & $(\mathrm{K})$ \\
\hline & & RAT & $(\mathrm{J})(\mathrm{K})$ & & & & \\
\hline & & CST & $(\mathrm{J})(\mathrm{K})$ & & & & \\
\hline & & DAT & $(\mathrm{J})$ & $(\mathrm{K})$ & & & \\
\hline
\end{tabular}

